\title{
Biomimetic and Theoretic Investigations of Unusual Iron-Sulphur Clusters
}

\author{
Dissertation \\ zur Erlangung des Doktorgrades \\ der Mathematisch-Naturwissenschaftlichen Fakultäten \\ der Georg-August-Universität zu Göttingen
}

\author{
vorgelegt von \\ Diplom-Chemiker \\ Michael Günther Georg Fuchs \\ aus Marburg
}

Göttingen 2009 
D7

Referent: Prof. Dr. Franc Meyer Korreferent: Prof. Dr. Ulf Ryde

Tag der mündlichen Prüfung: 21.10.2009 


\section{Contents}

1 Introduction 1

1.1 The Role of Fe/S Clusters in Biological Systems . . . . . . . . . . 1

1.2 General Features of Biological $\mathrm{Fe} / \mathrm{S}$ Clusters . . . . . . . . . . 2

1.2.1 Structural Features..................... 2

1.2.2 $\mathrm{Fe} / \mathrm{S}$ Cluster Assembly and Cluster Conversions ......... . 5

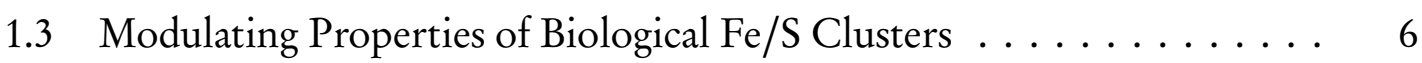

1.3.1 Ligand Exchange in $[2 \mathrm{Fe}-2 \mathrm{~S}]$ Clusters $\ldots \ldots \ldots \ldots \ldots \ldots$

1.3.2 Ligand Exchange in $[4 \mathrm{Fe}-4 \mathrm{~S}]$ Clusters . . . . . . . . . . 11

$1.4 \mathrm{Fe} / \mathrm{S}$ Clusters as the Source of Sulphur Atoms in Biological Radical Re-

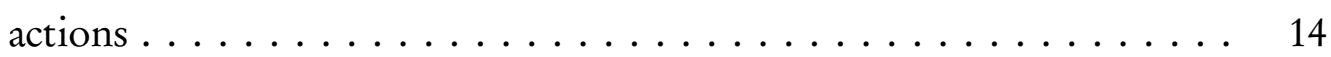

1.5 Biomimetic $[2 \mathrm{Fe}-2 \mathrm{~S}]$ and $[4 \mathrm{Fe}-4 \mathrm{~S}]$ Clusters $\ldots \ldots \ldots \ldots \ldots \ldots$

1.6 Missing Pieces: Models for Unusual Fe/S Clusters and Cluster Reactivity 19

2 [2Fe-2S] Clusters with Allyl-Substituted Biphenolate and Dithiophenolate Ligands 21

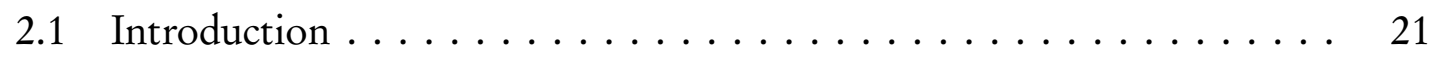

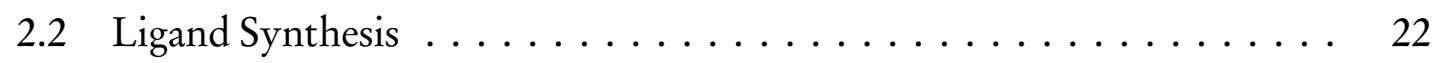

2.2.1 Synthesis of Allyl-Substituted Biphenol Ligands . . . . . . . . 22

2.2.2 Synthesis of Allyl-Substituted Dithiophenol Ligands . . . . . . . 23

2.3 Synthesis and Structural Characterisation of [2Fe-2S] Clusters . . . . . 29

2.4 Spectroscopic and Electrochemical Properties of [2Fe-2S] Clusters . . 34

2.5 Further Functionalisation of the Allyl Groups . . . . . . . . . . . . . 39

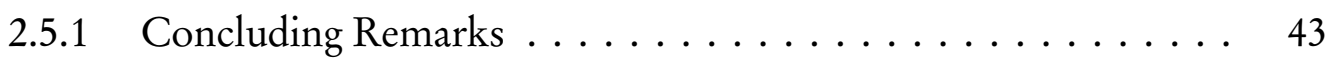

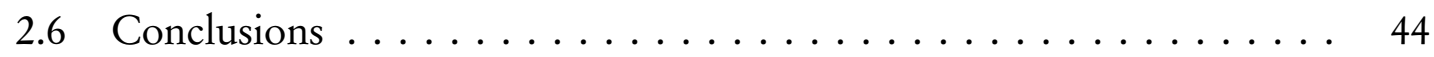

3 Synthesis of $\mathrm{N}$-Coordinated [2Fe-2S] and [4Fe-4S] Clusters 45

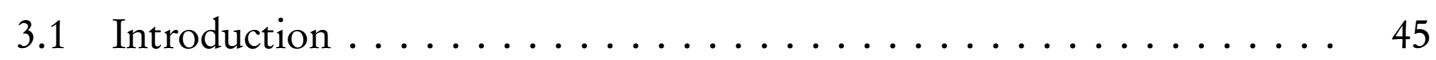


3.2 Initial Observations . . . . . . . . . . . . . . . . . 46

3.3 Synthesis and Characterisation of the $[2 \mathrm{Fe}-2 \mathrm{~S}]$ Cluster $\ldots \ldots \ldots \ldots 46$

3.4 Synthesis and Characterisation of the $[4 \mathrm{Fe}-4 \mathrm{~S}]$ Cluster $\ldots \ldots \ldots . . \ldots 50$

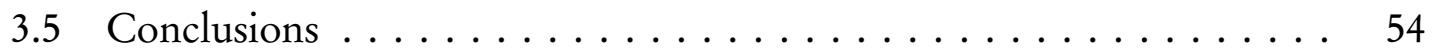

4 Synthesis of Five-Coordinate [2Fe-2S] Clusters 55

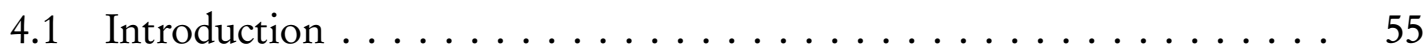

4.2 Synthesis of the Ligands $\ldots \ldots \ldots \ldots \ldots \ldots \ldots \ldots \ldots$

4.3 Complex Syntheses and General Observations . . . . . . . . . . . . 58

4.4 Characterisation of Five-Coordinate Fe/S Clusters . . . . . . . . . . 61

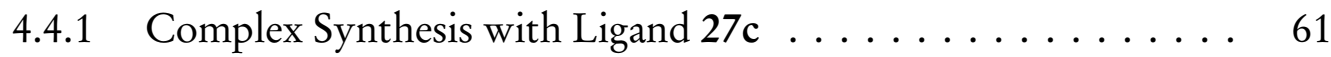

4.4.2 Complex Synthesis with Ligand 27a $\ldots \ldots \ldots \ldots \ldots \ldots . \ldots 2$

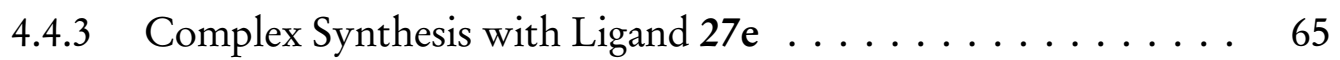

4.5 Further Characterisation of $[2 \mathrm{Fe}-2 \mathrm{~S}]$ Cluster $33 \ldots \ldots \ldots \ldots .68$

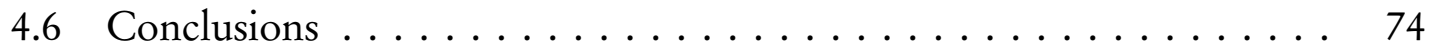

5 Radical Fe/S Cluster Chemistry $\quad 75$

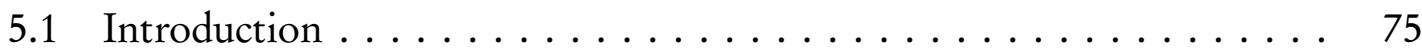

5.2 Results........................ 76

5.2.1 General Considerations $\ldots \ldots \ldots \ldots \ldots \ldots \ldots .76$

5.2.2 Reactions with Azo-Compounds V-70 and V-40 . . . . . . . 78

5.2.3 Reactions with Peroxo Compounds . . . . . . . . . . . . 78

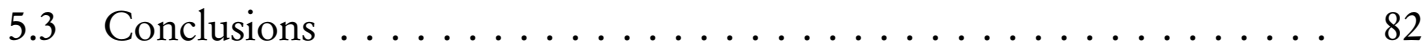

6 A Computational Investigation of the [2Fe-2S] Cluster in Biotin Synthase 83

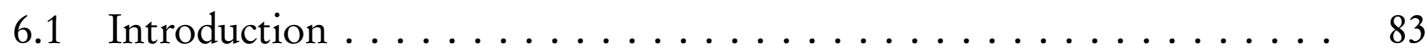

6.2 Results and Discussion $\ldots \ldots \ldots \ldots \ldots \ldots \ldots \ldots \ldots \ldots$

6.2.1 Explorative Calculations . . . . . . . . . . . . . . . . 85

6.2.2 Dicussion of Calculated Geometries . . . . . . . . . . . . 86

6.2.3 Calclulated Energies . . . . . . . . . . . . . . . . . . . . 88

6.2.4 Calculated Mössbauer Parameters . . . . . . . . . . . . . . 89

6.3 Conclusions . . . . . . . . . . . . . . . . . . . . . . . 90 
7 Experimental Part $\quad 91$

7.1 General Experimental Considerations . . . . . . . . . . . . . 91

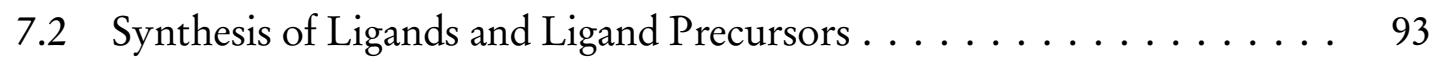

7.3 Synthesis of $\mathrm{Fe} / \mathrm{S}$ Clusters . . . . . . . . . . . . . . . . . . 103

7.4 Synthesis of Non-Iron Complexes . . . . . . . . . . . . . . . . . . 112

7.5 Electrochemical Measurements . . . . . . . . . . . . . . . . 114

7.6 Magnetic Susceptibility Measurements . . . . . . . . . . . . . 115

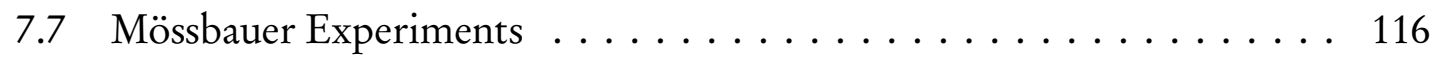

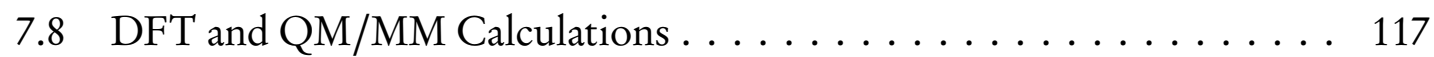

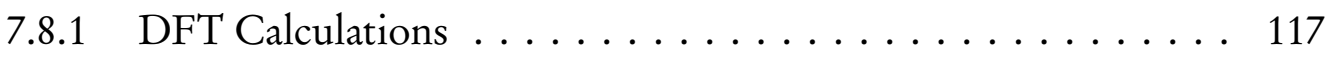

7.8 .2 QM/MM Calculations .................. 122

Appendix 125

Crystallography ............................... 125

Bibliography ........................ 131

Structures of Ligands and Ligand Precursors . . . . . . . . . . . . 148

Structures of Complexes and Clusters . . . . . . . . . . . . . . 151

List of Abbreviations . . . . . . . . . . . . . . . . . . . . . 154

List of Scientific Contributions $\ldots \ldots \ldots \ldots \ldots \ldots \ldots \ldots \ldots$

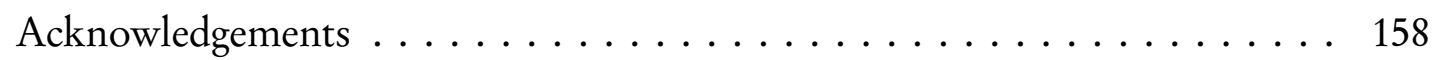

Curriculum Vitae ............................. 160 



\section{Introduction}

\subsection{The Role of Fe/S Clusters in Biological Systems}

Biological $\mathrm{Fe} / \mathrm{S}$ clusters are cofactors common to all living organisms. ${ }^{[1]}$ In fact, they are not only believed to belong to the most ancient biological cofactors ${ }^{[2]}$ but simple inorganic compounds which can be regarded as their predecessors are argued as critical factors of evolution of life on earth itself. ${ }^{[3]}$ The basic reaction

$$
\mathrm{FeS}+\mathrm{H}_{2} \mathrm{~S} \rightarrow \mathrm{FeS}_{2}+2 \mathrm{H}^{+}+2 \mathrm{e}^{-}
$$

is discussed as the first energy source of life. ${ }^{[4]}$ In experiments modelling the putative conditions under which life evolved - the Iron-Sulphur World ${ }^{[5]}$-, compounds containing iron, nickel and sulphur could be shown to catalyse the synthesis of activated thioesters and thereby performing carbon fixation. ${ }^{[6]}$

$\mathrm{Fe} / \mathrm{S}$ clusters were first discovered in 1960 by EPR spectroscopy. ${ }^{[7]}$ The earliest examples of enzymes containing Fe/S clusters, identified as non-haem iron-containing proteins and named ferredoxins ${ }^{[8]}$, were isolated shortly thereafter and their function in electron transport was recognised. ${ }^{[8,9]}$

Still in the 1960's the presence of "inorganic" or "acid-labile" sulphide $\mathrm{S}^{2-}$ was detected $^{[10]}$ as well as methods for its reconstitution ${ }^{[11]}$. The biological "choice" of iron ${ }^{[12]}$ and sulphur ${ }^{[13,14]}$ can be explained - apart from the natural abundance especially of iron - by their chemical versatility, e.g., in terms of the facile accessibility of different oxidation states. A prominent feature and a perfect qualification for their use in electron transfer and other redox processes is the delocalisation of the electrons over the cluster which allows for rapid redox reactions as well as electronic fine-tuning. ${ }^{[15,16]}$

This results in redox potentials of $\mathrm{Fe} / \mathrm{S}$ proteins ranging from -600 to $+400 \mathrm{mV}^{[13,17]}$ - a range unrivalled by any other class of biochemical cofactors. ${ }^{[18]}$ It is impressively illustrated by the existence of chains - as in the mitochondrial electron-transfer system - consistent of 13 or $14 \mathrm{Fe} / \mathrm{S}$ clusters and of single enzymes - like mammalian NADH 
dehydrogenases - containing 8 or 9 clusters. ${ }^{[13]}$

Indeed, electron-transfer still is their best-known role, yet other surprisingly diverse roles have been identified. A prominent example is catalytic substrate activation first discovered in aconitase. ${ }^{[19]}$ To date, putative roles of $\mathrm{Fe} / \mathrm{S}$ proteins or clusters include those in a) electron transfer (in part proton-coupled), b) catalysis, c) stabilisation of protein structure, d) regulation of metabolic pathways, e) sensing iron, nitric oxide, dioxygen and superoxide ions, $\mathrm{f}$ ) iron and sulphur storage, g) generation of radicals, h) providing sulphur atoms in radical sulphur insertion reactions. ${ }^{[13,20-23]}$ As many of these roles are strongly connected, some clusters fulfil several of them coevally.

Often an unusual role goes along with - or rather is enabled by - unusual coordination or other interaction with the protein scaffold; this will be discussed in detail for $[2 \mathrm{Fe}-2 \mathrm{~S}]$ and $[4 \mathrm{Fe}-4 \mathrm{~S}]$ clusters in Chapter 1.3. For many of these non-redox functions nature has devised differing enzymes using other cofactors. Thus it is now postulated that - because of their evolutionary age - Fe/S proteins represent ancient means for these purposes for some of which more efficient substitutes were developed. Yet because of their extreme versatility and efficiency they are still crucial for many challenging biochemical pathways, e.g., the activation of small molecules like dinitrogen, and will probably never be replaced. ${ }^{[20]}$

\subsection{General Features of Biological Fe/S Clusters}

Since $\mathrm{Fe} / \mathrm{S}$ clusters are textbook examples for biological cofactors and have been treated in several books and reviews, ${ }^{[1,13,21-25]}$ only a short principal overview covering the general features will be given here.

\subsubsection{Structural Features}

Common to all $\mathrm{Fe} / \mathrm{S}$ clusters is the presence of iron atoms coordinated by sulphur atoms originating from deprotonated cysteine residues and (except for rubredoxins) sulphide ions. The canonical or all-S coordinated Fe/S clusters are listed in Figure 1.1 together with their naturally occurring oxidation and spin states. Rubredoxins are counted among $\mathrm{Fe} / \mathrm{S}$ proteins because of their comparable characteristics although their [1Fe] cluster is simply an iron atom coordinated by four cysteines. ${ }^{[20]}$ They occur in the ferric $\left(\mathrm{Fe}^{\mathrm{III}}, S=5 / 2\right)$ or ferrous ( $\left.\mathrm{Fe}^{\mathrm{II}}, S=2\right)$ form just like the iron atoms in the more complex clusters. 


$$
\begin{aligned}
& \begin{array}{l}
\text { Cys } \\
{ }^{\text {Cys }} \cdot{ }^{\prime}{ }^{\prime} \text { Fe }^{-} S^{\text {Cys }}{ }^{\text {Cys }}
\end{array}
\end{aligned}
$$

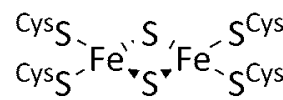

$$
\begin{aligned}
& {[1 \mathrm{Fe}]^{3+} S=5 / 2} \\
& {[2 \mathrm{Fe}-2 \mathrm{~S}]^{2+} \mathrm{S}=0} \\
& {[1 \mathrm{Fe}]^{2+} S=2} \\
& {[2 \mathrm{Fe}-2 \mathrm{~S}]^{+} S=1 / 2}
\end{aligned}
$$

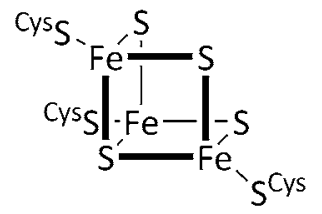

$[3 \mathrm{Fe}-4 \mathrm{~S}]^{+} S=1 / 2$

$[3 \mathrm{Fe}-4 \mathrm{~S}]^{0} S=2$

$[3 \mathrm{Fe}-4 \mathrm{~S}]^{-} S=5 / 2$

$[3 \mathrm{Fe}-4 \mathrm{~S}]^{2-}$

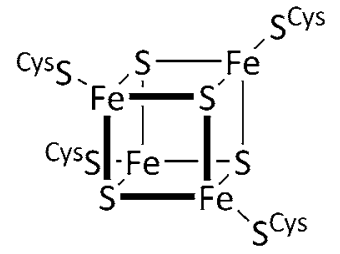

$[4 \mathrm{Fe}-4 \mathrm{~S}]^{3+} S=1 / 2$

$[4 \mathrm{Fe}-4 \mathrm{~S}]^{2+} S=0$

$[4 \mathrm{Fe}-4 \mathrm{~S}]^{+} S=1 / 2$

$[4 \mathrm{Fe}-4 \mathrm{~S}]^{0} \mathrm{~S}=4$

Figure 1.1: Small Fe/S clusters.

The simplest clusters containing sulphide ions are the [2Fe-2S] clusters mainly found in ferredoxins where they permit electron transfer by one-electron reduction. The oxidised all-ferric form $[2 \mathrm{Fe}-2 \mathrm{~S}]^{2+}$ has a diamagnetic ground state resulting from strong antiferromagnetic coupling of the high-spin iron atoms (total spin $S_{\mathrm{T}}=0$; for convenience, $S$ is used instead of $S_{\mathrm{T}}$ in the following). The reduced mixed-valent form $[2 \mathrm{Fe}-2 \mathrm{~S}]^{+}$obviously is paramagnetic and contains one ferric and one ferrous iron atom (valence-localised) which are also antiferromagnetically coupled $(S=1 / 2)$. Although the super-reduced, all-ferrous form $[2 \mathrm{Fe}-2 \mathrm{~S}]^{0}(S=0)$ is accessible by electrochemistry ${ }^{[26]}$ it probably is of no importance in nature.

The $[2 \mathrm{Fe}-2 \mathrm{~S}]$ clusters can be regarded as the building blocks for the larger and more complex clusters, with respect to both their biosynthesis and their electronic properties. Cubane-type [4Fe-4S] clusters are the most commonly found and also the most stable biological Fe/S clusters. In their usual mixed-valent $[4 \mathrm{Fe}-4 \mathrm{~S}]^{2+}$ ground state they contain an antiferromagnetically coupled pair of ferromagnetically coupled valencedelocalised $[2 \mathrm{Fe}-2 \mathrm{~S}]^{+}(S=9 / 2)$ units, resulting in a diamagnetic state $(S=0)$. The reasons for the different localisation patterns (localised in mixed-valent $[2 \mathrm{Fe}-2 \mathrm{~S}]^{+}$clusters and delocalised in the $[2 \mathrm{Fe}-2 \mathrm{~S}]^{+}$fragment of $[4 \mathrm{Fe}-4 \mathrm{~S}]^{2+}$ clusters) have been investigated by experimental and theoretical techniques, examining the importance of different electronic exchange paths. ${ }^{[21]}$ Like the $[2 \mathrm{Fe}-2 \mathrm{~S}]$ clusters, $[4 \mathrm{Fe}-4 \mathrm{~S}]$ clusters usually undergo one-electron reduction to the $[4 \mathrm{Fe}-4 \mathrm{~S}]^{+}(S=1 / 2)$ form, whereas in some cases - the high-potential iron-sulphur proteins or HiPIP's - the oxidation to the [4Fe-4S $]^{3+}$ $(S=1 / 2)$ form is utilised. The all-ferrous $[4 \mathrm{Fe}-4 \mathrm{~S}]^{0}$ state is at least accessible in one case under strongly reducing conditions and is discussed to play a role as a two-electron 
donor in nitrogenase. ${ }^{[27]}$

Removal of one iron atom leads to cuboidal [3Fe-4S] clusters - first interpreted as $[3 \mathrm{Fe}-3 \mathrm{~S}]$ clusters - as found in the inactive form of aconitase ${ }^{[28]}$ or in some ferredoxins ${ }^{[29,30]}$. Detected in four spin states so far, the cuboidal cluster in aconitase can be rearranged to the linear form in non-physiological $\mathrm{pH}$ ranges or in the presence of large amounts of urea. ${ }^{[31-33]}$

There are two examples known to date of even larger Fe/S units which contain no other metal, namely the $\mathrm{P}^{\mathrm{N}}$ cluster of nitrogenase and the $\mathrm{H}$ cluster of iron-only hydrogenase. Although of no direct importance for this work, they shall be described as examples of sophisticated Fe/S cluster architecture. Furthermore, the iron-molybdenum cofactor of nitrogenase containing an additional molybdenum ion is shortly introduced due to its outstanding importance in biochemistry (Figure 1.2). ${ }^{[25]}$

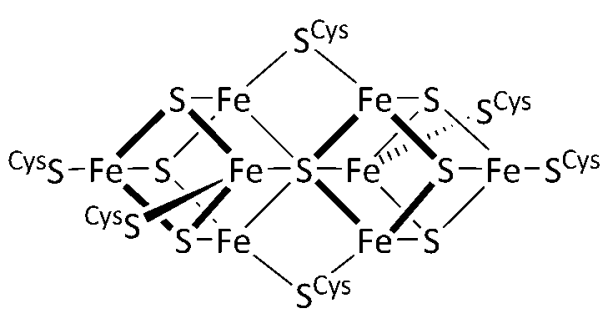

$\mathrm{P}^{\mathrm{N}}$ cluster

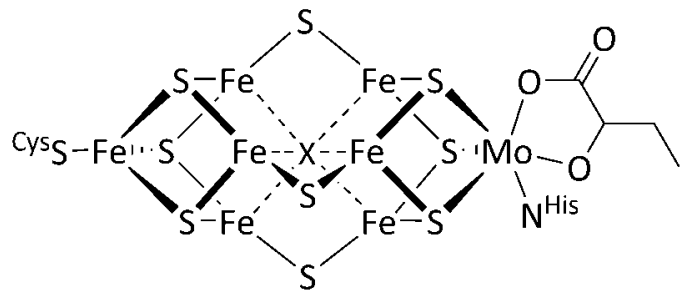

FeMoco

$[8 \mathrm{Fe}-7 \mathrm{~S}]^{3+} S=1 / 2$

$[8 \mathrm{Fe}-7 \mathrm{~S}]^{2+} S=0$

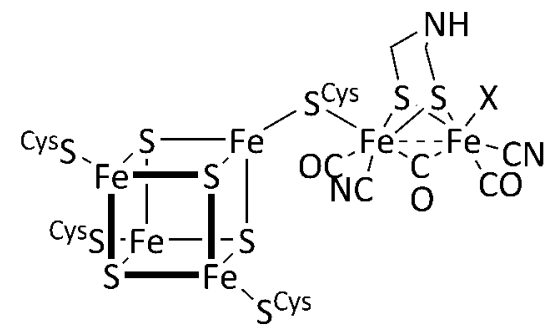

H cluster

Figure 1.2: Extended Fe/S clusters.

The $[8 \mathrm{Fe}-7 \mathrm{Fe}] \mathrm{P}^{\mathrm{N}}$ cluster from nitrogenase can be interpreted as a composite consisting of one $[4 \mathrm{Fe}-4 \mathrm{~S}]$ and one $[3 \mathrm{Fe}-4 \mathrm{~S}]$ cluster connected via a sulphide ion of the [4Fe-4S] cluster. The coordination spheres of the iron atoms are completed by six cysteines, two of which bridge two iron atoms each of the separate subclusters. The first of several crystal structures was published in 1992, showing also the iron-molybdenum cofactor or FeMoco in the active site to be a $[\mathrm{Mo}-7 \mathrm{Fe}-9 \mathrm{~S}]$ cluster. $^{[34]}$ The latter is attached 
to the protein backbone by only two residues, namely a cysteine on one iron atom and a histidine on the molybdenum atom which is additionally coordinated by a homocitrate ligand. The identification of an additional light atom, most probably nitrogen, inside the FeMoco has supported its likely role as the site of biological nitrogen fixation. ${ }^{[35]}$

The second example of a large cluster or cluster composite containing no other metal than iron is the $\mathrm{H}$ cluster of hydrogenase where a [4Fe-4S] cluster is connected to an unusual low-valent two-iron moiety via a bridging cysteine residue. ${ }^{[36]}$ The octahedral iron atoms are additionally bridged by a $\mathrm{CO}$ or $\mathrm{CN}$ molecule and coordinated by $\mathrm{CO}$ and CN ligands. The bridging sulphur donors are either modelled as sulphide ions or as a 1,3-propanedithiolate, or more probably a di(thiomethyl)amino moiety thus providing a base which can be protonated during hydrogenase reaction. ${ }^{[37,38]}$

The versatility of $\mathrm{Fe} / \mathrm{S}$ clusters is further expanded by coupling to other cofactors or metal ions like sirohaem in sulfite reductase. ${ }^{[39]}$ In carbon monoxide reductases a [4Fe$4 \mathrm{~S}]$ cluster was found, bridged by one of the coordinating cysteines to $\mathrm{a} \mathrm{Cu} / \mathrm{Ni}^{[40]}, \mathrm{a}$ $\mathrm{Zn} / \mathrm{Ni}^{[41]}$ or a $\mathrm{Ni} / \mathrm{Ni}^{[41,42]}$ site. While it is postulated that only the latter form containing two $\mathrm{Ni}$ ions is active, ${ }^{[41,42]} \mathrm{a}[\mathrm{Ni}-4 \mathrm{Fe}-5 \mathrm{~S}]$ cluster was found in a different carbon monoxide dehydrogenase ${ }^{[43]}$. Some carbon monoxide dehydrogenases also display acetyl coenzyme A synthase activity leading to some confusion in nomenclature. ${ }^{[44]}$ As for general $\mathrm{Fe} / \mathrm{S}$ proteins, there are some reviews and book chapters concentrating on these sophisticated enzymes. ${ }^{[25,38,45-48]}$

\subsubsection{Fe/S Cluster Assembly and Cluster Conversions}

In contrast to the identification of the different classes of $\mathrm{Fe} / \mathrm{S}$ clusters, a basic understanding of their biosynthesis has only emerged relatively late. ${ }^{[23]}$ It was shown very early that, in principle, Fe/S clusters can be reconstituted in an apoprotein by the addition of ferrous iron and sulphide ions. ${ }^{[11]}$ However, given the toxicity of free iron and sulphide ions in a cell this self-assembly reaction is certainly not the relevant pathway of biological Fe/S assembly. Several proteins and mechanisms have been identified that are crucial for $\mathrm{Fe} / \mathrm{S}$ cluster biosynthesis in different cellular compartments for eukaryotes. ${ }^{[49,50]}$ In bacteria, investigation of the nitrogenase system has given important insights. ${ }^{[51]}$ At least four different systems have been shown to exist, referred to as Nif, Isc, Suf and Cia. ${ }^{52-56]}$ The overall assembly of Fe/S clusters can be separated into two main steps, namely the de novo synthesis of the cluster on a scaffold protein, and the subsequent transfer of the cluster to the target protein. The first part includes a) sulphur 
donation by cysteine desulfurases, b) iron donation, c) electron transfer and d) cluster assembly, while in the second process [2Fe-2S] clusters seem to act as building blocks for the larger clusters. ${ }^{[52]}$ Although important progress has been achieved, there are still several challenging problems in this highly complex field of research.

Cluster assembly is by nature closely related with cluster conversions. ${ }^{[13,21]}$ As already illustrated on the conversion of the $[4 \mathrm{Fe}-4 \mathrm{~S}]$ cluster to a $[3 \mathrm{Fe}-4 \mathrm{~S}]$ cluster in aconitase, $\mathrm{Fe} / \mathrm{S}$ clusters are not invariable structures and cluster conversion is a frequent observation. Even when it is not relevant to the enzyme mechanism, it can make the identification of a biological $\mathrm{Fe} / \mathrm{S}$ cluster difficult, e.g., in proteins purified under nonphysiological conditions. Apart from the mentioned conversion of [4Fe-4S] to [3Fe$4 \mathrm{~S}$ ] clusters which is partially reversible, the interconversion of [2Fe-2S] and [4Fe-4S] clusters is most frequent; this feature is connected to the role of $\mathrm{Fe} / \mathrm{S}$ cluster as sensors. Finally, $[1 \mathrm{Fe}]$ centres of rubredoxins can be converted to [2Fe-2S] clusters, a fact that justifies that they are counted among $\mathrm{Fe} / \mathrm{S}$ proteins.

\subsection{Modulating Properties of Biological Fe/S Clusters: Unusual $[2 \mathrm{Fe}-2 \mathrm{~S}]$ and $[4 \mathrm{Fe}-4 \mathrm{~S}]$ Clusters}

Due to the sheer quantity of known Fe/S clusters which have already been reviewed thoroughly in the literature (see above) only a small part of the various cluster types shall be introduced in more detail here. The general motivation of the investigations presented here is to explore the means by which properties of small $\mathrm{Fe} / \mathrm{S}$ clusters are fine-tuned to be able to fulfil such diverse roles though sharing the same cluster core. Thus, the focus is laid on those clusters most relevant to this work, namely [2Fe-2S] and $[4 \mathrm{Fe}-4 \mathrm{~S}]$ clusters whose structural features and properties differ from the normal clusters, i.e., all-cysteine coordinated clusters used in electron transfer.

The most obvious modification is the mutational exchange of a coordinating cysteine residue by another amino acid. Similarly, the cysteine can also be replaced by a ligand that is no amino acid residue. Interestingly, natural occurence of non-cysteine coordination was only detected more than 20 years after the discovery of $\mathrm{Fe} / \mathrm{S}$ clusters: ${ }^{[57]}$ Solution of the crystal structure of aconitase in 1989 proved previous findings ${ }^{[32]}$ predicting oxygen coordination from a water molecule or hydroxide ion to one of the iron atoms. ${ }^{[58]}$ 


\subsubsection{Ligand Exchange in $[2 \mathrm{Fe}-2 \mathrm{~S}]$ Clusters}

\section{Replacement of Cysteines by Other Amino Acids}

As for the $[2 \mathrm{Fe}-2 \mathrm{~S}]$ clusters, the first protein-bound clusters to be discoverd bearing non-cysteine ligands (Figure 1.3a)) were those found in Rieske proteins, originally discovered in 1964. ${ }^{[59]}$ While coordination by atoms other than sulphur was known from spectroscopic studies, the crystal structure of a water soluble fragment ${ }^{[60]}$ and subsequently the whole cytochrome $b c_{1}$ complex ${ }^{[61]}$ of bovine heart mitochondria confirmed one iron atom to be bound to two histidine imidazole rings. This and other structures of Rieske proteins reveiled the $[2 \mathrm{Fe}-2 \mathrm{~S}]$ cluster to lie on the surface of the protein and thus to be solvent-exposed (Figure 1.3d)). ${ }^{[62]}$
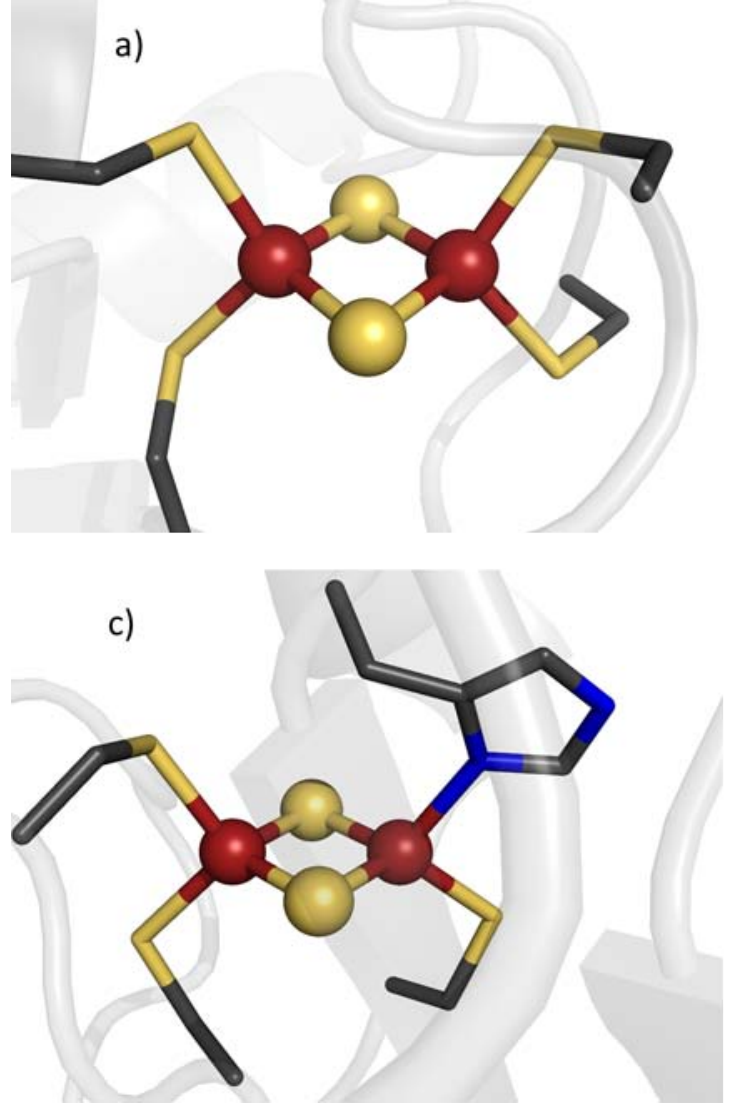

b)
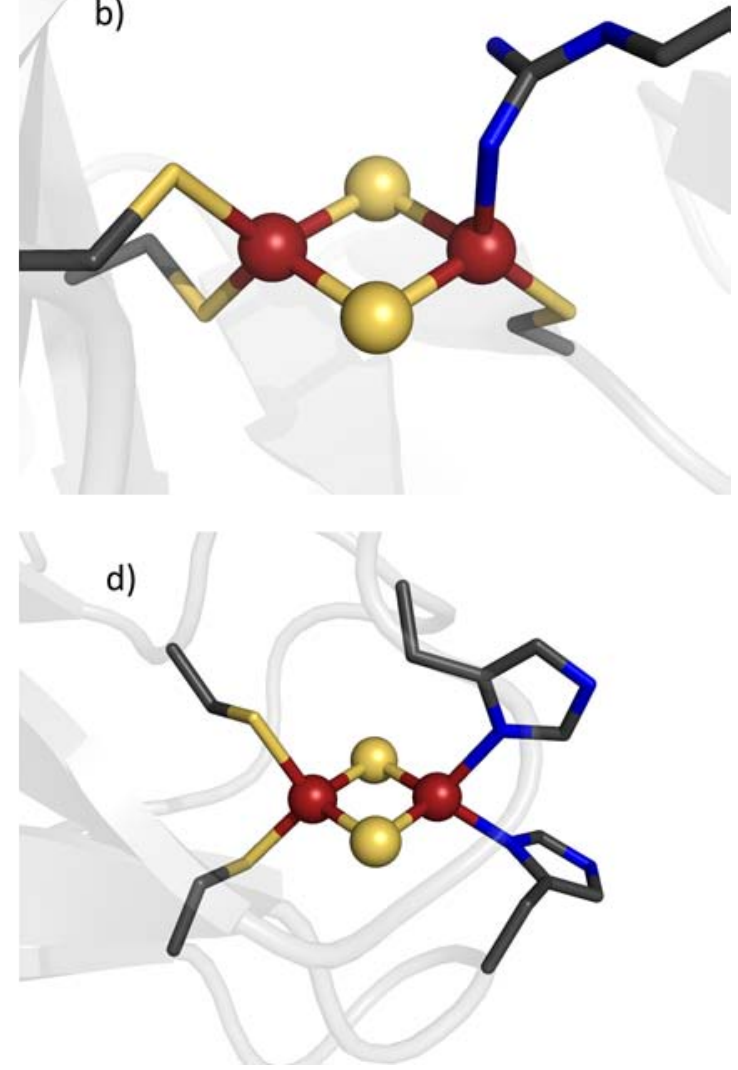

Figure 1.3: Naturally occurring [2Fe-2S] cluster variants with coordination by different amino acids.

- Details of the crystal structures of a) ferredoxin (PDB code 1QT9) ${ }^{[63]}$, b) biotin synthase (PDB code 1R30) ${ }^{[64]}, \mathrm{c}$ ) mitoNEET (PDB code $\left.2 \mathrm{QH7} 7\right)^{[65,66]}$ d) Rieske protein (PDB code 1RIE) ${ }^{[60]}$. 
Apart from the well-known Rieske type clusters there are others exhibiting noncysteine amino acid coordination. The first natural occuring example to be discovered although not structurally characterised was a [2Fe-2S] cluster from flavoprotein sulphide dehydrogenase with coordination by one aspartate residue in addition to three cysteine residues. ${ }^{67]}$

Some years before, mutation experiments were reported on ferredoxins in which different coordinating cysteines were exchanged by serines. ${ }^{[68]}$ EPR and Mössbauer experiments gave evidence for a reduced state in which the spins of the iron atoms are ferromagnetically coupled $(S=9 / 2)$ - in surprising contrast to other [2Fe-2S] clusters with antiferromagnetic coupling. ${ }^{[69,70]}$ Similar mutant proteins could later be crystallised. ${ }^{[71]}$

Probably the most unexpected natural variant was reported in 2004 when the crystal structure of biotin synthase reveiled a cluster coordinated by an arginine residue (Figure 1.3b)). ${ }^{[64]}$ However, both the exact coordination mode and the role of this highly exceptional ligand ${ }^{[72]}$ remained elusive.

In two crystallographically characterised proteins an exchange of just one cysteine by a histidine was found (Figure 1.3c)). The first is an outer mitochondrial membrane protein (called mitoNEET for its location in the mitochondria and the presence of the amino acid sequence Asn-Glu-Glu-Thr, NEET), crystallised independently by two groups. ${ }^{[65,66,73]}$ The redox-active $[2 \mathrm{Fe}-2 \mathrm{~S}]$ cluster can be removed under acidic conditions, probably due to protonation of the histidine residue. ${ }^{[65]}$ Obviously, mitoNEET is distinct from other known $\mathrm{Fe} / \mathrm{S}$ proteins as no structural homologues were found, and all four ligands are contained within a small modular unit of only 17 amino acid residues. However, this binding motif was then identified in seven distinct groups of proteins which are therefore also likely to be identified as yet unknown $\mathrm{Fe} / \mathrm{S}$ proteins. ${ }^{[73]}$ With its function still unknown, mitoNEET - originally identified as a binding target of an antidiabetic drug - is of special interest since it is the first identified outer mitochondrial membrane protein containing an $\mathrm{Fe} / \mathrm{S}$ cluster.

The other example of a natural coordination by three cysteines and one histidine was found in a protein involved in $\mathrm{Fe} / \mathrm{S}$ cluster assembly, namely Isc $\mathrm{U}$ which was crystallised as a homotrimer binding only one $[2 \mathrm{Fe}-2 \mathrm{~S}]$ cluster. ${ }^{[74]}$ Like in mitoNEET, the histidine is solvent-accessible. 


\section{Replacement of Protein-Bound Cysteines by Smaller Molecules}

Recently, two [2Fe-2S] clusters coordinated by ligands other than amino acid residues from the protein scaffold have been reported. In the first case, coordination is still provided by cysteine residues but not from the protein environment: In a crystal structure of a poplar glutaredoxin $\mathrm{C} 1$ tetramer the present [2Fe-2S] cluster was found to be coordinated by two cysteine residues of different protein monomers and by two glutathione cysteines, one on each iron atom (Figure 1.4a)). ${ }^{[75]}$ Glutathione, which usually acts as antioxidant and as a cysteine reservoir, was found to be important for Fe/S cluster maturation in yeast. ${ }^{[49]}$ In fact, structural evidence for delivery of an intact [2Fe-2S] cluster - in a similar coordination environment - by a monothiol glutaredoxin was reported very recently. ${ }^{[76]}$

An even more exotic coordination was found in the [FeFe]-hydrogenase maturase HydE where one cysteine residue is replaced by a water molecule (Figure 1.4b)). ${ }^{[77]}$ Together with HydF and HydG, HydE is crucial for the maturation of the active site of $[\mathrm{FeFe}]$-hydrogenase and thus - like the glutaredoxins mentioned above - involved in the assembly of $\mathrm{Fe} / \mathrm{S}$ proteins.
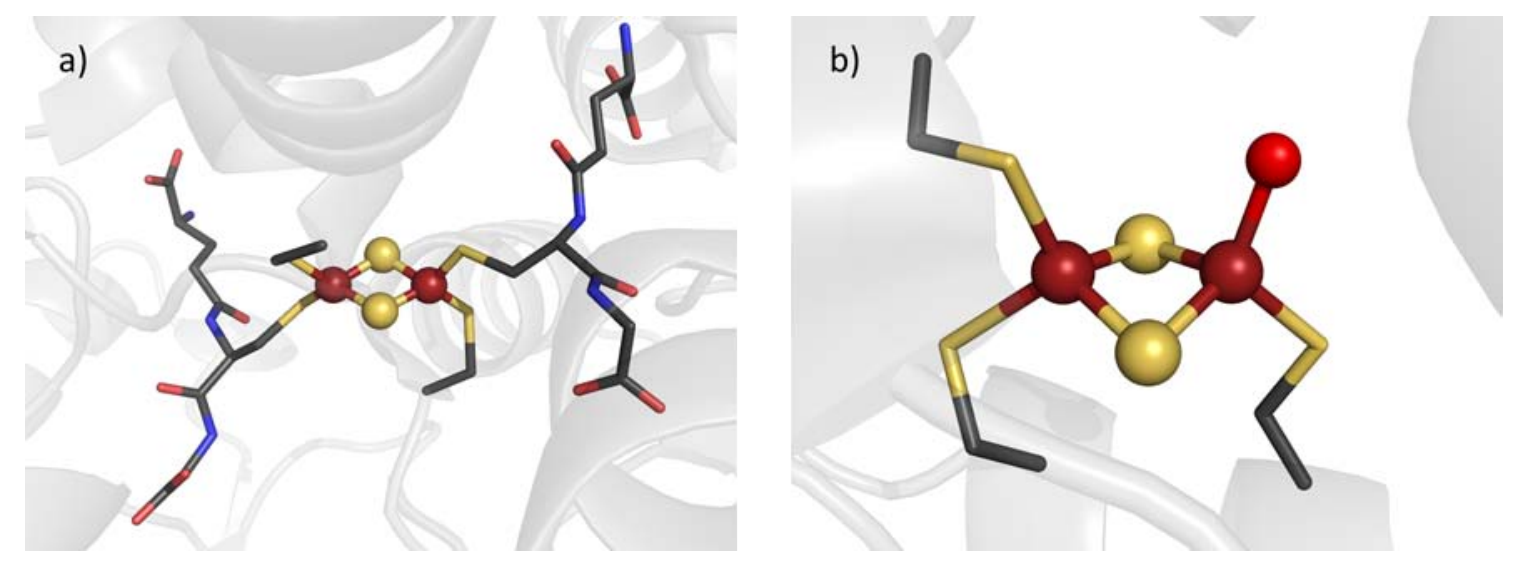

Figure 1.4: Naturally occurring [2Fe-2S] cluster variants with coordination by small molecules. - Details of the crystal structures of a) glutaredoxin C1 tetramer with two glutathion molecules bound (PDB code 2E7P) ${ }^{[75]}$, b) $[\mathrm{FeFe}]$-hydrogenase maturase HydE with a water molecule bound (PDB code $3 \mathrm{CIX})^{[77]}$.

\section{Minor Variations}

Even minor variations less obvious than ligand exchange can have significant influences on cluster properties. A prominent feature is the proton-coupled electron transfer 
displayed by the Rieske proteins, facilitated by protonation of the solvent-accessible histidine $\mathrm{N}^{\epsilon}$ atoms (Scheme 1.1). ${ }^{[78,79]}$ This leads to a drastically increased reduction potential compared to other ferredoxins. Differences in protonation of the histidine rings and in hydrogen bonds to the amino acid ligands as well as to the bridging sulphide ligands of the $[2 \mathrm{Fe}-2 \mathrm{~S}]$ cluster allow a tuning of the reduction potential in a vast range of -150 to $+400 \mathrm{mV}$ for Rieske proteins alone. The diverse interactions have been investigated extensively in the last few years using a combination of mutational, crystallographic, spectroscopic and computational techniques. ${ }^{[79-85]}$ Several characteristics allow a further separation of Rieske proteins into different groups, namely the highpotential $(+100$ to $+750 \mathrm{mV})$, the low-potential $(-150$ to $+5 \mathrm{mV})$ and the intermediatepotential proteins $(+60$ to $+100 \mathrm{mV}) .{ }^{[86]}$ Apart from their different potentials, they can also be distinguished by the strong $\mathrm{pH}$-dependence of the reduction potentials of the high-potential proteins in contrast to the relatively $\mathrm{pH}$-independent potentials of the low-potential proteins. Furthermore, only the former and the intermediate-potential proteins ${ }^{[87]}$ contain a disulphide bridge close to the $[2 \mathrm{Fe}-2 \mathrm{~S}]$ cluster. While this disulphide bridge is crucial for protein stability, it has only a minor influence on the redox potential.
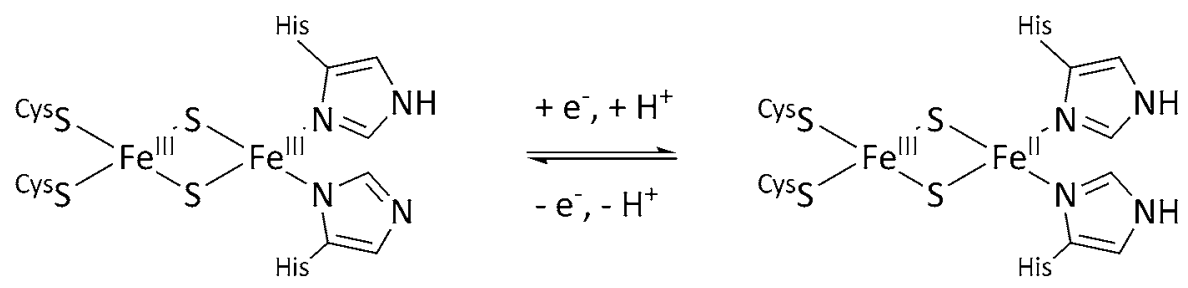

Scheme 1.1: Model reaction for the proton-coupled electron transport in Rieske proteins.

The other biologically relevant amino acid ligand allowing for interactions different from those offered by cysteine is arginine as found in biotin synthase. ${ }^{[64]}$ In contrast to cysteine, this arginine residue is a possible bidentate ligand coordinating one or two metal atoms in a bridging fashion. Furthermore, both $\mathrm{NH}$ or $\mathrm{NH}_{2}$ groups and the $\mathrm{N}^{\epsilon} \mathrm{H}$ group can act as hydrogen bond donors or acceptors, depending on the protonation state. Yet quite unlike the situation in the Rieske proteins, the role and even the exact coordination mode of this arginine are completely elusive to date. In a first approach, mutation experiments were performed which showed that this arginine ligand is not essential for the catalytic reaction which is described in detail in Chapter 1.4. ${ }^{[88]}$ It has been proposed that it may play electronic, mechanistic or structural roles, possibly re- 
lated to its bidentate nature or its positive charge in the protonated state.

Another example of secondary interactions was found in a $[2 \mathrm{Fe}-2 \mathrm{~S}]$ ferredoxin in which substantial conformational changes occurred upon reduction. ${ }^{[89]}$ First, the cluster itself was distorted from planar to a distorted lozenge. Second, a methionine side chain in close proximity was twisted by $180^{\circ}$ bringing its sulphur atom within hydrogen bonding distance of one of the sulphide bridges (Scheme 1.2). Although possibly connected with controlling the reduction potential of the cluster, its significance could not be explained yet.

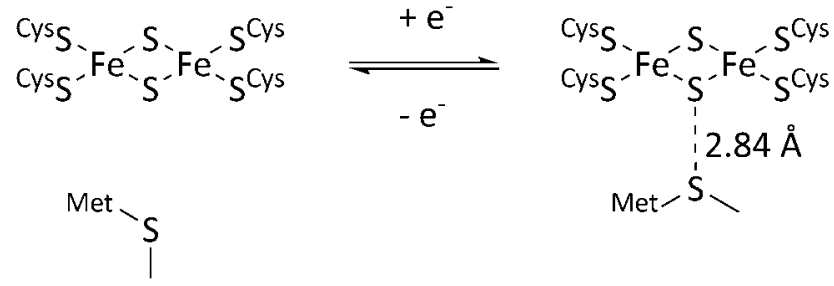

Scheme 1.2: Structural changes upon reduction of Rhodobacter capsulatus [2Fe-2S] ferredoxin. ${ }^{89]}$

\subsubsection{Ligand Exchange in [4Fe-4S] Clusters}

\section{Replacement of Cysteines by Other Amino Acids}

The first non-cysteine amino acid coordination on [4Fe-4S] clusters was found in the amino acid sequence of a Pyrococcus furiosus ferredoxin, where one cysteine is replaced by aspartate. The coordination by aspartate could be proven by spectroscopy ${ }^{[90]}$ and later by the crystal structure. ${ }^{[91]}$ As the first crystallographically characterised example, a $[4 \mathrm{Fe}-4 \mathrm{~S}]$ cluster coordinated by three cysteines and one histidine residue was found in a nickel-iron hydrogenase (Figure 1.5a)). ${ }^{[92]}$ Like in the Rieske proteins, the histidine residue is partially exposed on the protein surface possibly facilitating electron transfer. The same set of coordinating amino acids was shortly after found also in an Fe-only hydrogenase although in this case coordination occurred by $\mathrm{N}^{\epsilon}$ instead of $\mathrm{N}^{\delta}$ - unlike any other histidine-coordinated Fe/S cluster characterised so far (Figure 1.5b)). ${ }^{[36]}$ Again, the cluster is situated close to the protein surface but does not display an unusual redox potential.

In addition, the influence of amino acid exchange was investigated by several mutation experiments replacing one cysteine by either aspartate, serine or histidine. ${ }^{[93,94]}$ 

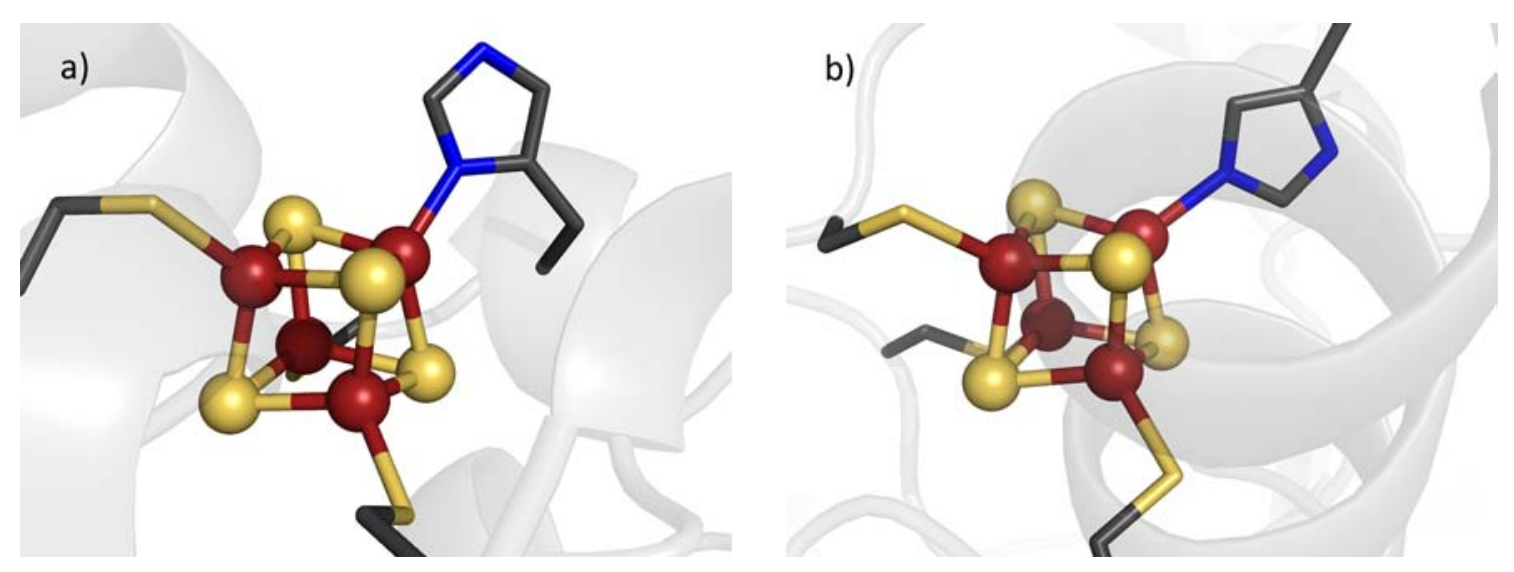

Figure 1.5: Naturally occurring [4Fe-4S] cluster variants with coordination by different amino acids.

- Details of the crystal structures of a) nickel-iron hydrogenase (PDB code 2FRV) ${ }^{[92,95]}$,

b) Fe-only hydrogenase (PDB code $1 \mathrm{FEH})^{[36]}$. The disordered structure of the Pyrococcus furiosus $[4 \mathrm{Fe}-4 \mathrm{~S}]$ ferredoxin containing an aspartate-coordinated iron atom has not been deposited at the $\mathrm{PDB} ;{ }^{[91]}$ as the unique iron atom is labile, only a structure of the [3Fe-4S] form has been deposited so far. ${ }^{[96]}$.

\section{Replacement of Protein-Bound Cysteines by Smaller Molecules}

There are two groups of naturally occurring [4Fe-4S] clusters coordinated by a small molecule (as compared to a protein) in addition to three cysteines which have been identified and crystallographically characterised so far. In both of them this molecule is a substrate which is activated by the binding or in a subsequent step. This is in contrast to the $[2 \mathrm{Fe}-2 \mathrm{~S}]$ clusters, where species bearing non-protein ligands rather seem to play a role in $\mathrm{Fe} / \mathrm{S}$ cluster assembly.

This kind of [4Fe-4S] cluster was first discovered in aconitase, where in the substratefree form a hydroxide ion is bound to one iron atom of the cluster exposed to the active centre (Figure 1.6a)). ${ }^{[58]}$ In the course of the reaction, citrate or isocitrate bind to the iron atom and they are interconverted via the intermediate aconitate. ${ }^{[20,97]}$

The second group is the radical SAM superfamily which has been identified as such in 2001 with over 600 members. ${ }^{[98]}$ Their common feature is a [4Fe-4S] cluster bound

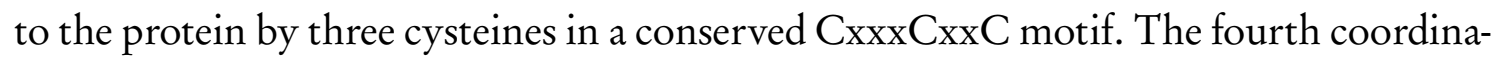
tion site may be occupied by $S$-adenosylmethionine (SAM) which could first be proven crystallographically in two cases, namely an oxygen-independent coproporphyrinogen III oxidase $(\mathrm{HemN})^{[99]}$ and biotin synthase $(\mathrm{BioB})^{[64]}$. SAM binds as a bidentate ligand via the amino and the carboxylate function (Figure 1.6b)). In addition, the sulfonium 
moiety is in close proximity to one of the sulphur atoms of the cluster. Initiated by oneelectron reduction of the $[4 \mathrm{Fe}-4 \mathrm{~S}]$ cluster, the $S$-adenosylmethionine cation is cleaved to generate methionine and an adenosyl radical which then can undergo a variety of reactions. Possibly reflecting an ancient conserved mechanism, these include unusual methylation, isomerisation, sulphur insertion, ring formation and further reactions. A general feature of the enzyme mechanisms is the cleavage of $\mathrm{C}-\mathrm{H}$ or similar unactivated bonds. Called a "poor man's adenosylcobalamine” in 1993[100] - since some of the reactions are in fact either catalysed by SAM or by adenosylcobalamine in different organisms - and still in $1998^{\text {[101] }}$, SAM was rather regarded a "rich man's adenosylcobalamine" only five years later as it is now recognised as the initiator of a greater diversity of radical reactions than adenosylcobalamin itself. ${ }^{[102]}$ Despite the relatively late discovery of the radical SAM superfamily they have been reviewed in some detail. [102-113]
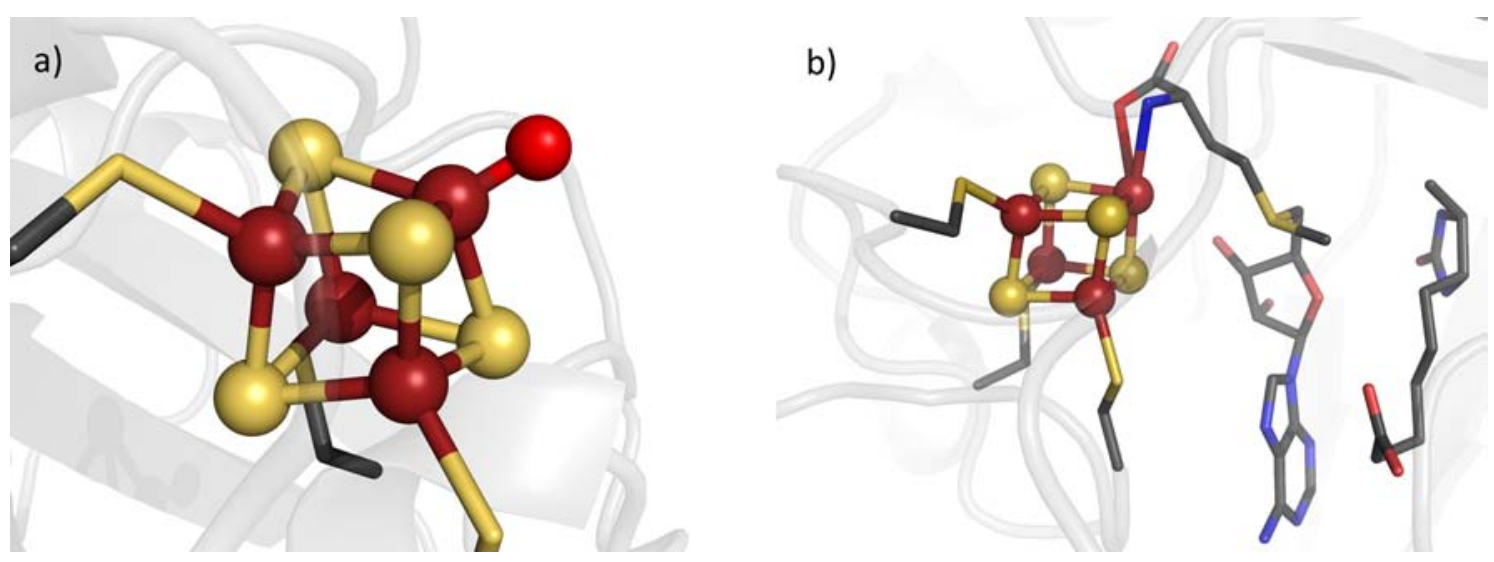

Figure 1.6: Naturally occurring [4Fe-4S] cluster variants with coordination by small molecules. - Details of the crystal structures of a) aconitase with a water molecule bound (PDB code $6 \mathrm{ACN})^{[58]}$, b) biotin synthase with SAM bound and DTB in the background (PDB code 1R30) ${ }^{[64]}$.

\section{Minor Variations}

There is a fascinating example of a $[4 \mathrm{Fe}-4 \mathrm{~S}]$ protein using the same redox couple as the HiPIPs, the redox potential of the cluster however is shifted to a far more negative potential due to the close proximity of a redox-active disulphide bridge. Reduction by one electron leads to cleavage of the disulphide bond and the additional coordination of one cysteine of the former disulphide bridge to one of the iron atoms. Upon a second one-electron reduction, this cysteinate dissociates and the whole system can then 
act as a two-electron reductant to reduce a disulphide bridge in chloroplast thioredoxin. Notably, both the presence of a five-coordinate iron atom and the use of an Fe/S cluster to reductively cleave a sulphur-containing substrate is reminiscent of radical SAM enzymes. ${ }^{[114]}$

\subsection{A Special Role: Fe/S Clusters as the Source of Sulphur Atoms in Biological Radical Reactions}

Among the superfamily of radical SAM enzymes there is a subclass of enzymes which catalyse sulphur insertion reactions via radical processes. ${ }^{[111]}$ To date, four enzymes of this class catalysing one of the most challenging reactions in chemical biology have been identified (Scheme 1.3): biotin synthase (BioB), lipoyl synthase (LipA), a tRNA-methylthiotransferase $(\mathrm{MiaB})$, and a ribosomal methylthiotransferase (RimO). ${ }^{[15]}$

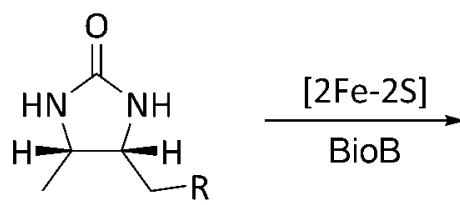<smiles></smiles><smiles>[R]C(=O)CCCCCCC</smiles>

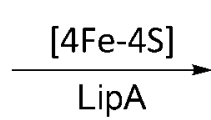<smiles>[R]C(=O)CCCCC(S)CCS</smiles><smiles>[R]c1ncnc2c1ncn2[R]</smiles>

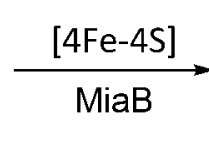<smiles>[R]c1nc(SC)nc2c1ncn2[R]</smiles><smiles>CNC(CC(=O)O)C(C)=O</smiles>

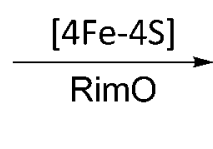<smiles>CNC(C(C)=O)C(SC)C(=O)O</smiles>

Scheme 1.3: C-S bond forming reactions catalysed by radical SAM enzymes.

The most extensively studied of those is biotin synthase which was first purified as a $[2 \mathrm{Fe}-2 \mathrm{~S}]$ protein ${ }^{[116]}$ and identified to be an enzyme using SAM in 1994. ${ }^{[117]}$ It was 
proved little later that biotin synthase produces biotin without any other protein, ${ }^{[118]}$ and that it uses neither cysteine nor adenosylmethionine ${ }^{[119]}$ but an Fe/S cluster as the direct sulphur source. ${ }^{[120]}$ Thus, biotin synthase and the related proteins are sometimes regarded as reagents rather than enzymes. ${ }^{[121]}$ Yet the exact assignment of the Fe/S clusters present in active biotin synthase proved difficult, in part due to its extreme oxygen sensitivity which leads to interconversion of the clusters. ${ }^{[122,123]}$ In 2000 the presence of two distinct clusters was reported ${ }^{[124]}$ and they were identified as one $[2 \mathrm{Fe}-2 \mathrm{~S}]$ and one $[4 \mathrm{Fe}-4 \mathrm{~S}]$ cluster the following year. ${ }^{[125]}$ It could then be shown that the $[2 \mathrm{Fe}-2 \mathrm{~S}]$ cluster is destroyed in the course of the reaction and a mechanism was proposed (Scheme 1.4). ${ }^{[126]}$
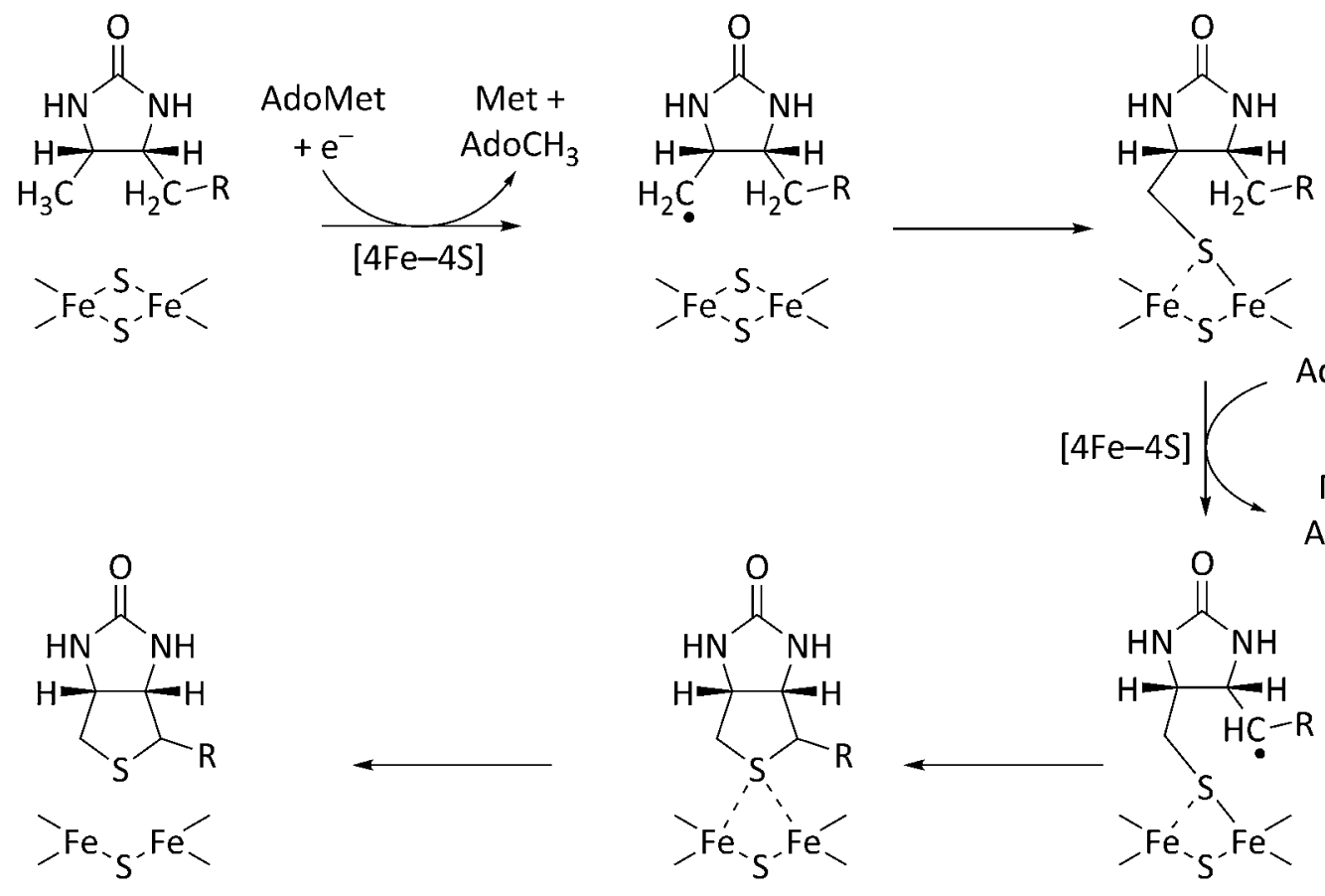

Scheme 1.4: Biotin synthase mechanism. ${ }^{[125]}$

- AdoMet: $\mathrm{S}$-adenosylmethionine, $\mathrm{AdoCH}_{3}$ : adenosine, Met: methionine.

The mechanism was later supported by the crystal structure showing all necessary cofactors, namely the [4Fe-4S] cluster, the $S$-adenosylmethionine molecule, the dethiobiotin substrate and the $[2 \mathrm{Fe}-2 \mathrm{~S}]$ cluster, lined up in a chain reflecting the reaction pathway (Figure 1.7). ${ }^{[64]}$

While the lipA gene product was connected with $\mathrm{C}-\mathrm{S}$ bond formation relatively early ${ }^{[127]}$ it almost took a decade to identify it as the enzyme catalysing the final step of lipoic acid biosynthesis. ${ }^{[128]}$ Subsequently it was shown that for insertion of the two 


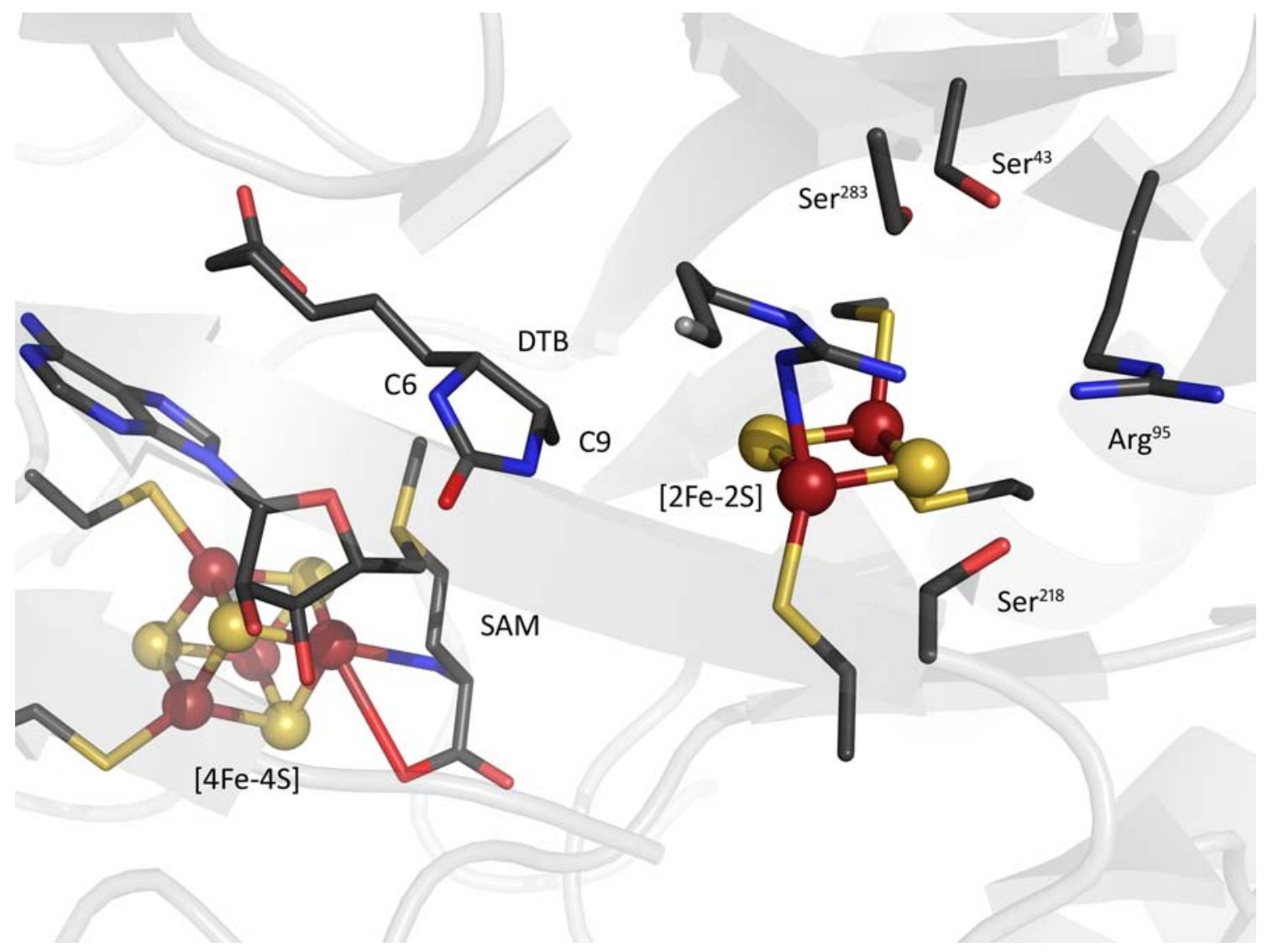

Figure 1.7: Detail of biotin synthase crystal structure. ${ }^{[64]}$

$-\mathrm{SAM}=S$-adenosylmethionine, $\mathrm{DTB}=$ dethiobiotin.

sulphur atoms of lipoic acid two SAM molecules are needed ${ }^{[129]}$ and that the whole reaction is catalysed by only one polypeptide ${ }^{[130]}$ in a stepwise manner ${ }^{[131]}$. The presence of two distinct [4Fe-4S] clusters - one used for radical generation and one as the probable source of both sulphur atoms - was also reported. [132]

Very recently $\mathrm{MiaB}$, which was already known to be an $\mathrm{Fe} / \mathrm{S}$ protein ${ }^{[133]}$ involved in methylthiolation of tRNA ${ }^{[134,135]}$, was also shown to contain two [4Fe-4S] clusters. ${ }^{[136]}$ RimO, the fourth protein of this subclass, bears strong similarity to MiaB and is involved in post-translational methylthiolation of an aspartic acid residue of a ribosomal protein. ${ }^{[137]}$ 


\subsection{Biomimetic $[2 \mathrm{Fe}-2 \mathrm{~S}]$ and $[4 \mathrm{Fe}-4 \mathrm{~S}]$ Clusters}

Not long after the initial discovery of Fe/S clusters it could be shown that analogues of these complexes could be chemically synthesised and that they do not require the presence of a protein environment. The first synthetic $[4 \mathrm{Fe}-4 \mathrm{~S}]^{2+}$ analogue was reported in $1972^{[138]}$ (Figure 1.8) followed by a [2Fe-2S $]^{2+}$ analogue in $1973^{[139]}$ (Figure 1.9). Thus, biomimetic analogues have ever been a powerful means to study assembly and conversion reactions and properties of the different $\mathrm{Fe} / \mathrm{S}$ species. ${ }^{[140,141]}$

$\left(\mathrm{NEt}_{4}\right)_{2}$<smiles>c1ccc2c(c1)CSC(SC1SCc3ccccc3S1)SC2</smiles><smiles>CC(C)SC(=NC(=O)N(C)C)SC(=NC(=O)N(C)C)SC(=N)N(C)C</smiles>

$\left(\mathrm{NEt}_{4}\right)_{2}$

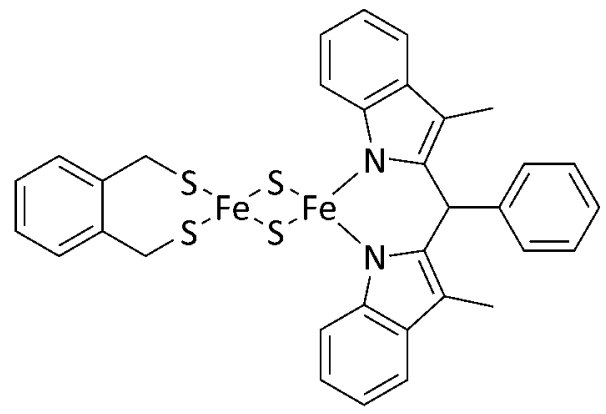

Figure 1.8: Biomimetic [2Fe-2S] cluster highlights.

- The first synthetic $[2 \mathrm{Fe}-2 \mathrm{~S}]$ cluster (top left) ${ }^{[139]}$, the first neutral [2Fe-2S] cluster (top right ${ }^{[142]}$, and the first structural analogue of Rieske type [2Fe-2S] clusters (bottom) ${ }^{[143]}$.

The range of available [2Fe-2S] clusters was fast extended to other clusters with thiolate ligands, both monodentate and bidentate, and about one decade later to clusters bearing ligands with oxygen donors, such as phenolates and diphenolates, ${ }^{[144,145]}$ and nitrogen donors in the case of a pyrrolate-coordinated cluster. ${ }^{[145]}$ This was inspired by the existence of the natural Rieske type clusters bearing non-sulphur ligands. Until very recently, all biomimetic [2Fe-2S] clusters were only isolated in the all-ferric form with anionic ligands, thus being dianions $\left[\mathrm{Fe}_{2} \mathrm{~S}_{2} \mathrm{~L}_{4}\right]^{2-}$. Compared to biological clusters, the reduction to the mixed-valent trianionic state is hampered as the excess negative charge cannot be delocalised via hydrogen bonds or similar interactions with an extended ligand scaffold. Nevertheless, reduction experiments were reported with [2Fe-2S] clusters bearing mainly bidentate oxygen, nitrogen and mixed S/O, N/O and N/S ligands, showing EPR signals which were compared to those of reduced Rieske proteins. ${ }^{146-148]}$ 
Despite this successful approach to reduced [2Fe-2S] clusters, none have yet been crystallised. A general observation is an increase in cluster stability by the use of bidentate ligands. This can in part be explained by the fact that upon reduction or in protic solvents, $[2 \mathrm{Fe}-2 \mathrm{~S}]$ clusters dimerise to give $[4 \mathrm{Fe}-4 \mathrm{~S}]$ clusters, yet this route is hindered by the bite angle of bidentate ligands and the resulting chelate ring size.

An important synthetic precursor for $[2 \mathrm{Fe}-2 \mathrm{~S}]$ clusters bearing organic ligands is $\left(\mathrm{NEt}_{4}\right)_{2}\left[\mathrm{Fe}_{2} \mathrm{~S}_{2} \mathrm{Cl}_{4}\right]^{[149,150]}$ which has terminal chloro ligands and allows easy ligand exchange reactions. Very recently, a novel synthetic route including ligand exchange on the indolate-coordinated cluster $\left(\mathrm{NEt}_{4}\right)_{2}\left[\mathrm{Fe}_{2} \mathrm{~S}_{2}\right.$ (indolate) $\left.{ }_{4}\right]$ was reported. ${ }^{[151]}$

More recently, the influence of hydrogen bonds was investigated on clusters with peptide ${ }^{[152]}$ and, also structurally, on clusters with simpler amide ligands ${ }^{[153]}$; the reduction potentials were indeed shifted to more positive values, yet no mixed-valent form could be crystallised. Very recently the influence of additional coordination by ether and thioether groups to the iron atoms was investigated. ${ }^{[154]}$ A major breakthrough was achieved by sequential ligand exchange on the chloride cluster leading to the first asymmetrically coordinated clusters including a structural analogue of Rieske type [2Fe-2S] clusters. ${ }^{[143]}$

Whereas all above-mentioned clusters are dianions, a neutral [2Fe-2S] cluster could be synthesised with two pairs of ligands based on a neutral thiourea derivative on the one hand and on a silylamide on the other hand. ${ }^{[142]}$ While solubility is different from the ionic species, the negative reduction potential is comparable to the dianionic complexes. Three of the highlights in biomimetic [2Fe-2S] cluster chemistry are shown in Figure 1.8.

Being of greater stability, biomimetic $[4 \mathrm{Fe}-4 \mathrm{~S}]$ clusters, like their biological counterparts, are more numerous than $[2 \mathrm{Fe}-2 \mathrm{~S}]$ analogues, and only three outstanding examples are shown in Figure 1.9. ${ }^{[140]}$ Apart from mixed-valent all-sulphur coordinated analogues $\left[\mathrm{Fe}_{4} \mathrm{~S}_{4}(\mathrm{SR})_{4}\right]^{2-}$, a focus was set on site-differentiated clusters and their reactivity, inspired by biological clusters like the active centre of aconitase (see Chapter 1.3) and relying on the use of a tridentate ligand leaving one accessible iron atom. ${ }^{[155-158]}$ Furthermore, isolation of [4Fe-4S] clusters in different oxidation states has been addressed, ${ }^{[159]}$ including recent examples of a fully-oxidised cluster with silylamide ligands ${ }^{[142]}$ and of a fully-reduced cluster bearing carbene ligands ${ }^{[160]}$. Like in the case of $[2 \mathrm{Fe}-2 \mathrm{~S}]$ clusters, ligands other than thiolates have been used such as chloride ${ }^{[149,161]}$ or phenolates ${ }^{[162]}$, and the influence of hydrogen bonds has been investigated. ${ }^{[153,163,164]}$

Concerning reactivity, cluster conversions have been thoroughly investigated with 

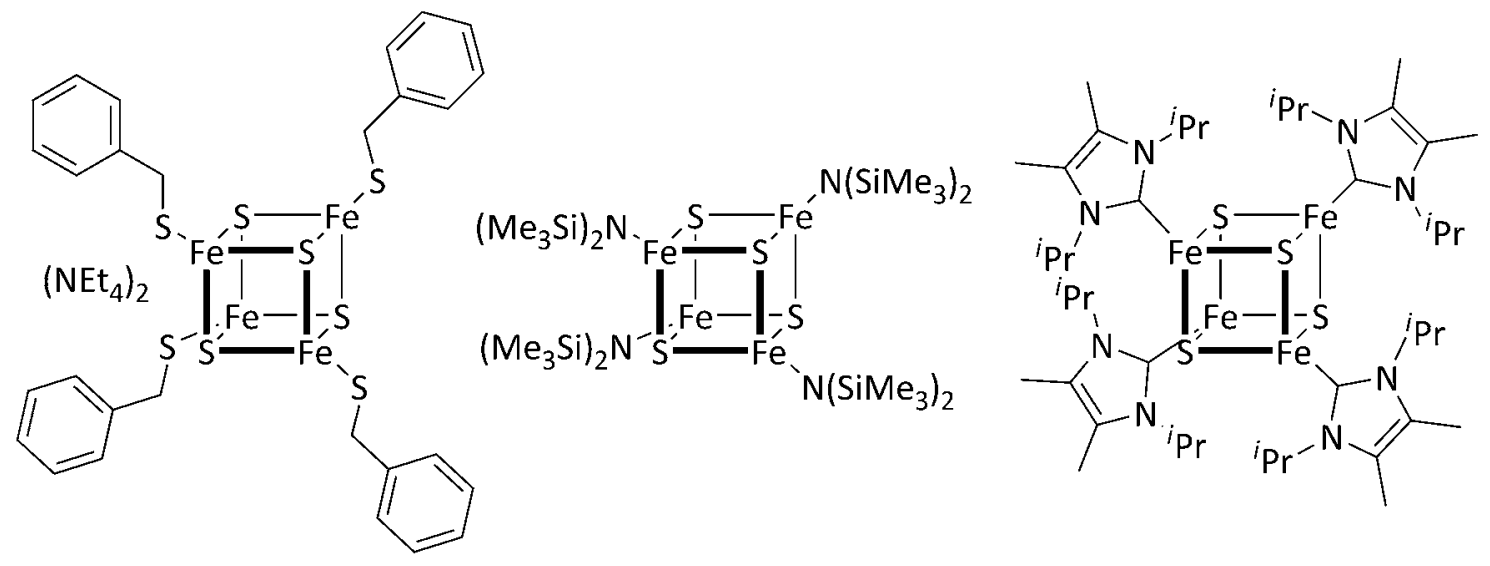

Figure 1.9: Biomimetic [4Fe-4S] cluster highlights.

- The first synthetic $[4 \mathrm{Fe}-4 \mathrm{~S}]$ cluster (left) ${ }^{[138]}$, the first all-ferric $[4 \mathrm{Fe}-4 \mathrm{~S}]$ cluster (centre $)^{[142]}$, and the first all-ferrous $[4 \mathrm{Fe}-4 \mathrm{~S}]$ cluster (right) ${ }^{[160]}$.

the observation of an overall trend to [4Fe-4S] cluster formation. ${ }^{[165,166]}$ Furthermore, reactions with protons ${ }^{[167,168]}$, with benzoyl chloride leading to the chloride coordinated cluster ${ }^{[169,170]}$ and with SAM-like sulfonium ions ${ }^{[171]}$ have been studied.

\subsection{Missing Pieces: Models for Unusual Fe/S Clusters and Cluster Reactivity - Motivation of this Work}

Despite more than three decades of very successful bioinorganic approaches, the biomimetic chemistry of small $\mathrm{Fe} / \mathrm{S}$ clusters, i.e., [2Fe-2S] and [4Fe-4S] clusters, is far from being settled, and there are still challenging tasks. The recent isolation of a model for Rieske type [2Fe-2S] clusters and the also asymmetrically coordinated intermediate are the only successful examples of [2Fe-2S] clusters with heteroleptic coordination of the two iron atoms so far. The approach relies on the steric bulk of one of the bidentate ligands and on a stepwise synthesis. Minimisation of by-product formation and their separation makes the synthesis of other complexes of this type considerably difficult. Therefore a different approach to asymmetrically coordinated [2Fe-2S] clusters was tested that uses one tetradentate instead of two bidentate ligands. Putative clusters with a tetradentate ligand are expected to have an increased stability compared to clusters bearing bidentate or even monodentate ligands. A variety of ligand precursors and [2Fe-2S] clusters of some ligand building blocks are presented in Chapter 2 along with other possible functionalisations of the ligands and their complexes. 
While in the design of tetradentate ligands dithiobiphenyls were employed as bidentate ligands mimicking the cysteine coordination of the Rieske type [2Fe-2S] cluster, the two coordinating histidine residues should be represented by monodentate $\mathrm{N}$ heterocyclic compounds. Since examples for clusters with non-chelating $\mathrm{N}$-coordinating ligands are still relatively rare, this type of complexes was extended by one species. In the course of the synthetic efforts to isolate a 2-methylindole coordinated [2Fe-2S] cluster, the respective $[4 \mathrm{Fe}-4 \mathrm{~S}]$ cluster was isolated as a by-product and subsequently rationally synthesised. Both the $[2 \mathrm{Fe}-2 \mathrm{~S}]$ and the $[4 \mathrm{Fe}-4 \mathrm{~S}]$ cluster are discussed in Chapter 3 , the latter being the first example of an all-N-coordinated $[4 \mathrm{Fe}-4 \mathrm{~S}]^{2+}$ cluster bearing organic ligands.

The importance of interactions other than the obvious coordination between the ligands and the cluster core is increasingly appreciated. For this reason the concept of secondary bonding interactions was further extended to genuine five-fold coordination of the iron atoms. A set of suitable ligands and their respective $\mathrm{Fe} / \mathrm{S}$ clusters was explored and one five-coordinate [2Fe-2S] cluster was thoroughly examined, as is described in Chapter 4.

While the role of $\mathrm{Fe} / \mathrm{S}$ clusters as the sulphur source in various SAM radical enzymes is widely accepted, analogous biomimetic reactions have not been reported by now. In order to open this field of research, explorative reactions of radicals and synthetic $\mathrm{Fe} / \mathrm{S}$ clusters have been examined. The first issues that have been addressed include the choice of suitable radical precursors, the possible need for special properties of the employed $\mathrm{Fe} / \mathrm{S}$ cluster and the means to follow the reaction and to identify reaction products. The first results in this intriguing field of $\mathrm{Fe} / \mathrm{S}$ cluster chemistry are presented in Chapter 5.

Finally, a closer look at the active centre of biotin synthase was taken. Like the Rieske type $[2 \mathrm{Fe}-2 \mathrm{~S}]$ clusters the cluster from biotin synthase has an asymmetric coordination environment. Moreover, the unique arginine residue coordinating one of the iron atoms is a highly unusual ligand in enzymes. Since the available crystal structure does not allow an exact interpretation of the coordination mode of the arginine side chain and of the overall geometry of the cluster, namely the highly exceptional Fe... Fe distance, a theoretical approach was employed to tackle this problem. The focus of this investigation was laid on the protonation state of the arginine's guanidine group, its exact coordination mode and the reason for the exceptional Fe...Fe distance. These questions and the conclusions that can be drawn from the calculations are described in Chapter 6. 


\section{2 [2Fe-2S] Clusters with Allyl-Substituted Biphenolate and Dithiophenolate Ligands}

\subsection{Introduction}

It has been shown that bidentate ligands are generally able to increase the stability of synthetic [2Fe-2S] clusters as compared to monodentate ligands. ${ }^{[172]}$ A tetradentate ligand should stabilise the cluster core even more - in fact, biological Fe/S clusters are stabilised by the protein environment to an extent that they do not desintegrate even when solvent-exposed. A [2Fe-2S] cluster coordinated by a tetradentate ligand might therefore be stable enough to allow for unprecedented biomimetic reactions like protoncoupled electron transfer in a protic solvent.

Moreover, the donor set of tetradentate ligands can be designed to lead to an asymmetrically coordinated $[2 \mathrm{Fe}-2 \mathrm{~S}]$ cluster. Until the recent isolation of an analogue of Rieske-type $[2 \mathrm{Fe}-2 \mathrm{~S}]$ clusters in our group, ${ }^{[143]}$ the use of bidentate ligands was not successful in the approach to asymmetrically coordinated $[2 \mathrm{Fe}-2 \mathrm{~S}]$ clusters.

Furthermore, other interactions are feasible with bidentate ligands bearing further substituents, such as weak interactions with the cluster core. Biological antetypes include hydrogen bonds as well as the interaction with a methionine thioether moiety upon reduction of a Rhodobacter capsulatus [2Fe-2S] ferredoxin ${ }^{[89]}$.

Based on these considerations, allyl-substituted biphenols are regarded as versatile building blocks for bidentate ligands allowing further functionalisation to form tetradentate ligands. ${ }^{[173,174]}$ A Miyazaki-Newman-Kwart rearrangement strategy was applied to synthesise the corresponding thiophenol analogues. ${ }^{[175,176]}$ Both ligand types were employed in the synthesis of [2Fe-2S] clusters. Furthermore, the functionalisation of the allyl groups towards the formation of tetradentate ligands was explored. 


\subsection{Ligand Synthesis}

\subsubsection{Synthesis of Allyl-Substituted Biphenol Ligands}

The reaction sequences leading to allyl-substituted biphenols 3 starting from biphenols 1 are illustrated in Scheme 2.1.

The synthesis of 3,3'-diallyl-2,2'-dihydroxybiphenyl (3a) starting from unsubstituted 2,2'-dihydroxybiphenyl 1a has been reported in literature. ${ }^{[173,174]}$ As the occurrence of mono-substituted by-products is a general problem encountered in reactions with biphenyl-based ligands, the synthesis of mono-allyl substituted derivatives was additionally explored. Thus, the novel analogue $3 \mathrm{~b}$ was similarly prepared by using only one equivalent of allyl bromide in the first step of the reaction sequence. After rearrangement of the obtained allylether $2 \mathrm{~b}$ at $170^{\circ} \mathrm{C}$, the target compound $3 \mathrm{~b}$ was obtained in $54 \%$ yield over two steps.

The same route was chosen for the synthesis of the tert-butyl-substituted derivative 3c. The di-tert-butyl substituted biphenol $1 \mathrm{c}$ is literature-known and was synthesised in two steps. ${ }^{[177]} 1 \mathrm{c}$ was then converted to the allylether $2 \mathrm{c}$ like the parent compound $1 \mathrm{a}$. Rearrangement yielded the target compound $3 \mathrm{c}$ in $47 \%$ yield over two steps. All new compounds were characterised by ${ }^{1} \mathrm{H}$ NMR, ${ }^{13} \mathrm{C}$ NMR and IR spectroscopy as well as EI mass spectrometry.<smiles>[R]c1ccc(O)c(-c2cc([R])ccc2O)c1</smiles>

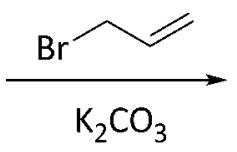

$$
\begin{aligned}
& 1 a\left(R^{\prime \prime}=H\right) \\
& 1 c\left(R^{\prime \prime}={ }^{t} B u\right)
\end{aligned}
$$<smiles>[R]Oc1ccc([R])cc1-c1cc([R])ccc1OCC=C</smiles>

2a $\left(R^{\prime \prime}=H, R^{\prime}=\right.$ allyl $)$

2b $\left(R^{\prime \prime}=H, R^{\prime}=H\right)$

2c $\left(R^{\prime \prime}={ }^{t} B u, R^{\prime}=\right.$ allyl)<smiles>[R7]c1cc([R])c(O)c(-c2cc([R10])cc(CC=C)c2O)c1</smiles>

3a $\left(R^{\prime \prime}=H, R^{\prime}=\right.$ allyl)

$3 b\left(R^{\prime \prime}=H, R^{\prime}=H\right)$

$3 c\left(R^{\prime \prime}={ }^{t} B u, R^{\prime}=\right.$ allyl)

Scheme 2.1: Synthesis of allyl-substituted biphenols 3. 


\subsubsection{Synthesis of Allyl-Substituted Dithiophenol Ligands}

In order to convert the allyl-substituted 2,2'-dihydroxybiphenyls 3 to the corresponding 2,2'-dithiobiphenyls 6, a Miyazaki-Newman-Kwart rearrangement strategy ${ }^{[175]}$ was applied (it was recently suggested to use this term instead of Newman-Kwart rearrangement, taking important studies of Miyazaki et al. on the mechanism of thione-to-thiol rearrangements into account ${ }^{[176]}$ ). The strategy was tested only for the biphenols $\mathbf{3 a}$ and $\mathbf{3 b}$ due to the time-consuming synthesis of the tert-butyl-substituted derivative $\mathbf{3 c}$.

The corresponding dithiols were obtained in a three step synthesis (Scheme 2.2). After deprotonation with sodium hydride, the biphenolates 3 were treated with dimethylcarbamothioic chloride. Although an excess of both base and dimethylcarbamothioic chloride was used, the reactions afforded the desired bis-O-thiocarbamate esters 4 only in moderate yields. The di-allyl substituted compound 3a could only be converted in a yield of around $30 \%$ with an equal amount of mono-O-thiocarbamate ester remaining. The two products could however be separated by column chromatography and the intermediate product could be converted to the target compound $4 \mathbf{a}$ by repeating the reaction.

In the case of the mono-allyl substituted biphenol $3 \mathbf{b}$ the conversion was therefore carried out in the presences of HMPA, which usually leads to a higher ratio of disubstituted to mono-substituted product. ${ }^{[178,179]}$ Nevertheless, mainly the intermediate mono-substituted product was detected by TLC and ${ }^{1} \mathrm{H}$ NMR in the crude product mixture. As separation of the products by column chromatography was difficult, the mixture was subjected to repeated reaction and column chromatography after which the pure target compound $4 \mathrm{~b}$ was obtained.

In the second step of the synthetic sequence the pure bis-O-thiocarbamate esters 4 were heated to $320^{\circ} \mathrm{C}$ for $1.5 \mathrm{~h}$. At this temperature, a Miyazaki-Newman-Kwart rearrangement takes place to furnish the bis-S-thiocarbamate esters 5 in yields of 54 (5a) and $31 \%(5 b)$, respectively. Formation of the free dithiols 6 was achieved by reduction with $\mathrm{LiAlH}_{4}$ and subsequent acidic work-up. To prevent possible oxidation to internal disulphides, the work-up was carried out under an inert nitrogen atmosphere. While $\mathrm{HCl}$ can be used in the synthesis of other dithiols, ${ }^{[175,179]}$ the allyl-substituted compounds 6 could not be obtained using the standard procedure. Instead, the formation of fused five-membered rings via intramolecular hydrosulphuration was observed. To avoid this known type of reaction, ${ }^{[180]}$ aqueous $\mathrm{NH}_{4} \mathrm{Cl}$ was used instead. Under these milder conditions, clean conversion to the free dithiols took place. 
<smiles>[R]c1cccc(-c2cccc([R])c2O)c1O</smiles>

3a $\left(R=R^{\prime}=\right.$ allyl) $3 b\left(R=\right.$ allyl, $\left.R^{\prime}=H\right)$
1. $\mathrm{NaH}, \mathrm{DMF}$ (HMPA)

2. $\mathrm{Me}_{2} \mathrm{NCSCl}$<smiles>[R]c1cccc(-c2cccc([R])c2OC(N)=S)c1OC(C)=S</smiles>

$4 a\left(R=R^{\prime}=\right.$ allyl)

$\mathbf{4 b}\left(R=\right.$ allyl, $\left.R^{\prime}=H\right)$

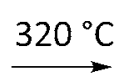<smiles>[R]c1cccc(-c2cccc([R])c2SC(C)=O)c1SC(C)=O</smiles>

$5 a\left(R=R^{\prime}=\right.$ allyl)

$5 b\left(R=\right.$ allyl, $\left.R^{\prime}=H\right)$

1. $\mathrm{LiAlH}_{4}$

2. $\mathrm{NH}_{4} \mathrm{Cl}$<smiles>[R]c1cccc(-c2cccc([R])c2S)c1S</smiles>

6a $\left(R=R^{\prime}=\right.$ allyl $)$

6b $\left(R=\right.$ allyl, $\left.R^{\prime}=H\right)$

Scheme 2.2: Synthesis of allyl-substituted dithiophenols 6 .

\section{An NMR Study of Compounds $4 a-6 a$}

The NMR features of the di-allyl substituted compounds $\mathbf{4 a - 6 a}$ were exemplarily examined in detail to gain information about structural properties.

At room temperature, four signals are found for the methyl groups attached to the carbamate nitrogen atoms in the ${ }^{1} \mathrm{H}$ and ${ }^{13} \mathrm{C}$ NMR spectra of the O-carbamate ester compound $4 \mathrm{a}$ in $\mathrm{CDCl}_{3}$ (Figure 2.1). This indicates slow rotation around two bonds due to energy barriers, namely the $\mathrm{C}-\mathrm{N}$ bond - because of delocalisation of the carbamate double bond - and the aryl-O bond. The temperature-dependence of these signals was investigated in toluene- $\mathrm{d}_{8}$ solution which allows for a wider temperature range (Figure 2.2). At low temperature $\left(-50^{\circ} \mathrm{C}\right)$, three distinct sets of signals (i.e., 6 methyl signals) are observed. The observations in the NMR spectra are in agreement with crystal structures of related compounds, ${ }^{[175]}$ in which both the aryl-aryl and aryl O-carbamate ester groups are twisted by nearly $90^{\circ}$ with respect to each other, resulting in two sterically favoured (racemic) diastereomers: a $C_{2}$-symmetric species with the same relative orientation of the ester groups, producing one set of NMR peaks, and a completely asymmetric species with opposite orientation of the ester groups, producing a split set of peaks with a 1:1 integral ratio. At $-50^{\circ} \mathrm{C}$, the signals of the split set slowly interconvert through 
rotation of the aryl-aryl bond, while at room temperature most of them have coalesced, as expected for an energetic barrier of about $60 \mathrm{~kJ} / \mathrm{mol} .{ }^{[181]}$ The barriers for rotation of the ester group and the carbamate $\mathrm{C}-\mathrm{N}$ bond are much higher (both about $75 \mathrm{~kJ} / \mathrm{mol}$ ), so that separate, albeit broad, signals are still observable at room temperature.

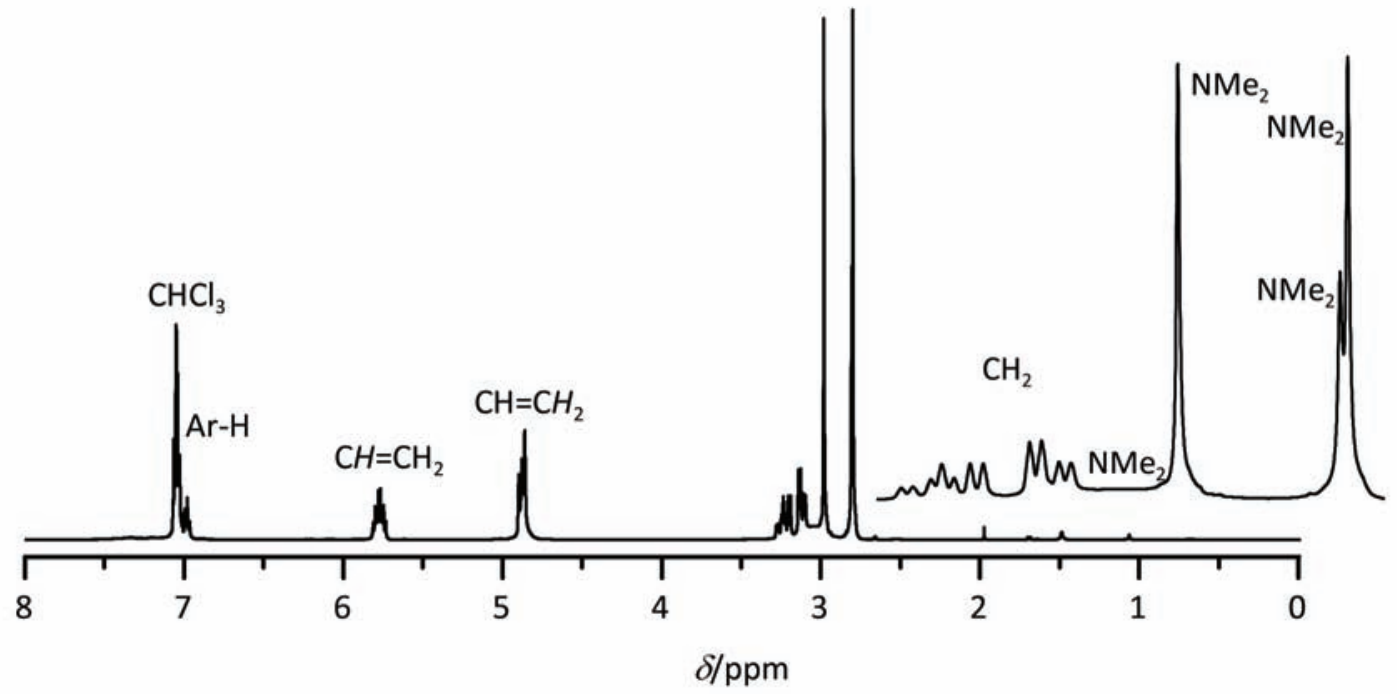

Figure 2.1: ${ }^{1} \mathrm{H}$ NMR spectrum of $4 \mathrm{a}$ at $500 \mathrm{MHz}$ in $\mathrm{CDCl}_{3}$. - The $\mathrm{NMe}_{2}$ signal at $3.22 \mathrm{ppm}$ is very broad and lies partly beneath the $\mathrm{CH}_{2}$ and the $\mathrm{NMe}_{2}$ signal at $3.16 \mathrm{ppm}$.

After the Miyazaki-Newman-Kwart rearrangement, only a single signal is found for the N-bonded methyl groups in $\mathbf{5 a}$ and two signals in the asymmetric mono-allyl substituted compound $\mathbf{5 b}$, which is in agreement with earlier reports for $S$-thiocarbamate esters. ${ }^{[181]}$ Furthermore, the ${ }^{13} \mathrm{C}$ resonance of the thione carbon undergoes a large upfield shift from about 186 to about $166 \mathrm{ppm}$. Thus, formation of the bis-S-thiocarbamate esters 5 can be monitored by NMR and IR (thione bands at $1535 \mathrm{~cm}^{-1}$ versus carbonyl bands at $1665 \mathrm{~cm}^{-1}$ ) spectroscopy.

As expected, bond rotations in the free dithiols 6 are not hindered, which is evident from sharp ${ }^{1} \mathrm{H}$ NMR signals for all aromatic resonances. 


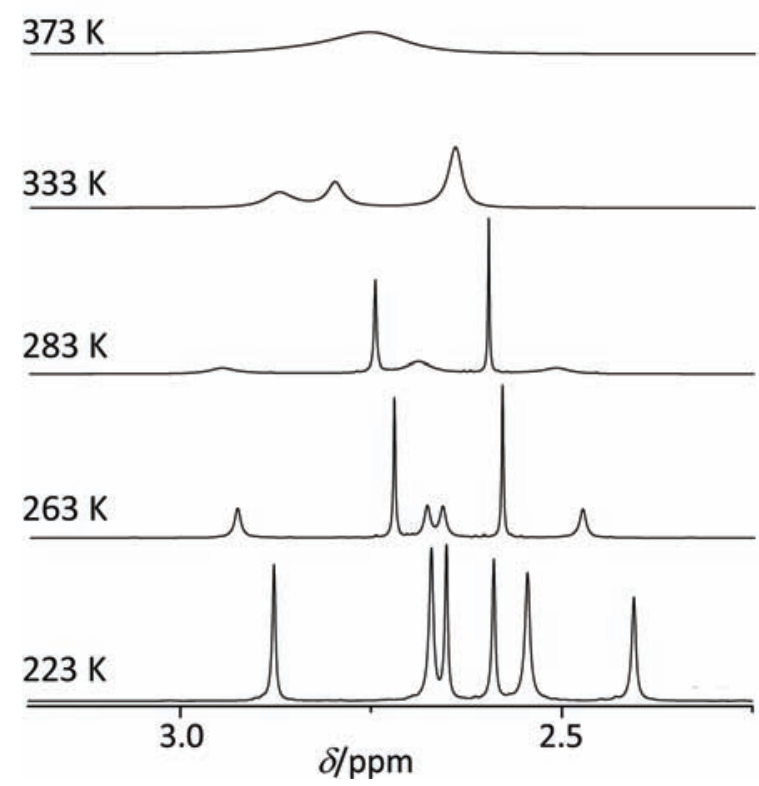

Figure 2.2: Detail of the ${ }^{1} \mathrm{H}$ NMR spectrum of 4 a (signals of the $\mathrm{NMe}_{2}$ groups) at $500 \mathrm{MHz}$ in toluene- $\mathrm{d}_{8}$ at different temperatures.

\section{Exploring the General Coordination Chemistry of the Dithiophenolate Ligands}

To probe the general coordination chemistry of the free thiols $\mathbf{6}$, ligand $\mathbf{6 a}$ was used in syntheses of zinc and tin complexes (Scheme 2.3). Zinc was thought as a suitable dblock metal for several reasons: Inter alia, diamagnetic zinc allows useful investigations by NMR spectroscopy, and S-coordination is prominent in various biological zinc sites. In view of the relevance of $\mathrm{S}_{2} \mathrm{~N}_{2}$-ligated zinc species as biomimetic model compounds

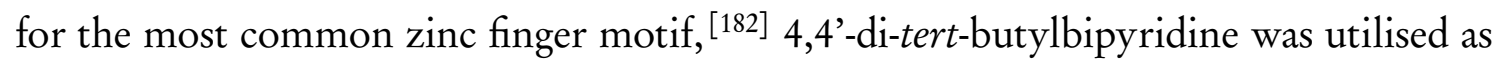
co-ligand in the present work.

In general, $\mathrm{S}_{2} \mathrm{~N}_{2}$-coordinated zinc complexes can be obtained by a two-step procedure. Reaction of dimethylzinc with the free ligands results in the formation of polymeric thiophenolate-zinc species, probably because of the bridging tendency of thiophenolates. These sparingly soluble intermediates can be separated by filtration and subsequently reacted with 4,4'-di-tert-butylbipyridine in benzene at reflux temperature, causing the polymers to break up. ${ }^{[179,183]}$ However, 7 could not be obtained this way. Examination of the polymeric mixture obtained after reaction of $\mathbf{6 a}$ with $\mathrm{ZnMe}_{2}$ by ${ }^{1} \mathrm{H}$ NMR spectroscopy revealed an unwanted reactivity of dimethylzinc with the allyl 


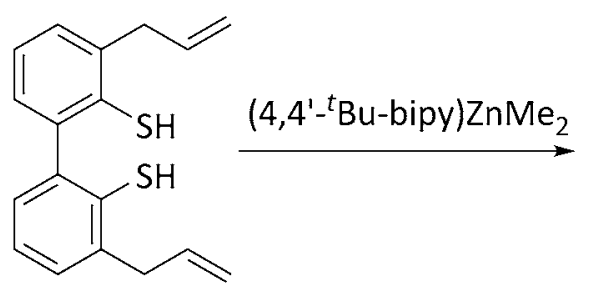

$6 a$

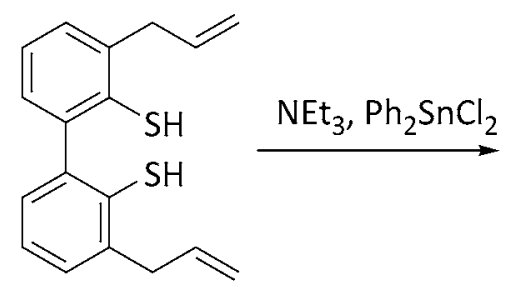

$6 a$

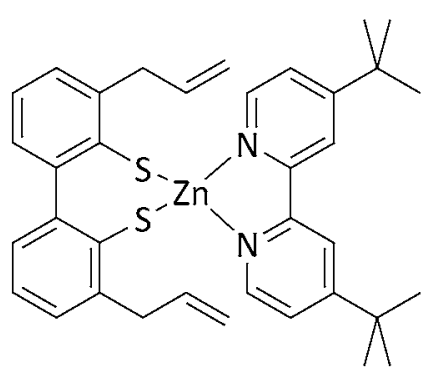

7<smiles>C=CCc1cccc(-c2cccc(CC=C)c2S[Sb](c2ccccc2)(c2ccccc2)c2ccccc2)c1</smiles>

8

Scheme 2.3: Synthesis of complexes 7 and 8.

residues, indicated by the absence of all olefinic proton resonances, even in high dilution and at low temperature. However, an attack of the highly reactive dimethylzinc on the allyl group could be avoided by changing the reaction sequence. Addition of dimethylzinc to a toluene solution of 4,4'-di-tert-butylbipyridine at $-78^{\circ} \mathrm{C}$ yielded the less reactive $\left(4,4^{\prime}{ }^{t} \mathrm{Bu}\right.$-bipy) $\mathrm{ZnMe}_{2}$ complex which then reacted smoothly with 6 a to give complex 7 (Scheme 2.3). Although no crystals suitable for X-ray diffraction could be obtained, complex 7 could be identified by ${ }^{1} \mathrm{H}$ and ${ }^{13} \mathrm{C}$ NMR spectroscopy as well as ESI mass spectrometry which confirmed the formation of a mononuclear complex.

Since related ligands have previously been shown to give dinuclear complexes, complex formation as well as nuclearity was further confirmed using diffusion-ordered spectroscopy (DOSY NMR). Diffusion coefficients of complex 7 (Figure 2.3) and the corresponding free ligand $\mathbf{6 a}$ were measured and the molecular radii obtained via the StokesEinstein relation were compared. The solution ratio $R_{\text {complex }} / R_{\text {ligand }}$ of 1.5 is similar to related mononuclear complexes and thus suggests a monomeric composition in solution. ${ }^{[179]}$ 


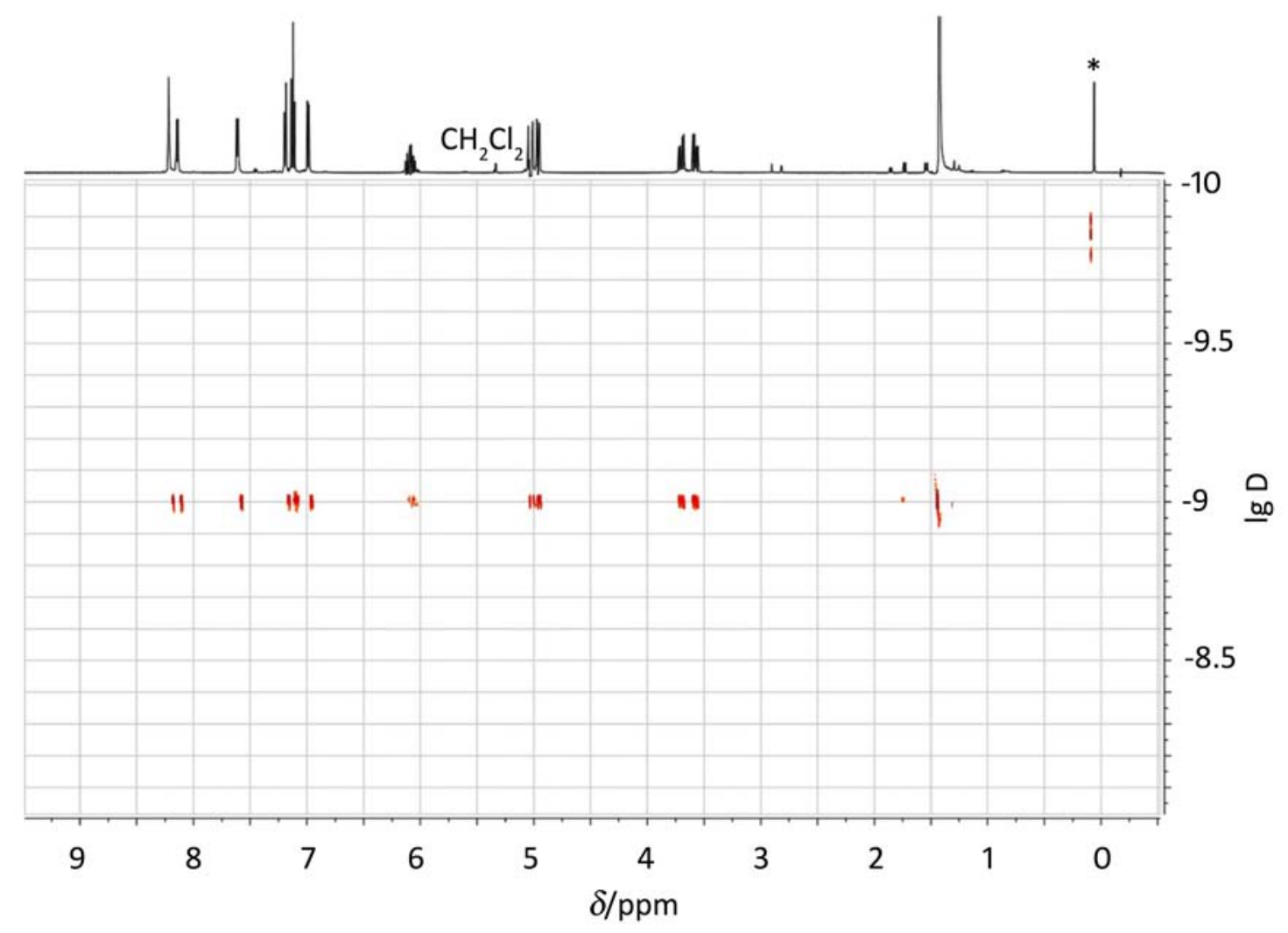

Figure 2.3: DOSY NMR spectrum of 7 at $500 \mathrm{MHz}$ in $\mathrm{CD}_{2} \mathrm{Cl}_{2}$.

${ }^{*}=$ residual silicon grease.

As after several attempts no crystals of 7 suitable for X-ray diffraction could be obtained, the coordination potential of $\mathbf{6 a}$ was further demonstrated by preparation of the corresponding diphenyl tin complex 8, obtained by reaction of the dithiol with diphenyltindichloride in the presence of triethylamine (Scheme 2.3). ${ }^{[184]}$ As expected, the tin atom has a distorted tetrahedral coordination sphere (Figure 2.4). Bond lengths

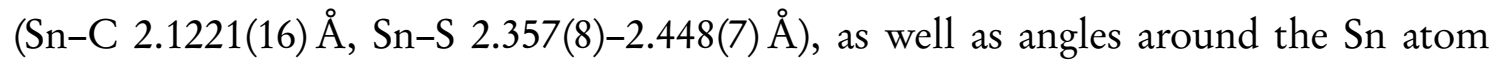
$\left(100.71(4)-120.00(14)^{\circ}\right)$, are comparable to the related compound $(\mathrm{PhS})_{2} \mathrm{SnPh}_{2}$ with nonchelating thiophenolates. ${ }^{[185]}$ The two phenyl groups of the biphenyl moiety in $\mathbf{8}$ are twisted by $62.4(4)^{\circ}$. 


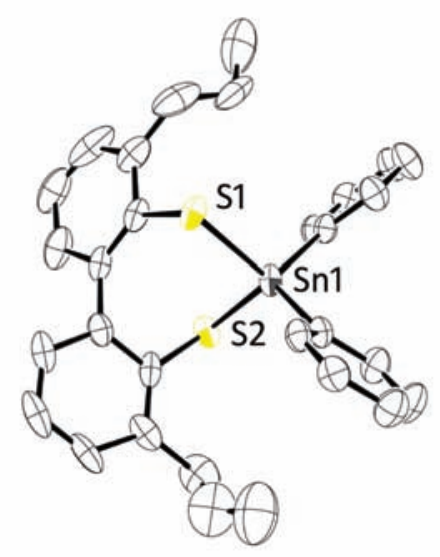

Figure 2.4: Molecular Structure of 8.

- ORTEP plot, $50 \%$ probability thermal ellipsoids; hydrogen atoms omitted for clarity.

\subsection{Synthesis and Structural Characterisation of [2Fe-2S] Clusters}

The synthesis of [2Fe-2S] clusters with ligands 3 and $\mathbf{6}$ was possible on two different literature-known routes, namely via the well-established salt metathesis reaction using $\left(\mathrm{NEt}_{4}\right)_{2}\left[\mathrm{Fe}_{2} \mathrm{~S}_{2} \mathrm{Cl}_{4}\right](9)^{[140]}$ (Scheme $2.4 \mathrm{i}$ ) or via the novel ligand-exchange route using $\left.\left(\mathrm{NEt}_{4}\right)_{2}\left[\mathrm{Fe}_{2} \mathrm{~S}_{2} \text { (indolate) }\right)_{4}\right](10)^{[151]}$ (Scheme $2.4 \mathrm{ii}$ ). Although the first is applicable to all ligands, it usually gives low yields (11: 13-17\%) and separation of by-products can be laborious. The second route - which only works for ligands with a significantly higher acidity than indole to allow for ligand exchange on the cluster and production of free, i.e., protonated indole - gave acceptable product yields for 11 (52-63\%) and 12 (54$72 \%)$. Salt metathesis reactions were performed in $\mathrm{THF} / \mathrm{MeCN}$ and the products were subsequently crystallised from $\mathrm{MeCN} / \mathrm{Et}_{2} \mathrm{O}$. The bulk material of all the complexes precipitated as a brown powder with only minor amounts of crystalline material. Using the novel ligand-exchange pathway, reactions were carried out in $\mathrm{MeCN}$ for 11 or $\mathrm{THF} / \mathrm{MeCN}$ for 12. In general, evaporation of the solvents in vacuo and subsequent washing with $\mathrm{THF} / \mathrm{Et}_{2} \mathrm{O}$ to remove free indole gave sufficiently pure target complexes. All five complexes are readily soluble in $\mathrm{MeCN}, \mathrm{DMF}$ and DMSO while only the tertbutyl-derivative 11c is sparingly soluble in THF and $\mathrm{CH}_{2} \mathrm{Cl}_{2}$.

Crystals suitable for X-ray diffraction were obtained for all complexes by diffusion of $\mathrm{Et}_{2} \mathrm{O}$ into a $\mathrm{MeCN}$ solution of the respective cluster. The O-coordinated clusters 
<smiles>[R]c1cc([R])c(O)c(-c2cc([R])cc([R])c2O)c1</smiles>

i) $1 . \mathrm{KH}$

2. $\left(\mathrm{NEt}_{4}\right)_{2}\left[\mathrm{Fe}_{2} \mathrm{~S}_{2} \mathrm{Cl}_{4}\right](9)$

or

ii) $\left.\left(\mathrm{NEt}_{4}\right)_{2}\left[\mathrm{Fe}_{2} \mathrm{~S}_{2} \text { (indolate) }\right)_{4}\right](\mathbf{1 0})$

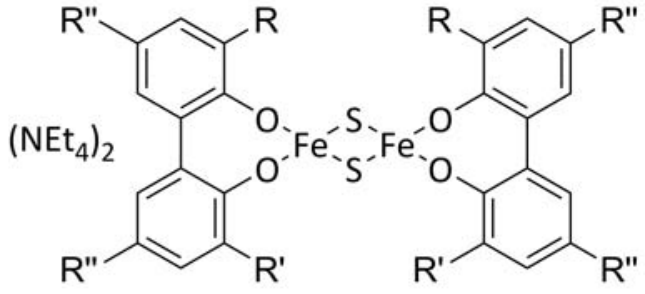

11a $\left(R^{\prime \prime}=H, R=R^{\prime}=\right.$ allyl) 11b $\left(R^{\prime \prime}=H, R=\right.$ allyl, $\left.R^{\prime}=H\right)$

11c $\left(R^{\prime \prime}={ }^{t} B u, R=R^{\prime}=\right.$ allyl)<smiles>[R]c1cccc(-c2cccc([R])c2S)c1S</smiles>

i) $1 . \mathrm{KH}$

2. $\left(\mathrm{NEt}_{4}\right)_{2}\left[\mathrm{Fe}_{2} \mathrm{~S}_{2} \mathrm{Cl} 4\right](9)$

or

ii) $\left.\left(\mathrm{NEt}_{4}\right)_{2}\left[\mathrm{Fe}_{2} \mathrm{~S}_{2} \text { (indolate }\right)_{4}\right](10$
$\left(\mathrm{NEt}_{4}\right)_{2}$<smiles>[R]c1cccc(-c2cccc([R])c2SCC(S)(SSc2c([R])cccc2[R])Sc2c([R])cccc2-c2ccccc2[R])c1</smiles>

12a $\left(R=R^{\prime}=\right.$ allyl $)$ 12b $\left(R=\right.$ allyl, $\left.R^{\prime}=H\right)$

Scheme 2.4: Synthesis of cluster compounds 11 and 12.

$11 \mathrm{a}$ and $11 \mathrm{c}$ crystallise as pseudo- $C_{2 \mathrm{~h}}$ symmetric molecules with a $C_{2}$ axis through the iron atoms and the perpendicular mirror plane through the sulphide ions. In $11 \mathrm{~b}$ the general symmetry is preserved although the $C_{2}$ axis is missing due to the inequivalent phenyl rings (Figure 2.5). The S-coordinated cluster 12a crystallises in the same manner (Figure 2.6). These meso-forms thus contain one axial- $R$ and one axial- $S$ configured ligand, this isomer probably crystallising preferably. The other isomers are either precipitated as powders or they racemise in solution. These findings are in accordance with other known biphenolate-coordinated ${ }^{[145,151,186]}$ and dithiophenolate-coordinated ${ }^{[187]}$ complexes.

However, 12b differs from that symmetry in its crystal structure as both ligands have the same configuration and the cluster is asymmetric $\left(C_{1}\right)$. This is accompanied by the loss of cluster core planarity (dihedral angle $\mathrm{Fe}-\mu-\mathrm{S}-\mathrm{Fe}-\mu-\mathrm{S}: 9.781(64)^{\circ}$ ) that is also observed, yet to a lesser extent, in some of the other structures (11a: 5.865(40) ${ }^{\circ}$, 11b: $\left.6.644(31)^{\circ}\right)$. 

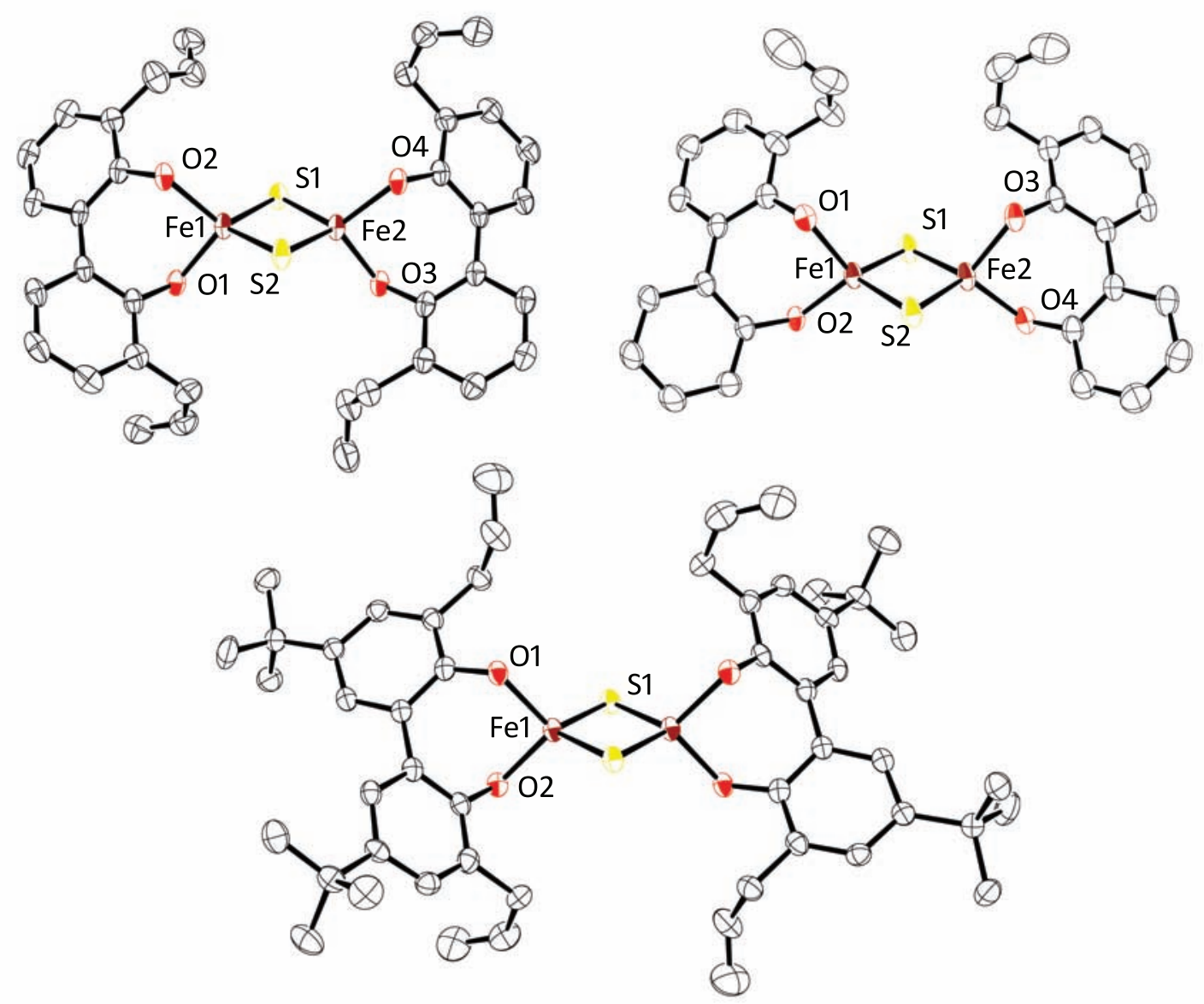

Figure 2.5: Molecular structures of O-coordinated complexes 11: 11a (upper left), 11b (upper right), 11c (bottom).

- ORTEP plots, $50 \%$ probability thermal ellipsoids; counterions, solvent molecules and hydrogen atoms omitted for clarity; only crystallographically independent heteroatoms labelled in case of $11 \mathrm{c}$.

A similar crystallisation behaviour has only been observed once in a crystal structure of a related dithiophenolate-coordinated [2Fe-2S] cluster, which crystallised with two different counterions. ${ }^{[187]}$ In contrast to the published structure where both enantiomers are present in the asymmetric unit, only one enantiomer of $\mathbf{1 2 b}$ was found in the crystal structure. While in the published example this is probably due to the counterions, the reason is unknown in case of $12 \mathrm{~b}$, especially as the phenolate derivative $11 \mathrm{~b}$ crystallises like the other related complexes. 


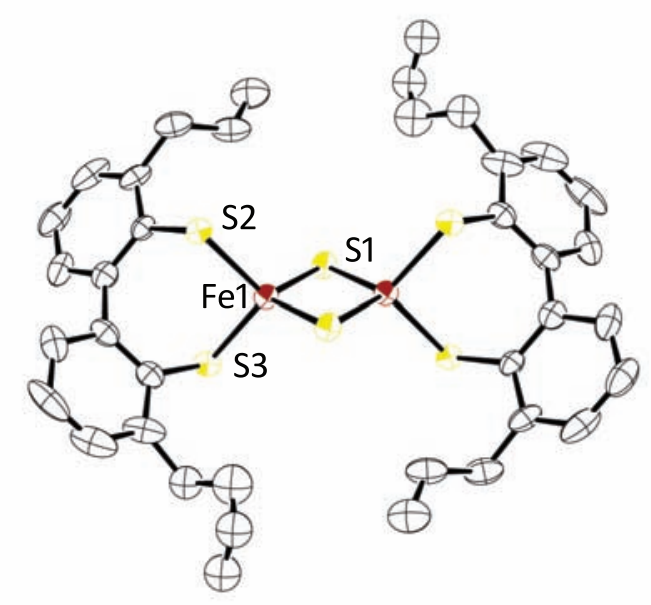

Figure 2.6: Molecular Structure of 12a.

- ORTEP plot, $50 \%$ probability thermal ellipsoids; counterions and hydrogen atoms omitted for clarity; only crystallographically independent heteroatoms labelled.

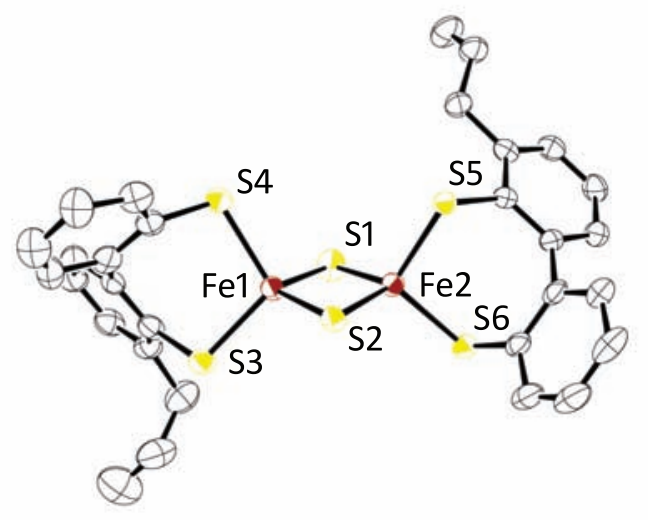

Figure 2.7: Molecular Structure of 12b.

- ORTEP plot, $50 \%$ probability thermal ellipsoids; counterions, solvent molecules and hydrogen atoms omitted for clarity. 
Table 2.1: Selected interatomic distances $d$ and angles $\alpha$ of complexes 11 and 12 .

\begin{tabular}{ccccccc}
\hline & $d(\mathrm{Fe} \cdots \mathrm{Fe})$ & $d(\mathrm{Fe}-\mu-\mathrm{S})$ & $d\left(\mathrm{Fe}-\mathrm{X}^{\mathrm{a})}\right)$ & $\alpha(\mathrm{Fe}-\mu-\mathrm{S}-\mathrm{Fe})$ & $\left.\alpha\left(\mathrm{X}^{\mathrm{a}}\right)-\mathrm{Fe}-\mathrm{X}^{\mathrm{a})}\right)$ & $\left.\tau_{4}{ }^{\mathrm{b}}\right)$ \\
& $/ \AA$ & $/ \AA$ & $/ \AA$ & $/{ }^{\circ}$ & \\
\hline & & $2.2114(8)$ & $1.8908(15)$ & $75.033(22)$ & $95.627(82)$ & 0.887 \\
$11 \mathrm{a}$ & $2.6965(5)$ & $2.2213(7)$ & $1.8965(22)$ & & & \\
& & $2.2153(8)$ & $1.8981(22)$ & $74.856(22)$ & $95.982(83)$ & 0.915 \\
& & $2.2164(7)$ & $1.9030(16)$ & & & \\
& & $2.2162(7)$ & $1.8948(20)$ & $75.004(27)$ & $94.522(79)$ & 0.896 \\
$11 \mathrm{~b}$ & $2.7029(5)$ & $2.2209(9)$ & $1.9083(18)$ & & & \\
& & $2.2188(7)$ & $1.8830(17)$ & $74.985(27)$ & $96.550(78)$ & 0.879 \\
& & $2.2245(9)$ & $1.9036(21)$ & & & \\
$11 \mathrm{c}$ & $2.6937(7)$ & $2.217(1)$ & $1.8984(25)$ & $75.147(44)$ & $95.902(107)$ & 0.921 \\
& & $2.244(10)$ & $1.9018(25)$ & & & \\
$12 \mathrm{a}$ & $2.7011(9)$ & $2.2129(13)$ & $2.2892(13)$ & $74.673(32)$ & $102.906(48)$ & 0.865 \\
& & $2.2168(13)$ & $2.3034(13)$ & & & \\
& & $2.1990(13)$ & $2.2850(16)$ & $75.273(45)$ & $104.914(59)$ & 0.856 \\
$12 \mathrm{~b}$ & $2.6918(9)$ & $2.2101(17)$ & $2.3152(18)$ & & & \\
& & $2.2091(14)$ & $2.2987(16)$ & $74.858(52)$ & $105.328(55)$ & 0.882 \\
& & $2.2189(14)$ & $2.3171(13)$ & & & \\
\hline
\end{tabular}

a) 11: $\mathrm{X}=\mathrm{O} ; 12: \mathrm{X}=\mathrm{S}$. b) Calculated according to $\tau_{4}=\frac{360^{\circ}-(\alpha+\beta)}{141^{\circ}}$ with $\alpha$ and $\beta$ being the two largest bond angles. ${ }^{[188]}$

Relevant bond distances and angles (see Table 2.1) are in perfect agreement with the above-mentioned literature-known analogues. Fe...Fe distances are unexceptional, ranging from 2.69 to $2.70 \AA$. In all complexes the iron atoms exhibit a slight deviation from tetrahedral coordination without a pronounced trend, as quantified by the $\tau_{4}$ value ${ }^{[188]}$. These observations reflect the minor influence that ligand substitution generally has on cluster core geometry. 


\subsection{Spectroscopic and Electrochemical Properties of [2Fe-2S] Clusters}

Like other [2Fe-2S] clusters, complexes 11 and 12 display characteristic ${ }^{1} \mathrm{H}$ NMR spectra with two sets of biphenyl protons (4,4'-Ar-H and 6,6'-Ar-H) producing two broad singlets between 9 and 10 ppm. For the complexes $11 \mathrm{~b}$ and $12 \mathrm{~b}$ with ligands bearing only one allyl group, the protons in the free position 3' give a signal between 6 and $7 \mathrm{ppm}$. When present, the 5,5'-Ar-H protons usually cause peaks which are shifted significantly to higher field (to $2-3 \mathrm{ppm}$ ). The allyl groups also give broadened signals between 5 and 7 ppm. Although ${ }^{1} \mathrm{H}$ NMR signals can easily be assigned by comparison with other complexes, the remaining paramagnetism of the clusters causes broadening of the signals and prevents detection of any coupling.

The ${ }^{1} \mathrm{H}$ NMR spectrum of $\mathbf{1 2 b}$ seems to contain a double set of signals as compared to the $\mathrm{O}$-analogue $\mathbf{1 1 b}$ although it is difficult to exactly separate the signals due to the line broadening and the asymmetry of the phenyl rings (Figure 2.8). The same signal distribution is obtained at higher temperatures $\left(70^{\circ} \mathrm{C}\right)$, indicating no racemisation at this temperature. However, other properties of $\mathbf{1 2 b}$ do not differ significantly from the other complexes 11 and $12 \mathrm{a}$.

$\mathrm{UV} /$ vis spectra of clusters 11 and 12 are shown in Figure 2.9 and the absorption maxima are collected in Table 2.2. They resemble those of related [2Fe-2S] clusters bearing biphenolate or bithiphenolate ligands. The O-coordinated clusters 11 can be compared to the parent compound bearing unsubstituted biphenol ligands ${ }^{[145]}$ and a cluster bearing a tetrachlorobiphenol ligand ${ }^{[151]}$. Compared to both, the main visible band is redshifted to 424 (11a, 11b) and $443 \mathrm{~nm}$ (11c) as compared to 416 and $413 \mathrm{~nm}$, respectively, due to the increase in electron density lowering the transition energies for ligand-tometal charge transfer. Likewise, the main visible bands of the S-coordinated clusters 12 are bathochromically shifted as compared to the unsubstituted parent dithiophenolate compound. ${ }^{[187]}$

Cyclic voltammograms were recorded for clusters 11 and 12 in acetonitrile to investigate general redox properties of the allyl-substituted clusters. Exemplarily, the voltammograms of clusters 11a and 12a are shown in Figure 2.10). While the O-coordinated clusters 11 show an irreversible reduction $(11 \mathrm{a}:-1.40 \mathrm{~V}, 11 \mathrm{~b}:-1.29 \mathrm{~V}$ halfwave potential vs. NHE), the S-coordinated complexes 12 are quasi-reversibly reducible (12a: $-1.05 \mathrm{~V}, 12 \mathrm{~b}$ : $-1.07 \mathrm{~V}$ midpoint potential vs. NHE; see Table 2.2 and Chapter 7.5 for 


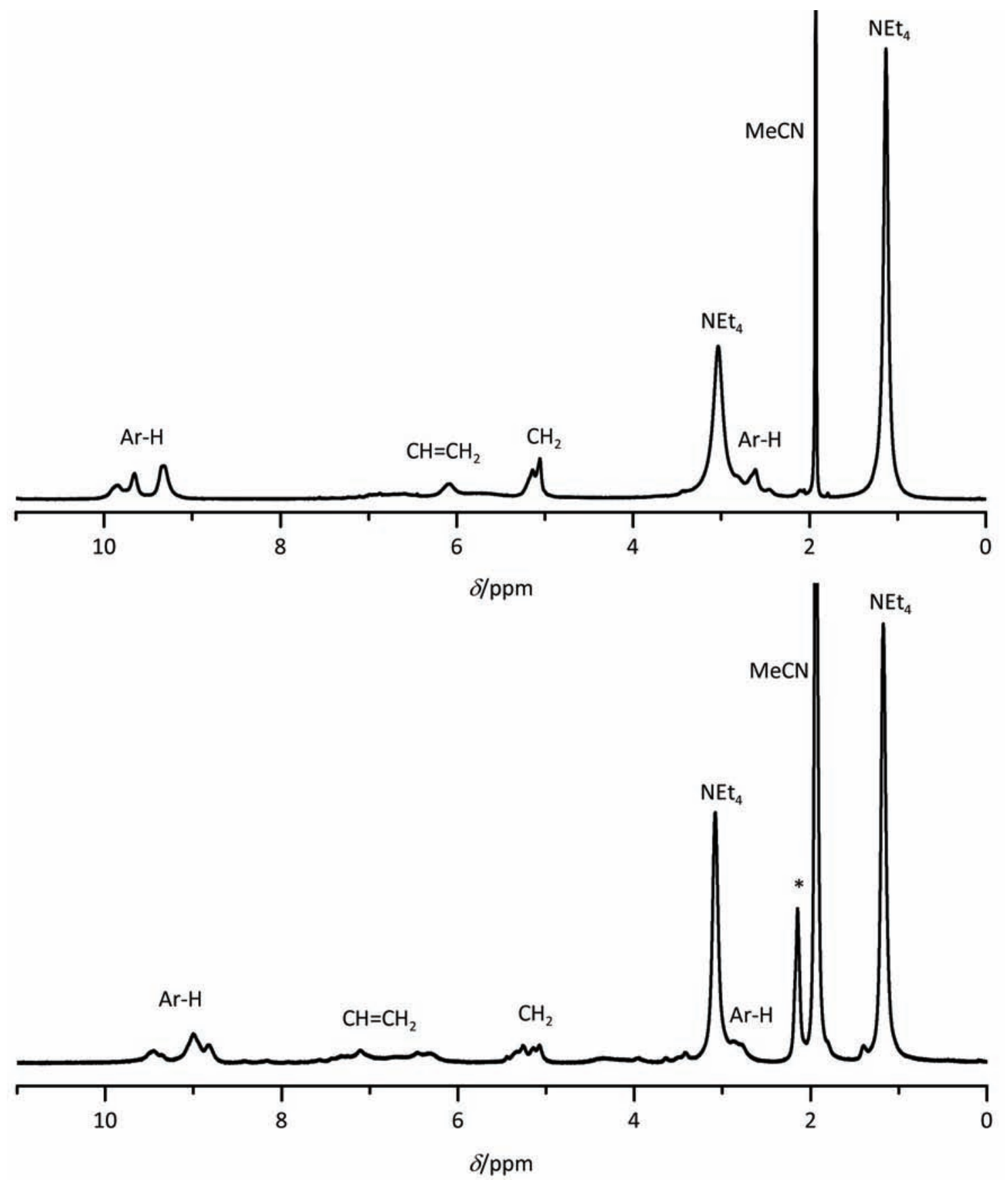

Figure 2.8: ${ }^{1} \mathrm{H}$ NMR spectra of clusters $11 \mathrm{~b}$ (top) and $12 \mathrm{~b}$ (bottom) at $500 \mathrm{MHz}$ in $\mathrm{MeCN}_{3}$. $-*$ = residual $\mathrm{H}_{2} \mathrm{O}$. 

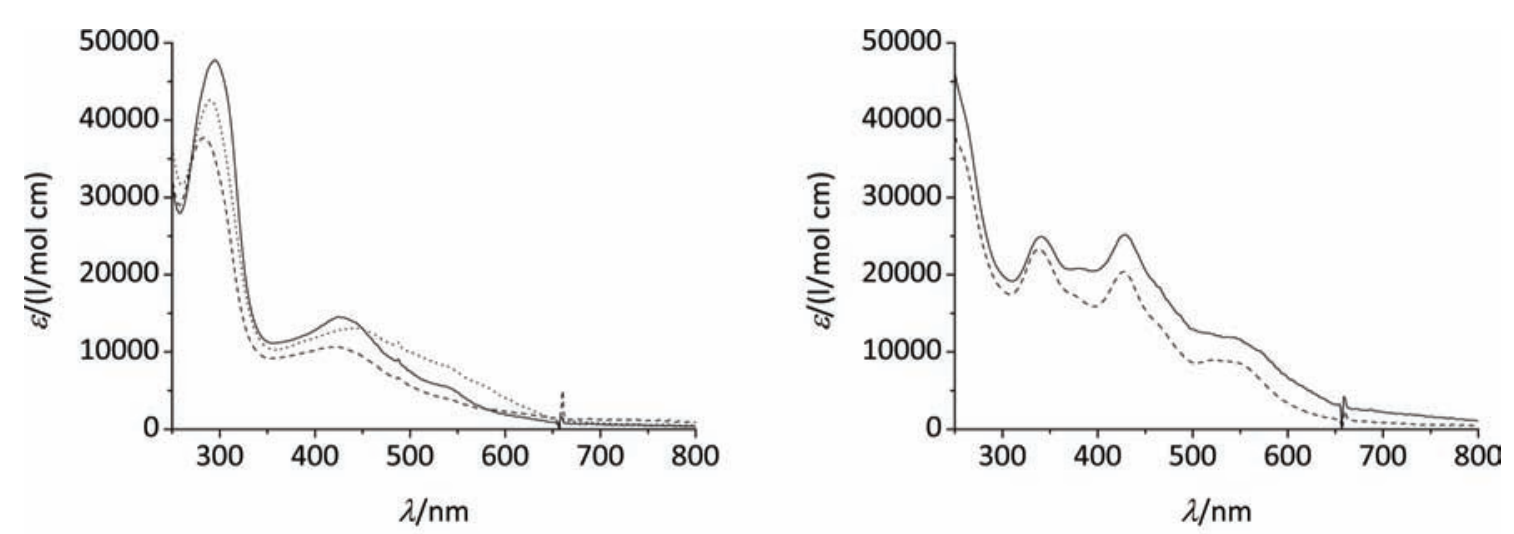

Figure 2.9: UV/vis spectra of clusters 11 (left; solid line: 11a, dashed line: $11 \mathrm{~b}$, dotted line: 11c) and 12 (right; solid line: 12a, dashed line: 12b) in $\mathrm{MeCN}$.

details). All values are comparable to other synthetic complexes but far more negative than reduction potentials of biological clusters $(-0.15 \text { to }-0.45 \mathrm{~V})^{[1]}$. The electron-rich tert-butyl derivative 11c only showed a weak reduction halfwave hardly separable from the background, indicating rapid decomposition upon reduction.

Solid samples were analysed by Mössbauer spectroscopy (Table 2.2 and Figure 2.11). While isomer shifts are in the same range for all complexes $(11: 0.32-0.33 \mathrm{~mm} / \mathrm{s}, 12$ : $0.29 \mathrm{~mm} / \mathrm{s}$ ), the quadrupole splittings of O-coordinated clusters are larger than for the S-coordinated complexes (11: $1.02-1.06 \mathrm{~mm} / \mathrm{s}, 12: 0.76-0.79 \mathrm{~mm} / \mathrm{s})$. Despite different substitution pattern, no pronounced trends could be rationalised.

The reduction potentials and the quadrupole splittings were additionally simulated using DFT calculations on the BP86/def2-SV(P) level of theory (Table 2.2; see Chapter 7.8.1 for details). For the calculation of reduction potentials, a solvent environment was simulated with a dielectric constant of $\epsilon=37$ for MeCN. Although ligand substitution has a neglectable influence on the calculated values, the obtained reduction potentials do not fit the experimental values. This can possibly be explained by the absence of the counterions in the calculations which usually take only the complex dianions into account. While the electrostatic potential of the cluster is lowered by the presence of the counterions in the experiment, this is not the case in the calculations. Furthermore, calculated potentials depend much on atomic radii and other values that have to be estimated to a certain extent, so absolute values are not very accurate. However, the calculations give similar reduction potentials for related complexes (11 and 12, respectively) and these values are more negative than those for clusters with higher potentials found 

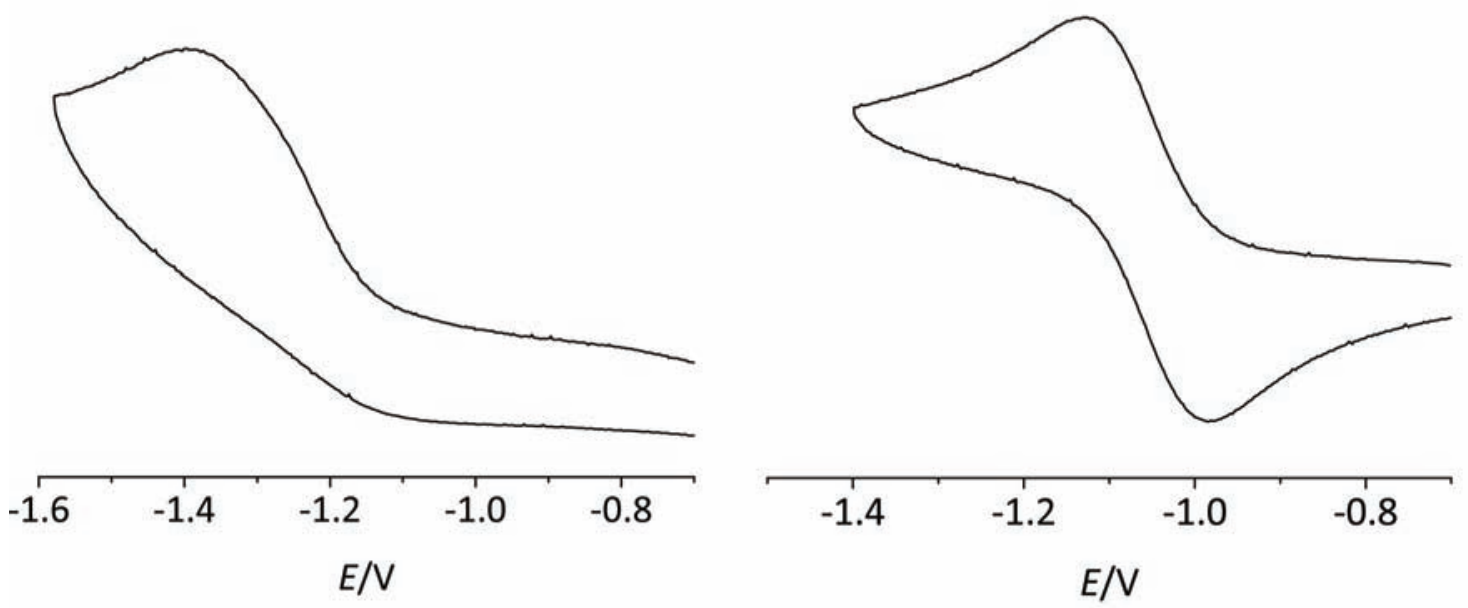

Figure 2.10: Cyclic voltammograms of clusters 11a (left) and 12a (right) in MeCN vs. NHE.

- Recorded at $100 \mathrm{mV} / \mathrm{s}$ vs. the $\mathrm{Cp}_{2}^{*} \mathrm{Fe} / \mathrm{Cp}_{2}^{*} \mathrm{Fe}^{+}$couple as internal standard and referenced vs. NHE ${ }^{[189]}$.

in experiments (see Chapters 4 and 7.5).

Theoretical quadrupole splittings were calculated on both crystallographic and optimised coordinates. While they are too low in all cases, only calculations based on optimised coordinates correctly reproduce the overall trend and therefore values obtained from crystal coordinates are not further considered. The theoretical splittings are larger for the O-coordinated complexes and even the subtle trend $\Delta E_{\mathrm{Q}, 11 \mathrm{c}}<\Delta E_{\mathrm{Q}, 11 \mathrm{~b}}<$ $\Delta E_{\mathrm{Q}, 11 \mathrm{a}}$ found among the $\mathrm{O}$-coordinated compounds is in agreement with experimental values. 

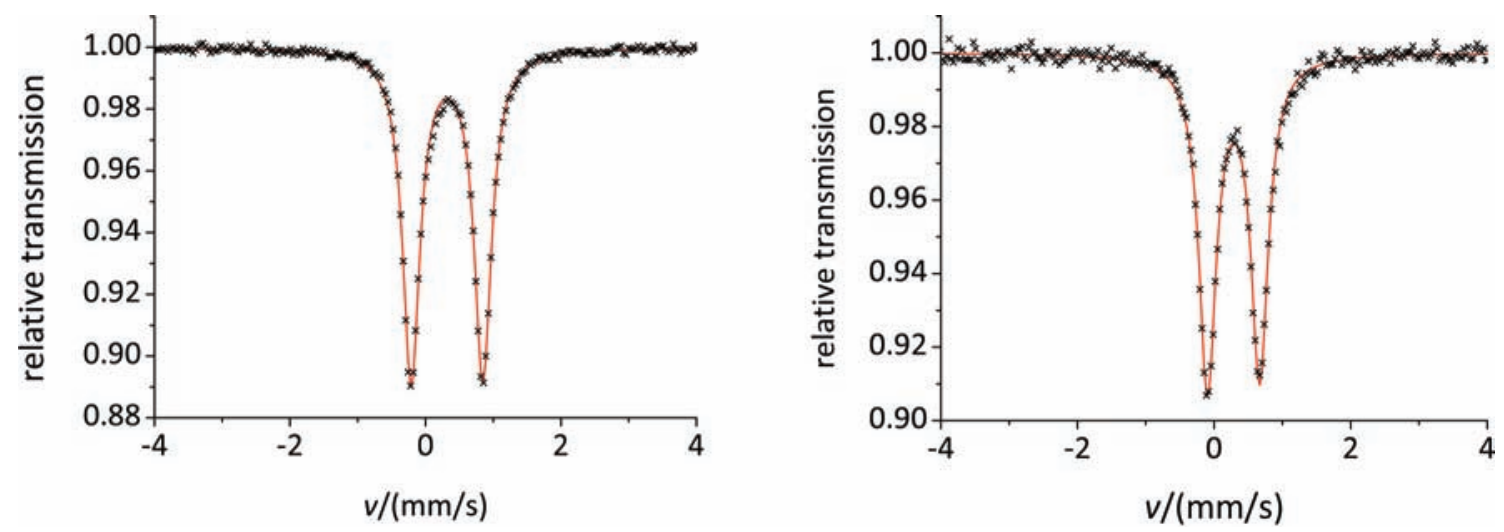

Figure 2.11: Mössbauer spectra of $11 \mathrm{a}$ (left) and 12a (right) at $80 \mathrm{~K}$.

Table 2.2: Selected electrochemical and spectroscopic data of complexes 11 and 12.

\begin{tabular}{|c|c|c|c|c|c|c|c|}
\hline & $\begin{array}{l}\lambda_{\max } \\
/ \mathrm{nm}\end{array}$ & $\begin{array}{c}\epsilon / \\
(1 /(\mathrm{mol} \cdot \mathrm{cm}))\end{array}$ & $\begin{array}{c}E_{1 / 2}^{\mathrm{a})} \\
/ \mathrm{V}\end{array}$ & $\begin{array}{c}\left.E_{1 / 2}(\text { calc. })^{\mathrm{b}}\right) \\
/ \mathrm{V}\end{array}$ & $\begin{array}{c}\delta / \\
(\mathrm{mm} / \mathrm{s})\end{array}$ & $\begin{array}{c}\Delta E_{\mathrm{Q}} / \\
(\mathrm{mm} / \mathrm{s})\end{array}$ & $\begin{array}{c}\Delta E_{\mathrm{Q}}(\text { calc. })^{\mathrm{c})} \\
/(\mathrm{mm} / \mathrm{s})\end{array}$ \\
\hline $11 \mathrm{a}$ & $\begin{array}{l}295 \\
424\end{array}$ & $\begin{array}{l}48000 \\
14500\end{array}$ & $-1.40^{\mathrm{d})}$ & -2.14 & 0.32 & 1.06 & $0.47 / 0.48$ \\
\hline $11 b$ & $\begin{array}{l}283 \\
424\end{array}$ & $\begin{array}{l}38000 \\
10700\end{array}$ & $-1.29^{d)}$ & -2.20 & 0.32 & 1.04 & $0.44 / 0.45$ \\
\hline $11 \mathrm{c}$ & $\begin{array}{l}290 \\
443\end{array}$ & $\begin{array}{l}43000 \\
13000\end{array}$ & -e) $^{\mathrm{e}}$ & -2.17 & 0.33 & 1.02 & $0.44 / 0.44$ \\
\hline $12 a$ & $\begin{array}{l}341 \\
379 \\
429 \\
544\end{array}$ & $\begin{array}{c}25000 \\
21000 \\
25000 \\
12000(\mathrm{sh})\end{array}$ & $-1.05^{f)}$ & -2.04 & 0.29 & 0.76 & $0.29 / 0.39$ \\
\hline $12 b$ & $\begin{array}{l}338 \\
373 \\
427 \\
521\end{array}$ & $\begin{array}{c}23000 \\
17500(\mathrm{sh}) \\
20000 \\
9000\end{array}$ & $-1.07^{\mathrm{g})}$ & -1.99 & 0.29 & 0.79 & $0.20 / 0.28$ \\
\hline
\end{tabular}

a) Reduction potentials were measured $v$ s. the $\mathrm{Cp}_{2}^{*} \mathrm{Fe} / \mathrm{Cp}_{2}^{*} \mathrm{Fe}^{+}$couple as internal standard and referenced vs. NHE; ${ }^{[189]}$ data from Table 7.1. b) Calculated reduction potentials were obtained from optimised coordinates; data from Table 7.4. c) Calculated quadrupole splittings were obtained from the eigenvalues of the electric field gradient at the positions of the iron atoms on optimised coordinates; data from Table 7.7. See Chapter 7.8.1 for details. d) Irreversible reduction; potential of the reduction halfwave. e) No potential could be determined due to decomposition upon reduction. f) $\Delta E=140 \mathrm{mV}$ ( $\mathrm{Cp}_{2}^{*} \mathrm{Fe} / \mathrm{Cp}_{2}^{*} \mathrm{Fe}^{+}$: $\Delta E=64 \mathrm{mV}) . \mathrm{g}) \Delta E=120 \mathrm{mV}\left(\mathrm{Cp}_{2}^{*} \mathrm{Fe} / \mathrm{Cp}_{2}^{*} \mathrm{Fe}^{+}: \Delta E=69 \mathrm{mV}\right)$. 


\subsection{Further Functionalisation of the Allyl Groups}

In order to convert the allyl-substituted biphenol 3a to a tetradentate ligand, several approaches were investigated. In the following section, different reaction strategies shall be discussed that were tested towards the isolation of a ligand bearing additional sulphur (thioether or thiophenol) or nitrogen (indole or benzimidazole) donors. The substrate for most of the tested reactions was the literature-known derivative 13 in which the phenol groups were protected with benzyl groups and the allyl groups were replaced by methanesulfonyl leaving groups (Scheme 2.5) ${ }^{[190]}$

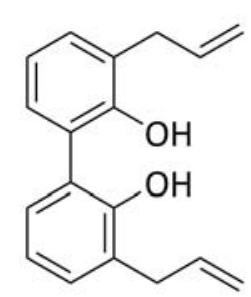

$3 a$
1. a) $\mathrm{NaH}$ b) $\mathrm{BnCl}$

2. a) $\mathrm{BH}_{3} \cdot \mathrm{SMe}_{2}$

b) $\mathrm{NaOH}, \mathrm{H}_{2} \mathrm{O}$ c) $\mathrm{H}_{2} \mathrm{O}_{2}$

3. $\mathrm{NEt}_{3}, \mathrm{MsCl}$<smiles>COCCCc1cccc(-c2cccc(CCCOC)c2OCc2ccccc2)c1OC</smiles>

13

Scheme 2.5: Synthesis of ligand precursor 13. [190]

In order to explore the general coordination properties of biphenols bearing even longer side arms than allyl groups, the derivative 15 with two methylthiol groups attached to the side arms was synthesised according to the literature (Scheme 2.6). ${ }^{[190]} \mathrm{A}$ standard salt metathesis synthesis towards the corresponding [2Fe-2S] cluster 16 was employed yielding a small amount of the desired product identified by ${ }^{1} \mathrm{H}$ NMR spectroscopy (Figure 2.12), yet purification proved difficult and no crystalline material was obtained. A possible interaction of the thioether moiety with the cluster core resembling that seen in a Rhodobacter capsulatus [2Fe-2S] ferredoxin upon reduction ${ }^{\left[{ }^{89}\right]}$ could therefore not be investigated. While it could be shown that cluster formation is possible, the long aliphatic sidearm is unfavourable with respect to crystallisation.

The introduction of two thiophenol moieties containing sulphur atoms to provide an $\mathrm{O}_{2} \mathrm{~S}_{2}$ donor set was approached in two different ways. In a first attempt, attachment via $\mathrm{C}-\mathrm{C}$ bond formation using lithiated 2-methylthiophenols as nucleophiles was tried (Scheme 2.7). These species were reported to act as $\mathrm{C}$-nucleophiles at low temperatures in $\mathrm{D}_{2} \mathrm{O}$ quenching reactions; ${ }^{[191]}$ however, only S-nucleophilic reactivity was observed in reactions with 13 even at low temperatures, as illustrated by the isolation of products 
<smiles>COCCCc1cccc(-c2cccc(CCCOC)c2Br)c1O</smiles>

13<smiles>CSCCCc1cccc(-c2cccc(CCCSC)c2Br)c1Br</smiles>

14<smiles>CSCCCc1cccc(-c2cccc(CCCSC)c2O)c1O</smiles>

15
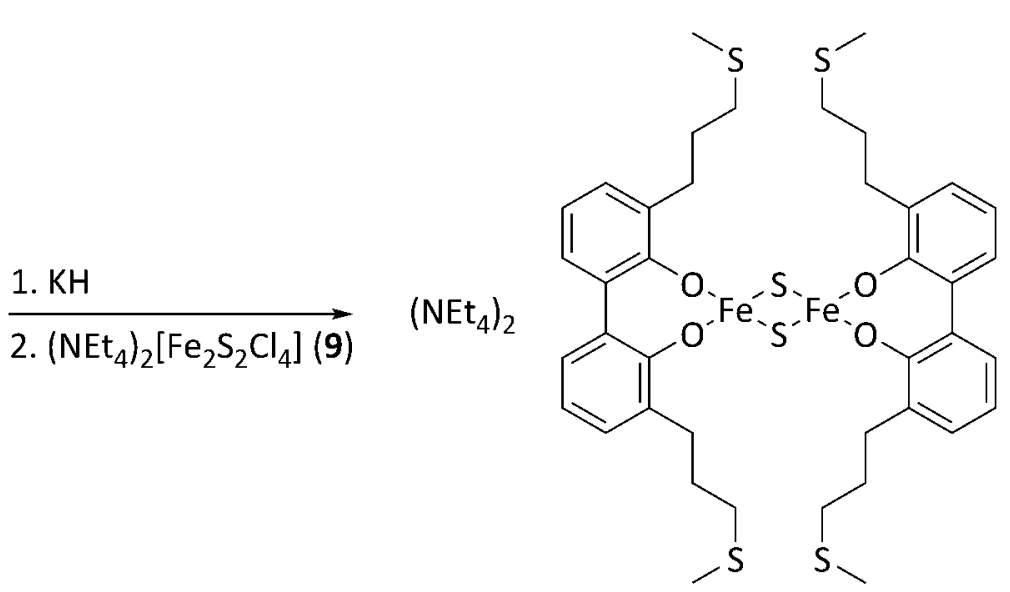

16

Scheme 2.6: Synthesis of ligand $15^{[190]}$ and complex 16.

arising from C-S bond formation.

In a second attempt, attachment of a thiophenol moiety via C-S bond formation using 1,2-benzenedithiol was utilised (Scheme 2.8). This was first protected with a benzyl group on one sulphur atom by a two-step procedure including mono-benzylation on a corresponding iron(II) complex. ${ }^{[192]}$ The other thiol group of 18 could then be lithiated and attached to the sidearm of 13 in good yield of the crude product 19 of $77 \%$. This was deprotected without purification using aluminium bromide yielding ligand 20 . Due to the flexible sidearm, all compounds of this synthetic route are oils and as such difficult to purify, especially the free tetradentate ligand 20 which was handled under inert conditions to avoid oxidation of the free thiophenol groups. Although several approaches towards a $[2 \mathrm{Fe}-2 \mathrm{~S}]$ cluster with ligand 20 were investigated - direct routes as well as two-step procedures including the isolation of a lithium or potassium salt of $\mathbf{2 0}$ -, the desired cluster 21 could not be isolated. This might be due to the low solubility of the deprotonated tetraanionic ligand or the formation of polymeric coordination chains rather than monomeric clusters. On the other hand, the coordination pocket might not 


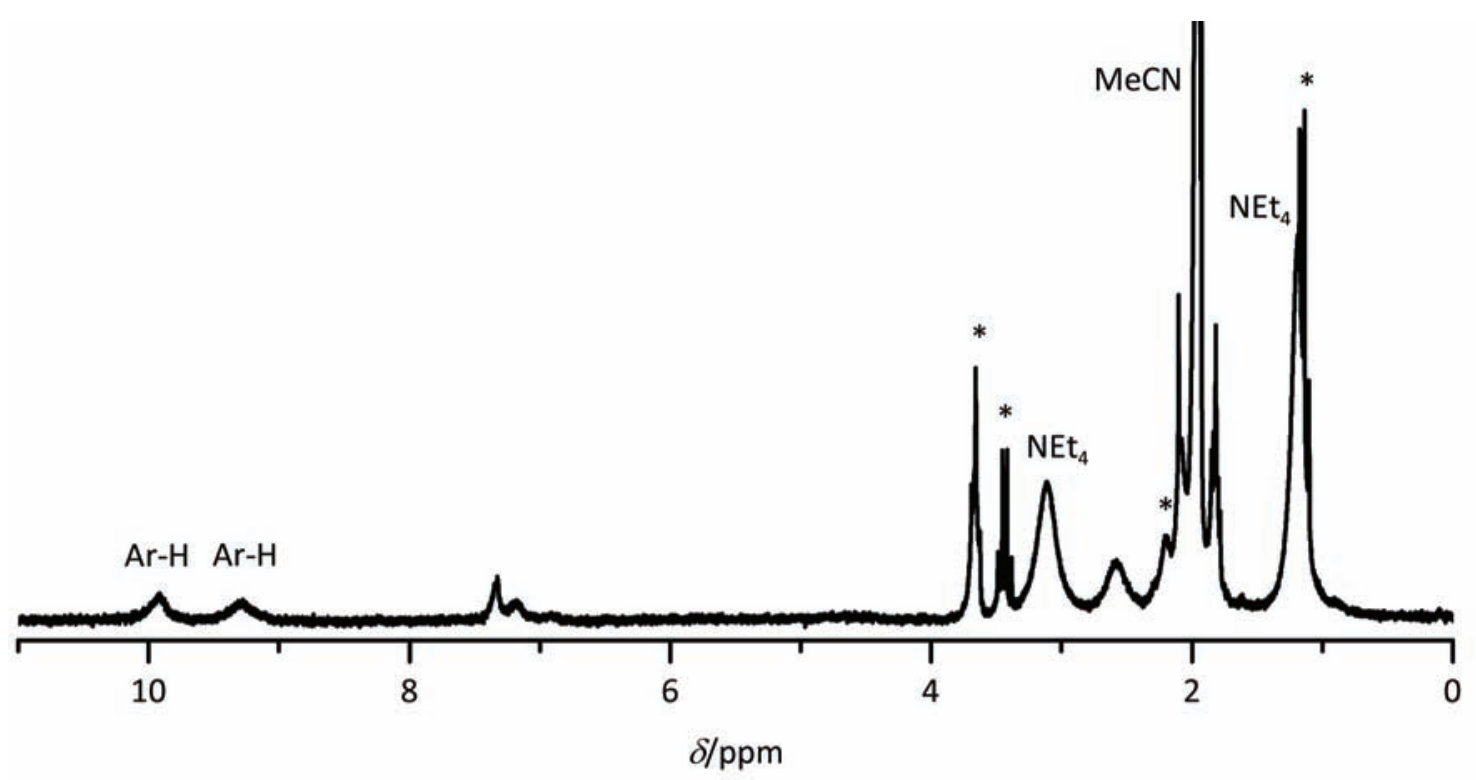

Figure 2.12: ${ }^{1} \mathrm{H}$ NMR spectrum of 16 at $200 \mathrm{MHz}$ in $\mathrm{MeCN}-\mathrm{d}_{3}$.

$-*=$ solvent signals $\left(\mathrm{THF}, \mathrm{Et}_{2} \mathrm{O}\right.$ ); although not all protons could be assigned, the signals at 9 and $10 \mathrm{ppm}$ prove formation of a [2Fe-2S] cluster.

have the right size to house a $[2 \mathrm{Fe}-2 \mathrm{~S}]$ cluster core although an overall favourable geometry was confirmed by rough computational modelling.

The synthesis of a ligand bearing an $\mathrm{O}_{2} \mathrm{~N}_{2}$ donor set was also attempted using two different approaches. The first was based on the formation of a $\mathrm{C}-\mathrm{C}$ bond on 13 with lithiated 2-methylindole as the nucleophile (Scheme 2.9). It was reported that 2-methylindole can be lithiated both on the nitrogen atom and on the methyl carbon atom by a combination of ${ }^{n} \mathrm{BuLi}$ and $\mathrm{KO}^{t} \mathrm{Bu}$ and used as a $\mathrm{C}$-nucleophile at low temperatures. ${ }^{\text {[193] }}$ However, the same unwanted heteroatom nucleophilicity as in the reaction with the methylthiophenols (see above) was observed and only the product from C-N coupling was isolated.

In the other approach towards an $\mathrm{O}_{2} \mathrm{~N}_{2}$ ligand, both $\mathbf{3 a}$ and the benzyl-protected derivative ${ }^{[190]}$ were tested as substrates in a Heck reaction (Scheme 2.10). The reaction partner was an iodobenzene substituted with a benzimidazole moiety prepared by a modified literature-known procedure ${ }^{[194]}$ and palladium acetylacetonate was used as catalyst. ${ }^{[195]}$ However, no coupling product could be isolated by running the reaction under various conditions (different reaction time and temperature, DMF or DMA solution, microwave irradiation) although mass spectra showed signals which could be assigned to the desired product 23. 
<smiles>COCCCc1cccc(-c2cccc(CCCOC)c2Br)c1O</smiles>

13

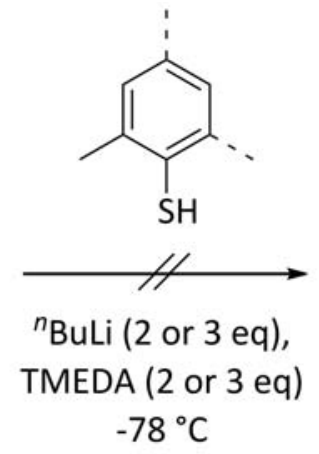

$-78^{\circ} \mathrm{C}$

Scheme 2.7: Attempted synthesis of ligand 17 using 2,4-dimethylthiophenol or 2,6-dimethylthiophenol.<smiles>COCCCc1cccc(-c2cccc(CCCOC)c2Br)c1O</smiles>

13

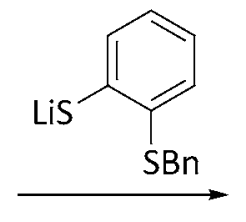

1. $\mathrm{KH}$ or ${ }^{n} \mathrm{BuLi}$

2. $\left(\mathrm{NEt}_{4}\right)_{2}\left[\mathrm{Fe}_{2} \mathrm{~S}_{2} \mathrm{Cl}_{4}\right](9)$ $\left(\mathrm{NEt}_{4}\right)_{2}$

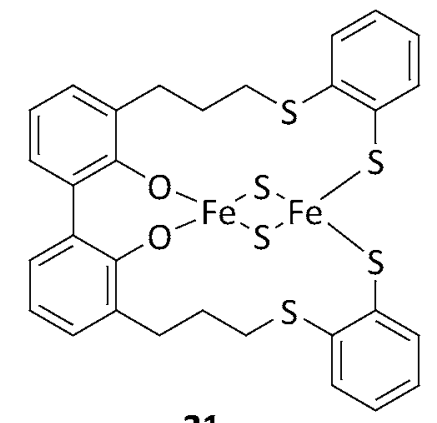

21

Scheme 2.8: Synthesis of ligand 20 and attempted synthesis of complex 21. 
<smiles>COCCCc1cccc(-c2cccc(CCCOC)c2Br)c1O</smiles>

13

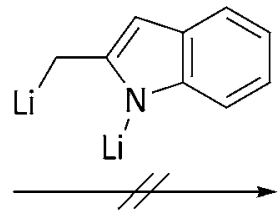<smiles></smiles>

Scheme 2.9: Attempted synthesis of ligand precursor 22.<smiles>C=CCc1cccc(-c2cccc(CC=C)c2O)c1O</smiles>

$3 a$

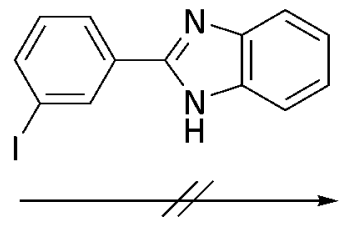

"Pd", DAB-Cy $\mathrm{Cs}_{2} \mathrm{CO}_{3}, \mathrm{~N}^{n} \mathrm{Bu}_{4} \mathrm{Br}$ DMA or DMF

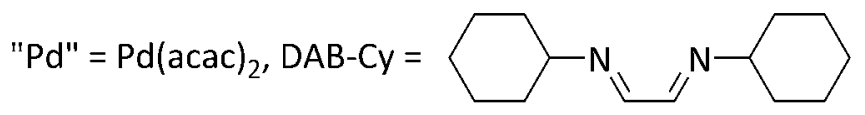

Scheme 2.10: Attempted synthesis of ligand 23.

\subsubsection{Concluding Remarks}

Although some progress was made, the synthesis of tetradentate ligands based on allyl-substituted biphenols had some major disadvantages. As mentioned above, separation of the desired products from mono-substituted by-products is a general problem. Furthermore, the substitution by long and flexible allyl or aliphatic sidearms negatively influences crystallisation properties of the biphenols leading to sticky oils which are difficult to purify. When additionally substituted with thiophenol groups, sensitivity towards oxidation makes the compounds even more difficult to handle. The realisation of a biomimetic $\mathrm{S}_{2} \mathrm{~N}_{2}$ donor set with respect to Rieske-type [2Fe-2S] clusters is even more complicated as the biphenol has to be converted to a dithiophenol at some point. While 
the Miyazaki-Newman-Kwart rearrangement needs high temperatures not compatible with most of the functional sidearms, a functionalisation on a dithiophenol after the rearrangement imposes severe problems with respect to protection of the thiol groups.

Finally, tetradentate ligands are conceivably difficult to deprotonate to yield tetraanions, and the resulting clusters most probably display the same crystallisation problems as the free ligands.

\subsection{Conclusions}

A set of three biphenol ligands was synthesised that carry either one or two allyl sidearms which allow for diverse functionalisation. Two biphenols were successfully transformed to dithiophenol ligands in a three-step Miyazaki-Newman-Kwart procedure. The general coordination chemistry of the dithiophenols was exemplarily investigated on one ligand by the synthesis of a zinc and a tin complex.

All five ligands were used as ligands in the synthesis of [2Fe-2S] clusters using two different complexation strategies. The $[2 \mathrm{Fe}-2 \mathrm{~S}]$ clusters were thoroughly examined with respect to their structural and spectroscopic features. In one example, a very rare ligand orientation was observed in the crystal structure.

In addition, one biphenol ligand was used as a building block in various synthetic attempts towards tetradentate ligands. One tetradentate ligand with an $\mathrm{O}_{2} \mathrm{~S}_{2}$ donor set was synthesised but could not be successfully employed in the synthesis of an asymmetrically coordinated [2Fe-2S] cluster. Generally, the synthesis of tetradentate ligands based on allyl-substituted biphenols displayed several problems.

Nevertheless, the synthesis and isolation of five novel [2Fe-2S] complexes has significantly increased the variety of available analogues of one of nature's most fascinating cofactors. While most of their properties are relatively similar to known [2Fe-2S] clusters, some unique characteristics were observed such as a high solubility for the tertbutyl derivative or the unusual ligand orientation in the crystal structure of the monoallyl substituted dithiophenolate complex. The substitution with allyl groups opens the route to a vast range of imaginable substitution reactions either on the ligands or even on the clusters. 


\section{Synthesis of N-Coordinated [2Fe-2S] and [4Fe-4S] Clusters}

\subsection{Introduction}

Although cysteines are by far the most common ligands of biological Fe/S clusters, the importance of non-sulphur coordination is more and more appreciated. This applies in particular to $[2 \mathrm{Fe}-2 \mathrm{~S}]$ and $[4 \mathrm{Fe}-4 \mathrm{~S}]$ clusters possessing unusual properties like the Rieske type clusters, or having other than electron-transfer function like the [2Fe-2S] cluster in biotin synthase. Apart from oxygen, being the lower homologue of sulphur, it is mainly nitrogen that plays an important role as donor to biological $\mathrm{Fe} / \mathrm{S}$ clusters.

Some biomimetic [2Fe-2S] clusters exhibiting pure nitrogen coordination, both monodentate $^{[145,151]}$ and bidentate ${ }^{[148,172]}$, have been isolated and published to date. Yet this has not been the case for $[4 \mathrm{Fe}-4 \mathrm{~S}]$ clusters ${ }^{[140,141]}$ with the exception of the recent characterisation of an all-ferric $[4 \mathrm{Fe}-4 \mathrm{~S}]^{4+}$ cluster bearing amide ligands. ${ }^{[142]}$ The stable oxidation state however is different from biological [4Fe-4S] clusters and the amide ligands do not correctly mimic coordination by histidine which is most often found as $\mathrm{N}$-donor in $\mathrm{Fe} / \mathrm{S}$ proteins (see Chapter 1.3). Apart from this example, an $\mathrm{N}$ coordinated $[4 \mathrm{Fe}-4 \mathrm{~S}]^{2+}$ cluster bearing prolinato ligands has been characterised by ${ }^{1} \mathrm{H}$ NMR spectroscopy but has not been isolated. ${ }^{[196]}$ Although there have been several approaches to site-differentiated clusters with one exchangable ligand including imidazoles and other $\mathrm{N}$-donor ligands, ${ }^{[157,158]}$ no other fully $\mathrm{N}$-coordinated $[4 \mathrm{Fe}-4 \mathrm{~S}]$ cluster has been reported so far, to the best of the author's knowledge. In addition, there is only one other structural example of a $[4 \mathrm{Fe}-4 \mathrm{~S}]$ cluster with non-S coordination, namely $\left(\mathrm{NEt}_{4}\right)_{2}\left[\mathrm{Fe}_{4} \mathrm{~S}_{4}(\mathrm{OPh})_{4}\right]$. $^{[162]}$ All other examples are rather counted among abiological clusters carrying non-biomimetic ligands like NO, CO or Cp. ${ }^{[197]}$ Although there is no natural $[4 \mathrm{Fe}-4 \mathrm{~S}]$ cluster known to date with coordination by more than one histidine, a biomimetic model might help to identify unusual biological [4Fe-4S] clusters and would further extend the biomimetic Fe/S chemistry. 


\subsection{Initial Observations}

Among the few examples of purely N-ligated synthetic [2Fe-2S] clusters that have been structurally characterised, ${ }^{[142,143,145,172,198]}$ there is only one with a monodentate ligand, namely pyrrole ${ }^{[145]}$, although the complexes of two other ligands, indole and carbazole, ${ }^{[151]}$ have been characterised in detail.

Since 2-methylindole was thought as a building block for a tetradentate ligand by functionalisation on the methyl group ( $c f$. Chapter 2), it was also applied as a ligand in $[2 \mathrm{Fe}-2 \mathrm{~S}]$ cluster synthesis. The standard salt metathesis reaction using ${ }^{n} \mathrm{BuLi}$ and $\left(\mathrm{NEt}_{4}\right)_{2}\left[\mathrm{Fe}_{2} \mathrm{~S}_{2} \mathrm{Cl}_{4}\right]$ (9) lead to the formation of a cluster product as indicated by typical resonances in the ${ }^{1} \mathrm{H}$ NMR spectra, yet $\left(\mathrm{NEt}_{4}\right)_{2}\left[\mathrm{Fe}_{2} \mathrm{~S}_{2}\right.$ (2-methylindolate) $\left.{ }_{4}\right]$ (24) could not be isolated by crystallisation. Instead, compound decomposition was obvious from colour changes in $\mathrm{MeCN}$ or DMF solution and from precipitation of amorphous sticky material.

However, a relatively dilute solution in $\mathrm{MeCN} / \mathrm{Et}_{2} \mathrm{O}$ from one of the synthetic attempts, which exhibited the red colour indicative of the presence of a [2Fe-2S] cluster was left standing to precipitate small black crystals suitable for X-ray diffraction. This compound could then be identified as $\left.\left(\mathrm{NEt}_{4}\right)_{2}\left[\mathrm{Fe}_{4} \mathrm{~S}_{4} \text { (2-methylindolate) }\right)_{4}\right]$ (25) which turned out to be insoluble in $\mathrm{MeCN}$ and soluble only in DMF or DMSO under rapid decomposition.

Based on these observations - initial formation of the [2Fe-2S] cluster but decomposition in $\mathrm{MeCN}$ solution and reaction to the [4Fe-4S] cluster which in turn is highly unstable - a rational approach to both clusters was searched (Scheme 3.1).

\subsection{Synthesis and Characterisation of the $[2 \mathrm{Fe}-2 \mathrm{~S}]$ Cluster}

The synthesis of the desired [2Fe-2S] cluster was first attempted in pure THF to avoid the more polar $\mathrm{MeCN}$, yet product formation was not observed due to the insolubility of the starting complex 9 in THF. Thus the reaction was perfomed with addition of a small amount of $\mathrm{MeCN}$ to enable complete dissolution of 9 . The precipitate that formed within some minutes was filtered off after $1 \mathrm{~h}$ and washed with $\mathrm{Et}_{2} \mathrm{O}$ to remove remaining $\mathrm{MeCN}$ (Scheme 3.1). The crude ${ }^{1} \mathrm{H} \mathrm{NMR}$ in $\mathrm{CD}_{2} \mathrm{Cl}_{2}$ showed characteristic signals for a $[2 \mathrm{Fe}-2 \mathrm{~S}]$ cluster which is unusual as most of the other [2Fe-2S] clusters are insoluble in dichloromethane. A complex was extracted from the residue, indicated by the intense red colour, with a large amount of dichloromethane and precipitated by 


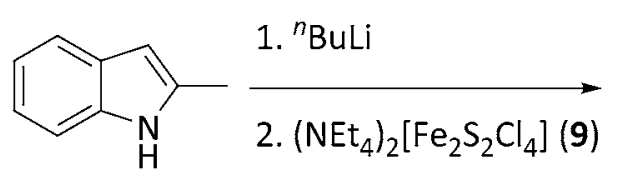

$\left(\mathrm{NEt}_{4}\right)_{2}$

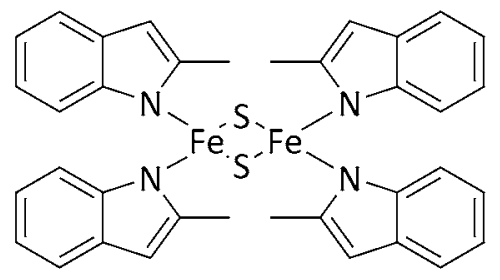

24

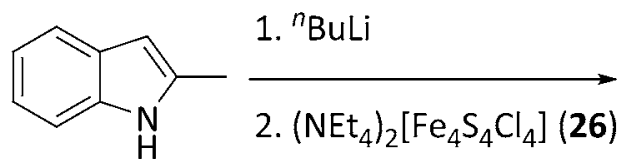

$\left(\mathrm{NEt}_{4}\right)_{2}$

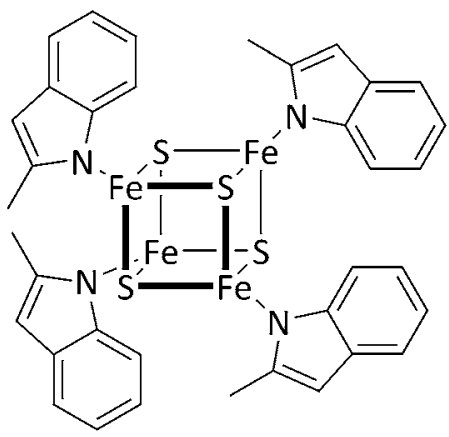

25

Scheme 3.1: Synthesis of cluster compounds 24 and 25.

slow diffusion of $\mathrm{Et}_{2} \mathrm{O}$ and subsequent diffusion of pentane into the solution. Some crystals suitable for X-ray diffraction where likewise obtained, although the quality of the crystals obtained under several conditions was insufficient for proper refinement. Yet the cluster could be identified as $\left.\left(\mathrm{NEt}_{4}\right)_{2}\left[\mathrm{Fe}_{2} \mathrm{~S}_{2} \text { (2-methylindolate) }\right)_{4}\right]$ (24) by the unrefined structure (Figure 3.1). Due to the short reaction time - important to prevent cluster decomposition - and the relatively poor solubility of $\mathbf{2 4}$ in dichloromethane, it could only be isolated in a moderate yield of $17 \%$.

In order to evaluate whether the problems with solubility and crystallisation behaviour could be solved by the use of a different counterion, cluster syntheses were also performed using $\left(\mathrm{NMe}_{4}\right)_{2}\left[\mathrm{Fe}_{2} \mathrm{~S}_{2} \mathrm{Cl}_{4}\right]$ and $\left(\mathrm{N}\left(\mathrm{PPh}_{3}\right)_{2}\right)_{2}\left[\mathrm{Fe}_{2} \mathrm{~S}_{2} \mathrm{Cl}_{4}\right]$. However, the $\mathrm{NEt}_{4}^{+}$ salt gave the best results.

ESI mass spectrometry confirmed cluster formation. The ${ }^{1} \mathrm{H}$ NMR spectrum of 24 shows broad singlets typical for [2Fe-2S] clusters. The UV/vis spectrum shows a highenergy band at $288 \mathrm{~nm}$ as well as two broad visible bands at 457 and $540 \mathrm{~nm}$ (Figure 3.2). Compared to the parent indole-coordinated cluster $(410$ and $520 \mathrm{~nm}),{ }^{[151]}$ the latter bands are red-shifted due to increased electron density donated by the additional methyl groups in 24 . Owing to the lability in solution no electrochemical study was performed. 


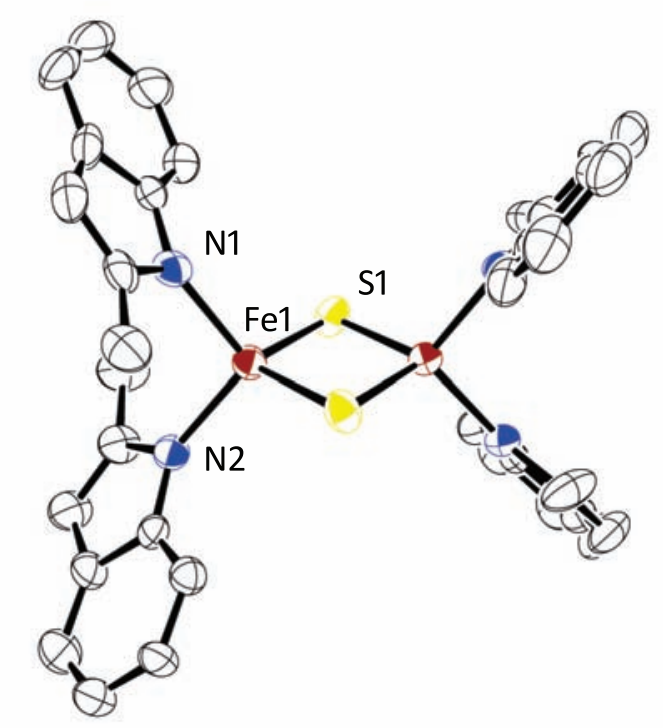

Figure 3.1: Molecular structure of 24.

- ORTEP plot, $50 \%$ probability thermal ellipsoids; counterions, solvent molecules and hydrogen atoms omitted for clarity. Note: Crystallographic data was insufficient for proper refinement due to the minor quality of the crystal; therefore the structure should be regarded as an educated guess only.

The Mössbauer spectrum of $\mathbf{2 4}$ shows a quadrupole doublet featuring an isomer shift typical for [2Fe-2S] clusters and a relatively small quadrupole splitting $(\delta=0.29 \mathrm{~mm} / \mathrm{s}$, $\Delta E_{\mathrm{Q}}=0.53 \mathrm{~mm} / \mathrm{s}$, Figure 3.3). The values are in good agreement with those obtained for the parent indolate-coordinated complex $\left(\delta=0.27 \mathrm{~mm} / \mathrm{s}, \Delta E_{\mathrm{Q}}=0.61 \mathrm{~mm} / \mathrm{s}\right) .{ }^{[151]}$ The theoretical quadrupole splitting has also been calculated on the BP86/def2-SV(P) level using DFT methods (see Chapter 7.8.1). While the calculated value is slightly larger on optimised than on crystal coordinates $(0.25$ and $0.20 \mathrm{~mm} / \mathrm{s}$, respectively), both values are too low. Compared to the values of the O- and S-coordinated clusters 11 and 12 described in Chapter 2, however, the general trend is correctly reproduced.

Magnetic susceptibility measurements were performed at $2 \mathrm{~T}$ from 295 to $2 \mathrm{~K}$ (see Chapter 7.6 for details). The magnetic moment $\mu_{\text {eff }}$ decreases upon cooling, indicating a diamagnetic ground state $\left(S_{\mathrm{T}}=0\right)$ with strongly antiferromagnetically coupled ferric iron atoms. The coupling constant $J$ was calculated using a fitting procedure to the appropriate Heisenberg spin Hamiltonian for isotropic exchange coupling and Zeeman 
interaction according to

$$
\mathscr{H}=-2 J \overrightarrow{S_{1}} \cdot \overrightarrow{S_{2}}+g \mu_{B}\left(\overrightarrow{S_{1}}+\overrightarrow{S_{2}}\right) \cdot \vec{B}
$$

The determined coupling constant of $J=-180 \mathrm{~cm}^{-1}$ proves strong antiferromagnetic coupling and lies in between the values for the related indolate and carbazolate-coordinated complexes $\left(-159 \text { and }-199 \mathrm{~cm}^{-1} \text {, respectively }\right)^{[151]}$.

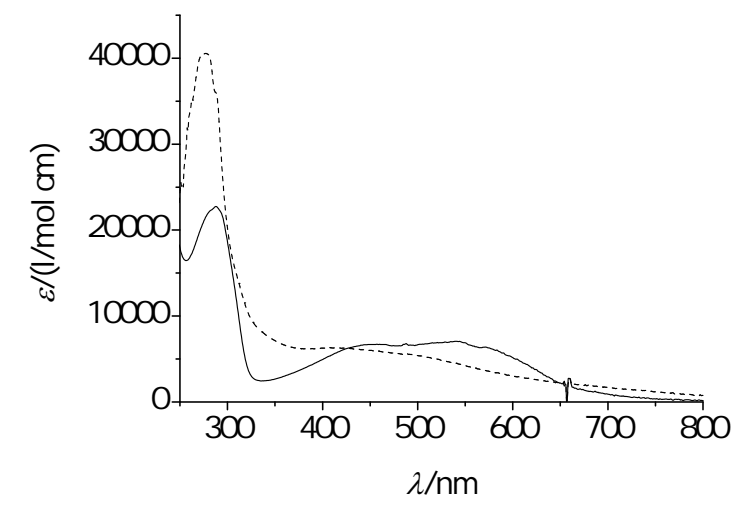

Figure 3.2: $\mathrm{UV} /$ vis spectra of clusters 24 in $\mathrm{MeCN}$ (solid line) and 25 in DMF (dashed line).
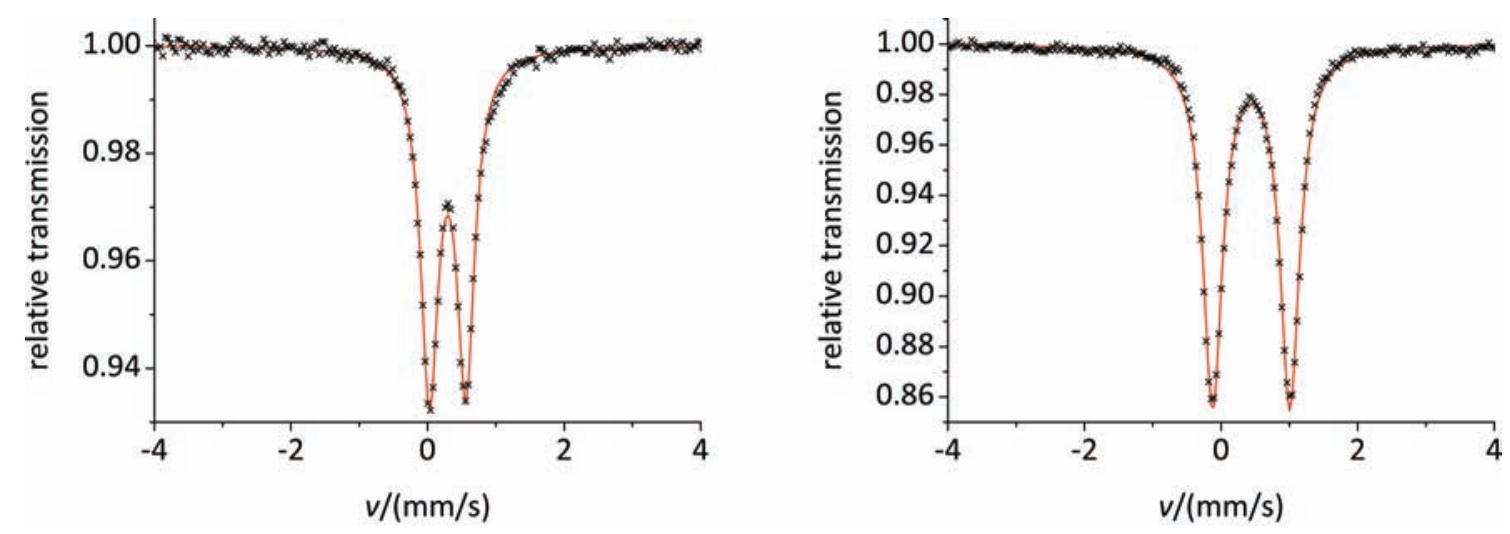

Figure 3.3: Mössbauer spectra of 24 (left) and 25 (right) at $80 \mathrm{~K}$. 


\subsection{Synthesis and Characterisation of the [4Fe-4S] Cluster}

The synthesis of the corresponding [4Fe-4S] cluster was also first attempted in pure THF using ${ }^{n} \mathrm{BuLi}$ and $\left(\mathrm{NEt}_{4}\right)_{2}\left[\mathrm{Fe}_{4} \mathrm{~S}_{4} \mathrm{Cl}_{4}\right](26)^{[161]}$ giving the same negative result as for the $[2 \mathrm{Fe}-2 \mathrm{~S}]$ cluster. However, when repeated in the presence of a sufficient amount of $\mathrm{MeCN}$ to allow complete dissolution of $\mathbf{2 6}$, an immediate colour change from greenish brown to deep red occurred, accompanied by the precipitation of a black powder. This was filtered off and washed with THF and $\mathrm{Et}_{2} \mathrm{O}$. Like the crystals obtained from the decomposition of $\mathbf{2 4}$ mentioned above, this product was only soluble but highly unstable in DMF and DMSO and recrystallisation therefore impossible, yet it was moderately pure by ${ }^{1} \mathrm{H}$ NMR and Mössbauer spectroscopy. Therefore, the structure that is discussed is the one obtained from the synthesis of the [2Fe-2S] cluster (see above), whereas spectroscopic characterisation is based on the bulk material obtained from the rational approach.

Like for the corresponding [2Fe-2S] cluster, the synthesis of derivatives with other counterions $\left(\mathrm{NMe}_{4}^{+}, \mathrm{N}^{n} \mathrm{Bu}_{4}^{+}\right)$was explored. Although the solubility of the latter was increased compared to the $\mathrm{NEt}_{4}^{+}$compound, the isolation of a pure complex by crystallisation from acetonitrile, acetone or dichloromethane was not successful.

In addition, the synthesis of corresponding indolate-coordinated [4Fe-4S] clusters was investigated. Although in several approaches cluster formation was detected by ${ }^{1} \mathrm{H}$ NMR spectroscopy, precipitation of a pure product was not successful. Likewise, no distinct decomposition product could be identified.

The [4Fe-4S] cluster 25 crystallises as an $S_{4}$-symmetric complex with crystallographically identical iron atoms, sulphide ions and ligands, and the symmetry axis going through two of the cluster core plains (Figure 3.4). Relevant interatomic distances and angles are listed in Table 3.1 and are compared with those obtained for the most common all-S coordinated clusters ${ }^{[140]}$, the $\mathrm{N}$-coordinated cluster $\left[\mathrm{Fe}_{4} \mathrm{~S}_{4}\left(\mathrm{~N}\left(\mathrm{SiMe}_{3}\right)_{2}\right)_{4}\right]^{[142]}$ as well as the O-coordinated cluster $\left(\mathrm{NEt}_{4}\right)_{2}\left[\mathrm{Fe}_{4} \mathrm{~S}_{4}(\mathrm{OPh})_{4}\right]^{[162]}$. To the best of the author's knowledge, the two latter clusters are the only examples of non-S coordinated [4Fe-4S] clusters that have been structurally characterised, with the exception of abiological clusters bearing ligands like NO, CO or Cp. ${ }^{[197]}$

The distances between the iron atoms in 25 range from 2.76 to $2.79 \AA$ which is slightly larger than what is found for biological and biomimetic S-coordinated $[4 \mathrm{Fe}-4 \mathrm{~S}]^{2+}$ clusters (2.72-2.74 $\AA$ ) and the O-coordinated cluster (2.73-2.76 $)$. The N-coordinated [4Fe$4 \mathrm{~S}]^{4+}$ cluster has larger Fe...Fe distances of 2.87 to $3.00 \AA$ but is not completely com- 

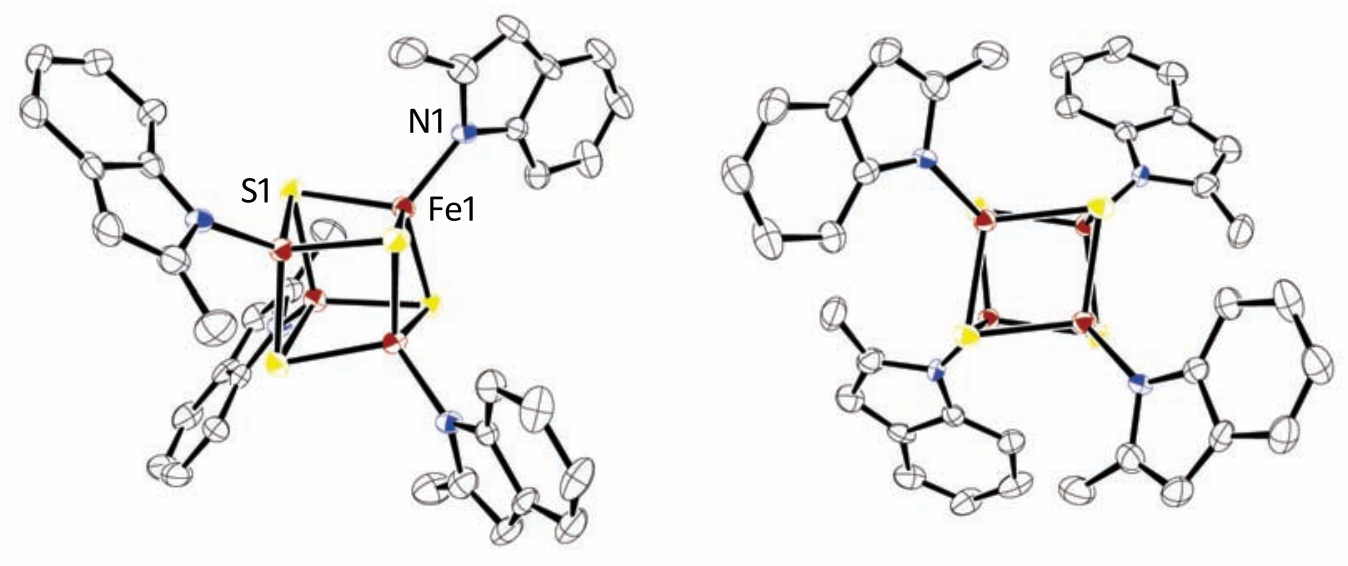

Figure 3.4: Molecular structure of $\mathbf{2 5}$ in two different orientations; in the right picture, the symmetry axis is perpendicular to the paper plane.

- ORTEP plot, $50 \%$ probability thermal ellipsoids; counterions and hydrogen atoms omitted for clarity; only crystallographically independent heteroatoms labelled.

parable due to the different oxidation states of the iron atoms. The Fe-S distances in 25 range from 2.27 to $2.31 \AA$ which is in accordance with the distances found in the other two complexes, as are the angles $\mathrm{Fe}-\mu-\mathrm{S}-\mathrm{Fe}\left(74.71-74.99^{\circ}\right)$. In general, the cluster core geometry does not change much upon formal exchange of a thiolate by an indolate ligand, an observation which was already made on the O-coordinated cluster. ${ }^{[162]}$

Despite fast decomposition in DMF, a ${ }^{1} \mathrm{H}$ NMR could be recorded showing signals at 2.2 (methyl group), 5.6, 6.1, 7.0 and $8.1 \mathrm{ppm}$ (one signal is either hidden beneath a solvent signal or too broad and could thus not be detected). Likewise, ESI mass spectrometry confirmed cluster formation (Figure 3.5). Like for the [2Fe-2S] cluster, no electrochemical experiments were performed. The UV/vis spectrum shows absorptions at 277 and $414 \mathrm{~nm}$ which are in accordance with data for the O-coordinated cluster $\left(\mathrm{NEt}_{4}\right)_{2}\left[\mathrm{Fe}_{4} \mathrm{~S}_{4}(\mathrm{OPh})_{4}\right](270 \text { and } 410 \mathrm{~nm})^{[162]}$.

The Mössbauer spectrum of 25 could be fitted best as a single doublet with $\delta=$ $0.44 \mathrm{~mm} / \mathrm{s}$ and $\Delta E_{\mathrm{Q}}=1.13 \mathrm{~mm} / \mathrm{s}$ (Figure 3.3). Compared to the two-iron analogue 24, the isomer shift is more positive which is in accordance with the decreased oxidation number of 2.5; this has also been observed for similar complexes. ${ }^{[140,162]}$ The quadrupole splitting of $1.13 \mathrm{~mm} / \mathrm{s}$ is relatively small compared to the O-coordinated cluster $\left(\Delta E_{\mathrm{Q}}=1.21 \mathrm{~mm} / \mathrm{s}\right)^{[162]}$ and with S-coordinated clusters ${ }^{[138]}$; unfortunately, no Mössbauer data are available for the amide-coordinated cluster. The quadrupole splittings calculated using DFT methods are in good agreement when using crystal coor- 


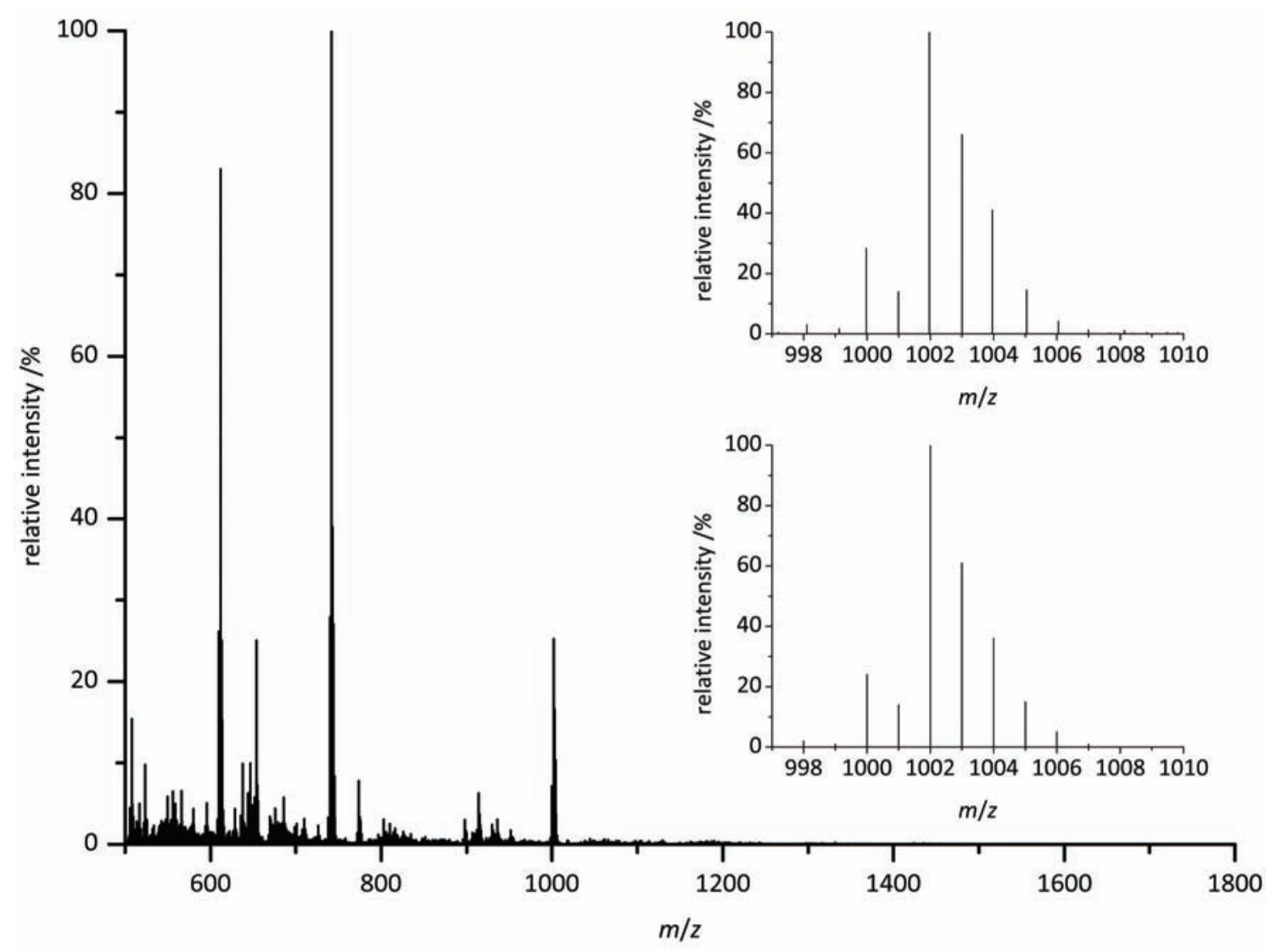

Figure 3.5: ESI(-) mass spectrum of 25 in MeCN/DMF solution.

- The insets show the experimental (top) and calculated (bottom) isotopic distribution pattern for $\left[\mathrm{M}-\mathrm{NEt}_{4}\right]^{-}$.

dinates $(1.02-1.04 \mathrm{~mm} / \mathrm{s})$ and less when using DFT-optimised coordinates $(0.75 \mathrm{~mm} / \mathrm{s}$, see Chapter 7.8.1). When compared to the [2Fe-2S] clusters for which optimised coordinates always gave more reliable values, the theoretical value - like the experimental value - for 25 is the largest. 
Table 3.1: Selected interatomic distances $d$ and angles $\alpha$ of complexes $24^{\text {a) }}$ and $\mathbf{2 5 .}$

\begin{tabular}{cccccc}
\hline & $d(\mathrm{Fe} \cdots \mathrm{Fe}) / \AA$ & $d(\mathrm{Fe}-\mu-\mathrm{S}) / \AA$ & $d(\mathrm{Fe}-\mathrm{N}) / \AA$ & $\alpha(\mathrm{Fe}-\mu-\mathrm{S}-\mathrm{Fe}) /^{\circ}$ & $\alpha(\mathrm{N}-\mathrm{Fe}-\mathrm{N})^{\mathrm{b}} /{ }^{\circ}$ \\
\hline \multirow{2}{*}{$24^{\mathrm{a})}$} & $2.7855(7)$ & $2.2079(12)$ & $1.9792(35)$ & $78.003(33)$ & $103.960(146)$ \\
& & $2.2181(9)$ & $2.0016(36)$ & & \\
\multirow{2}{*}{$\mathbf{2 5}$} & $2.7683(15)$ & $2.2732(24)$ & & $74.733(84)$ & $115.413(190)$ \\
& $2.7921(15)$ & $2.2880(25)$ & $1.9575(57)$ & $74.990(62)$ & $114.236(190)$ \\
& $2.7683(17)$ & $2.3135(27)$ & & $74.710(62)$ & $115.553(150)$ \\
\hline
\end{tabular}

a) Note: Crystallographic data was insufficient for proper refinement due to the minor quality of the crystal; therefore the structure should be regarded as an educated guess only.; b) $\alpha(\mathrm{N}-\mathrm{Fe}-\mu-\mathrm{S})$ for $\mathbf{2 5}$.

Table 3.2: Selected electrochemical and spectroscopic data of complexes 24 and 25.

\begin{tabular}{cccccc}
\hline & $\lambda_{\max } / \mathrm{nm}$ & $\epsilon /(1 /(\mathrm{mol} \cdot \mathrm{cm}))$ & $\delta /(\mathrm{mm} / \mathrm{s})$ & $\Delta E_{\mathrm{Q}}(\mathrm{mm} / \mathrm{s})$ & $\Delta E_{\mathrm{Q}}(\mathrm{calc} .)^{\mathrm{a})} /(\mathrm{mm} / \mathrm{s})$ \\
\hline \multirow{2}{*}{24} & 288 & 23000 & & & \\
& 457 & 6700 & 0.29 & 0.53 & 0.25 \\
& 540 & 7100 & & & \\
& 277 & 41000 & & & 0.75 \\
& $287(\mathrm{sh})$ & 36000 & 0.44 & 1.13 & \\
& 414 & 6300 & & & \\
\hline
\end{tabular}

a) Calculated quadrupole splittings were obtained from the eigenvalues of the electric field gradient at the positions of the iron atoms on optimised coordinates; data from Table 7.7. See Chapter 7.8.1 for details. 


\subsection{Conclusions}

Two new Fe/S clusters coordinated by 2-methylindole could be synthesised and characterised by mass spectrometry, ${ }^{1} \mathrm{H}$ NMR, UV/vis, and Mössbauer spectroscopy. The [2Fe-2S] cluster is comparable to other complexes bearing monodentate nitrogen ligation although its stability is relatively low. The [4Fe-4S] cluster is the first example of an all-N ligated $[4 \mathrm{Fe}-4 \mathrm{~S}]^{2+}$ cluster that has been isolated and structurally characterised. The cluster core is only slightly distorted as compared to $\mathrm{O}$ - and S-ligated clusters. The isomer shifts obtained by Mössbauer spectroscopy are in typical ranges. Notably, quadrupole splittings are rather low for both $[2 \mathrm{Fe}-2 \mathrm{~S}]$ and $[4 \mathrm{Fe}-4 \mathrm{~S}]$ clusters as compared to monodentate $\mathrm{S}$ - and O-ligation. The theoretical quadrupole splittings obtained by DFT calculations are in accordance with the experimental values. Both clusters undergo rapid decomposition in solution. 


\section{Synthesis of Five-Coordinate [2Fe-2S] Clusters}

\subsection{Introduction}

The coordination geometry of the vast majority of biological Fe/S clusters has long been known to be distorted tetrahedral. This geometry has been successfully mimicked by many biomimetic clusters and most of the electronic properties have likewise been reproduced. Yet the natural protein environment has more means to influence cluster properties than the small ligands used in synthetic complexes and some properties of naturally occurring $\mathrm{Fe} / \mathrm{S}$ clusters have not been mimicked yet.

Although reduction potentials and other properties of biomimetic [2Fe-2S] clusters can be tuned to a certain extent by variation of the ligand substitution, ${ }^{[187]}$ these influences are not sufficient to accomplish the extreme versatility exhibited by natural clusters. Probably the most prominent example is the exceptionally positive redox potential displayed by the Rieske type [2Fe-2S] clusters coordinated by two cysteines and two histidines; Even though a structural analogue has been reported, the most important feature - the redox potential - is not comparable to the natural archetype. ${ }^{[143]}$

Apart from the Rieske type clusters bearing histidine ligands it is mainly the [2Fe2S] cluster in biotin synthase which has a ligand sphere different from other clusters. One of the ligands is an arginine residue ${ }^{[64]}$ which is very unusual for biological metal ligation. ${ }^{[72]}$ Although the low resolution of the only available crystal structure does not allow for definite assignment of the protonation state and the coordination mode of this arginine residue, several unusual interactions are conceivable including bidentate coordination and the involvement in various hydrogen bonds.

In part, interactions other than via the four terminal ligands have been explored in synthetic $[2 \mathrm{Fe}-2 \mathrm{~S}]$ clusters, namely hydrogen bonding ${ }^{[153]}$ and weak coordination by an additional donor atom ${ }^{[154]}$. The latter concept of secondary bonding interaction, inspired particularly by the possible bidentate coordination by arginine, was extended towards $[2 \mathrm{Fe}-2 \mathrm{~S}]$ clusters containing iron atoms with the coordination number five. 


\subsection{Synthesis of the Ligands}

Since a possible tridentate ligand should provide a pre-organised pocket with three donor atoms binding equally, mononuclear iron complexes in an octahedral coordination with such ligands were searched. A frequent motif is the terpyridine motif, a triaryl system consisting of three N-heterocycles. Especially 2,6-disubstituted pyridines offer a binding pocket of the correct five-membered chelate ring size while ensuring complex stability by their rigidity. ${ }^{[199]}$<smiles>c1cc(-c2ccn[nH]2)nc(-c2ccn[nH]2)c1</smiles>

$27 a$<smiles>Cc1ccc(-c2cccc(-c3ccc(C)[nH]3)n2)[nH]1</smiles>

27d<smiles>c1cc(-c2nc3ccccc3[nH]2)nc(-c2nc3ccccc3[nH]2)c1</smiles>

27b<smiles>c1cc(-c2ncc[nH]2)nc(-c2ncc[nH]2)c1</smiles>

$27 c$<smiles>SCc1cccc(CS)n1</smiles>

$27 e$<smiles>O=C(O)c1cccc(C(=O)O)n1</smiles>

$27 f$<smiles>c1c[nH]c(-c2ccc(-c3ncc[nH]3)o2)n1</smiles>

27g

Figure 4.1: Tridentate ligands 27 employed in the synthesis of five-coordinate [2Fe-2S] clusters.

Three of these ligands which have been reported in mononuclear iron complexes were investigated, namely 2,6-bis(pyrazol-3-yl)pyridine ${ }^{[200,201]}$ (27a), 2,6-bis(benzimidazol-2yl)pyridine ${ }^{[202]}$ (27b) and 2,6-bis(imidazol-2-yl)pyridine ${ }^{[203]}(27 \mathrm{c})$. All three are azole derivatives of pyridine with pyrazole, benzimidazole or imidazole sidearms, respectively. Notably, the latter has been shown to give iron complexes whose reduction potential could be tuned by protonation of the non-coordinating $\mathrm{N}$ atoms. ${ }^{[204]}$ Although the role of biological histidine coordination was considered in this publication, the striking analogy to the proton-coupled electron transfer observed in Rieske proteins (see Chapter 1.3) was obviously not realised at that time.

To probe the influence of the non-coordinating $\mathrm{N}$ atom present in the azoles, a pyrrole derivative which lacks such a moiety was also synthesised. While two synthetic approaches were first considered - on the one hand, catalytic coupling of 2,6dibromopyridine and two pyrrole derivatives; ${ }^{[205]}$ on the other hand, pyrrole ring formation on a substituted pyridine ${ }^{[206,207]}$ - the latter was employed due to the lower syn- 
thetic cost. Via this route, $\alpha$-substituted pyrrole rings are formed by condensation of a 1,4-diketone and an ammonium salt, mainly explored with large aryl substituents. ${ }^{[206]}$ To avoid steric demand as far as possible without losing the protecting character of an $\alpha$-substituent, the synthetic approach was modified and the methyl-substituted diketone $28^{[207]}$ was employed to yield ligand $27 \mathrm{~d}$ (Scheme 4.1). Ligand $\mathbf{2 7 d}$ was characterised by NMR and IR spectroscopy as well as EI mass spectrometry.<smiles>CC(=O)CCC(=O)c1cccc(C(=O)CCC(C)=O)n1</smiles>

28<smiles>Cc1ccc(-c2cccc(-c3ccc(C)[nH]3)n2)[nH]1</smiles>

27d

Scheme 4.1: Synthesis of ligand $\mathbf{2 7 d}$.

To mimic biological cysteine coordination without major changes in ligand geometry, the pyridine-based aliphatic dithiol $27 \mathrm{e}$ with the same chelate ring size was employed. ${ }^{[208]}$ Since aliphatic alcohols have not been successfully used as ligands for [2Fe$2 \mathrm{~S}$ ] clusters, the carboxylic acid $\mathbf{2 7 f}$ was instead utilised to explore oxygen coordination.

Since ethers could be shown to act as secondary donors in [2Fe-2S] clusters, ${ }^{[154]}$ the di-substituted furane $\mathbf{2 7} \mathrm{g}$ was also synthesised in which the pyridine moiety of $27 \mathrm{c}$ was formally exchanged by a furane ring. Thus, 2,5-dibromofurane (29) ${ }^{[209]}$ (instead of 2,6-dibromopyridine) was treated with protected imidazole 30 in a Negishi coupling under similar conditions as in the synthesis of $27 \mathrm{c}$. After purification, the product was deprotected to yield 2,5-bis(imidazol-2-yl)furane $27 \mathrm{~g}$ in $61 \%$ yield over 2 steps (Scheme 4.2). All seven ligands are depicted in Figure 4.1.

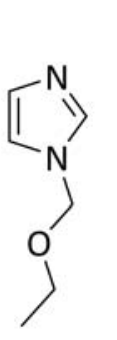

30
1. ${ }^{n} \mathrm{BuLi}$

2. $\mathrm{ZnCl}_{2}$<smiles>Brc1ccc(Br)o1</smiles>

29<smiles>CCOCn1ccnc1-c1ccc(-c2nccn2COCC)o1</smiles>

31<smiles>Clc1c[nH]c(-c2ccc(-c3ncc[nH]3)o2)n1</smiles>

$27 \mathrm{~g}$

Scheme 4.2: Synthesis of ligand $\mathbf{2 7 g}$. 


\subsection{Complex Syntheses and General Observations}

In a standard approach, the ligand 27 was deprotonated using ${ }^{n} \mathrm{BuLi}$ or $\mathrm{KH}$ in THF or DMF and the resulting salt was treated with $\left(\mathrm{NEt}_{4}\right)_{2}\left[\mathrm{Fe}_{2} \mathrm{~S}_{2} \mathrm{Cl}_{4}\right](9)$ either as a solid, or in $\mathrm{MeCN}$ or DMF solution. To probe the formation of [2Fe-2S] clusters, the reaction mixture was then usually layered with $\mathrm{Et}_{2} \mathrm{O}$ to precipitate crystalline material or evaporated to dryness and analysed by ${ }^{1} \mathrm{H}$ NMR or ESI mass spectrometry.

In some cases, cluster degradation was obvious by colour change of the reaction mixture from deep red to greenish brown. In case of the pyridine carboxylate $27 \mathrm{f}$ and the furane derivative $27 \mathrm{~g}$ no $[2 \mathrm{Fe}-2 \mathrm{~S}]$ cluster was observed and no crystalline material could be obtained. Likewise, no [2Fe-2S] cluster could be detected using ligands $27 \mathrm{~b}$ and $27 \mathrm{~d}$, probably due to steric demand with respect to repulsion between two ligands caused by the annelated benzene rings or the methyl groups, respectively. Only with ligands 27a, 27c and 27e some clusters were obtained as will be described in Chapter 4.4.

Generally, ligand geometry seemed to favour the formation of mononuclear complexes with destruction of the cluster core. This could be proven in case of the all-N ligands $(27 \mathrm{a}, 27 \mathrm{~b}, 27 \mathrm{c}, 27 \mathrm{~d})$ by the isolation of small amounts of crystalline material in each case which could be identified as mononuclear iron complexes 32 crystallographically (Figures 4.2 and 4.3). As is illustrated in Table 4.1, Fe-N distances (1.90-1.91 and 1.93-1.99 $\AA$ to the sidearm and pyridine $\mathrm{N}$ atoms, respectively) do not allow for an assignment of the oxidation state which must be decided by the number of counterions present in the unit cell and by spectroscopic methods.

While iron(II) complexes of ligand 27a have been extensively investigated as spincrossover compounds, ${ }^{[199,201,210-212]}$ structures of iron(III) complexes have not been published to the best of the author's knowledge. In contrast to the literature-known examples, the ligand is deprotonated in $\mathbf{3 2} \mathbf{a}$ and the complex therefore anionic.

In case of ligand $27 \mathrm{~b}$, the dianionic iron(II) complex $\mathbf{3 2 b}$ was crystallised. In the literature, dicationic iron(II) complexes with neutral ligands were investigated as spincrossover compounds. ${ }^{[202,213]}$ Although neutral iron(II) complexes with partially deprotonated ligands have been reported, ${ }^{[214]}$ a structure of an anionic complex has not been published to the best of the author's knowledge.

The structure of the complex obtained from ligand $27 \mathrm{c}$ could not be properly refined due to the minor quality of the crystal. The detection of only one counterion in the unit cell allows the identification of $\mathbf{3 2 c}$ as an iron(III) complex closely similar to a reported example with a different cation. ${ }^{[204]}$ 
Since iron complexes of all three ligands have been investigated already, no further studies were performed on complexes 32a-c. It can be concluded however that structural parameters do neither depend much on the protonation state of the ligand nor on the oxidation state of the iron atom.

The crystal structure of the iron(III) complex 32d obtained from the novel ligand 27d is shown in Figure 4.3. All relevant interatomic distance and angles are comparable to those of the related iron(II) and iron(III) complexes (Table 4.1). The oxidation state of 32d was proven by Mössbauer spectroscopy which gave values typical for a low-spin iron(III) complex in an octahedral environment $\left(\delta=0.14 \mathrm{~mm} / \mathrm{s}, \Delta E_{\mathrm{Q}}=3.31 \mathrm{~mm} / \mathrm{s}\right.$ at $7 \mathrm{~K})$. The quadrupole doublet (Figure 4.4) exhibits a strong asymmetry in line width which has previously been reported in similar cases to be depending on intermolecular spin-spin relaxation. ${ }^{[215]}$

Table 4.1: Selected interatomic distances $d$ and angles $\alpha$ of mononuclear iron complexes 32 .

\begin{tabular}{|c|c|c|c|}
\hline & $d\left(\mathrm{Fe}-\mathrm{N}_{\text {pyridine }}\right) / \AA$ & $d\left(\mathrm{Fe}-\mathrm{N}^{\mathrm{a})}\right) / \AA$ & $\left.\alpha\left(\mathrm{N}^{\mathrm{a}}\right)-\mathrm{Fe}-\mathrm{N}^{\mathrm{a}}\right) /^{\circ}$ \\
\hline \multirow{2}{*}{$32 a$} & $1.9119(11)$ & $\begin{array}{l}1.9320(12) \\
1.9343(12)\end{array}$ & $161.850(54)$ \\
\hline & $1.9084(11)$ & $\begin{array}{l}1.9407(13) \\
1.9323(13)\end{array}$ & $161.845(53)$ \\
\hline \multirow{2}{*}{$32 b^{b)}$} & $1.9026(19) / 1.9050(22)$ & $\begin{array}{l}1.9773(24) / 1.9795(23) \\
1.9812(23) / 1.9854(23)\end{array}$ & $160.801(89) / 160.244(98)$ \\
\hline & $1.903(2) / 1.9071(25)$ & $\begin{array}{l}1.9938(22) / 1.9862(23) \\
1.9803(12) / 1.9900(23)\end{array}$ & $160.505(19) / 160.465(93)$ \\
\hline \multirow{2}{*}{$32 d^{b)}$} & $1.9112(19) / 1.9097(19)$ & $\begin{array}{l}1.9773(18) / 1.9665(19) \\
1.9746(18) / 1.9762(18)\end{array}$ & $162.280(74) / 163.131(78)$ \\
\hline & $1.9138(19) / 1.9131(19)$ & $\begin{array}{l}1.9627(18) / 1.9652(20) \\
1.9775(18) / 1.9693(18)\end{array}$ & $162.662(74) / 162.765(79)$ \\
\hline
\end{tabular}

a) pyrazole, benzimidazole, or pyrrole; b) two molecules present in the unit cell. 

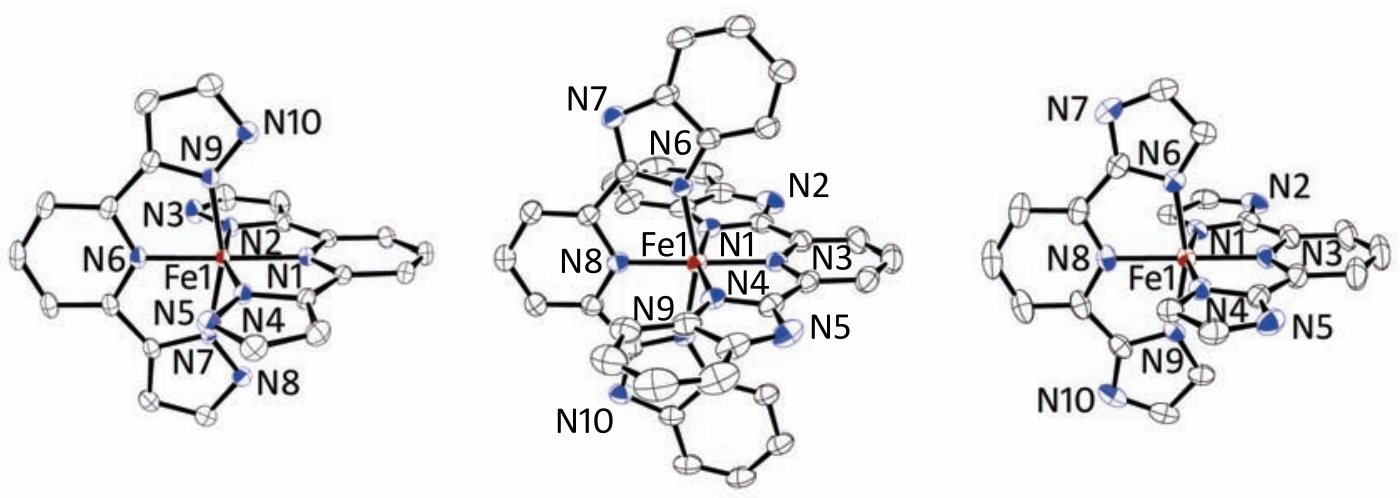

Figure 4.2: Molecular structures of mononuclear complexes 32.

-32a $=\left(\mathrm{NMe}_{4}\right)\left[\mathrm{L}_{2} \mathrm{Fe}\right]\left(\mathrm{H}_{2} \mathrm{~L}=27 \mathrm{a}\right.$, left $) ; 32 \mathbf{b}=\left(\mathrm{NEt}_{4}\right)_{2}\left[\mathrm{~L}_{2} \mathrm{Fe}\right]\left(\mathrm{H}_{2} \mathrm{~L}=\mathbf{2 7} \mathbf{b}\right.$, centre, only one of the two complex cations found in the unit cell is shown); $32 \mathrm{c}=\left(\mathrm{NEt}_{4}\right)_{\times}\left[\mathrm{L}_{2} \mathrm{Fe}\right]\left(\mathrm{H}_{2} \mathrm{~L}=27 \mathrm{c}\right.$, right). ORTEP plots, $50 \%$ probability thermal ellipsoids; counterions, solvent molecules and hydrogen atoms omitted for clarity. Note: Crystallographic data was insufficient for refinement due to the minor quality of the crystal in case of $32 c$; therefore the structure should be regarded as an educated guess only.

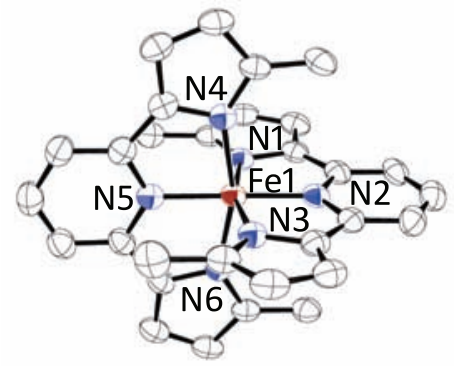

Figure 4.3: Molecular Structure of 32d.

- 32d $=\left(\mathrm{NEt}_{4}\right)\left[\mathrm{L}_{2} \mathrm{Fe}\right]\left(\mathrm{H}_{2} \mathrm{~L}=27 \mathrm{~d}\right)$. ORTEP plot, $50 \%$ probability thermal ellipsoids; only one of the two complex cations found in the unit cell is shown; counterions, solvent molecules and hydrogen atoms omitted for clarity. 


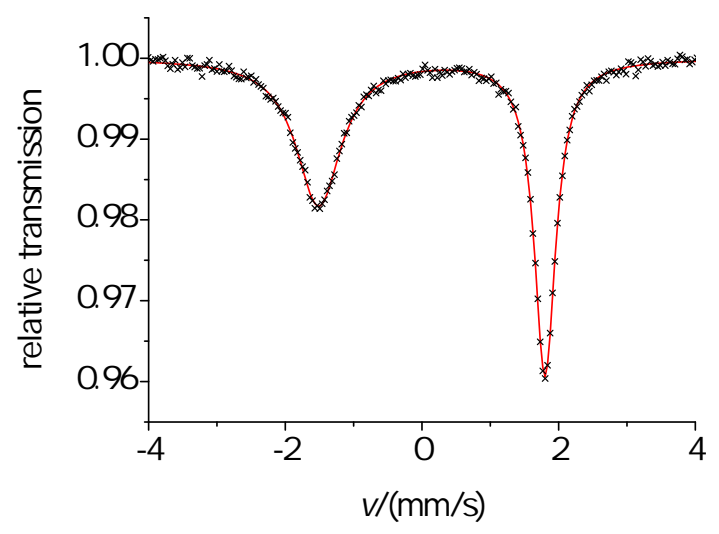

Figure 4.4: Mössbauer spectrum of $32 \mathrm{c}$ recorded at $7 \mathrm{~K}$.

\subsection{Characterisation of Five-Coordinate Fe/S Clusters}

\subsubsection{Complex Synthesis with Ligand 27c}

When $27 \mathrm{c}$ was treated with ${ }^{n} \mathrm{BuLi}$ or $\mathrm{KH}$ in $\mathrm{DMF}$ and $\left(\mathrm{NEt}_{4}\right)_{2}\left[\mathrm{Fe}_{2} \mathrm{~S}_{2} \mathrm{Cl}_{4}\right]$ (9) was subsequently added, the deep red colour typical for [2Fe-2S] clusters was retained. Slow diffusion of $\mathrm{Et}_{2} \mathrm{O}$ into a complex solution lead to precipitation of a powder which showed typical signals in the ${ }^{1} \mathrm{H}$ NMR spectrum. In addition, crystals suitable for X-ray diffraction were obtained and the product could be identified as the target complex 33 . Due to gradual decomposition in DMF (and more so in DMSO) no pure bulk material could be obtained by recrystallisation from $\mathrm{DMF} / \mathrm{Et}_{2} \mathrm{O}$. However, when the synthesis was perfomed in THF/MeCN, 33 precipitated within a few hours and the precipitate could be collected by filtration (Scheme 4.3). Pure by NMR and Mössbauer spectroscopy, the product is only sparingly soluble but stable in MeCN while it decomposes in DMF and DMSO solution.

The crystal structure of $\mathbf{3 3}$ shows an intact cluster core coordinated by two ligands with a crystallographic $C_{2}$ symmetry axis through the [2Fe-2S] plane (Figure 4.5). Although the distances between the iron atoms and the imidazole $\mathrm{N}$ atoms are shorter (2.11 and $2.12 \AA$ ), the pyridine $\mathrm{N}$ atoms are also within bond distance (2.18 $\mathrm{A}$, Table 4.2). With an $\mathrm{N}-\mathrm{Fe}-\mathrm{N}$ angle of $141.3^{\circ}$ between the two imidazole $\mathrm{N}$ atoms the coordination is far from tetrahedral, disregarding the additional coordination by the pyridine $\mathrm{N}$ atom. The Fe...Fe distance is increased to $2.79 \AA$ but still in a normal range ( $c f$. 
<smiles>c1cc(-c2ncc[nH]2)nc(-c2ncc[nH]2)c1</smiles>

27c
1. ${ }^{n} \mathrm{BuLi}$ or $\mathrm{KH}$

2. $\left(\mathrm{NEt}_{4}\right)_{2}\left[\mathrm{Fe}_{2} \mathrm{~S}_{2} \mathrm{Cl}_{4}\right](9)$
$\left(\mathrm{NEt}_{4}\right)_{2}$

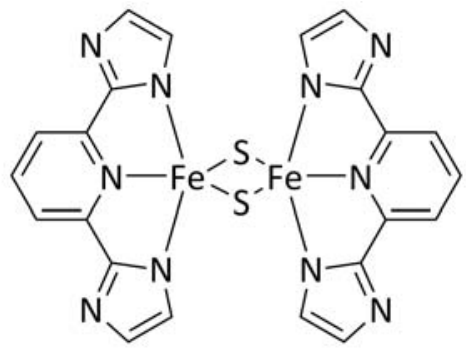

33

Scheme 4.3: Synthesis of complex 33 using ligand 27c.

$2.80 \AA$ in a cluster with additional thioether coordination $\left.{ }^{[154]}\right)$. This goes along with an increase of the Fe- $\mu$-S-Fe angle to $77.66^{\circ}$ (Table 4.3) compared to $74-76^{\circ}$ for normal, four-coordinate $[2 \mathrm{Fe}-2 \mathrm{~S}]$ clusters $^{[140]}$. The degree of trigonality can be quantified by calculation of the $\tau_{5}$ value; ${ }^{[216]}$ with a $\tau_{5}$ value of 0.085 , the coordination geometry of the iron atoms in $\mathbf{3 3}$ is almost perfectly square pyramidal with one of the bridging sulphide ions occupying the apical position and the other sulphide ion lying opposite to the pyridine $\mathrm{N}$ atom.

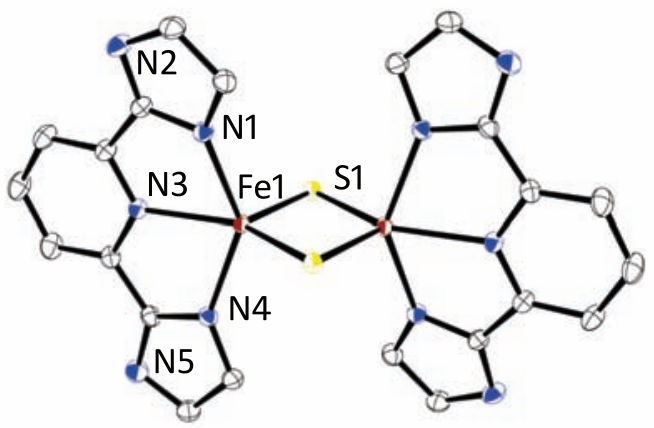

Figure 4.5: Molecular Structure of 33.

- ORTEP plot, $50 \%$ probability thermal ellipsoids; counterions and hydrogen atoms omitted for clarity; only crystallographically independent heteroatoms labelled.

\subsubsection{Complex Synthesis with Ligand 27a}

Although ligand $27 \mathrm{a}$ is structurally closely related to $27 \mathrm{c}$ by the formal exchange of the heterocyclic sidearms (imidazole in $27 \mathrm{c}$ and pyrazole in 27a), the isolation of an analogous [2Fe-2S] cluster as bulk material was not successful. However, a few single crystals of a fascinating cluster compound 34 were obtained from a synthesis using ${ }^{n} \mathrm{BuLi}$ and DMF (Scheme 4.4 and Figure 4.6). 


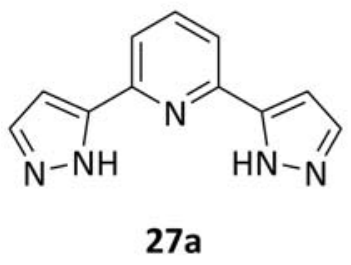

1. ${ }^{n}$ BuLi, DMF

2. $\left(\mathrm{NEt}_{4}\right)_{2}\left[\mathrm{Fe}_{2} \mathrm{~S}_{2} \mathrm{Cl}_{4}\right](9)$

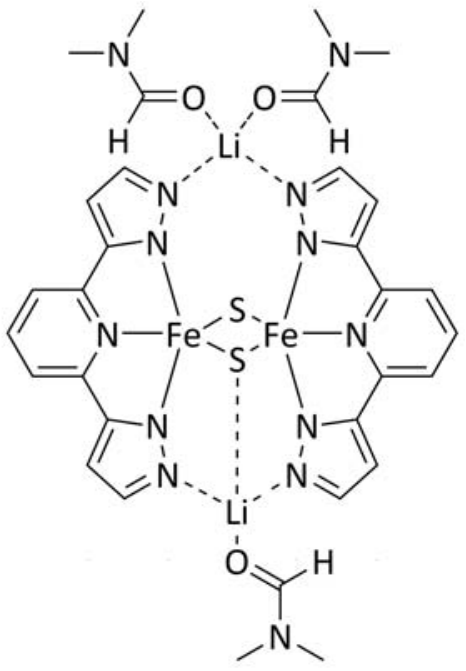

34

Scheme 4.4: Synthesis of complex 34 using ligand 27a.

The $[2 \mathrm{Fe}-2 \mathrm{~S}]$ core is retained and the three-fold ligand binding is comparable to that in 33. However, the non-coordinating $\mathrm{N}$ atoms of the azole rings from two different ligands face each other in 34. Thus the two pairs of pyrazole rings act as a bidentate ligand, and two lithium ions are found in the structure of 34 . The complex has a noncrystallographic mirror plane through the sulphide and the lithium ions perpendicular to the cluster core plane. The hemispheres above and below the cluster core plane however are different as one of the lithium atoms carries two additional DMF ligands while the other is coordinated by only one DMF molecule and shows interaction with one of the sulphide ions $(d(\mathrm{Li}-\mathrm{S})=2.79 \AA)$. Other relevant bond distances and angles are listed in Tables 4.2 and 4.3 .

As in $\mathbf{3 3}$, the Fe...Fe distance in 34 is relatively large $(2.79 \AA)$ as are the Fe- $\mu$-S-Fe angles $\left(76.82\right.$ and $\left.78.21^{\circ}\right)$. The Fe-N distances are in a range from 2.11 to $2.14 \AA$ for the pyrazole $\mathrm{N}$ atoms and almost equally short for the pyridine $\mathrm{N}$ atoms (2.16 and $2.19 \AA$ ). The bite angle between the pyrazole $\mathrm{N}$ atoms is $139^{\circ}$. The $\tau_{5}$ value ${ }^{[216]}$ of 0.188 and 0.223 is less definite than in case of $\mathbf{3 3}$ but still indicative of a square pyramid.

Unfortunately, no further characterisation of $\mathbf{3 4}$ was possible because only a small amount of crystals was obtained and the synthesis could not be reproduced. 

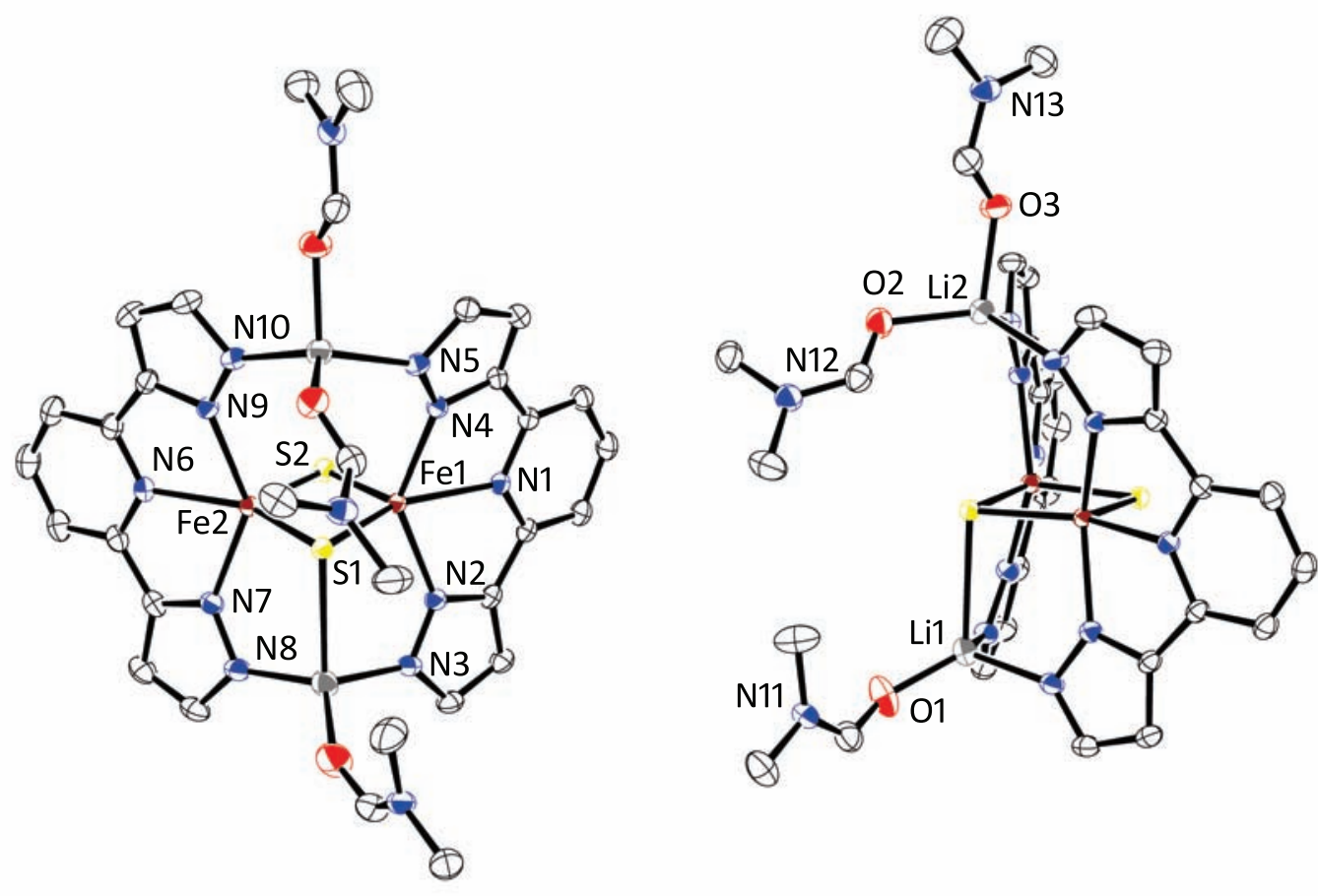

Figure 4.6: Molecular Structure of $\mathbf{3 4}$ in two different orientations.

- ORTEP plot, $50 \%$ probability thermal ellipsoids; hydrogen atoms omitted for clarity.

Table 4.2: Selected interatomic distances $d$ of complexes 33 and 34 .

\begin{tabular}{ccccc}
\hline & $d(\mathrm{Fe} \cdots \mathrm{Fe}) / \AA$ & $d(\mathrm{Fe}-\mu-\mathrm{S}) / \AA$ & $d\left(\mathrm{Fe}-\mathrm{N}_{\text {imidazole } / \text { pyrrole }}\right) / \AA$ & $d\left(\mathrm{Fe}-\mathrm{N}_{\text {pyridine }}\right) / \AA$ \\
\hline \multirow{2}{*}{$2.7911(3)$} & $2.2136(4)$ & $2.1139(16)$ & $2.1799(12)$ \\
& & $2.2377(4)$ & $2.1177(13)$ & \\
& & $2.2076(4)$ & $2.1406(15)$ & $2.1644(14)$ \\
& $2.7871(3)$ & $2.2322(5)$ & $2.1317(14)$ & $2.1859(15)$ \\
& & $2.2110(5)$ & $2.1396(14)$ & \\
\hline
\end{tabular}


Table 4.3: Selected interatomic angles of complexes 33 and 34 .

\begin{tabular}{ccccc}
\hline & $\alpha(\mathrm{Fe}-\mu-\mathrm{S}-\mathrm{Fe}) /^{\circ}$ & $\left.\alpha\left(\mathrm{N}^{\mathrm{a}}\right)-\mathrm{Fe}-\mathrm{N}^{\mathrm{a})}\right) /^{\circ}$ & $\alpha\left(\mathrm{Fe} \cdots \mathrm{Fe}-\mathrm{N}_{\text {pyridine }}\right) /^{\circ}$ & $\tau_{5}{ }^{\mathrm{b})}$ \\
\hline 33 & $77.660(14)$ & $141.300(56)$ & $162.81(3)$ & 0.085 \\
34 & $76.819(15)$ & $138.904(54)$ & $155.59(4)$ & 0.223 \\
& $78.213(16)$ & $139.218(56)$ & $158.26(4)$ & 0.188 \\
\hline
\end{tabular}

a) 33: $\mathrm{N}_{\text {imidazole }}$; 34: $\mathrm{N}_{\text {pyrrole }}$. b) Calculated according to $\tau_{5}=\frac{\beta-\alpha}{60^{\circ}}$ with $\alpha$ and $\beta$ being the two largest bond angles. ${ }^{[216]}$

\subsubsection{Complex Synthesis with Ligand 27e}

A third cluster compound was obtained using ligand $27 \mathrm{e}, \mathrm{KH}$ and $\left(\mathrm{NEt}_{4}\right)_{2}\left[\mathrm{Fe}_{2} \mathrm{~S}_{2} \mathrm{Cl}_{4}\right]$ (9), yet again only in minor amounts (Scheme 4.5). Diffusion of $\mathrm{Et}_{2} \mathrm{O}$ into a $\mathrm{MeCN}$ solution of the crude reaction product yielded a small amount of crystals suitable for $\mathrm{X}$-ray diffraction. The crystal structure showed the product to be no [2Fe-2S] cluster but the $[3 \mathrm{Fe}-1 \mathrm{~S}]$ cluster $\left(\mathrm{NEt}_{4}\right)_{2}\left[\mathrm{Fe}_{3} \mathrm{SL}_{3}\right]\left(35, \mathrm{H}_{2} \mathrm{~L}=2\right.$,6-bis(mercaptomethyl)pyridine (27e)) containing three ferrous iron atoms (Figure 4.7).<smiles>SCc1cccc(CS)n1</smiles>

$27 e$

\section{1. ${ }^{n}$ BuLi or $\mathrm{KH}$}

2. $\left(\mathrm{NEt}_{4}\right)_{2}\left[\mathrm{Fe}_{2} \mathrm{~S}_{2} \mathrm{Cl}_{4}\right](9)$

$\left(\mathrm{NEt}_{4}\right)_{2}$

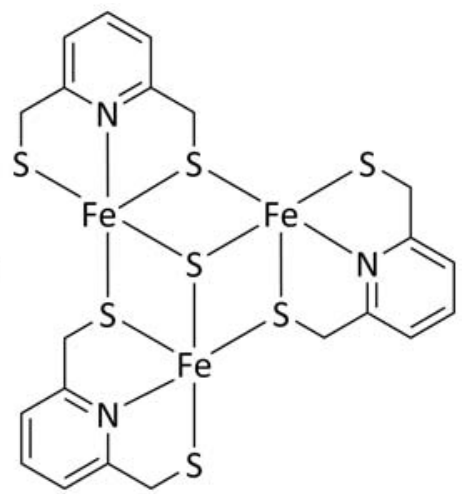

35

Scheme 4.5: Synthesis of complex 35 using ligand 27e.

While the mechanism of its formation and the reduction of the iron atoms is unclear, the structure (for relevant bond distances and angles, see Tables 4.4 and 4.5) can be compared to two similar clusters that have been reported. ${ }^{[217,218]}$ In these the iron atoms are tetrahedrally coordinated by 1,2-bis(mercaptomethyl)phenyl derivatives while in $\mathbf{3 5}$ the 
iron atoms are five-coordinate. In 35 , the $\mathrm{Fe} \cdots \mathrm{Fe}$ distance ranges from 3.04 to $3.07 \AA$ compared to $2.799 \AA^{[217]}$ and $2.78-2.86 \AA^{[218]}$ in the published structures. The larger distance in 35 can probably be explained by the increased coordination number. Likewise, the average $\mathrm{Fe}-\mathrm{S}$ distances are increased $(2.35 \AA$ as compared to 2.30 and $2.32 \AA$ for the sulphide ion, $2.43 / 2.48 \AA$ as compared to $2.36 \AA$ and $2.36 \AA$ for the bridging and $2.41 \AA$ as compared to 2.29 and $2.29 \AA$ for the terminal thiolates).

The average Fe-N distance $(2.25 \AA)$ is longer than in the [2Fe-2S] complexes 33 and 34, probably because of the larger sulphur atoms as compared to the nitrogen atoms. With an average $\mathrm{S}-\mathrm{Fe}-\mathrm{S}$ angle of $146^{\circ}$ the coordination is similarly far from tetrahedral. The average $\tau_{5}$ value $^{[216]}$ of 0.055 is again indicative of almost ideal square pyramidal coordination with the sulphide ion occupying the apical position.
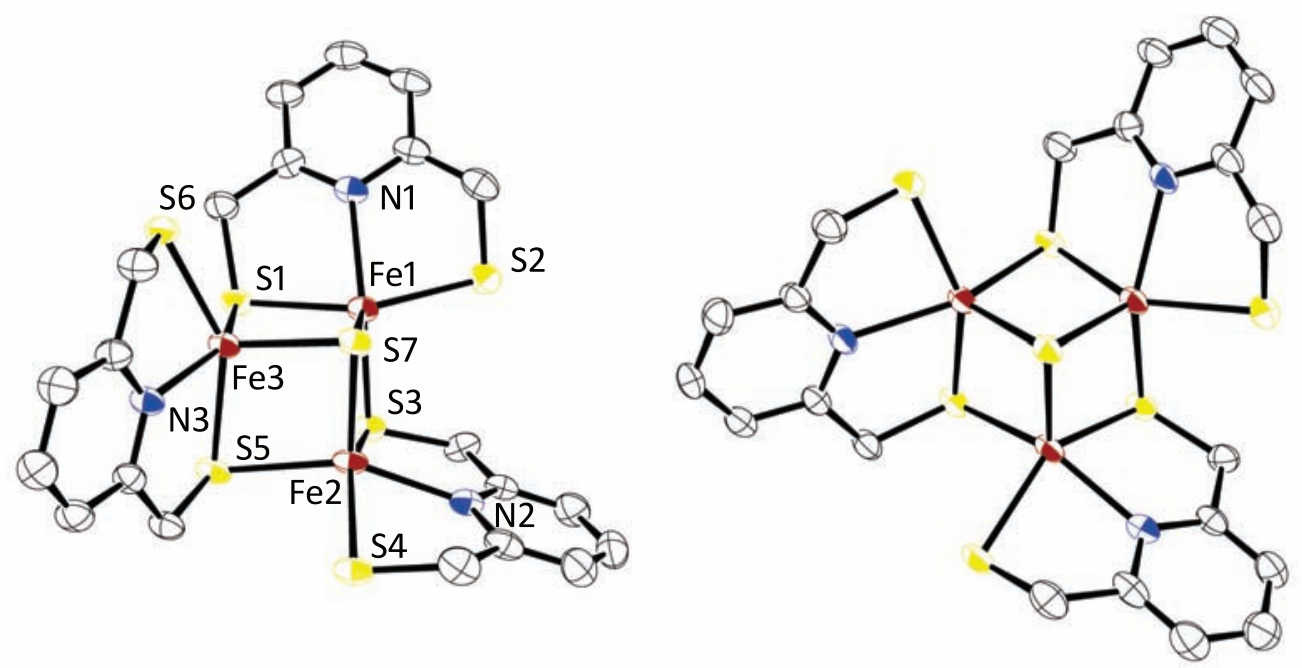

Figure 4.7: Molecular Structure of $\mathbf{3 5}$ in two different orientations.

- ORTEP plot, $50 \%$ probability thermal ellipsoids; counterions, solvent molecules and hydrogen atoms omitted for clarity.

Although the mechanism of the cluster formation was not investigated, initial formation of a $[2 \mathrm{Fe}-2 \mathrm{~S}]$ cluster is feasible in which the relatively large $\mathrm{S}$ atoms (as compared to the smaller $\mathrm{N}$ atoms in ligands $27 \mathrm{a}$ and $27 \mathrm{c}$ ) induce repulsion between the two ligands leading to cluster conversion.

In contrast to ${ }^{1} \mathrm{H}$ NMR spectra of [2Fe-2S] clusters, the spectrum of 35 showed significant paramagnetic shift with peaks at $\delta=5,20,25,30,56,83$ and $101 \mathrm{ppm}$ for the ligand protons caused by spin frustration (Figure 4.8). While this spectrum did not match with a [2Fe-2S] cluster, signals are comparable to data published for one of the $[3 \mathrm{Fe}-$ 
$1 \mathrm{~S}]$ clusters $\left(\delta=5,6,7,8,40,73,83\right.$ and $110 \mathrm{ppm}$ for the complex $\left(\mathrm{NEt}_{4}\right)_{2}\left[\mathrm{Fe}_{3} \mathrm{SL}_{3}\right]$ $\left.\left(\mathrm{H}_{2} \mathrm{~L}=o \text {-xylene- } \alpha, \alpha^{\prime} \text {-dithiol }\right)^{[218]}\right)$. While the signals for the aliphatic methylene protons in $\alpha$-position to the coordinating thiolates are more or less comparable $(30,56,83$ and $101 \mathrm{ppm}$ as compared to 40,73, 83 and $110 \mathrm{ppm}$ ), the aryl protons are more shifted in the spectrum of $35(5,20$, and $25 \mathrm{ppm}$ as compared to $5,6,7$ and $8 \mathrm{ppm})$, indicating coordination by the pyridine moiety.

Although these [3Fe-1S] clusters are structurally related to biological [3Fe-4S] clusters, they contain bridging thiolates instead of $\mu_{2}$-sulphide ions and are therefore not regarded as synthetic analogues.

Table 4.4: Selected interatomic distances $d$ of complex 35.

\begin{tabular}{|c|c|c|c|c|c|}
\hline & $d(\mathrm{Fe} \cdot \cdots \mathrm{Fe}) / \AA$ & $d\left(\mathrm{Fe}-\mu_{3}-\mathrm{S}\right) / \AA$ & $d\left(\mathrm{Fe}-\mathrm{S}^{\mathrm{a})}\right) / \AA$ & $d\left(\mathrm{Fe}-\mathrm{S}^{\mathrm{b}}\right) / \AA$ & $d(\mathrm{Fe}-\mathrm{N}) / \AA$ \\
\hline \multirow{4}{*}{35} & $3.0670(12)$ & $2.3553(17)$ & $2.4453(17)$ & \multirow[t]{2}{*}{$2.3948(18)$} & \multirow[t]{2}{*}{$2.2494(41)$} \\
\hline & & & $\begin{array}{l}2.4 / 10(16) \\
2.4293(19)\end{array}$ & & \\
\hline & $3.0725(13)$ & $2.3548(15)$ & $\begin{array}{l}2.4290(19) \\
2.4677(17)\end{array}$ & $2.4189(19)$ & $2.2618(47)$ \\
\hline & $3.0371(12)$ & $2.3534(17)$ & $\begin{array}{l}2.4156(15) \\
2.5075(19)\end{array}$ & $2.4034(16)$ & $2.2313(53)$ \\
\hline
\end{tabular}

a) bridging; b) terminal.

Table 4.5: Selected interatomic angles $\alpha$ of complex 35.

\begin{tabular}{ccccc}
\hline & $\alpha\left(\mathrm{Fe}-\mu_{3}-\mathrm{S}-\mathrm{Fe}\right) /^{\circ}$ & $\alpha\left(\mathrm{Fe}-\mu_{2}-\mathrm{S}-\mathrm{Fe}\right) /^{\circ}$ & $\left.\alpha\left(\mathrm{S}^{\mathrm{a}}\right)-\mathrm{Fe}-\mathrm{S}^{\mathrm{a})}\right) /^{\circ}$ & $\tau_{5}{ }^{\mathrm{b})}$ \\
\hline \multirow{3}{*}{35} & $81.25(5)$ & $77.48(5)$ & $148.77(7)$ & 0.011 \\
& $80.34(5)$ & $76.91(5)$ & $146.75(6)$ & 0.027 \\
& $81.46(5)$ & $76.67(5)$ & $142.90(6)$ & 0.127 \\
\hline
\end{tabular}

a) Both $S$ atoms of one ligand. b) Calculated according to $\tau_{5}=\frac{\beta-\alpha}{60^{\circ}}$ with $\alpha$ and $\beta$ being the two largest bond angles. ${ }^{[216]}$ 


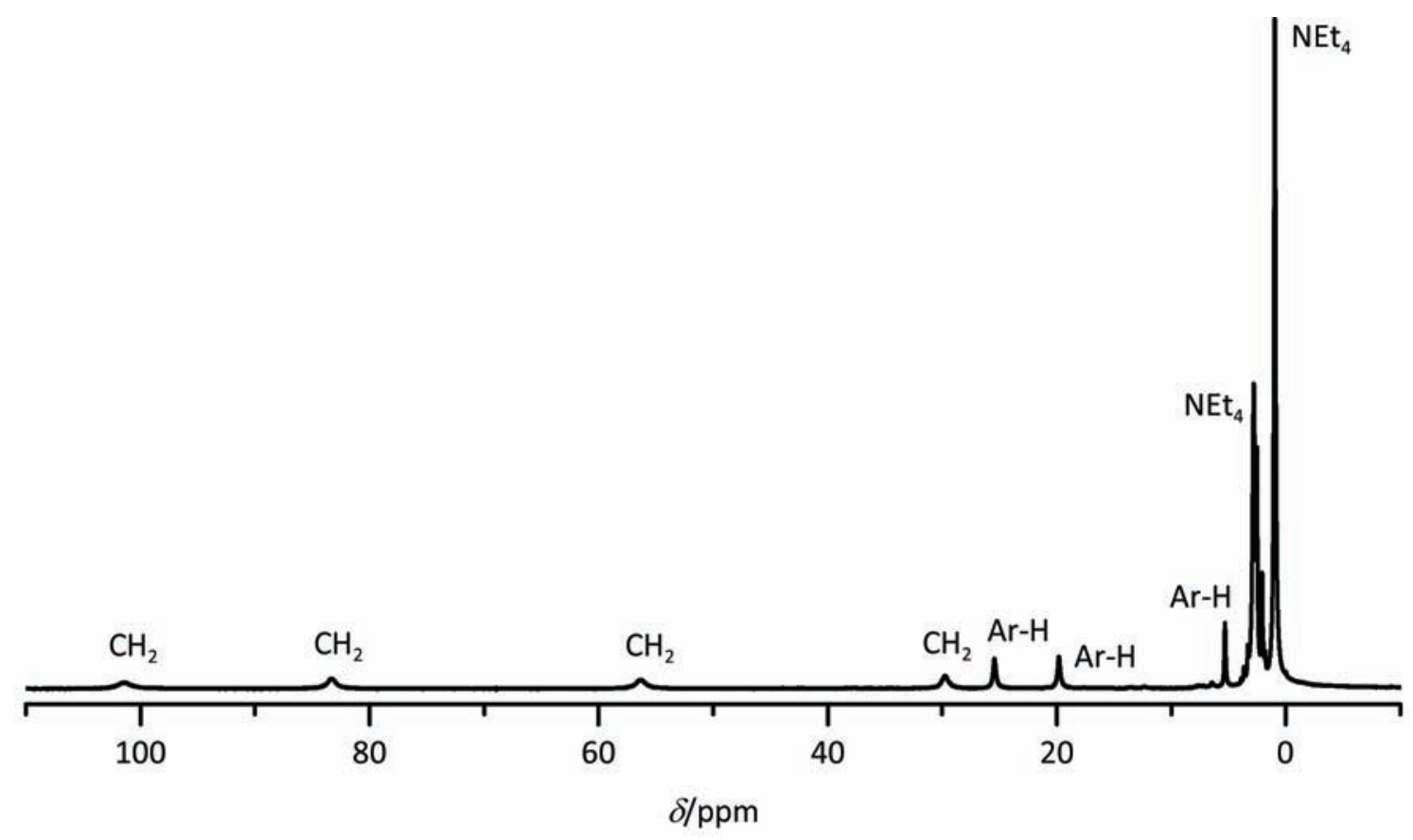

Figure 4.8: ${ }^{1} \mathrm{H}$ NMR spectrum of 35 recorded at $200 \mathrm{MHz}$ in DMSO-d 6 .

\subsection{Further Characterisation of [2Fe-2S] Cluster 33}

More detailed studies were performed on compound 33. The ${ }^{1} \mathrm{H}$ NMR spectrum shows typically broad signals at 12.83 and $13.71 \mathrm{ppm}$ for the imidazole protons and at 6.90 and $9.00 \mathrm{ppm}$ for the pyridine protons (Figure 4.9). The extreme broadening of the latter signal is further proof for genuine coordination by the pyridine moiety. The two imidazole signals appear at a remarkably low field compared to other ligands.

The UV/vis spectrum of 33 resembles that of other [2Fe-2S] clusters (Figure 4.10). Besides an intense band at $310 \mathrm{~nm}$ there is one main visible band at $489 \mathrm{~nm}$ with much lower intensity. Compared to clusters bearing bidentate ligands with $\mathrm{N}$ donors, ${ }^{[172]}$ both bands are shifted to higher energies.

Cyclic voltammetry of $\mathbf{3 3}$ was perfomed in DMF solution (Figure 4.11) giving a quasireversible reduction at a surprisingly positive potential (halfwave potential at $-0.72 \mathrm{~V}$ vs. the $\mathrm{Cp}_{2}^{*} \mathrm{Fe} / \mathrm{Cp}_{2}^{*} \mathrm{Fe}^{+}$couple or $-0.49 \mathrm{~V}$ vs. NHE) and an irreversible reduction (halfwave potential at $-1.37 \mathrm{~V}$ vs. the $\mathrm{Cp}_{2}^{*} \mathrm{Fe} / \mathrm{Cp}_{2}^{*} \mathrm{Fe}^{+}$couple or $-1.14 \mathrm{~V}$ vs. NHE, see Chapter 7.5 for details). Although clusters stabilised by NH...S hydrogen bonds exhibit even more positive reduction potentials up to $-0.35 \mathrm{~V}$ vs. NHE, ${ }^{[153]}$ the potential of 33 is 


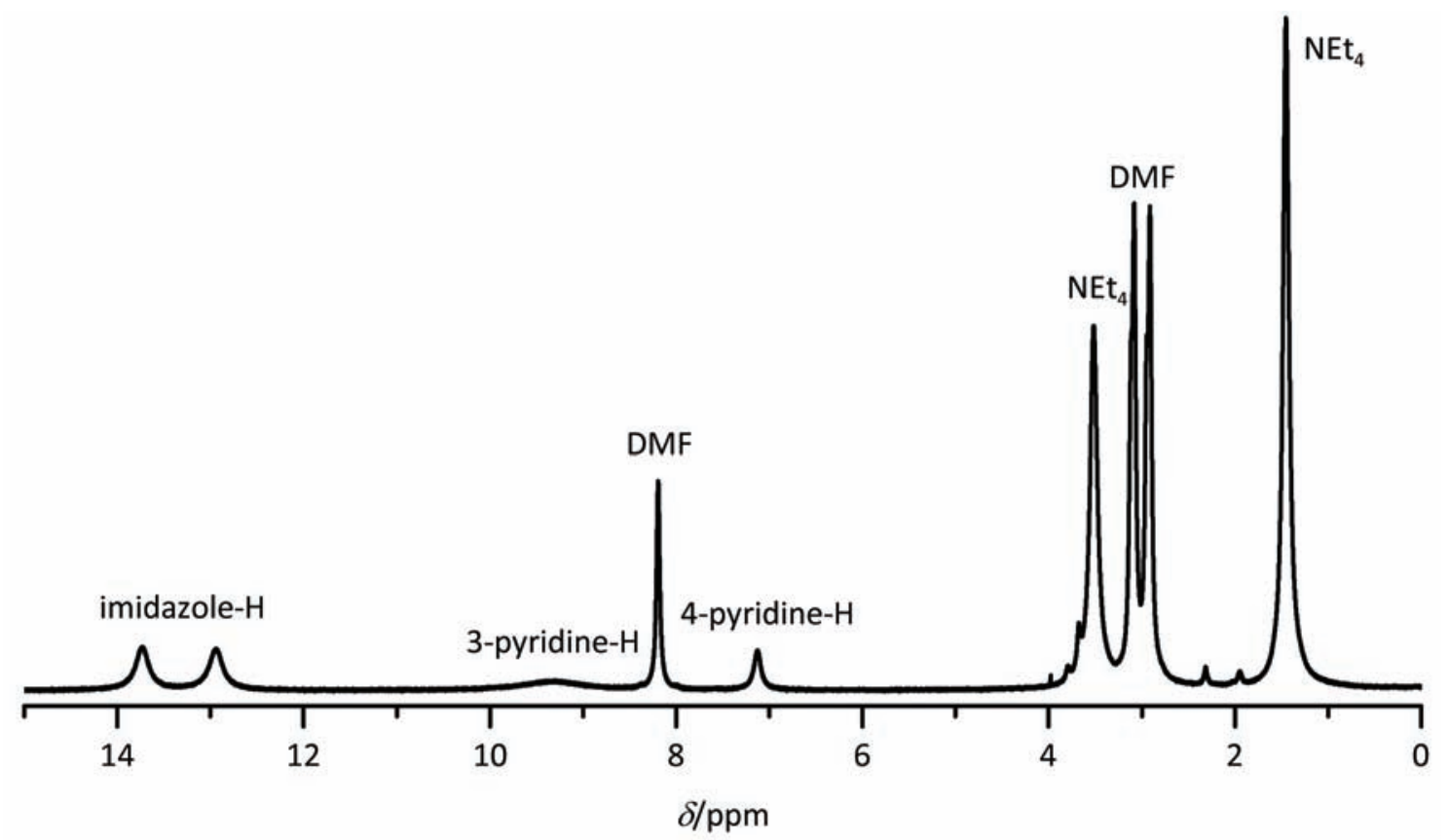

Figure 4.9: ${ }^{1} \mathrm{H}$ NMR spectrum of 33 at $500 \mathrm{MHz}$ in $\mathrm{DMF}^{\mathrm{d}} \mathrm{d}_{7}$.

among the most positive found for synthetic $[2 \mathrm{Fe}-2 \mathrm{~S}]$ clusters and almost in the range of $[2 \mathrm{Fe}-2 \mathrm{~S}]$ ferredoxins $(-0.15 \text { to }-0.45 \mathrm{~V})^{[1]}$.

The Mössbauer spectrum (Figure 4.12) shows an isomer shift of $\delta=0.44 \mathrm{~mm} / \mathrm{s}$ which is rather positive compared to other $\mathrm{N}$-coordinated [2Fe-2S] clusters like $24(\delta$ $=0.29 \mathrm{~mm} / \mathrm{s}$, see Chapter 3). While a linear correlation between the oxidation state $s$ of the iron atoms and the isomer shift $\delta$ according to $\delta=1.4-0.4 s$ was reported in the literature, this calculation holds only for tetrahedral sites and thus cannot be applied to the present five-coordinate iron atoms. ${ }^{[219]}$ However, a shift to larger values is known from site-differentiated $[4 \mathrm{Fe}-4 \mathrm{~S}]$ clusters with coordination numbers greater than four for one of the iron atoms. ${ }^{[140,155]}$ While this is explained by the decrease in the spectroscopic oxidation number due to the electron density donated by the additional atom, a mathematical correlation has not been found.

Furthermore, a surprisingly small quadrupole doublet was found $\left(\Delta E_{\mathrm{Q}}=0.43 \mathrm{~mm} / \mathrm{s}\right)$. This value was compared to theoretical quadrupole splittings obtained by DFT calculations using two different levels of theory, namely the BP86 and B3LYP functionals (see Chapter 7.8.1 for details). Calculations on crystal coordinates gave lower values than those on optimised coordinates (Table 4.6); as the latter were previously found to be more reliable (see Chapters 2 and 3), only these are discussed. On both levels of theory, 


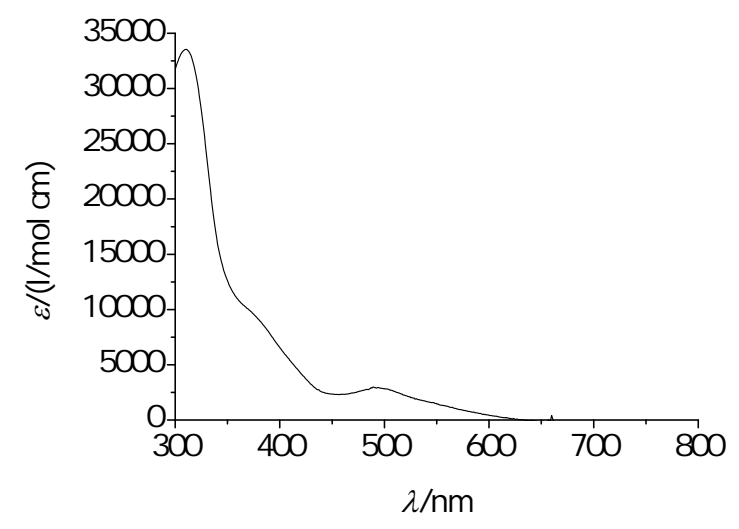

Figure 4.10: UV/vis spectrum of cluster 33 in DMSO.

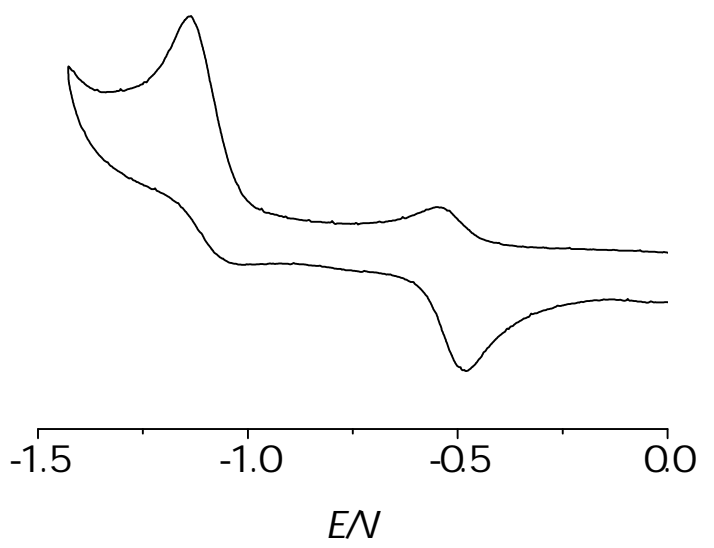

Figure 4.11: Cyclic voltammogram of cluster 33 in DMF vs. NHE.

- Recorded at $100 \mathrm{mV} / \mathrm{s}$ vs. the $\mathrm{Cp}_{2}^{*} \mathrm{Fe} / \mathrm{Cp}_{2}^{*} \mathrm{Fe}^{+}$couple as internal standard and referenced vs. $\mathrm{NHE}^{[189]}$. 
a relatively small value was obtained (BP86: $0.30 \mathrm{~mm} / \mathrm{s}$, B3LYP: $0.22 \mathrm{~mm} / \mathrm{s}$ ) while the method without exact exchange (BP86) was closer to the value experimentally found. Compared to other clusters, however, the value is too large as it is larger than that calculated for other $\mathrm{N}$ - and for O-coordinated clusters (see Table 7.3).

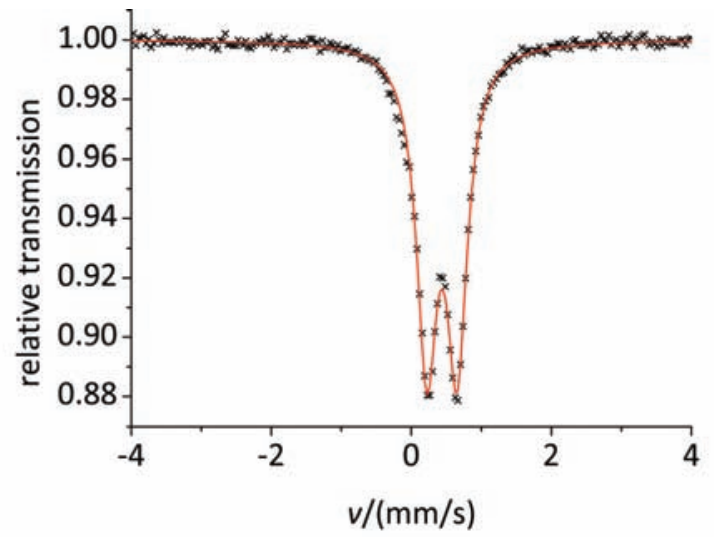

Figure 4.12: Mössbauer spectrum of 33 at $80 \mathrm{~K}$.

Magnetic susceptibility measurements were performed at $0.5 \mathrm{~T}$ from 295 to $2 \mathrm{~K}$ (see Chapter 7.6 for details). As for other [2Fe-2S] clusters (see Chapter 3), the magnetic moment $\mu_{\text {eff }}$ decreases upon cooling, indicating a diamagnetic ground state $\left(S_{\mathrm{T}}=0\right)$ with strongly antiferromagnetically coupled ferric iron atoms. The coupling constant $J$ was calculated using a fitting procedure to the appropriate Heisenberg spin Hamiltonian for isotropic exchange coupling and Zeeman interaction according to

$$
\mathscr{H}=-2 J \overrightarrow{S_{1}} \cdot \overrightarrow{S_{2}}+g \mu_{B}\left(\overrightarrow{S_{1}}+\overrightarrow{S_{2}}\right) \cdot \vec{B}
$$

The determined coupling constant of $J=-167 \mathrm{~cm}^{-1}$ is significantly weaker than for the 2-methylindolate coordinated complex 24 (see Chapter 3). However, it is in the same range as the coupling constant determined for clusters with bidentate dipyrromethane ligands. ${ }^{[172]}$ Notably, the coupling is much stronger than in a cluster with a bidentate thiolate ligand imposing additional secondary bonding interaction by a thioether group $\left(J=-126 \mathrm{~cm}^{-1}\right) .{ }^{[154]}$ Since the relevant distances and angles within the cluster core of the two complexes are very similar $(d(\mathrm{Fe} \cdots \mathrm{Fe})=2.79 \AA$ as compared to $2.80 \AA, \alpha(\mathrm{Fe}-\mu$ $\mathrm{S}-\mathrm{Fe})=77.66^{\circ}$ as compared to $\left.78.06 / 78.45^{\circ}\right)$, the large differences in electronic coupling cannot be explained by the geometry of the $[2 \mathrm{Fe}-2 \mathrm{~S}]$ cluster core alone. In conclusion, the cluster core of $\mathbf{3 3}$ is only slightly distorted with respect to its electronic properties. 
Table 4.6: Selected electrochemical and spectroscopic data of complex 33.

\begin{tabular}{cccccccc}
\hline & $\begin{array}{c}\lambda_{\max } \\
/ \mathrm{nm}\end{array}$ & $\begin{array}{c}\epsilon / \\
(\mathrm{l} /(\mathrm{mol} \cdot \mathrm{cm}))\end{array}$ & $\begin{array}{c}\left.E_{1 / 2}{ }^{\mathrm{a}}\right) \\
/ \mathrm{V}\end{array}$ & $\begin{array}{c}E_{1 / 2}(\mathrm{calc} .)^{\mathrm{b})} \\
/ \mathrm{V}\end{array}$ & $\begin{array}{c}\delta / \\
(\mathrm{mm} / \mathrm{s})\end{array}$ & $\begin{array}{c}\Delta E_{\mathrm{Q}} / \\
(\mathrm{mm} / \mathrm{s})\end{array}$ & $\begin{array}{c}\left.\Delta E_{\mathrm{Q}}(\mathrm{calc} .)^{\mathrm{c}}\right) \\
/(\mathrm{mm} / \mathrm{s})\end{array}$ \\
\hline \multirow{3}{3}{33} & 310 & 34000 & & $-1.85(\mathrm{BP} 86)$ & & & $0.30(\mathrm{BP} 86)$ \\
& 370 & $10000(\mathrm{sh})$ & $-0.49^{\mathrm{d})}$ & & 0.44 & 0.43 & \\
& 489 & 3000 & & $-1.68(\mathrm{~B} 3 \mathrm{LYP})$ & & & $0.22(\mathrm{~B} 3 \mathrm{LYP})$ \\
\hline
\end{tabular}

a) Reduction potentials were measured $v$ s. the $\mathrm{Cp}_{2}^{*} \mathrm{Fe} / \mathrm{Cp}_{2}^{*} \mathrm{Fe}^{+}$couple and referenced $v$ s. NHE. ${ }^{[189]} \mathrm{b}$ ) Calculated reduction potentials were obtained from optimised coordinates; data from Table 7.4. c) Calculated quadrupole splittings were obtained from the eigenvalues of the electric field gradient at the positions of the iron atoms on optimised coordinates; data from Table 7.7. See Chapter 7.8.1 for details. d) $\Delta E=$ $116 \mathrm{mV}\left(\mathrm{Cp}_{2}^{*} \mathrm{Fe} / \mathrm{Cp}_{2}^{*} \mathrm{Fe}^{+}: \Delta E=87 \mathrm{mV}\right)$.

In order to further prove the five-coordinate nature of the iron atoms in $\mathbf{3 3}$, the spin densities on relevant atoms were calculated in the ferromagnetically and the antiferromagnetically coupled state on both crystal and optimised coordinates. In addition, these calculations were performed in the reduced state on optimised coordinates. All values are listed in Table 4.7. In all cases, the spin density is mainly localised on the iron atoms and only little spin density is almost equally distributed over the coordinating $\mathrm{N}$ atoms ( 0.05 a.u. for each $\mathrm{N}$ atom). The spin density is approximately seven times higher on the bridging sulphide ions, adding up to 0.70 a.u. (0.35 a.u. from each iron atom) in the ferromagnetically coupled state, and neutralising each other in the antiferromagnetically coupled state (Figure 4.13). The equal distribution of spin densities over all coordinating $\mathrm{N}$ atoms is indicative of an approximately equally strong binding by these atoms.

The energy difference between the relevant spin states (antiferromagnetic, AF, and ferromagnetic, F) is large in case of the oxidised state, favouring the antiferromagnetically coupled state which is also experimentally found. In the reduced state, however, the energy difference becomes very narrow. Although calculated reduction potentials are too low for both BP86 and B3LYP, like in the other examples (cf. Table 2.2), they are more positive than those for the $\mathrm{O}$ - and $\mathrm{S}$ - coordinated examples. 
Table 4.7: Calculated spin densities on relevant atoms of 33. ${ }^{\mathrm{a})}$

\begin{tabular}{|c|c|c|c|c|c|c|c|}
\hline & \multicolumn{2}{|c|}{ functional } & $\begin{array}{c}E_{\text {relative }}{ }^{\mathrm{b}} \\
\mathrm{kJ} / \mathrm{mol}\end{array}$ & \multicolumn{4}{|c|}{$\rho / a . u}$. \\
\hline \multicolumn{8}{|c|}{ crystal coordinates } \\
\hline \multirow{4}{*}{33} & \multirow{2}{*}{ BP86 } & $\mathrm{F}$ & +106 & 3.91 & 0.76 & 0.05 & 0.07 \\
\hline & & $\mathrm{AF}$ & 0 & 3.62 & 0.04 & 0.05 & 0.05 \\
\hline & \multirow{2}{*}{ B3LYP } & $\mathrm{F}$ & +63 & 4.02 & 0.72 & 0.04 & 0.07 \\
\hline & & $\mathrm{AF}$ & 0 & 3.94 & 0.03 & 0.05 & 0.06 \\
\hline \multicolumn{8}{|c|}{ optimised coordinates } \\
\hline \multirow{4}{*}{33} & \multirow{2}{*}{ BP86 } & $\mathrm{F}$ & +81 & 3.97 & 0.75 & 0.04 & 0.06 \\
\hline & & $\mathrm{AF}$ & 0 & 3.66 & 0.03 & 0.05 & 0.05 \\
\hline & \multirow{2}{*}{ B3LYP } & $\mathrm{F}$ & +40 & 4.06 & 0.71 & 0.04 & 0.06 \\
\hline & & $\mathrm{AF}$ & 0 & 4.00 & 0.03 & 0.04 & 0.06 \\
\hline \multirow{4}{*}{$33^{\text {red }}$} & \multirow{2}{*}{ BP86 } & $\mathrm{F}$ & +25 & 3.78 & 0.53 & 0.03 & 0.04 \\
\hline & & $\mathrm{AF}$ & 0 & $3.72 /-3.50$ & $0.18 / 0.22$ & 0.03 & $-0.03 / 0.04$ \\
\hline & \multirow{2}{*}{ B3LYP } & $\mathrm{F}$ & +5 & 3.89 & 0.48 & 0.02 & 0.03 \\
\hline & & $\mathrm{AF}$ & 0 & $-3.77 / 3.97$ & $0.39 / 0.30$ & 0.02 & $0.02 / 0.04$ \\
\hline
\end{tabular}

a) Spins are calculated at two levels of theory (BP86 and B3LYP) for the ferromagnetic (F) or antiferromagnetic (AF) states. The oxidised state was considered on crystal and optimised coordinates, the reduced state on optimised coordinates only. When only one value is given, the value on the other respective atom was equal or the negative equivalent; the $\mathrm{N}_{\text {imidazole }}$ atoms are considered as two pairs of similar atoms. $\mathrm{b}$ ) Data from Table 7.5. See Chapter 7.8.1 for details. 


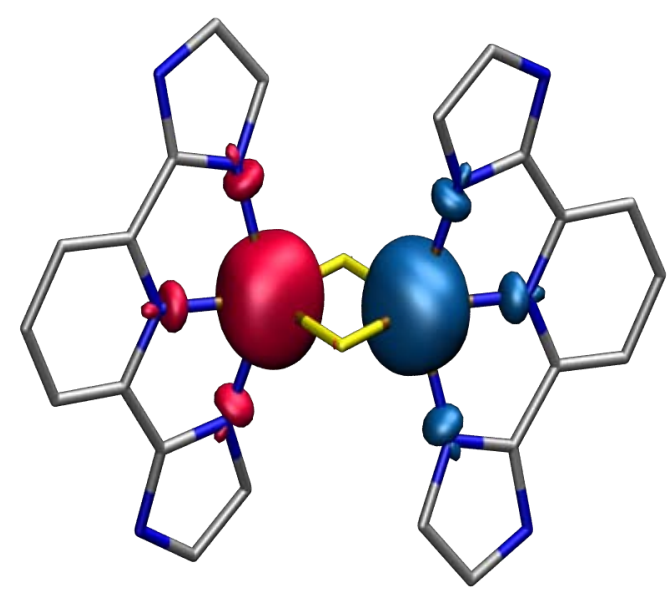

Figure 4.13: Spin density distribution on 33.

-0.01 a.u. contour value; see Chapter 7.8.1 for details.

\subsection{Conclusions}

Seven ligands were applied in synthetic approaches towards five-coordinate [2Fe-2S] clusters. In general, limited stability of the five-coordinate clusters and a strong tendency towards cluster core destruction was observed. While in most cases (ligands $27 \mathrm{~b}, 27 \mathrm{~d}$, $27 \mathrm{e}, 27 \mathrm{f}$, and $27 \mathrm{~g}$ ) no [2Fe-2S] cluster was detected at all, the clusters 33 and 34 obtained with ligands $27 \mathrm{c}$ and $27 \mathrm{a}$ were prone to degradation in solution. Likewise, the [3Fe-1S] cluster 35 could only be obtained in a small amount.

Only 33 could be isolated and investigated in more detail. It is the first synthetic example of a [2Fe-2S] cluster with five-coordinate iron atoms. This leads to a slight increase in the Fe...Fe distance and the Fe-S-Fe angles. The Mössbauer parameters are also disturbed: While the isomer shift is more positive than that of related fourcoordinate clusters, the quadrupole splitting is relatively small. The equal distribution of spin densities over all coordinating $\mathrm{N}$ atoms obtained from DFT calculations supports a true five-coordinate nature of the iron atoms. This is furthermore confirmed by the line broadening of the pyridine signals in the ${ }^{1} \mathrm{H}$ NMR spectrum. The reduction potential of cluster 33 is remarkably positive.

The investigation of $\mathbf{3 3}$ or related clusters in a proton-coupled electron transfer is conceivable due to the presence of non-coordinating $\mathrm{N}$ atoms comparable to Rieske type [2Fe-2S] clusters. Nevertheless, the limited stability in solution has hindered further investigation so far. 


\section{Radical Fe/S Cluster Chemistry}

\subsection{Introduction}

While $\mathrm{Fe} / \mathrm{S}$ clusters were first discovered as electron transfer cofactors, they are by now known to fulfil an impressive variety of functions. ${ }^{[13,20-23]}$ Although in most of the processes in which they are involved the $\mathrm{Fe} / \mathrm{S}$ clusters stay intact, there are others that require cluster conversion or even cluster decomposition. This is well-known in aconitase where the $[4 \mathrm{Fe}-4 \mathrm{~S}]$ cluster can be transformed to a [3Fe-4S] cluster. $^{[19,28]}$ Furthermore, their role as sensors is partly dependent on the ability to undergo interconversion between different cluster types. ${ }^{[13]}$

In some enzymes catalysing C-S bond formation - namely, biotin synthase (BioB) and lipoyl synthase (LipA) -, the direct source of the sulphur atoms had remained elusive for some time. ${ }^{[119]}$ They were identified as $\mathrm{Fe} / \mathrm{S}$ proteins, yet it proved difficult to identify the number and the type of the present $\mathrm{Fe} / \mathrm{S}$ clusters. ${ }^{[122,124]}$ In fact, both contain two distinct $\mathrm{Fe} / \mathrm{S}$ clusters displaying different functions. ${ }^{[125,}{ }^{132]}$ Belonging to the superfamily of radical SAM enzymes, they share a [4Fe-4S] cluster needed for generation of a C-centered radical. ${ }^{[98]}$ Furthermore, they both contain a second cluster - a $[2 \mathrm{Fe}-2 \mathrm{~S}]$ in case of biotin synthase ${ }^{[125]}, \mathrm{a}$ [4Fe-4S] cluster in case of lipoyl synthase ${ }^{[132]}$ - acting as the direct sulphur source in the respective C-S bond forming reaction. ${ }^{[120]}$ Both are now counted among a subclass of radical SAM enzymes in which sulphur atoms from an $\mathrm{Fe} / \mathrm{S}$ cluster are incorporated in a substrate in a radical mechanism. ${ }^{[111]}$ So far, two more members of this subclass have been identified: a tRNA-methylthiotransferase $(\mathrm{MiaB})^{[136]}$, and a ribosomal methylthiotransferase $(\mathrm{RimO})^{[137]}$.

As one of the $\mathrm{Fe} / \mathrm{S}$ clusters is destroyed during the reaction - thereby deactivating the enzyme -, the clusters are often regarded as substrates rather than cofactors ${ }^{[121]}$ and the enzymes named suicide enzymes. ${ }^{[220]}$ In case of biotin synthase, the solution of its crystal structure has strongly supported these observations. ${ }^{[64]}$ One of the carbon atoms of prebiotin which forms a C-S bond during the reaction is situated $4.6 \AA$ away from one of the sulphur atoms of the present $[2 \mathrm{Fe}-2 \mathrm{~S}]$ cluster. 
In order to study possible reaction mechanisms and to identify which properties of an $\mathrm{Fe} / \mathrm{S}$ cluster are important for this highly fascinating and biologically difficult reaction, a biomimetic approach was employed. Explorative reactions should first tackle the basic problems, namely the demands an cluster properties, the identification of suitable radical precursors and the means to study the reaction.

Most of biomimetic Fe/S chemistry has focused on structural and spectroscopic issues so far. While it is increasingly realised that reactivity and structural flexibility of biological Fe/S clusters is an important characteristic, reactions of their synthetic analogues are relatively difficult to investigate. Cluster conversion has been studied quite early and a general trend towards [4Fe-4S] cluster formation has been observed. ${ }^{[165,166]}$ In general, $[2 \mathrm{Fe}-2 \mathrm{~S}]$ clusters are less stable and often undergo cluster fusion to yield the corresponding [4Fe-4S] clusters, especially with monodentate ligands ( $c f$. Chapter 3 ) or under reductive conditions. Apart from reactivity connected with their assembly from simple iron and sulphide ions and with their interconversion, their reactions with other substrates has hardly been studied. Recently, cluster protonation ${ }^{[167,168]}$ and methylation ${ }^{[221]}$ has been studied as well as the reaction with benzoyl chloride leading to the chloride coordinated cluster ${ }^{[169,170]}$. Furthermore, biomimetic reactions with SAM-like sulfonium ions ${ }^{[171]}$ and with $\mathrm{NO}^{[222,223]}$ and nitrosothiols ${ }^{[223]}$ have been investigated. To the best of the author's knowledge, no reaction studies with carbon-centered radicals mimicking reactivity of enzymes like biotin synthase have been reported so far.

\subsection{Results}

Since no examples of radical reactions with synthetic [2Fe-2S] clusters were known, some basic considerations had to be done first and a general approach had to be developed as well as the means to follow the reaction.

\subsubsection{General Considerations}

As both $[2 \mathrm{Fe}-2 \mathrm{~S}]$ and $[4 \mathrm{Fe}-4 \mathrm{~S}]$ clusters are discussed as the biological sulphur source in BioB and in LipA, MiaB and RimO, respectively (see Chapter 1.4), biomimetic analogues of both were used in the reactions summarised here. To evaluate a possible ligand influence, $[2 \mathrm{Fe}-2 \mathrm{~S}]$ clusters coordinated by oxygen donors (viz. biphenols, see Chapter 2), sulphur donors (viz. thiophenols ${ }^{[151]}$ and dithiophenols, see Chapter 2), nitrogen donors (viz. indole ${ }^{[151]}$ ) and chloride ions were investigated as well as [4Fe-4S] clusters 
with sulphur donors (viz. thiophenols ${ }^{[224]}$ ) in the initial assays. In addition, the all-ferric cluster $\left[\mathrm{Fe}_{4} \mathrm{~S}_{4} \mathrm{Cp}_{4}\right]$ was used. ${ }^{\text {[225] }}$

While there are manyfold radical precursors available, several demands need to be met for their use in biomimetic radical chemistry. First, generation of a C-centered radical was required. Radical generation should take place under mild conditions in which $[2 \mathrm{Fe}-2 \mathrm{~S}]$ and $[4 \mathrm{Fe}-4 \mathrm{~S}]$ clusters stay intact. Photolytic radical generation was not considered due to the extremely high absorption coefficients of $\mathrm{Fe} / \mathrm{S}$ clusters. Chemical generation of radicals by, e.g., reduction, was also not further considered. Thus, precursors were searched which yield radicals under thermic decay at relatively low temperatures. Commercially available precursors include mainly azo compounds on the one hand and peroxo compounds on the other hand; the latter yielding carbon-centered radicals by rapid decomposition of initially forming oxygen-centered radicals (Scheme 5.1).<smiles>COC(C)(C)C[C@H](C)N=NC(C)(C)CC(C)(C)N=NC(C)(C)OC</smiles>

V-70

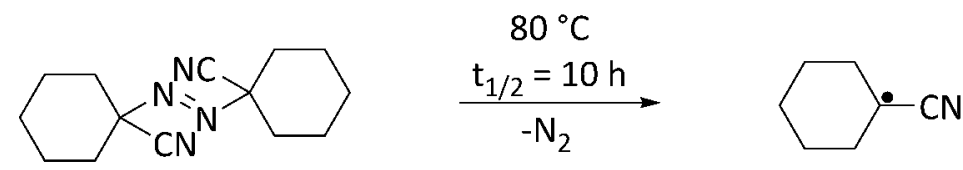

V-40
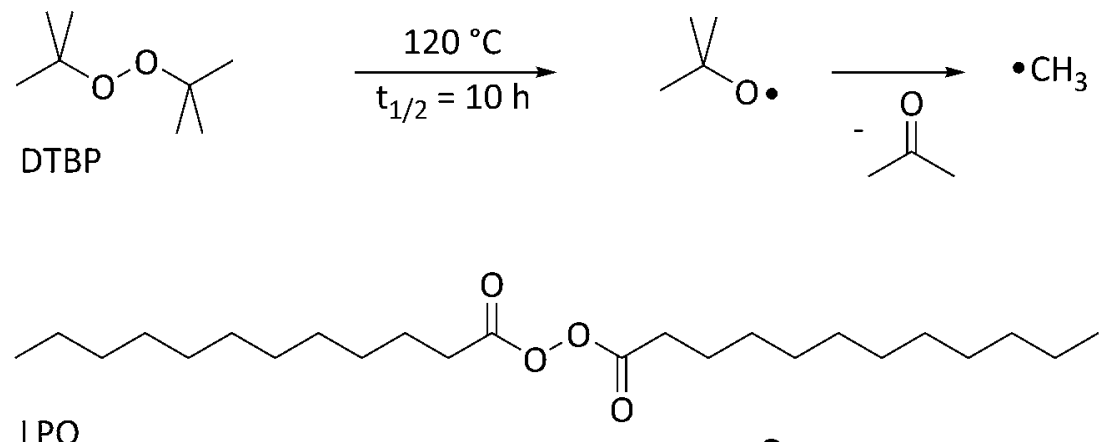

LPO

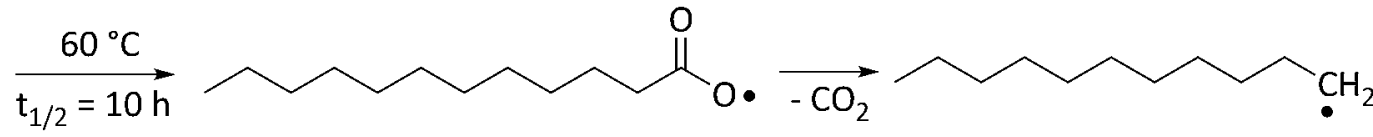

Scheme 5.1: Decomposition reactions of the radical precursors used in this work. 
While cluster destruction is in principle quite obvious from the loss of the intensive colour of $[2 \mathrm{Fe}-2 \mathrm{~S}]$ and $[4 \mathrm{Fe}-4 \mathrm{~S}]$ cluster solutions, it is also very unspecific and does not prove a radical reaction. The identification of decomposition products is relatively easy yet only of limited use; even when a carbon-centered radical is initially attacking the cluster, the initial products are also potential substrates and an observed product might arise from a side reaction. Therefore, $[2 \mathrm{Fe}-2 \mathrm{~S}]$ clusters $^{[151]}$ and $[4 \mathrm{Fe}-4 \mathrm{~S}]$ clusters $^{[224,226]}$ with $p$-fluorothiophenol ligands were additionally synthesised and the reactions were followed by ${ }^{19} \mathrm{~F}$ NMR. In this way cluster decomposition is detectable in situ by the appearence of new signals and a comparison with different putative reaction products might be possible.

\subsubsection{Reactions with Azo-Compounds V-70 and V-40}

The first radical starter to be tested was V-70 due to its low half-life temperature $\left(t_{1 / 2}\right.$ $=10 \mathrm{~h}$ at $\left.30^{\circ} \mathrm{C}\right)$. V-40 was also employed as a similar compound with a higher half-life temperature $\left(t_{1 / 2}=10 \mathrm{~h}\right.$ at $\left.80^{\circ} \mathrm{C}\right)$. In the initial assays, different clusters were dissolved in $\mathrm{MeCN}$ and treated with an approximately stoichiometric amount of radical precursor V-70 or V-40. Preliminary experiments in our group had suggested that a radical attack takes places surprisingly at the ligand sulphur atoms and not at the bridging sulphide ions in reactions with thiolate-coordinated clusters. However, when trying to reproduce these investigations no reaction was observed after several days. As [2Fe-2S] clusters usually give $[4 \mathrm{Fe}-4 \mathrm{~S}]$ clusters along with free ligands under protic or reductive conditions, ${ }^{[166]}$ the previously observed reaction was most probably due to the water content of the radical precursors which were at that time stored in a fridge outside the glovebox. In reactions with an intact cluster, these radicals are obviously not reactive enough as they are tertiary radicals additionally stabilised by a nitrile group.Yet this illustrates a major problem of this approach: the need to exclude that an observed reaction occurs due to side reactions or decomposition products.

\subsubsection{Reactions with Peroxo Compounds}

Two different peroxo compounds were subsequently tested, namely di-tert-butylperoxide (DTBP) and lauroylperoxide (LPO). DTBP undergoes homolytic O-O cleavage and subsequent fragmentation to yield acetone and a methyl radical $\left(t_{1 / 2}=10 \mathrm{~h}\right.$ at $120^{\circ} \mathrm{C}$ ); LPO is an acid peroxide yielding carbon dioxide and an undecyl radical af- 
ter initial $\mathrm{O}-\mathrm{O}$ bond cleavage $\left(t_{1 / 2}=10 \mathrm{~h}\right.$ at $\left.60^{\circ} \mathrm{C}\right) .{ }^{[227]}$ It should be noted however that the primary products are oxygen-centered radicals which are then rapidly cleaved to yield the desired carbon-centered radicals; an undesired reaction with the more reactive oxygen-centered radicals therefore has to be excluded in future experiments.

When working with thiolate-coordinated clusters and LPO, an immediate reaction was observed by loss of the deep colour of the Fe/S cluster solutions within minutes. Taking into account that cluster-bound thiolates are able to attack benzoyl chloride, ${ }^{[169,170]}$ a similar mechanism seems likely in which the thiolate attacks the carbonyl group in LPO and that thus a reaction occurs which is not initiated by radical decay.

A significantly slower decolouring occurs however in reactions with DTBP and likewise in reactions with LPO and clusters not coordinated by thiolates. Reaction mixtures

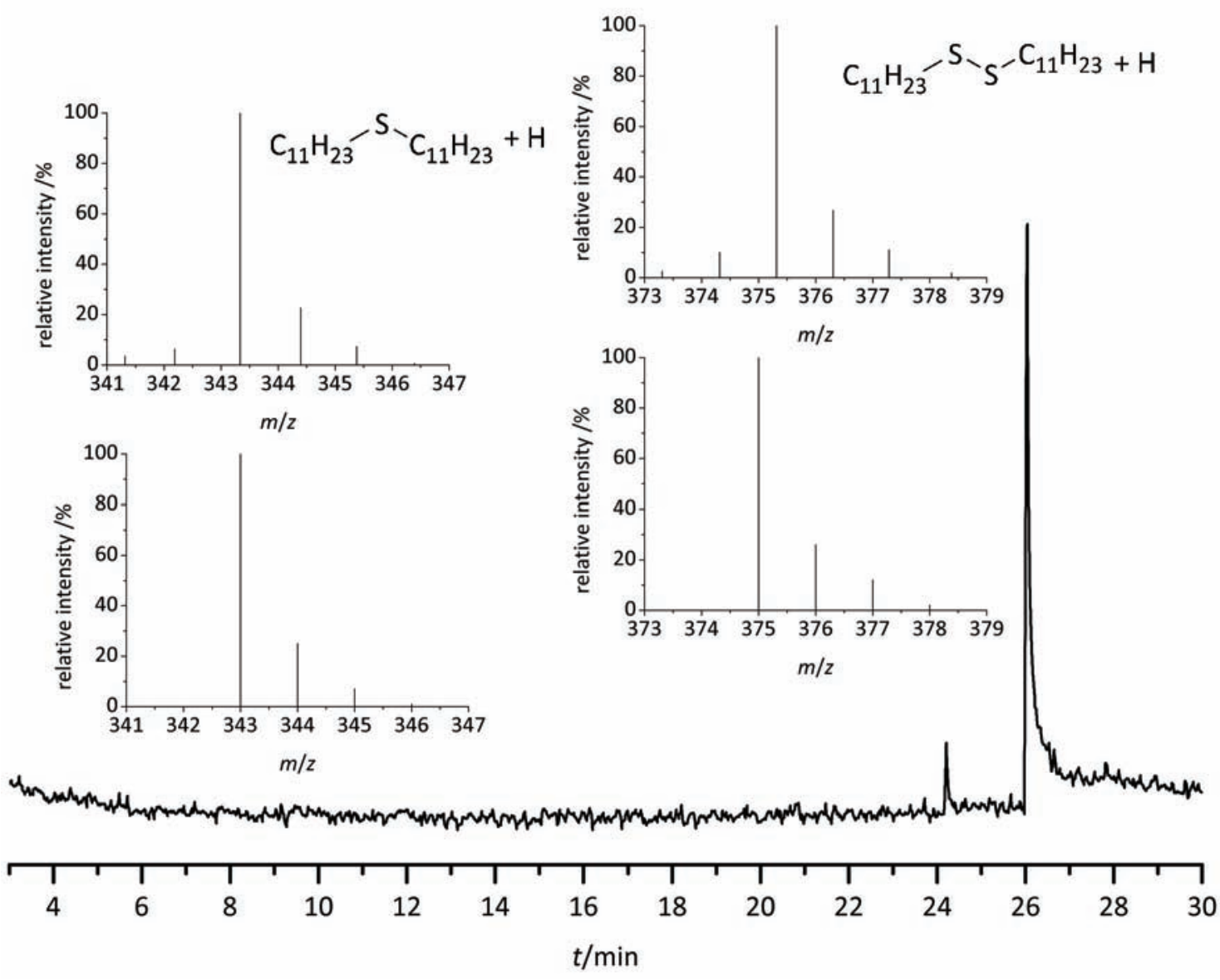

Figure 5.1: GC/MS data of a reaction of $\left(\mathrm{NEt}_{4}\right)_{2}\left[\mathrm{Fe}_{2} \mathrm{~S}_{2} \mathrm{Cl}_{4}\right]$ (9) and LPO.

- Chromatogram and experimental (top) and calculated (bottom) isotopic distribution patterns for reaction products $\left(\mathrm{C}_{11} \mathrm{H}_{23}\right)-\mathrm{S}-\left(\mathrm{C}_{11} \mathrm{H}_{23}\right)$ (left, peak at $\left.t=24 \mathrm{~min}\right)$ and $\left(\mathrm{C}_{11} \mathrm{H}_{23}\right)-\mathrm{S}$ $\mathrm{S}-\left(\mathrm{C}_{11} \mathrm{H}_{23}\right)$ (right, peak at $\left.t=26 \mathrm{~min}\right)$. 
from these attempts were filtered over silica to remove iron-containing decomposition products and subsequently GC/MS was performed to identify reaction products. In case of thiolate-coordinated clusters, products of a reaction between the radical and the ligand as well as disulphides arising from oxidative coupling of two ligands were generally observed. From a reaction of $\left(\mathrm{NEt}_{4}\right)_{2}\left[\mathrm{Fe}_{2} \mathrm{~S}_{2} \mathrm{Cl}_{4}\right](9)$ and $\mathrm{LPO}$, however, the only organic products in the reaction mixture were di(undecyl)sulphide and di(undecyl)disulphide which could indeed be formed in a radical reaction (Figure 5.1). With respect to possible side reactions, this can however only be a first evidence of a radical reaction.

Investigation of ${ }^{19} \mathrm{~F}$ NMR spectra should therefore give a more direct insight. Indeed, the slow formation of new signals was observed when [2Fe-2S] or [4Fe-4S] clusters with $p$-fluorothiophenol ligands were treated with DTBP in $\mathrm{MeCN}_{-} \mathrm{d}_{3}$ solution (Figures 5.2 and 5.3). Control samples without radical precursor confirmed principle stability of both clusters under these conditions. Being quite remote with respect to the reaction site, the chemical shift of the fluorine atoms does not change much, however, and feasible reaction products as well as $[2 \mathrm{Fe}-2 \mathrm{~S}]$ and $[4 \mathrm{Fe}-4 \mathrm{~S}]$ clusters show signals in a relatively narrow range and cannot be identified with certainty. Nevertheless, ${ }^{19} \mathrm{~F}$ NMR spectroscopy was shown to be a valuable tool in reaction monitoring.

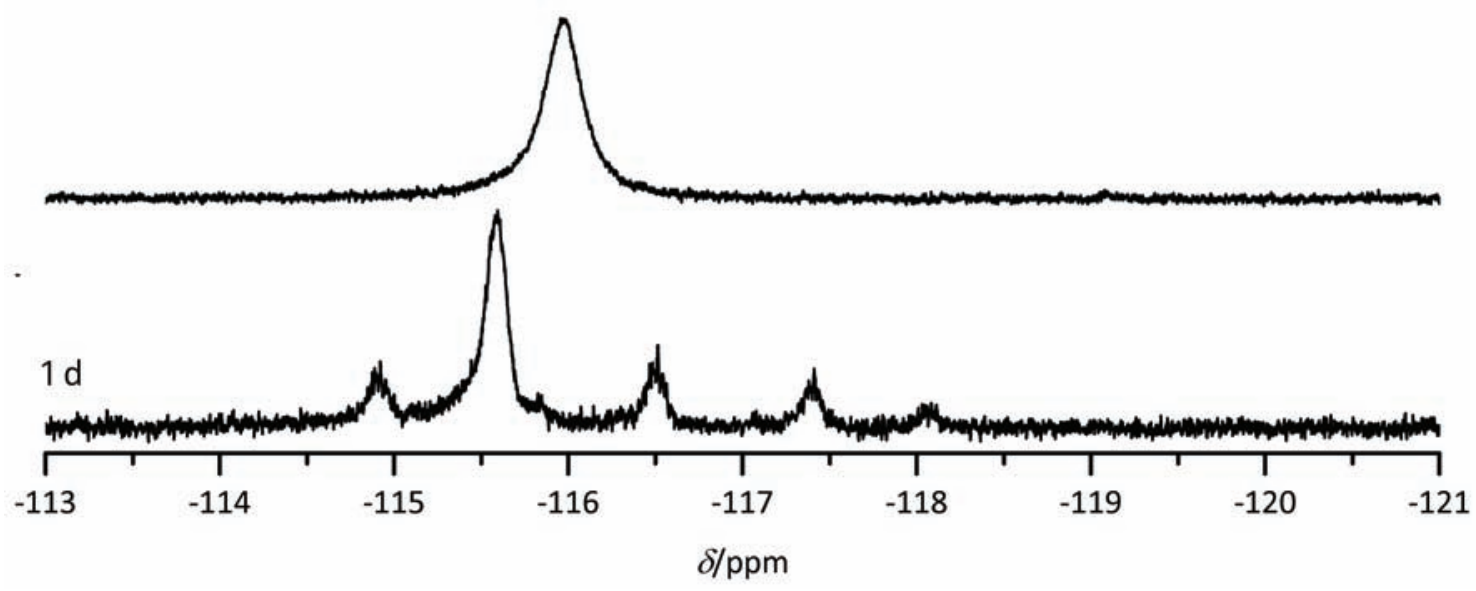

Figure 5.2: ${ }^{19} \mathrm{~F}$ NMR spectra of a reaction mixture of $\left.\left(\mathrm{NEt}_{4}\right)_{2}\left[\mathrm{Fe}_{2} \mathrm{~S}_{2}\left(\mathrm{Ar}_{\mathrm{F}}\right)_{4}\right]\right)$ and TBPO. $-\mathrm{Ar}_{\mathrm{F}}=p$-fluorothiophenolate. 


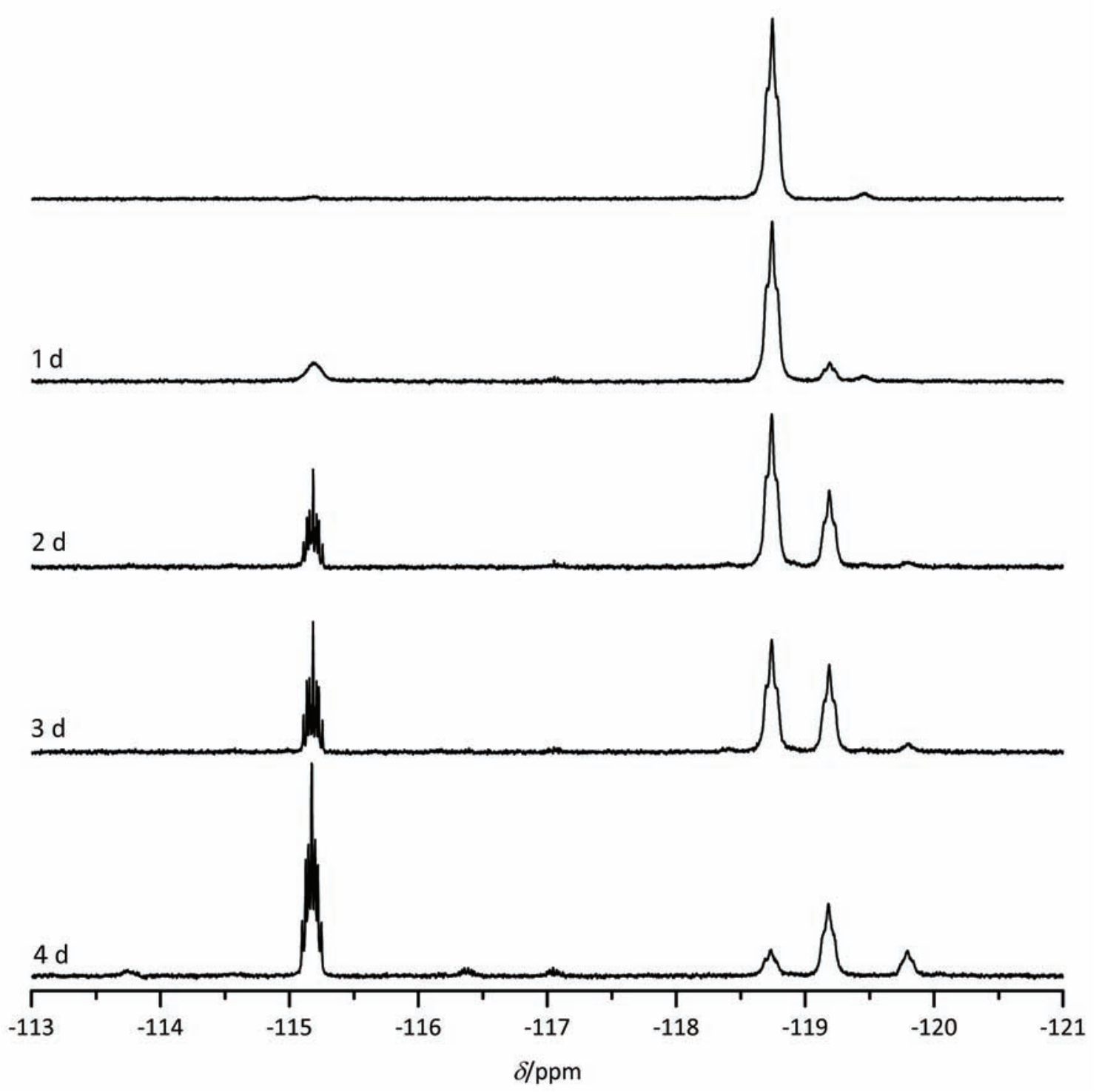

Figure 5.3: ${ }^{19} \mathrm{~F}$ NMR spectra of a reaction mixture of $\left.\left(\mathrm{N}^{n} \mathrm{Bu}_{4}\right)_{2}\left[\mathrm{Fe}_{4} \mathrm{~S}_{4}\left(\mathrm{Ar}_{\mathrm{F}}\right)_{4}\right]\right)$ and TBPO. $-\mathrm{Ar}_{\mathrm{F}}=p$-fluorothiophenolate.

In order to have a probe closer to the reaction site, perfluoroacetylperoxide which has a low half-life temperature was synthesised according to literature ${ }^{[228]}$ and tested in reactions with Fe/S clusters. Being an acid peroxide however, the same problems as with LPO apply. Although several signals appeared in the ${ }^{19} \mathrm{~F}$ NMR spectra during reaction, a definite assignment could not be made. Moreover, reactions with perfluoroacetylperoxide were relatively fast and possible reaction products like the corresponding thioether are volatile, which makes the reactions more difficult to monitor. 


\subsection{Conclusions}

Valuable progress was made on the novel topic of radical Fe/S cluster chemistry. Firstly, radical precursors have been identified that cannot be applied under the conditions that were investigated, namely azo compounds that yield radicals stabilised by nitrile groups to an extent that no reaction takes place. Likewise, acid peroxides cannot be used with certain clusters, namely thiolate-coordinated clusters that attack the radical precursor by a cluster-bound thiol group initiating non-radical reactions. The reaction of radicals with impurities or decomposition products of the clusters, such as free ligands, were observed as problematic side reactions that have to be taken into account and excluded if possible.

Nevertheless, reactions that were observed in some cases where the above-mentioned problems do not occur are indicative of radical reactions. Moreover, only a small number of products were observed both in ${ }^{19} \mathrm{~F}$ NMR spectra and in GC mass spectra which should therefore be identifiable, and the elucidation of reaction mechanisms should be possible in the future. 


\section{A Computational Investigation of the [2Fe-2S] Cluster in Biotin Synthase}

\subsection{Introduction}

In the past few years, an increasing number of fascinating functions of $\mathrm{Fe} / \mathrm{S}$ clusters other than electron-transfer have been discovered. ${ }^{[21]}$ Among those, their use as the source for $\mathrm{S}$ atoms in biological radical reactions has been striking with regards to the complex mechanisms of $\mathrm{Fe} / \mathrm{S}$ cluster assembly. ${ }^{[23]}$ As the Fe/S cluster is destroyed during this reaction, these enzymes are regarded as suicide enzymes and their respective clusters as substrates rather than cofactors. ${ }^{[220]}$ To date, $\mathrm{Fe} / \mathrm{S}$ clusters have been identified as the source of $S$ atoms in reactions catalysed by four different enzymes belonging to a distinctive class ${ }^{[111]}$ within the radical SAM (S-adenosylmethionine) superfamily ${ }^{[108]}$ : biotin synthase $(\mathrm{BioB})^{[120]}$, lipoyl synthase $(\mathrm{LipA})^{[130]}$, a tRNA-methylthiotransferase $(\mathrm{MiaB})^{[136]}$, and a ribosomal methylthiotransferase $(\mathrm{RimO})^{[137]}$.

While the latter three enzymes contain $[4 \mathrm{Fe}-4 \mathrm{~S}]$ clusters as the assumed sulphur source, biotin synthase (BioB) contains a $[2 \mathrm{Fe}-2 \mathrm{~S}]$ cluster which has been shown to be destroyed during catalytic turnover. ${ }^{[125]}$ Of the four enzymes, BioB is the most extensively investigated and also the only one whose crystal structure has been solved. ${ }^{[64]}$ A mechanism for its reaction was first published in $2001^{[125]}$ and has been closely investigated since (Scheme 1.4). ${ }^{[229]}$ The proposed mechanism is supported by the close proximity of the $[2 \mathrm{Fe}-2 \mathrm{~S}]$ cluster to the prebiotin molecule found in the crystal structure. The closest bridging sulphide of the cluster is situated $4.6 \AA$ away from C9 of prebiotin, one of the two $\mathrm{C}$ atoms to which sulphur is attached in the course of the reaction (Figure 1.7).

Surprisingly, the $[2 \mathrm{Fe}-2 \mathrm{~S}]$ cluster carries one strictly conserved arginine ligand in addition to three cysteine ligands typical for Fe/S clusters. Since arginine is highly exceptional as a ligand coordinating a metal ion in biological systems, ${ }^{[72]}$ its importance has been much discussed since publication of the crystal structure. Mutation experiments 
showed that this arginine ligand is not essential for the catalytic reaction. It has been proposed that it may play electronic, mechanistic or structural roles, possibly related to its bidentate nature or its positive charge in the protonated state. ${ }^{[88]}$

A basic question to be answered is the charge of the arginine guanidine group in the active enzyme. Usually Arginine is protonated at physiological $\mathrm{pH}$ (the $\mathrm{p} K_{\mathrm{a}}$ in water solution is approximately $12^{[230]}$ ), thereby bearing a positive charge. A positively charged guanidine group however could not be regarded as a true ligand from a coordination chemist's point of view - for that, it should rather be deprotonated and neutral. This uncertainty is reflected by suggestions of both $\mathrm{NH}^{[231]}$ and $\mathrm{NH}_{2}{ }^{[72,232]}$ coordination in the literature.

In addition to the protonation issue, the role of the second, non-coordinating guanidine $\mathrm{NH} / \mathrm{NH}_{2}$ group is to be ascertained. Secondary bonding interactions ${ }^{[154]}$ are conceivable, as well as an involvement in hydrogen bonds with the protein backbone or with the cluster $\mathrm{S}$ atoms. Furthermore, the crystal structure shows an Fe $\cdots$ Fe distance of $3.3 \AA$ that is significantly longer than what is found in any other known [2Fe-2S] cluster (approximately $2.7 \AA)^{[140]}$. As these issues cannot be solved with the published structural data alone, owing to the low resolution of the crystal structure (3.4 $\AA$ ), and the importance of the unusual arginine ligand remains elusive, theoretical methods seem to be a promising strategy to answer the above-mentioned questions. This investigation focuses on the structural properties of the highly unusual [2Fe-2S] cluster of BioB in order to improve our understanding of its importance for the enzyme mechanism.

\subsection{Results and Discussion}

Because of the importance of interactions of the [2Fe-2S] cluster and its four ligands with the surrounding protein and solvent, a QM/MM approach including the protein environment is the theoretical method of choice (details are given in the experimental part, Chapter 7.8.2).

Four different structures were studied depending on the protonation state of $\operatorname{Arg}^{260}$, as is illustrated in Figure 6.1. In the first (i), $\mathrm{Arg}^{260}$ is protonated, and therefore positively charged. In the other three, one of the terminal $\mathrm{NH}_{2}$ groups of $\mathrm{Arg}^{260}$ is deprotonated. The three structures differ in whether the deprotonated NH group (ii) or the protonated $\mathrm{NH}_{2}$ group coordinates to $\mathrm{Fe}$. In the latter case, the non-coordinating $\mathrm{NH}$ group can either have the $\mathrm{H}$ atom pointing towards the cluster (iii) or away from the cluster (iv). 


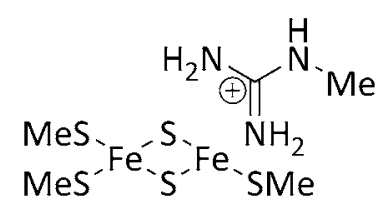

i

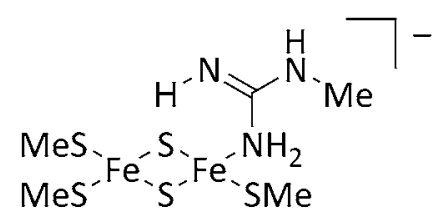

iii

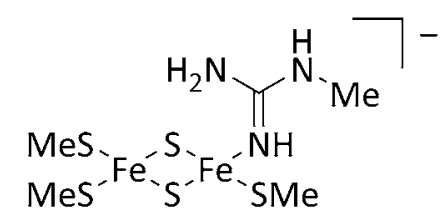

ii

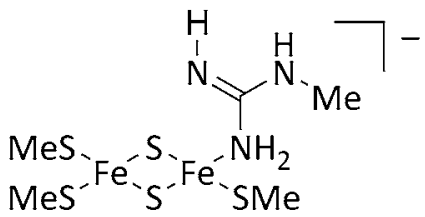

iv

Figure 6.1: Conceivable coordination modes for arginine in the protonated (i) or neutral state (ii-iv) as represented in the QM/MM calculations (i.e., system 1).

\subsubsection{Explorative Calculations}

For convenience, all discussed geometry optimisations were started from an initial optimisation with structure ii. In order to verify that this is acceptable, it was first tested to what extent the optimised geometry depends on the starting geometry. In addition, the influence of the spin and oxidation states of the [2Fe-2S] cluster on structural properties was investigated. These explorative calculations were performed in vacuum (i.e., system 1 only, see Chapter 7.8.2 for details), starting from the crystal geometry.

The optimisations for structure ii in different oxidation states $\left(\mathrm{Fe}^{\mathrm{III}} / \mathrm{Fe}^{\mathrm{III}}, \mathrm{Fe}^{\mathrm{II}} / \mathrm{Fe}^{\mathrm{III}}\right.$ or $\mathrm{Fe}^{\mathrm{II}} / \mathrm{Fe}^{\mathrm{II}}$ ) and spin states (AF or $\mathrm{F}$ ) showed that the final geometries of the intact clusters, especially the $\mathrm{Fe}$...Fe distances and the orientation of the arginine residue, do not depend on starting geometries. The oxidised AF and F states were also tested for the other protonation states (structures $\mathbf{i}$, iii and iv) with similar results. In all calculations, the AF state was energetically favoured (by 18 to $118 \mathrm{~kJ} / \mathrm{mol}$ ). Short Fe...Fe distances were found in all cases, although they were slightly longer for the F states (AF: 2.572.65 Å, F: 2.42-2.89 A); no additional electronic states with larger Fe... Fe distances were detected. In order to verify this observation, the Fe...Fe distance was fixed to values between 2.5 and $3.5 \AA$ (structure ii, oxidised, AF state) and the rest of the geometry was optimised. Only one energy minimum was found at approximately $2.6 \AA(61 \mathrm{~kJ} / \mathrm{mol}$ more stable than the distance in the crystal structure) and no evidence for a second 
minimum close to the crystal structure distance was found.

Similar explorative calculations were performed with the B3LYP functional [233, 234] to examine the effect of another functional with exact exchange, giving similar results $\left(E_{\mathrm{AF}}-E_{\mathrm{F}}=-20\right.$ to $-55 \mathrm{~kJ} / \mathrm{mol}, d(\mathrm{Fe} \cdots \mathrm{Fe})=2.55-2.72(\mathrm{AF})$ and $2.70-2.96 \AA(\mathrm{F})$ and an energy minimum at $2.8 \AA, 36 \mathrm{~kJ} / \mathrm{mol}$ lower than the crystal structure).

\subsubsection{Dicussion of Calculated Geometries}

The optimised structures obtained from the calculations are shown in Figure 6.2. At first glance, the geometry is quite similar in all cases. The Fe-N distances (Table 6.1) are in a range that agrees with the crystal structure $(2.4 \AA)$ considering its low resolution (3.4 $\AA$ ) in all three structures with neutral arginine (ii: $2.05 \AA$, iii: $2.25 \AA$, iv: $2.27 \AA$ ), as well as in the protonated structure (i: $2.45 \AA$ ). Judging from these distances, the $\mathrm{Fe}-$ $\mathrm{N}$ bond is strongest in ii, which could be expected as the $\mathrm{NH}$ group has an $\mathrm{sp}^{2}$-like, nucleophilic lone pair whereas the p-like lone pair of the $\mathrm{NH}_{2}$ group is involved in $\pi$ interactions within the guanidine group. The $\mathrm{Fe} \cdots \mathrm{N}$ distance in $\mathbf{i}$ is too long to assign a $\mathrm{Fe}-\mathrm{N}$ bond in the protonated case. Nevertheless, the guanidinium group still is in close proximity to the $[2 \mathrm{Fe}-2 \mathrm{~S}]$ cluster.

The $\mathrm{Fe} \cdots \mathrm{Fe}$ distance is also quite independent of the coordination as well as the protonation state of the arginine group (2.63-2.69 $\AA$ ) and is in perfect agreement with those of other [2Fe-2S] clusters that have been structurally characterised. None of the calculated structures reproduce the long $\mathrm{Fe} \cdots \mathrm{Fe}$ distance found in the BioB crystal structure (3.24-3.28 ̊).

As metal sites are often reduced during X-ray experiments, reduced clusters containing $\mathrm{Fe}^{\mathrm{II}}$ ions were also optimised $\left(\mathrm{Fe}^{\mathrm{II}} / \mathrm{Fe}^{\mathrm{III}}\right.$ and $\left.\mathrm{Fe}^{\mathrm{II}} / \mathrm{Fe}^{\mathrm{II}}\right)$ but they do not show any increased $\mathrm{Fe} \cdots \mathrm{Fe}$ distance. The main geometric change upon reduction is the dissociation of the $\mathrm{NH}_{2}$ group (i, iii, iv).

However, when one of the bridging $\mathrm{S}$ atom was removed from the cluster (and the two $\mathrm{Fe}$ atoms thereby reduced), the $\mathrm{Fe} \cdots \mathrm{Fe}$ distance increased in the structures with neutral arginine (ii: $3.08 \AA$, iii: $2.79 \AA$, iv: $2.74 \AA$ ). In this case, only the protonated arginine (i) dissociates from the $\mathrm{Fe}$ atom. It is possible that one of the $S$ atoms has been removed from the cluster (and has been inserted into dethiobiotin) in the crystal since the enzyme reaction is started by reduction of the [4Fe-4S] cluster, which could happen due to radiation damage during the measurement. It is not possible to decide whether or not there is a sulphur atom in the (dethio)biotin molecule in the crystal by examination 

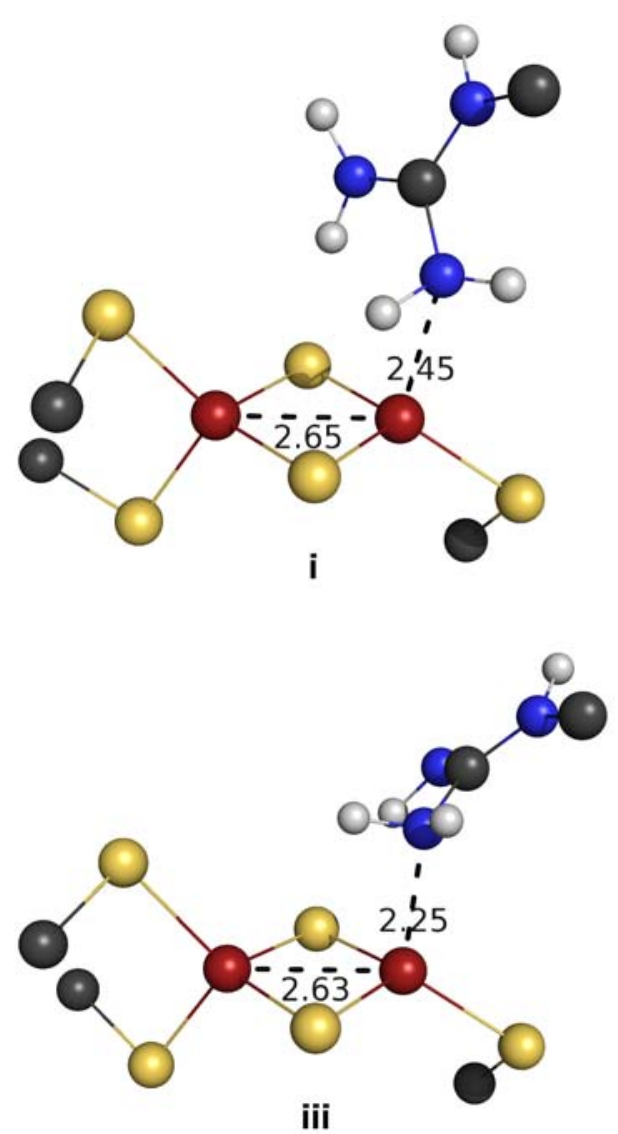
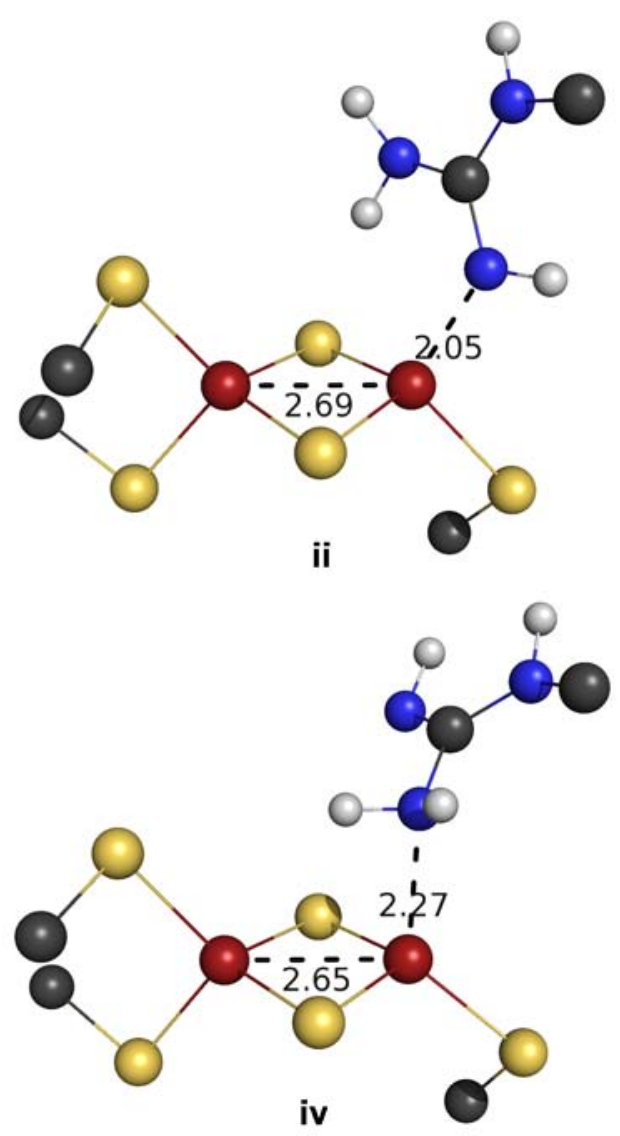

Figure 6.2: Optimised structures from the DFT calculations.

of the electron density map due to the low resolution.

The non-coordinating $\mathrm{NH} / \mathrm{NH}_{2}$ group acts as a hydrogen-bond donor in the structures with a proton pointing towards the bridging sulphide (i, ii, iv). Additional hydrogen bonds can be found between $\mathrm{Arg}^{260}$ and four surrounding amino acids $\left(\mathrm{Ser}^{43}\right.$, $\mathrm{Ser}^{218}, \mathrm{Ser}^{283}$ and $\mathrm{Arg}{ }^{95}$ ). Except for Ser ${ }^{283}$, which accepts a hydrogen bond from the non-terminal NH group in all cases, these residues seem to be quite flexible. Thus the positively charged $\mathrm{Arg}^{95}$ can act as hydrogen bond donor towards the bridging sulphide of the [2Fe-2S] cluster (i, ii) or the NH group of $\operatorname{Arg}^{260}$ (iii, iv). Ser ${ }^{218}$ acts as acceptor towards the $\mathrm{NH}_{2}$ group of $\mathrm{Arg}^{95}$ in all structures and can in addition donate a hydrogen bond towards the bridging sulphide (ii, iii), whereas $\mathrm{Ser}^{43}$ can accept hydrogen bonds from the non-coordinating $\mathrm{NH}_{2}$ group of $\operatorname{Arg}^{260}(\mathbf{i}, \mathbf{i i})$. In all cases, the arginine acts as a monodentate ligand; no evidence for secondary bonding interactions were found. 
Table 6.1: Structural parameters from the crystal structure and from QM/MM calculations.

\begin{tabular}{lcc}
\hline & $\mathrm{Fe}-\mathrm{N} / \AA$ & $\mathrm{Fe} \cdots \mathrm{Fe} / \AA$ \\
\hline Crystal structure & $2.40,2.35$ & $3.28,3.24$ \\
$\mathrm{i}$ & 2.45 & 2.65 \\
ii & 2.05 & 2.69 \\
iii & 2.25 & 2.63 \\
iv & 2.27 & 2.65 \\
$\mathrm{i}+\mathrm{e}^{-}$ & 3.26 & 2.59 \\
ii $+\mathrm{e}^{-}$ & 2.11 & 2.66 \\
iii $+\mathrm{e}^{-}$ & 3.26 & 2.57 \\
$\mathrm{iv}+\mathrm{e}^{-}$ & 3.42 & 2.58 \\
$\mathrm{i}+2 \mathrm{e}^{-}$ & 3.19 & 2.62 \\
ii $+2 \mathrm{e}^{-}$ & 2.18 & 2.68 \\
iii $+2 \mathrm{e}^{-}$ & 3.24 & 2.62 \\
iv $+2 \mathrm{e}^{-}$ & 3.23 & 2.60 \\
$\mathrm{i}-\mathrm{S}$ & 4.15 & 2.54 \\
ii $-\mathrm{S}$ & 2.01 & 3.08 \\
iii $-\mathrm{S}$ & 2.14 & 2.79 \\
iv $-\mathrm{S}$ & 2.15 & 2.74 \\
\hline
\end{tabular}

\subsubsection{Calclulated Energies}

Of the three structures with a neutral arginine, ii has the lowest energy, 80 and $88 \mathrm{~kJ} / \mathrm{mol}$ lower than that of structures iii and iv, respectively. This shows that coordination by the more nucleophilic $\mathrm{NH}$ group is preferred over $\mathrm{NH}_{2}$ coordination. The energy of $\mathbf{i}$ cannot be compared directly because of the additional proton in the system. Comparing the protonated structure $\mathbf{i}$ with the best neutral structure ii, only minor differences can be found, besides the $\mathrm{Fe}-\mathrm{N}$ distance. The other relevant distances are similar, as are the hydrogen bonds close to the $[2 \mathrm{Fe}-2 \mathrm{~S}]$ cluster. 


\subsubsection{Calculated Mössbauer Parameters}

Mössbauer parameters of the [2Fe-2S] cluster in biotin synthase show a single quadrupole doublet a quadrupole splitting of $\Delta E_{\mathrm{Q}}=0.51-0.53 \mathrm{~mm} / \mathrm{s}^{[122,235,236]}$ This is quite unexpected, because for a cluster containing two iron atoms with different coordination environment, two doublets would be expected. Quadrupole splittings $\Delta E_{\mathrm{Q}}$ were calculated from the electric field gradients at the position of the iron atoms for the optimised geometries of structures i-iv (Table 6.2).

Table 6.2: Experimental ${ }^{[122,235,236]}$ and calculated ${ }^{\text {a) }}$ quadrupole splittings $\Delta E_{\mathrm{Q}}$.

\begin{tabular}{lcc}
\hline & $\Delta E_{\mathrm{Q}}\left(\mathrm{S}_{4}\right) /(\mathrm{mm} / \mathrm{s})$ & $\Delta E_{\mathrm{Q}}\left(\mathrm{S}_{3} \mathrm{~N}\right) /(\mathrm{mm} / \mathrm{s})$ \\
\hline Experimental & 0.53 & 0.53 \\
i & 0.33 & 1.27 \\
ii & 0.33 & 0.59 \\
iii & 0.45 & 1.14 \\
iv & 0.43 & 1.23 \\
\hline
\end{tabular}

a) Data from Table 7.8; see Chapter 7.8.2 for details.

While the quadrupole splittings calculated for the all-S coordinated iron atoms are roughly the same in all four cases $(0.33-0.45 \mathrm{~mm} / \mathrm{s})$, the uniquely coordinated iron atom exhibits very different values depending on the exact coordination mode. While $\Delta E_{\mathrm{Q}}$ is quite large with the $\mathrm{NH}_{2}$ coordinating (i: 1.27 , iii: 1.14 , iv: $1.23 \mathrm{~mm} / \mathrm{s}$ ) it is relatively small in case of $\mathrm{NH}$ coordination (ii: $0.59 \mathrm{~mm} / \mathrm{s}$ ). Taking into account that calculated quadrupole splittings are usually too low in similar cases ${ }^{[154]}$ and that the accuracy of calculated $\Delta E_{\mathrm{Q}}$ (i.e., the amount by which they are lower than experimental values) seems to be dependent on the coordination ${ }^{[143,154]}$ the neutral state with the NH group coordinating (ii) fits the experimental data best. As biological samples usually exhibit weak Mössbauer signals due to their low iron content, especially when another Fe/S cluster is present, it seems reasonable that the experimentally found doublet is the sum of two doublets with similar quadrupole splittings. 


\subsection{Conclusions}

In conclusion, the presented $\mathrm{QM} / \mathrm{MM}$ calculations are helpful in interpreting the crystal structure of biotin synthase. Interestingly, QM/MM geometries do not differ much depending on the protonation state of $\mathrm{Arg}^{260}$. However, calulated energies strongly indicate that it is more favourable for the deprotonated $\mathrm{Arg}^{260}$ to coordinate to Fe via the deprotonated $\mathrm{NH}$ group (structure ii), rather than by the $\mathrm{NH}_{2}$ group (structures iii and iv), even if hydrogen bonds with the surrounding residues are considered. Although the energy of the protonated state (structure i) cannot be compared directly, the calculated Mössbauer parameters fit the experimental data best for the neutral structure ii. Thus, it is quite clear that the $\mathrm{Arg}^{260}$ ligand is deprotonated in the crystal structure.

Finally, it also seems clear that the $\mathrm{Fe} \cdots \mathrm{Fe}$ distance in the $[2 \mathrm{Fe}-2 \mathrm{~S}]$ cluster is not as long as the crystal structure indicated. Instead, it is most likely similar to what is found in all normal [2Fe-2S] clusters, i.e., approximately $2.7 \AA$. The reason for the long bond in the crystal structure may either be the low resolution or that the structure is a mixture of different states of the [2Fe-2S] cluster, e.g., caused by a successive reduction of the cluster during data collection or the reductive loss of a sulphur atom. These findings are also supported by quantum refinement. ${ }^{[237]}$ Clearly, more accurate crystal structures are needed, as well as further theoretical investigations of the reaction intermediates, which should help to understand this fascinating enzyme. 


\section{Experimental Part}

\subsection{General Experimental Considerations}

All manipulations were performed under an anaerobic and anhydrous atmosphere of dinitrogen using standard Schlenk techniques or in a glovebox unless otherwise mentioned. Glassware was dried at $120^{\circ} \mathrm{C}$ overnight. Work-up procedures except those for free thiols were performed in air.

$\mathrm{Et}_{2} \mathrm{O}$ and pentane were dried over sodium benzophenone ketyl; THF and benzene were dried over potassium benzophenone ketyl; DMF, DMSO and MeCN were dried over $\mathrm{CaH}_{2}, \mathrm{CH}_{2} \mathrm{Cl}_{2}, \mathrm{CHCl}_{3}$ and $\mathrm{CCl}_{4}$ were dried over $\mathrm{P}_{4} \mathrm{O}_{10}$. All were distilled prior to use. Deuterated solvents were similarly dried and distilled. Alternatively, $\mathrm{CH}_{2} \mathrm{Cl}_{2}$, hexane and toluene were dried over molecular sieves using an MBraun SPS.

$\mathrm{NaH}$ and $\mathrm{KH}$ were purchased as dispersions in mineral oil and washed with hexane extensively prior to use.

Compounds 5,5'-di-tert-butyl-2,2'-dihydroxybiphenyl (1c) ${ }^{[177]}, 3,3^{\prime}$-diallyl-2,2'-dihydroxybiphenyl (3a) ${ }^{[174]}, 3,3^{\prime}$-bis(3-((methylsulfonyl)oxy)-1-propyl)-2,2'-bis(benzyloxy)biphenyl (13) ${ }^{[100]}, 3,3^{\prime}$-bis(3-(methylthio)-1-propyl)-2,2'-bishydroxybiphenyl (15) ${ }^{[100]}$, $o$-benzylthiobenzenethiol (18) ${ }^{[192]}, 2,6$-bis(pyrazol-3-yl)pyridine $(27 \mathrm{a})^{[200]}$, 2,6-bis(imidazol-2-yl)pyridine (27c) ${ }^{[203]}, 2,6$-bis(mercaptomethyl)pyridine (27e) ${ }^{[208]}$, 2,6-bis(4methyl-1,4-dioxobutyl)pyridine (28) ${ }^{[206]}$ 2,5-dibromofurane (29) ${ }^{[209]}, N$-ethoxymethylimidazole (30) ${ }^{[238]}$, and complexes $\left.\left(\mathrm{NEt}_{4}\right)_{2}\left[\mathrm{Fe}_{2} \mathrm{~S}_{2} \mathrm{Cl}_{4}\right](9)^{[150]},\left(\mathrm{NEt}_{4}\right)_{2}\left[\mathrm{Fe}_{2} \mathrm{~S}_{2} \text { (indolate) }\right)_{4}\right]$ (10) ${ }^{[151]}$ and $\left(\mathrm{NEt}_{4}\right)_{2}\left[\mathrm{Fe}_{4} \mathrm{~S}_{4} \mathrm{Cl}_{4}\right](26)^{[161]}$ were synthesised according to published procedures.

All other chemicals were used as purchased.

${ }^{1} \mathrm{H}$ NMR, ${ }^{13} \mathrm{C}$ NMR, ${ }^{19} \mathrm{~F}$ NMR, ${ }^{119} \mathrm{Sn}$ NMR, and DOSY NMR spectra were recorded on Bruker Avance $200 \mathrm{MHz}, 300 \mathrm{MHz}$ and $500 \mathrm{MHz}$ spectrometers. DOSY spectra were recorded with a z-gradient ramped linearly from 1 to $53 \mathrm{G} / \mathrm{cm}$, bipolar gradient pulses of $2 \mathrm{~ms}$, and a diffusion delay of $70 \mathrm{~ms}$ (reduced to $30 \mathrm{~ms}$ to prevent exchange).

$\mathrm{UV} /$ vis spectra were recorded on a Specord $S 100$ spectrometer using quartz cuvettes. 
Microanalyses were performed by the Analytisches Labor des Instituts für Anorganische Chemie der Universität Göttingen. ESI-HRMS was applied where accurate analyses were difficult to obtain.

Infrared spectra were recorded on a Digilab Excalibur FTS3000 spectrometer.

Melting points were determined using a SRS OptiMelt apparatus.

EI mass spectra were measured on a Finnigan MAT 8200, ESI mass spectra on a Thermo Finnigan Trace LCQ spectrometer, ESI-HRMS spectra on a Bruker FTICR APEX IV instrument. GC/MS spectra were performed on a ThermoFinnigan TRACE GC using chemical ionisation. 


\subsection{Synthesis of Ligands and Ligand Precursors}

\section{3,3'-Diallyl-2,2'-bis( $N, N$-dimethylthiocarbamoyloxy)biphenyl (4a)}

A solution of 3,3'-diallyl-2,2'-dihydroxybiphenyl (3a, $12.3 \mathrm{~g}, 45.2 \mathrm{mmol}$ ) in DMF $(120 \mathrm{ml})$ was treated with sodium hydride $(2.48 \mathrm{~g}, 103 \mathrm{mmol})$ in portions at $0^{\circ} \mathrm{C}$ and stirred for $2 \mathrm{~h}$. Dimethylcarbamothioic chloride $(13.3 \mathrm{~g}, 108 \mathrm{mmol})$ was added in portions and the suspension was stirred at $90^{\circ} \mathrm{C}$ for $4 \mathrm{~h}$. After cooling to room temperature, the reaction mixture was treated with aqueous $\mathrm{KOH}(1 \%, 500 \mathrm{ml})$ and extracted with $\mathrm{CH}_{2} \mathrm{Cl}_{2}(500 \mathrm{ml})$. The organic phase was washed with brine, dried over $\mathrm{Na}_{2} \mathrm{SO}_{4}$, filtered, and evaporated to dryness. The resulting brown oil was purified via column chromatography (silica, hexane $/ \mathrm{CH}_{2} \mathrm{Cl}_{2} 1 / 3, \mathrm{R}_{\mathrm{f}}=0.5$ ) to afford the product as a white solid (6.5 g, $15 \mathrm{mmol}, 32 \%)$.

$\mathrm{Mp}$ (uncorrected) $99^{\circ} \mathrm{C}$.

${ }^{1} \mathrm{H}$ NMR (500 MHz, $\left.\mathrm{CDCl}_{3}\right): \delta=2.97$ (s, 4H, $\left.\mathrm{NMe}_{2}\right), 2.98$ (s, 2H, $\mathrm{NMe}_{2}$ ), 3.16 (s, 4H, $\mathrm{NMe}_{2}$ ), 3.22 (br s, 2H, $\mathrm{NMe}_{2}$ ), 3.27-3.45 (m, 4H, $\mathrm{CH}_{2}$ ), 5.04 (m, 2H, $\left.\mathrm{CH}=\mathrm{CH} H_{\text {trans }}\right), 5.06\left(\mathrm{dq},{ }^{3} J_{\mathrm{H}, \mathrm{H}}=10.5 \mathrm{~Hz},{ }^{2} J_{\mathrm{H}, \mathrm{H}}=1.5 \mathrm{~Hz}, 2 \mathrm{H}, \mathrm{CH}=\mathrm{C} H_{\text {cis }} \mathrm{H}\right), 5.95(\mathrm{ddt}$, $\left.{ }^{3} J_{\mathrm{H}, \mathrm{H}}=17.1,10.5,6.3 \mathrm{~Hz}, 2 \mathrm{H}, \mathrm{CH}=\mathrm{CH}_{2}\right), 7.14-7.24(\mathrm{~m}, 6 \mathrm{H}, \mathrm{Ar}-\mathrm{H})$.

${ }^{13} \mathrm{C}$ NMR $\left(125 \mathrm{MHz}, \mathrm{CDCl}_{3}\right): \delta=35.0\left(\mathrm{CH}_{2}\right), 35.1\left(\mathrm{CH}_{2}\right), 38.0\left(\mathrm{NMe}_{2}\right), 43.0$ $\left(\mathrm{NMe}_{2}\right), 115.9\left(\mathrm{CH}=\mathrm{CH}_{2}\right), 124.9$ (Ar-C), 125.9 (Ar-C), 129.5 (Ar-C), 129.6 (Ar-C), 130.1 (Ar-C), 131.7 (Ar-C), 132.7 (Ar-C), $136.3\left(\mathrm{CH}=\mathrm{CH}_{2}\right), 136.5\left(\mathrm{CH}=\mathrm{CH}_{2}\right), 149.5$ (Ar-C), 149.8 (Ar-C), 186.4 (CS).

MS $(\mathrm{EI}(+)): m / z(\%)=440(70)[\mathrm{M}]^{+}, 425(5)\left[\mathrm{M}-\mathrm{CH}_{3}\right]^{+}, 368(100)[\mathrm{M} \mathrm{-}$ $\left.\mathrm{C}(\mathrm{O}) \mathrm{N}\left(\mathrm{CH}_{3}\right)_{2}\right]^{+}, 352(40)\left[\mathrm{M}-\mathrm{C}(\mathrm{S}) \mathrm{N}\left(\mathrm{CH}_{3}\right)_{2}\right]^{+}, 336(40)\left[\mathrm{M}-\mathrm{OC}(\mathrm{S}) \mathrm{N}\left(\mathrm{CH}_{3}\right)_{2}\right]^{+}, 264$ (45) $\left[\mathrm{M}-2 \mathrm{C}(\mathrm{S}) \mathrm{N}\left(\mathrm{CH}_{3}\right)_{2}\right]^{+}$.

IR $(\mathrm{KBr}): \nu\left(\mathrm{cm}^{-1}\right)=1535(\mathrm{CS}, \mathrm{s})$.

Elemental analysis: calcd (\%) for $\mathrm{C}_{24} \mathrm{H}_{28} \mathrm{~N}_{2} \mathrm{O}_{2} \mathrm{~S}_{2}$ : C 65.42, H 6.41, N 6.36. Found: C 66.33, H 6.34, N 6.21.

\section{3,3'-Diallyl-2,2'-bis(N,N-dimethylcarbamoylthio)biphenyl (5a)}

A $250 \mathrm{ml}$ Schlenk flask was charged with 3,3'-diallyl-2,2'-bis( $N, N$-dimethylthiocarbamoyloxy)biphenyl (4a, $2.8 \mathrm{~g}, 6.4 \mathrm{mmol})$ and heated to $320^{\circ} \mathrm{C}$ for $1 \mathrm{~h}$ without agitation. The resulting brown oil was cooled to room temperature and purified by column chromatography (silica, hexane/EtOAc $5 / 1, \mathrm{R}_{\mathrm{f}}=0.2$ ) to yield the product as a colourless solid (1.5 g, $3.4 \mathrm{mmol}, 54 \%)$. 
$\mathrm{Mp}$ (uncorrected) $114^{\circ} \mathrm{C}$.

${ }^{1} \mathrm{H}$ NMR $\left(500 \mathrm{MHz}, \mathrm{CDCl}_{3}\right): \delta=2.81\left(\mathrm{~s}, 12 \mathrm{H}, \mathrm{NMe}_{2}\right), 3.56\left(\mathrm{dd},{ }^{2} J_{\mathrm{H}, \mathrm{H}}=16.0 \mathrm{~Hz}\right.$, $\left.{ }^{3} J_{\mathrm{H}, \mathrm{H}}=6.5 \mathrm{~Hz}, 2 \mathrm{H}, \mathrm{CH}_{2}\right), 3.66\left(\mathrm{dd},{ }^{2} J_{\mathrm{H}, \mathrm{H}}=16.0 \mathrm{~Hz},{ }^{3} J_{\mathrm{H}, \mathrm{H}}=6.5 \mathrm{~Hz}, 2 \mathrm{H}, \mathrm{CH}_{2}\right), 5.02(\mathrm{dq}$, $\left.{ }^{3} J_{\mathrm{H}, \mathrm{H}}=17.0 \mathrm{~Hz},{ }^{2} J_{\mathrm{H}, \mathrm{H}}=2.0 \mathrm{~Hz}, 2 \mathrm{H}, \mathrm{CH}=\mathrm{CH} H_{\text {trans }}\right), 5.06\left(\mathrm{dq},{ }^{3} J_{\mathrm{H}, \mathrm{H}}=10.0 \mathrm{~Hz},{ }^{2} J_{\mathrm{H}, \mathrm{H}}=\right.$ $\left.1.5 \mathrm{~Hz}, 2 \mathrm{H}, \mathrm{CH}=\mathrm{CH}_{c i s} \mathrm{H}\right), 6.01\left(\mathrm{ddt},{ }^{3} J_{\mathrm{H}, \mathrm{H}}=17.0,10.0,6.5 \mathrm{~Hz}, 2 \mathrm{H}, \mathrm{CH}=\mathrm{CH}_{2}\right), 7.11$ $\left(\mathrm{d},{ }^{3} J_{\mathrm{H}, \mathrm{H}}=2 \mathrm{~Hz}, \mathrm{Ar}-\mathrm{H}\right), 7.13\left(\mathrm{~d},{ }^{3} J_{\mathrm{H}, \mathrm{H}}=2 \mathrm{~Hz}, \mathrm{Ar}-\mathrm{H}\right), 7.26-7.32(\mathrm{~m}, 4 \mathrm{H}, \mathrm{Ar}-\mathrm{H})$.

${ }^{13} \mathrm{C} \mathrm{NMR}\left(125 \mathrm{MHz}, \mathrm{CDCl}_{3}\right): \delta=36.9\left(\mathrm{NMe}_{2}\right), 39.1\left(\mathrm{CH}_{2}\right), 115.8\left(\mathrm{CH}=\mathrm{CH}_{2}\right), 127.7$ (Ar-C), 128.7 (Ar-C), 128.8 (Ar-C), 129.0 (Ar-C), $137.4\left(\mathrm{CH}=\mathrm{CH}_{2}\right), 144.8$ (Ar-C), 148.2 (Ar-C), $166.2(\mathrm{CO})$.

MS $(\mathrm{EI}(+)): m / z(\%)=440(50)[\mathrm{M}]^{+}, 368(70)\left[\mathrm{M}-\mathrm{C}(\mathrm{O}) \mathrm{N}\left(\mathrm{CH}_{3}\right)_{2}\right]^{+}, 336(100)$ $\left[\mathrm{M}-\mathrm{SC}(\mathrm{O}) \mathrm{N}\left(\mathrm{CH}_{3}\right)_{2}\right]^{+}, 295(30)\left[\mathrm{M}-2 \mathrm{C}(\mathrm{O}) \mathrm{N}\left(\mathrm{CH}_{3}\right)_{2}-\mathrm{H}\right]^{+}, 264$ (90) $[\mathrm{M}-$ $\left.\mathrm{C}(\mathrm{O}) \mathrm{N}\left(\mathrm{CH}_{3}\right)_{2}-\mathrm{SC}(\mathrm{O}) \mathrm{N}\left(\mathrm{CH}_{3}\right)_{2}\right]^{+}$.

$\operatorname{IR}(\mathrm{KBr}): \nu\left(\mathrm{cm}^{-1}\right)=1661(\mathrm{CO}, \mathrm{s})$.

Elemental analysis: calcd (\%) for $\mathrm{C}_{24} \mathrm{H}_{28} \mathrm{~N}_{2} \mathrm{O}_{2} \mathrm{~S}_{2}$ : C 65.42, H 6.41, N 6.36. Found: C 65.33, H 6.36, N 6.18.

\section{3,3'-Diallyl-2,2'-dithiobiphenyl (6a)}

To a suspension of $\mathrm{LiAlH}_{4}(1.90 \mathrm{~g}, 50.1 \mathrm{mmol})$ in THF $(80 \mathrm{ml})$ was slowly added a solution of 3,3'-diallyl-2,2'-bis( $N, N$-dimethylcarbamoylthio)biphenyl (5a, 6.90 g, $15.7 \mathrm{mmol})$ in THF $(60 \mathrm{ml})$, and the reaction mixture was refluxed for $3 \mathrm{~h}$. After cooling to $0^{\circ} \mathrm{C}$ degassed water was carefully added to destroy excess $\mathrm{LiAlH}_{4}$, and the mixture was neutralised with degassed aqueous $\mathrm{NH}_{4} \mathrm{Cl}$ solution $(200 \mathrm{ml})$. The mixture was extracted with $\mathrm{Et}_{2} \mathrm{O}(3 \times 100 \mathrm{ml})$. The combined organic phases were dried over $\mathrm{Na}_{2} \mathrm{SO}_{4}$, filtered, and evaporated to give the product as a pale yellow oil $(2.94 \mathrm{~g}, 9.85 \mathrm{mmol}, 63 \%)$.

${ }^{1} \mathrm{H} \mathrm{NMR}\left(500 \mathrm{MHz}, \mathrm{CDCl}_{3}\right): \delta=3.25(\mathrm{~s}, 2 \mathrm{H}, \mathrm{SH}), 3.50\left(\mathrm{~d},{ }^{3} J_{\mathrm{H}, \mathrm{H}}=5.0 \mathrm{~Hz}, 4 \mathrm{H}\right.$, $\left.\mathrm{CH}_{2}\right), 5.13\left(\mathrm{~m}, 4 \mathrm{H}, \mathrm{CH}=\mathrm{CH}_{2}\right), 6.01\left(\mathrm{ddt},{ }^{3} \mathrm{H}_{\mathrm{H}, \mathrm{H}}=20.8,13.3,3.7 \mathrm{~Hz}, 2 \mathrm{H}, \mathrm{CH}=\mathrm{CH}_{2}\right)$, 7.03-7.24 (m, 6H, Ar-H).

${ }^{13} \mathrm{C} \mathrm{NMR}\left(125 \mathrm{MHz}, \mathrm{CDCl}_{3}\right): \delta=39.1\left(\mathrm{CH}_{2}\right), 116.8\left(\mathrm{CH}=\mathrm{CH}_{2}\right), 125.4(\mathrm{Ar}-\mathrm{C}), 128.2$ (Ar-C), 129.2 (Ar-C), 131.8 (Ar-C), $135.3\left(\mathrm{CH}=\mathrm{CH}_{2}\right.$ ), 138.1 (Ar-C), 140.2 (Ar-C).

$\mathrm{MS}(\mathrm{EI}(+)): m / z(\%)=298(100)[\mathrm{M}]^{+}, 265(30)[\mathrm{M}-\mathrm{SH}]^{+}$.

$\operatorname{IR}(\mathrm{KBr}): \nu\left(\mathrm{cm}^{-1}\right)=2576(\mathrm{SH}, \mathrm{m})$.

HRMS (EI(+)): calcd $(m / z)$ for $\mathrm{C}_{18} \mathrm{H}_{18} \mathrm{~S}_{2}$ : 298.0850. Found: 298.0854. 


\section{2-(Allyloxy)-2'-hydroxybiphenyl (2b)}

A solution of 2,2'-dihydroxybiphenyl (1a, $25.7 \mathrm{~g}, 138 \mathrm{mmol})$ and allylbromide (16.7 g, $138 \mathrm{mmol})$ in acetone $(250 \mathrm{ml})$ was treated with $\mathrm{K}_{2} \mathrm{CO}_{3}(50 \mathrm{~g})$ and refluxed for $18 \mathrm{~h}$. After cooling to room temperature the reaction mixture was filtered and the filtrate concentrated in vacuo. The resulting brown oil was dissolved in $\mathrm{CH}_{2} \mathrm{Cl}_{2}(250 \mathrm{ml})$, washed with aqueous $\mathrm{NaOH}$ solution $(1 \mathrm{~mol} / 1,250 \mathrm{ml})$ and water $(250 \mathrm{ml})$, dried over $\mathrm{Na}_{2} \mathrm{SO}_{4}$, filtered and evaporated to dryness. The remaining brown oil was purified by column chromatography (hexane/ $\mathrm{CH}_{2} \mathrm{Cl}_{2} / \mathrm{MeOH} 49 / 49 / 2$ ) to yield the product as a colourless oil (22.1 g, $98 \mathrm{mmol}, 71 \%)$.

${ }^{1} \mathrm{H} \mathrm{NMR}\left(500 \mathrm{MHz}, \mathrm{CDCl}_{3}\right): \delta=4.61\left(\mathrm{dt},{ }^{3} J_{\mathrm{H}, \mathrm{H}}=5.0 \mathrm{~Hz},{ }^{2} J_{\mathrm{H}, \mathrm{H}}=1.5 \mathrm{~Hz}, 2 \mathrm{H}\right.$, $\left.\mathrm{CH}_{2}\right), 5.27\left(\mathrm{dd},{ }^{3} J_{\mathrm{H}, \mathrm{H}}=10.5 \mathrm{~Hz},{ }^{2} J_{\mathrm{H}, \mathrm{H}}=1.5 \mathrm{~Hz}, 1 \mathrm{H}, \mathrm{CH}=\mathrm{CH}_{\text {cis }} \mathrm{H}\right), 5.35\left(\mathrm{dq},{ }^{3} J_{\mathrm{H}, \mathrm{H}}=\right.$ $\left.17.0 \mathrm{~Hz},{ }^{2} J_{\mathrm{H}, \mathrm{H}}=1.5 \mathrm{~Hz}, 1 \mathrm{H}, \mathrm{CH}=\mathrm{CH} H_{\text {trans }}\right), 5.98\left(\mathrm{ddt},{ }^{3} J_{\mathrm{H}, \mathrm{H}}=17.0,10.5,5.0 \mathrm{~Hz}, 1 \mathrm{H}\right.$, $\mathrm{CH}=\mathrm{CH}_{2}$ ), 6.23 (br s, 1H, OH), 7.03-7.09 (m, 3H, Ar-H), $7.15\left(\mathrm{dt},{ }^{3} J_{\mathrm{H}, \mathrm{H}}=7.5 \mathrm{~Hz}\right.$, $\left.{ }^{4} J_{\mathrm{H}, \mathrm{H}}=1.0 \mathrm{~Hz}, 1 \mathrm{H}, \mathrm{Ar}-\mathrm{H}\right), 7.30-7.40(\mathrm{~m}, 4 \mathrm{H}, \mathrm{Ar}-\mathrm{H})$.

${ }^{13} \mathrm{C}$ NMR (125 MHz, $\left.\mathrm{CDCl}_{3}\right): \delta=70.0\left(\mathrm{CH}_{2}\right), 113.4$ (Ar-C), 117.5 (Ar-C), 118.2 $\left(\mathrm{CH}=\mathrm{CH}_{2}\right.$ ), 120.9 (Ar-C), 122.4 (Ar-C), 126.3 (Ar-C), 127.7 (Ar-C), 129.1 (Ar-C), 129.1 (Ar-C), 131.2 (Ar-C), $132.1\left(\mathrm{CH}=\mathrm{CH}_{2}\right), 132.5$ (Ar-C), 153.7 (Ar-C), 154.4 (Ar-C).

MS (EI(+)): $m / z(\%)=226(100)[\mathrm{M}]^{+}, 185(70)\left[\mathrm{M}-\mathrm{CH}_{2} \mathrm{CHCH}_{2}\right]^{+}$.

IR (KBr): $\nu\left(\mathrm{cm}^{-1}\right)=3404(\mathrm{~s}), 3067(\mathrm{~m}), 3029(\mathrm{~m}), 2927(\mathrm{w}), 2872(\mathrm{w}), 1500(\mathrm{~s}), 1480$ (s), 1442 (s), 1276 (s), 1226 (s).

Elemental analysis: calcd (\%) for $\mathrm{C}_{15} \mathrm{H}_{14} \mathrm{O}_{2}$ : C 79.62, H 6.24. Found: C 79.45, H 6.42.

\section{3-Allyl-2,2'-dihydroxybiphenyl (3b)}

Neat 2-(allyloxy)-2'-hydroxybiphenyl (2b, $22 \mathrm{~g}, 97 \mathrm{mmol}$ ) was heated to $170^{\circ} \mathrm{C}$ for $4 \mathrm{~d}$. After cooling to room temperature the brown solid was purified by recrystallisation from $\mathrm{MeOH}(100 \mathrm{ml})$ to yield the product as a white powder $(16.6 \mathrm{~g}, 73 \mathrm{mmol}, 76 \%)$.

$\mathrm{Mp}$ (uncorrected) $83^{\circ} \mathrm{C}$.

${ }^{1} \mathrm{H}$ NMR $\left(500 \mathrm{MHz}, \mathrm{CDCl}_{3}\right): \delta=3.39\left(\mathrm{~d},{ }^{3} J_{\mathrm{H}, \mathrm{H}}=6.5 \mathrm{~Hz}, 2 \mathrm{H}, \mathrm{CH}_{2}\right), 4.98(\mathrm{dq}$, $\left.{ }^{3} J_{\mathrm{H}, \mathrm{H}}=10.0 \mathrm{~Hz},{ }^{2} J_{\mathrm{H}, \mathrm{H}}=1.5 \mathrm{~Hz}, 1 \mathrm{H}, \mathrm{CH}=\mathrm{CH}_{c i s} \mathrm{H}\right), 5.03\left(\mathrm{dq},{ }^{3} J_{\mathrm{H}, \mathrm{H}}=17.0 \mathrm{~Hz},{ }^{2} J_{\mathrm{H}, \mathrm{H}}=\right.$ $\left.1.5 \mathrm{~Hz}, 1 \mathrm{H}, \mathrm{CH}=\mathrm{CH} H_{\text {trans }}\right), 5.96\left(\mathrm{ddt},{ }^{3} J_{\mathrm{H}, \mathrm{H}}=17.0,10.0,6.5 \mathrm{~Hz}, 1 \mathrm{H}, \mathrm{CH}=\mathrm{CH}_{2}\right), 6.42$ (br s, 2H, OH), 6.86-7.08 (m, 7H, Ar-H), $7.17\left(\mathrm{dt},{ }^{3} J_{\mathrm{H}, \mathrm{H}}=7.6 \mathrm{~Hz},{ }^{4} J_{\mathrm{H}, \mathrm{H}}=1.0 \mathrm{~Hz}, 1 \mathrm{H}\right.$, Ar-H).

${ }^{13} \mathrm{C} \mathrm{NMR}\left(125 \mathrm{MHz}, \mathrm{CDCl}_{3}\right): \delta=35.0\left(\mathrm{CH}_{2}\right), 116.3\left(\mathrm{CH}=\mathrm{CH}_{2}\right), 116.6(\mathrm{Ar}-\mathrm{C}), 121.3$ (Ar-C), 121.4 (Ar-C), 123.4 (Ar-C), 123.6 (Ar-C), 127.2 (Ar-C), 129.3 (Ar-C), 130.0 (Ar- 
C), 130.5 (Ar-C), 131.2 (Ar-C), $136.4\left(\mathrm{CH}=\mathrm{CH}_{2}\right), 151.1$ (Ar-C), 153.1 (Ar-C). MS $(\mathrm{EI}(+)): m / z(\%)=226(100)[\mathrm{M}]^{+}$.

IR (KBr): $\nu\left(\mathrm{cm}^{-1}\right)=3183(\mathrm{~s}), 2710(\mathrm{w}), 2568(\mathrm{w}), 1634(\mathrm{~m}), 1460$ (s), $1430(\mathrm{~s}), 1428$ (s), 1213 (s).

Elemental analysis: calcd (\%) for $\mathrm{C}_{15} \mathrm{H}_{14} \mathrm{O}_{2}$ : C 79.62, H 6.24. Found: C 79.42, H 6.40.

\section{3-Allyl-2,2'-bis( $N, N$-dimethylthiocarbamoyloxy)biphenyl (4b)}

A solution of 3-allyl-2,2'-dihydroxybiphenyl (3b, $21.2 \mathrm{~g}, 93.9 \mathrm{mmol})$ in DMF $(160 \mathrm{ml})$ was treated with $\mathrm{NaH}(4.59 \mathrm{~g}, 191 \mathrm{mmol})$ in portions at $0{ }^{\circ} \mathrm{C}$. Then HMPA $(35 \mathrm{ml})$ was added and the suspension stirred for $2 \mathrm{~h}$. Dimethylcarbamothioic chloride $(31.8 \mathrm{~g}$, $256 \mathrm{mmol}$ ) was added in portions, and the suspension was stirred at $60^{\circ} \mathrm{C}$ for $18 \mathrm{~h}$. After cooling to room temperature the reaction mixture was treated with water $(500 \mathrm{ml})$ and extracted with $\mathrm{CH}_{2} \mathrm{Cl}_{2}(4 \times 100 \mathrm{ml})$. The organic phase was washed with $\mathrm{NaOH}$ solution $(10 \%, 200 \mathrm{ml})$ and brine, dried over $\mathrm{MgSO}_{4}$, filtered, and evaporated to dryness. The resulting brown oil was purified via column chromatography (hexane $/ \mathrm{CH}_{2} \mathrm{Cl}_{2} 2 / 3$ ) to afford a mixture of the two mono-substituted intermediates and the di-substituted product $(9.30 \mathrm{~g})$.

This mixture $(8.9 \mathrm{~g})$ was again dissolved in DMF $(80 \mathrm{ml})$ and treated with $\mathrm{NaH}(0.68 \mathrm{~g}$, $28.4 \mathrm{mmol})$ in portions at $0^{\circ} \mathrm{C}$. After $1 \mathrm{~h}$, dimethylcarbamothioic chloride $(4.56 \mathrm{~g}$, $36.9 \mathrm{mmol}$ ) was added in portions and the suspendion was stirred at $90^{\circ} \mathrm{C}$ for $17 \mathrm{~h}$. After cooling to room temperature the reaction mixture was treated with aqueous $\mathrm{KOH}$ $(1 \%, 200 \mathrm{ml})$ and extracted with $\mathrm{CH}_{2} \mathrm{Cl}_{2}(3 \times 100 \mathrm{ml})$. The organic phase was dried over $\mathrm{MgSO}_{4}$, filtered, and evaporated to dryness. Column chromatography (hexane $/ \mathrm{CH}_{2} \mathrm{Cl}_{2}$ $2 / 3$ ) afforded the product $4 \mathrm{~b}$ as a colourless oil ( $8.1 \mathrm{~g}, 20 \mathrm{mmol}, 22 \%$ over two steps).

${ }^{1} \mathrm{H}$ NMR (500 MHz, $\left.\mathrm{CDCl}_{3}\right): \delta=2.98$ (s, 3H, $\mathrm{NMe}_{2}$ ), 3.01 (s, $3 \mathrm{H}, \mathrm{NMe}_{2}$ ), 3.18 (s, $3 \mathrm{H}, \mathrm{NMe}_{2}$ ), 3.24 (br s, $3 \mathrm{H}, \mathrm{NMe}_{2}$ ), $3.30\left(\mathrm{dd},{ }^{2} J_{\mathrm{H}, \mathrm{H}}=16.0 \mathrm{~Hz},{ }^{3} J_{\mathrm{H}, \mathrm{H}}=6.5 \mathrm{~Hz}, 1 \mathrm{H}, \mathrm{CH}_{2}\right.$ ), $3.41\left(\mathrm{dd},{ }^{2} J_{\mathrm{H}, \mathrm{H}}=16.0 \mathrm{~Hz},{ }^{3} J_{\mathrm{H}, \mathrm{H}}=6.5 \mathrm{~Hz}, 1 \mathrm{H}, \mathrm{CH}_{2}\right), 5.04(\mathrm{br} \mathrm{s}, 1 \mathrm{H}, \mathrm{CH}=\mathrm{CH} H), 5.06$ (br s, $1 \mathrm{H}, \mathrm{CH}=\mathrm{CHH}), 5.95\left(\mathrm{ddt},{ }^{3} J_{\mathrm{H}, \mathrm{H}}=17.0,10.5,6.5 \mathrm{~Hz}, 2 \mathrm{H}, \mathrm{CH}=\mathrm{CH}_{2}\right), 7.15-7.42$ (m, 7H, Ar-H).

${ }^{13} \mathrm{C} \mathrm{NMR}\left(125 \mathrm{MHz}, \mathrm{CDCl}_{3}\right): \delta=34.9\left(\mathrm{CH}_{2}\right), 38.2\left(\mathrm{NMe}_{2}\right), 38.4\left(\mathrm{NMe}_{2}\right), 43.0$ $\left(\mathrm{NMe}_{2}\right), 43.0\left(\mathrm{NMe}_{2}\right), 116.0\left(\mathrm{CH}=\mathrm{CH}_{2}\right), 123.9$ (br, Ar-C), 125.4 (br, Ar-C), 125.6 (ArC), 128.2 (Ar-C), 129.6 (Ar-C), 131.0 (br, Ar-C), 131.2 (Ar-C), 131.5 (Ar-C), 133.4 (Ar-C), $136.3\left(\mathrm{CH}=\mathrm{CH}_{2}\right), 149.6$ (Ar-C), 151.3 (Ar-C), 186.3 (CS), 187.2 (CS).

MS $(\mathrm{EI}(+)): m / z(\%)=400(50)[\mathrm{M}]^{+} 328(100)\left[\mathrm{M}-\mathrm{C}(\mathrm{O}) \mathrm{N}\left(\mathrm{CH}_{3}\right)_{2}\right]^{+} 312(20)[\mathrm{M}$ 
$\left.-\mathrm{C}(\mathrm{S}) \mathrm{N}\left(\mathrm{CH}_{3}\right)_{2}\right]^{+}, 296(30)\left[\mathrm{M}-\mathrm{OC}(\mathrm{S}) \mathrm{N}\left(\mathrm{CH}_{3}\right)_{2}\right]^{+}$.

IR $(\mathrm{KBr}): \nu\left(\mathrm{cm}^{-1}\right)=1535(\mathrm{CS}, \mathrm{s})$.

Elemental analysis: calcd (\%) for $\mathrm{C}_{21} \mathrm{H}_{24} \mathrm{~N}_{2} \mathrm{O}_{2} \mathrm{~S}_{2}$ : C 62.97, H 6.04, N 6.99, S 16.01 . Found: C 62.40, H 6.14, N 6.93, S 15.94 .

\section{3-Allyl-2,2'-bis( $N, N$-dimethylcarbamoylthio)biphenyl (5b)}

A $250 \mathrm{ml}$ Schlenk flask was charged with 3-allyl-2,2'-bis( $N, N$-dimethylthiocarbamoyloxy)biphenyl (4b, $8.1 \mathrm{~g}, 20 \mathrm{mmol}$ ) and heated to $320^{\circ} \mathrm{C}$ for $1 \mathrm{~h}$ without agitation. The resulting brown oil was cooled to room temperature and purified by column chromatography (hexane/EtOAc 3/1) to yield the product as a colourless oil $(2.5 \mathrm{~g}, 6.3 \mathrm{mmol}$, $31 \%)$.

${ }^{1} \mathrm{H}$ NMR $\left(500 \mathrm{MHz}, \mathrm{CDCl}_{3}\right): \delta=2.81\left(\mathrm{~s}, 6 \mathrm{H}, \mathrm{NMe}_{2}\right), 2.87\left(\mathrm{~s}, 6 \mathrm{H}, \mathrm{NMe}_{2}\right), 3.58(\mathrm{dd}$, $\left.{ }^{2} J_{\mathrm{H}, \mathrm{H}}=16.0 \mathrm{~Hz},{ }^{3} J_{\mathrm{H}, \mathrm{H}}=6.5 \mathrm{~Hz}, 2 \mathrm{H}, \mathrm{CH}_{2}\right), 3.67\left(\mathrm{dd},{ }^{2} J_{\mathrm{H}, \mathrm{H}}=16.0 \mathrm{~Hz},{ }^{3} J_{\mathrm{H}, \mathrm{H}}=6.5 \mathrm{~Hz}\right.$, $\left.2 \mathrm{H}, \mathrm{CH}_{2}\right), 5.01-5.08\left(\mathrm{~m}, 2 \mathrm{H}, \mathrm{CH}=\mathrm{CH}_{2}\right), 6.01\left(\mathrm{ddt},{ }^{3} J_{\mathrm{H}, \mathrm{H}}=17.0,10.0,6.5 \mathrm{~Hz}, 1 \mathrm{H}\right.$, $\left.\mathrm{CH}=\mathrm{CH}_{2}\right), 7.13-7.35(\mathrm{~m}, 7 \mathrm{H}, \mathrm{Ar}-\mathrm{H})$.

${ }^{13} \mathrm{C}$ NMR $\left(125 \mathrm{MHz}, \mathrm{CDCl}_{3}\right): \delta=36.9\left(\mathrm{br}, \mathrm{NMe}_{2}\right), 39.1\left(\mathrm{CH}_{2}\right), 115.9\left(\mathrm{CH}=\mathrm{CH}_{2}\right)$, 127.7 (Ar-C), 127.9 (Ar-C), 128.3 (Ar-C), 128.5 (Ar-C), 128.8 (Ar-C), 129.1 (Ar-C), 129.2 (Ar-C), 130.6 (Ar-C), 136.7 (Ar-C), $137.3\left(\mathrm{CH}=\mathrm{CH}_{2}\right), 144.9$ (Ar-C), 146.5 (Ar-C), 147.2 (Ar-C), $166.1(\mathrm{CO}), 166.7$ (CO).

MS $(\mathrm{EI}(+)): m / z(\%)=400(20)[\mathrm{M}]^{+}, 328(100)\left[\mathrm{M}-\mathrm{C}(\mathrm{O}) \mathrm{N}\left(\mathrm{CH}_{3}\right)_{2}\right]^{+}, 296(50)[\mathrm{M}$ $\left.-\mathrm{SC}(\mathrm{O}) \mathrm{N}\left(\mathrm{CH}_{3}\right)_{2}\right]^{+}, 224(60)\left[\mathrm{M}-\mathrm{SC}(\mathrm{O}) \mathrm{N}\left(\mathrm{CH}_{3}\right)_{2}-\mathrm{C}(\mathrm{O}) \mathrm{N}\left(\mathrm{CH}_{3}\right)_{2}\right]^{+}$.

$\operatorname{IR~}(\mathrm{KBr}): \nu\left(\mathrm{cm}^{-1}\right)=1668(\mathrm{CO}, \mathrm{s})$.

Elemental analysis: calcd (\%) for $\mathrm{C}_{21} \mathrm{H}_{24} \mathrm{~N}_{2} \mathrm{O}_{2} \mathrm{~S}_{2}$ : C 62.97, H 6.04, N 6.99, S 16.01. Found: C 61.83, H 6.11, N 6.54, S 15.60.

\section{3-Allyl-2,2'-dithiobiphenyl (6b)}

To a suspension of $\mathrm{LiAlH}_{4}(0.60 \mathrm{~g}, 15.8 \mathrm{mmol})$ in THF $(40 \mathrm{ml})$ was slowly added a solution of 3-allyl-2,2'-bis( $N, N$-dimethylcarbamoylthio)biphenyl (5b, $2.2 \mathrm{~g}, 5.0 \mathrm{mmol})$ in THF $(40 \mathrm{ml})$, and the reaction mixture was refluxed for $2 \mathrm{~h}$. After cooling to $0^{\circ} \mathrm{C}$ degassed water was carefully added to destroy excess $\mathrm{LiAlH}_{4}$, and the mixture was neutralised with degassed aqueous $\mathrm{NH}_{4} \mathrm{Cl}$ solution $(80 \mathrm{ml})$. The mixture was extracted with $\mathrm{Et}_{2} \mathrm{O}(3 \times 50 \mathrm{ml})$. The combined organic phases were dried over $\mathrm{MgSO}_{4}$, filtered, and evaporated to give the product as a pale yellow oil $(1.1 \mathrm{~g}, 4.3 \mathrm{mmol}, 85 \%)$. 
${ }^{1} \mathrm{H}$ NMR $\left(500 \mathrm{MHz}, \mathrm{CDCl}_{3}\right): \delta=3.30$ (s, 1H, SH), 3.31 (s, 1H, SH), 3.55 (d, 2H, $\left.{ }^{3} J_{\mathrm{H}, \mathrm{H}}=6.0 \mathrm{~Hz}, \mathrm{CH}_{2}\right), 5.14\left(\mathrm{dq},{ }^{3} J_{\mathrm{H}, \mathrm{H}}=17.0 \mathrm{~Hz},{ }^{2} J_{\mathrm{H}, \mathrm{H}}=1.5 \mathrm{~Hz}, 1 \mathrm{H}, \mathrm{CH}=\mathrm{CH} H_{\text {trans }}\right)$, $5.19\left(\mathrm{dq},{ }^{3} J_{\mathrm{H}, \mathrm{H}}=10.0 \mathrm{~Hz},{ }^{2} J_{\mathrm{H}, \mathrm{H}}=1.5 \mathrm{~Hz}, 1 \mathrm{H}, \mathrm{CH}=\mathrm{CH}_{c i s} \mathrm{H}\right), 6.06\left(\mathrm{ddt},{ }^{3} J_{\mathrm{H}, \mathrm{H}}=17.0\right.$, 10.0, 6.0 Hz, $\left.1 \mathrm{H}, \mathrm{CH}=\mathrm{CH}_{2}\right), 7.07-7.43(\mathrm{~m}, 7 \mathrm{H}, \mathrm{Ar}-\mathrm{H})$.

${ }^{13} \mathrm{C} \mathrm{NMR}\left(125 \mathrm{MHz}, \mathrm{CDCl}_{3}\right): \delta=39.1\left(\mathrm{CH}_{2}\right), 116.7\left(\mathrm{CH}=\mathrm{CH}_{2}\right), 125.2(\mathrm{Ar}-\mathrm{C}), 125.7$ (Ar-C), 128.0 (Ar-C), 128.5 (Ar-C), 129.2 (Ar-C), 130.2 (Ar-C), 131.5 (Ar-C), 131.9 (ArC), $135.2\left(\mathrm{CH}=\mathrm{CH}_{2}\right), 137.9$ (Ar-C), 139.4 (Ar-C), 149.5 (Ar-C).

MS $(\mathrm{EI}(+)): m / z(\%)=258(80)[\mathrm{M}]^{+}, 225(60)[\mathrm{M}-\mathrm{SH}]^{+}, 184(60)[\mathrm{M}-\mathrm{SH}-$ $\left.\mathrm{CH}_{2} \mathrm{CHCH}_{2}\right]^{+}$.

$\operatorname{IR}(\mathrm{KBr}): \nu\left(\mathrm{cm}^{-1}\right)=2566(\mathrm{SH}, \mathrm{m})$.

HRMS (EI(+)): calcd $(m / z)$ for $\mathrm{C}_{15} \mathrm{H}_{15} \mathrm{~S}_{2}[\mathrm{M}+\mathrm{H}]^{+}:$259.06097. Found: 259.06098 .

\section{2,2'-Di(allyloxy)-5,5'-di-tert-butylbiphenyl (2c)}

A solution of 5,5'-di-tert-butyl-2,2'-dihydroxybiphenyl (1c, $9.0 \mathrm{~g}, 30 \mathrm{mmol}$ ) and allylbromide $(8.4 \mathrm{~g}, 68 \mathrm{mmol})$ in acetone $(45 \mathrm{ml})$ was treated with $\mathrm{K}_{2} \mathrm{CO}_{3}(10.5 \mathrm{~g})$ and refluxed for $32 \mathrm{~h}$. After cooling to room temperature the reaction mixture was filtered and the filtrate concentrated in vacuo. The resulting brown oil was dissolved in $\mathrm{CH}_{2} \mathrm{Cl}_{2}$ $(500 \mathrm{ml})$, washed with aqueous $\mathrm{NaOH}$ solution $(1 \mathrm{~mol} / 1,500 \mathrm{ml})$, dried over $\mathrm{MgSO}_{4}$, filtered and evaporated to dryness. The remaining brown oil was purified by column chromatography (hexane $\left./ \mathrm{CH}_{2} \mathrm{Cl}_{2} 3 / 2\right)$ to yield the product as a colourless oil $(8.6 \mathrm{~g}$, $23 \mathrm{mmol}, 75 \%)$.

${ }^{1} \mathrm{H} \mathrm{NMR}\left(300 \mathrm{MHz}, \mathrm{CDCl}_{3}\right): \delta=1.35\left(\mathrm{~s}, 18 \mathrm{H},{ }^{t} \mathrm{Bu}\right), 4.50\left(\mathrm{dt},{ }^{3} J_{\mathrm{H}, \mathrm{H}}=4.8 \mathrm{~Hz},{ }^{2} J_{\mathrm{H}, \mathrm{H}}=\right.$ $\left.1.8 \mathrm{~Hz}, 4 \mathrm{H}, \mathrm{CH}_{2}\right), 5.14\left(\mathrm{dq},{ }^{3} J_{\mathrm{H}, \mathrm{H}}=10.5 \mathrm{~Hz},{ }^{2} J_{\mathrm{H}, \mathrm{H}}=1.8 \mathrm{~Hz}, 2 \mathrm{H}, \mathrm{CH}=\mathrm{CH}_{\text {cis }} \mathrm{H}\right), 5.26$ $\left(\mathrm{dq},{ }^{3} J_{\mathrm{H}, \mathrm{H}}=17.1 \mathrm{~Hz},{ }^{2} J_{\mathrm{H}, \mathrm{H}}=1.8 \mathrm{~Hz}, 2 \mathrm{H}, \mathrm{CH}=\mathrm{CH} H_{\text {trans }}\right), 5.95\left(\mathrm{ddt},{ }^{3} J_{\mathrm{H}, \mathrm{H}}=17.4\right.$, 10.5, $\left.4.8 \mathrm{~Hz}, 2 \mathrm{H}, \mathrm{CH}=\mathrm{CH}_{2}\right), 6.92\left(\mathrm{~d},{ }^{3} \mathrm{~J}_{\mathrm{H}, \mathrm{H}}=8.4 \mathrm{~Hz}, 2 \mathrm{H}, \mathrm{Ar}-\mathrm{H}\right), 7.31\left(\mathrm{dd},{ }^{3} J_{\mathrm{H}, \mathrm{H}}=\right.$ 8.7, 2.7 Hz, 2H, Ar-H), 7.40 (d, ${ }^{3} J_{\mathrm{H}, \mathrm{H}}=2.7 \mathrm{~Hz}, 4 \mathrm{H}$, Ar-H).

${ }^{13} \mathrm{C}$ NMR $\left(125 \mathrm{MHz}, \mathrm{CDCl}_{3}\right): \delta=31.6\left({ }^{t} \mathrm{Bu}\right), 34.1\left(\mathrm{CMe}_{3}\right), 69.2\left(\mathrm{CH}_{2}\right), 112.2\left(3,3{ }^{\prime}-\right.$ Ar-C), $116.4\left(\mathrm{CH}=\mathrm{CH}_{2}\right), 124.8$ (4,4'-Ar-C), 127.7 (1,1'-Ar-C), 129.4 (6,6'-Ar-C), 133.9 $\left(\mathrm{CH}=\mathrm{CH}_{2}\right), 142.8$ (5,5'-Ar-C), 153.8 (2,2'-Ar-C).

MS $\left.(\mathrm{EI}(+)): m / z(\%)=378(90)[\mathrm{M}]^{+}, 363(30)\left[\mathrm{M}-\mathrm{CH}_{3}\right]^{+}\right]^{+}, 307(40)\left[\mathrm{M}-\mathrm{CH}_{3}\right.$ $\left.-\mathrm{C}_{4} \mathrm{H}_{8}\right]^{+}, 281(50)\left[\mathrm{M}-\mathrm{CH}_{2} \mathrm{CHCH}_{2}-\mathrm{C}_{4} \mathrm{H}_{8}\right]^{+}, 225$ (100) $\left[\mathrm{M}-\mathrm{CH}_{2} \mathrm{CHCH}_{2}-2\right.$ $\left.\mathrm{C}_{4} \mathrm{H}_{8}\right]^{+}$.

IR (KBr): $\nu\left(\mathrm{cm}^{-1}\right)=2960(\mathrm{~s}), 2900(\mathrm{~s}), 2866(\mathrm{~s}), 1648(\mathrm{~m}), 1603(\mathrm{~m}), 1490(\mathrm{~s}), 1458$ (m), 1361 (m), 1258 (s), 1159 (m). 
Elemental analysis: calcd (\%) for $\mathrm{C}_{26} \mathrm{H}_{34} \mathrm{O}_{2}$ : C 82.49, H 9.05. Found: C 82.03, H 9.09.

\section{3,3'-Diallyl-5,5'-di-tert-butyl-2,2'-dihydroxybiphenyl (3c)}

Neat 2,2'-di(allyloxy)-5,5'-di-tert-butylbiphenyl (2c, $7.1 \mathrm{~g}, 19 \mathrm{mmol}$ ) was heated to $200^{\circ} \mathrm{C}$ for $24 \mathrm{~h}$. After cooling to room temperature the brown oil was purified by column chromatography (hexane/EtOAc 20/1) to yield the product as a colourless oil (4.5 g, $12 \mathrm{mmol}, 63 \%)$.

${ }^{1} \mathrm{H}$ NMR $\left(500 \mathrm{MHz}, \mathrm{CDCl}_{3}\right): \delta=1.33\left(\mathrm{~s}, 18 \mathrm{H},{ }^{t} \mathrm{Bu}\right), 3.50\left(\mathrm{br} \mathrm{d},{ }^{3} J_{\mathrm{H}, \mathrm{H}}=7.0 \mathrm{~Hz}, 4 \mathrm{H}\right.$, $\left.\mathrm{CH}_{2}\right), 5.13\left(\mathrm{dq},{ }^{3} J_{\mathrm{H}, \mathrm{H}}=10.0 \mathrm{~Hz},{ }^{2} J_{\mathrm{H}, \mathrm{H}}=1.5 \mathrm{~Hz}, 2 \mathrm{H}, \mathrm{CH}=\mathrm{CH}_{\text {cis }} \mathrm{H}\right), 5.19\left(\mathrm{dq},{ }^{3} J_{\mathrm{H}, \mathrm{H}}=\right.$ $\left.17.0 \mathrm{~Hz},{ }^{2} J_{\mathrm{H}, \mathrm{H}}=1.5 \mathrm{~Hz}, 2 \mathrm{H}, \mathrm{CH}=\mathrm{CH} H_{\text {trans }}\right), 5.38(\mathrm{~s}, 2 \mathrm{H}, \mathrm{OH}), 6.09\left(\mathrm{ddt},{ }^{3} J_{\mathrm{H}, \mathrm{H}}=17.0\right.$, 10.0, 6.5 Hz, 2H, $\left.\mathrm{CH}=\mathrm{CH}_{2}\right), 7.16\left(\mathrm{~d},{ }^{3} \mathrm{~J}_{\mathrm{H}, \mathrm{H}}=2.5,2 \mathrm{H}, \mathrm{Ar}-\mathrm{H}\right), 7.26-7.21(\mathrm{~m}, 2 \mathrm{H}, \mathrm{Ar}-\mathrm{H})$.

${ }^{13} \mathrm{C}$ NMR $\left(125 \mathrm{MHz}, \mathrm{CDCl}_{3}\right): \delta=31.6\left({ }^{t} \mathrm{Bu}\right), 34.2\left(\mathrm{CMe}_{3}\right), 35.3\left(\mathrm{CH}_{2}\right), 116.0$ $\left(\mathrm{CH}=\mathrm{CH}_{2}\right), 123.1$ (3,3'-Ar-C), 125.9 (4,4'-Ar-C), 126.6 (1,1'-Ar-C), 127.5 (6,6'-Ar-C), $136.8\left(\mathrm{CH}=\mathrm{CH}_{2}\right), 143.9$ (5,5'-Ar-C), 148.9 (2,2'-Ar-C).

MS $(\mathrm{EI}(+)): m / z(\%)=378(70)[\mathrm{M}]^{+}, 363(100)\left[\mathrm{M}-\mathrm{CH}_{3}\right]^{+}, 307(70)\left[\mathrm{M}-\mathrm{CH}_{3}\right.$ $\left.-\mathrm{C}_{4} \mathrm{H}_{8}\right]^{+}$.

IR (KBr): $\nu\left(\mathrm{cm}^{-1}\right)=3406(\mathrm{~m}), 2962(\mathrm{~s}), 2906(\mathrm{~m}), 2869(\mathrm{~m}), 1726(\mathrm{~m}), 1655(\mathrm{~m}), 1618$ (m), 1480 (s), 1364 (m), 1276 (m), 1228 (m).

Elemental analysis: calcd (\%) for $\mathrm{C}_{26} \mathrm{H}_{34} \mathrm{O}_{2}$ : C 82.49, H 9.05. Found: C 81.38, H 9.00.

\section{3,3'-Bis(3-((2-(benzylthio)phenyl)thio)-1-propyl)-2,2'-bis(benzyloxy)-} biphenyl (19)

To a solution of $o$-benzylthiobenzenethiol $(18,0.71 \mathrm{~g}, 3.1 \mathrm{mmol})$ in THF $(15 \mathrm{ml})$ was dropwise added ${ }^{n} \mathrm{BuLi}(2.0 \mathrm{~mol} / \mathrm{l}$ in hexane, $1.5 \mathrm{ml}, 3.0 \mathrm{mmol})$ at $0^{\circ} \mathrm{C}$. Addition was terminated once the initial yellow colour of the solution after the addition of one drop did not disappear. Stirring was continued for $30 \mathrm{~min}$ at room temperature and subsequently a solution of 3,3'-bis(3-((methylsulfonyl)oxy)-l-propyl)-2,2'-bis(benzyloxy)biphenyl (13, $0.96 \mathrm{~g}, 1.5 \mathrm{mmol})$ in THF (20 ml) was added and stirring was continued for $12 \mathrm{~h}$.

The reaction was quenched by the addition of water and the mixture was acidified with aqueous $\mathrm{HCl}$. Extraction with $\mathrm{CH}_{2} \mathrm{Cl}_{2}$, washing with brine, drying the organic phase over $\mathrm{Na}_{2} \mathrm{SO}_{4}$, filtration and evaporation in vacuo yielded a colourless oil which was used without further purification.

${ }^{1} \mathrm{H} \mathrm{NMR}\left(500 \mathrm{MHz}, \mathrm{CDCl}_{3}\right): \delta=1.97\left(\mathrm{q},{ }^{3} J_{\mathrm{H}, \mathrm{H}}=7.5 \mathrm{~Hz}, 4 \mathrm{H}, \mathrm{CH}_{2}\right), 2.82\left(\mathrm{t},{ }^{3} J_{\mathrm{H}, \mathrm{H}}=\right.$ 
$\left.7.3 \mathrm{~Hz}, 4 \mathrm{H}, \mathrm{CH}_{2}\right), 2.88\left(\mathrm{t},{ }^{3} \mathrm{~J}_{\mathrm{H}, \mathrm{H}}=7.2 \mathrm{~Hz}, 4 \mathrm{H}, \mathrm{CH}_{2}\right), 4.09$ (s, 4H, SCH $\mathrm{Ph}_{2} \mathrm{Ph}, 4.50$ (br s, $\left.4 \mathrm{H}, \mathrm{OCH}_{2} \mathrm{Ph}\right), 7.00-7.30$ (m, 34H, Ar-H).

${ }^{13} \mathrm{C}$ NMR (125 MHz, $\left.\mathrm{CDCl}_{3}\right): \delta=29.6\left(\mathrm{CH}_{2}\right), 29.7\left(\mathrm{CH}_{2}\right), 32.9\left(\mathrm{CH}_{2}\right), 38.2$ $\left(\mathrm{SCH}_{2} \mathrm{Ph}\right), 74.9\left(\mathrm{OCH}_{2} \mathrm{Ph}\right), 123.8$ (Ar-H), 125.9 (Ar-H), 126.8 (Ar-H), 127.1 (Ar-H), 127.7 (Ar-H), 127.9 (Ar-H), 128.2 (Ar-H), 128.4 (Ar-H), 128.4 (Ar-H), 129.0 (Ar-H), 129.7 (Ar-H), 129.8 (Ar-H), 130.2 (Ar-H), 132.8 (Ar-H), 135.0 (Ar-H), 136.2 (Ar-H), 137.0 (Ar-H), 137.3 (Ar-H), 138.0 (Ar-H), 155.0 (Ar-H).

MS $(\mathrm{EI}(+)): m / z(\%)=910(100)[\mathrm{M}]^{+}, 819(100)\left[\mathrm{M}-\mathrm{CH}_{2} \mathrm{Ph}\right]^{+}$.

Elemental analysis: calcd (\%) for $\mathrm{C}_{58} \mathrm{H}_{54} \mathrm{O}_{2} \mathrm{~S}_{4}$ : C 76.44, H 5.97, S 14.07. Found: C 74.23, H 5.99, S 14.31.

\section{3,3'-Bis(3-((2-thiophenyl)thio)-1-propyl)-2,2'-dihydroxybiphenyl (20)}

A solution of 3,3'-Bis(3-((2-(benzylthio)phenyl)thio)-1-propyl)-2,2'-bis(benzyloxy)biphenyl $(19,1.7 \mathrm{~g}, 1.9 \mathrm{mmol})$ in benzene $(20 \mathrm{ml})$ was treated with $\mathrm{AlBr}_{3}(2.7 \mathrm{~g}, 10 \mathrm{mmol})$ and stirred for $1 \mathrm{~h}$. Degassed aqueous $\mathrm{HCl}$ was added and the mixture was extracted with $\mathrm{CH}_{2} \mathrm{Cl}_{2}$. The organic phase was washed with degassed brine, dried over $\mathrm{Na}_{2} \mathrm{SO}_{4}$, filtered and evaporated in vacuo to yield a yellow oil which was washed with pentane to remove residual benzylbromide.

${ }^{1} \mathrm{H} \mathrm{NMR}\left(500 \mathrm{MHz}, \mathrm{CDCl}_{3}\right): \delta=2.00\left(\mathrm{q},{ }^{3} J_{\mathrm{H}, \mathrm{H}}=7.3 \mathrm{~Hz}, 4 \mathrm{H}, \mathrm{CH}_{2}\right), 2.85\left(\mathrm{t},{ }^{3} J_{\mathrm{H}, \mathrm{H}}=\right.$ $\left.7.5 \mathrm{~Hz}, 4 \mathrm{H}, \mathrm{CH}_{2}\right), 2.96\left(\mathrm{t},{ }^{3} \mathrm{~J}_{\mathrm{H}, \mathrm{H}}=7.2 \mathrm{~Hz}, 4 \mathrm{H}, \mathrm{CH}_{2}\right), 4.27$ (s, 2H, SH), 5.25 (br s, $2 \mathrm{H}$, $\mathrm{OH}), 6.92-7.39$ (m, 14H, Ar-H).

${ }^{13} \mathrm{C} \mathrm{NMR}\left(125 \mathrm{MHz}, \mathrm{CDCl}_{3}\right): \delta=28.9\left(\mathrm{CH}_{2}\right), 29.4\left(\mathrm{CH}_{2}\right), 34.1\left(\mathrm{CH}_{2}\right), 121.1(\mathrm{Ar}-\mathrm{C})$, 122.5 (Ar-C), 125.9 (Ar-C), 126.0 (Ar-C), 127.4 (Ar-C), 128.9 (Ar-C), 129.2 (Ar-C), 130.9 (Ar-C), 132.0 (Ar-C), 133.6 (Ar-C), 135.5 (Ar-C), 151.3 (Ar-C).

\section{2,5-Bis( $N$-ethoxymethylimidazol-2-yl)furane (31)}

A solution of $N$-ethoxymethylimidazole $(30,2.4 \mathrm{~g}, 19 \mathrm{mmol})$ in THF $(25 \mathrm{ml})$ was cooled to $-78^{\circ} \mathrm{C}$ and treated with ${ }^{n} \mathrm{BuLi}(3.0 \mathrm{~mol} / 1$ in hexane, $6.9 \mathrm{ml}, 21 \mathrm{ml})$. After stirring for $15 \mathrm{~min}$ a solution of anhydrous $\mathrm{ZnCl}_{2}(2.6 \mathrm{~g}, 19 \mathrm{mmol})$ in THF $(15 \mathrm{ml})$ was added and the reaction mixture warmed to room temperature. Subsequently, $\mathrm{Pd}\left(\mathrm{PPh}_{3}\right)_{4}$ $(0.77 \mathrm{~g}, 0.67 \mathrm{mmol}), 2,5$-dibromofurane $(1.1 \mathrm{~g}, 4.9 \mathrm{mmol})$ and a further portion of $\mathrm{ZnCl}_{2}$ $(5.2 \mathrm{mg}, 38 \mathrm{mmol})$ was added and the reaction mixture was refluxed for $5 \mathrm{~h}$. After cooling to room temperature the mixture was poured into an aqueous solution of EDTA. $2 \mathrm{H}_{2} \mathrm{O}$ 
$(44 \mathrm{~g}, 118 \mathrm{mmol}$ in $500 \mathrm{ml})$ and neutralised with an aqueous $\mathrm{Na}_{2} \mathrm{CO}_{3}$ solution $(10 \%$, ca. $250 \mathrm{ml}$, final $\mathrm{pH} \approx 8)$. After extraction with $\mathrm{CH}_{2} \mathrm{Cl}_{2}(5 \times 100 \mathrm{ml})$, drying over $\mathrm{Na}_{2} \mathrm{SO}_{4}$, filtration and evaporation the product was purified by column chromatography (EtOAc/hexane 4/1). Separation from the mono-substituted by-product by recrystallisation from $\mathrm{CHCl}_{3} /$ hexane yielded a colourless solid $(1.2 \mathrm{~g}, 3.8 \mathrm{mmol}, 78 \%$ ).

$\mathrm{Mp}$ (uncorrected) $112^{\circ} \mathrm{C}$.

${ }^{1} \mathrm{H} \mathrm{NMR}\left(300 \mathrm{MHz}, \mathrm{CDCl}_{3}\right): \delta=1.14\left(\mathrm{t},{ }^{3} J_{\mathrm{H}, \mathrm{H}}=7.0 \mathrm{~Hz}, 6 \mathrm{H}, \mathrm{CH}_{3}\right), 3.50\left(\mathrm{q},{ }^{3} J_{\mathrm{H}, \mathrm{H}}=\right.$ $\left.7.0 \mathrm{~Hz}, 4 \mathrm{H}, \mathrm{CH}_{2}\right), 5.60$ (s, 4H, furane-H), $7.09\left(\mathrm{~d},{ }^{3} J_{\mathrm{H}, \mathrm{H}}=1.3 \mathrm{~Hz}, 2 \mathrm{H}\right.$, furane-H), 7.14 (m, 4H, imidazole-H).

${ }^{13} \mathrm{C}$ NMR $\left(75 \mathrm{MHz}, \mathrm{CDCl}_{3}\right): \delta=14.8\left(\mathrm{CH}_{3}\right), 64.6\left(\mathrm{CH}_{2}\right), 112.6$ (imidazole-C), 121.5 (furane-C), 128.7 (imidazole-C), 138.7 (Ar-C), 145.2 (Ar-C).

MS (EI(+)): $m / z(\%)=316(100)[\mathrm{M}]^{+}$,

IR $(\mathrm{KBr}): \nu\left(\mathrm{cm}^{-1}\right)=3130(\mathrm{~m}), 3109(\mathrm{~m}), 2976(\mathrm{~m}), 2933(\mathrm{w}), 2869(\mathrm{~m}), 1509(\mathrm{~m})$, 1385 (m), 1288 (m), 1257 (m), 1310 (s), 1295 (s).

Elemental analysis: calcd (\%) for $\mathrm{C}_{16} \mathrm{H}_{20} \mathrm{~N}_{4} \mathrm{O}_{3}: \mathrm{C} 60.75, \mathrm{H}$ 6.37, N 17.71. Found: C 58.31, H 5.98, N 16.61.

HRMS $(\mathrm{EI}(+))$ : calcd $(m / z)$ for $\mathrm{C}_{16} \mathrm{H}_{21} \mathrm{~N}_{4} \mathrm{O}_{3}[\mathrm{M}+\mathrm{H}]^{+}:$317.16082. Found: 317.16068.

\section{2,5-Bis(imidazol-2-yl)furane (27g)}

A solution of 2,5-bis $(N$-ethoxymethylimidazol-2-yl)furane $31(1.1 \mathrm{~g}, 3.5 \mathrm{mmol})$ in $\mathrm{EtOH}(30 \mathrm{ml})$ was treated with aqueous $\mathrm{HCl}(37 \%, 40 \mathrm{ml})$ and refluxed for $12 \mathrm{~h}$. After complete evaporation the crude product was dissolved in water $(50 \mathrm{ml})$, neutralised with $\mathrm{NaOH}$ solution $(1 \mathrm{~mol} / \mathrm{l}$, final $\mathrm{pH} \approx 9)$ and extracted with EtOAc $(5 \times 100 \mathrm{ml})$. The organic phases were dried over $\mathrm{Na}_{2} \mathrm{SO}_{4}$, filtered, evaporated and the residue recrystallised from $\mathrm{CHCl}_{3}(20 \mathrm{ml})$ to yield a colourless solid $(0.55 \mathrm{~g}, 2.7 \mathrm{mmol}, 78 \%$ ).

$\mathrm{Mp} 150^{\circ} \mathrm{C}$ (decomposition).

${ }^{1} \mathrm{H}$ NMR $\left(300 \mathrm{MHz}, \mathrm{DMSO}-\mathrm{d}_{6}\right): \delta=6.40$ (br s, 2H, NH), 7.08 (s, 2H, furane-H), 7.26 (s, 4H, imidazole-H).

${ }^{13} \mathrm{C}$ NMR (75 MHz, DMSO-d ${ }_{6}$ ): $\delta=109.7$ (furane-C), 122.8 (imidazole-C), 137.5 (Ar-C), 144.6 (Ar-C).

MS $(\mathrm{EI}(+)): m / z(\%)=200(100)[\mathrm{M}]^{+}$,

IR $(\mathrm{KBr}): \nu\left(\mathrm{cm}^{-1}\right)=3144(\mathrm{w}), 3110(\mathrm{~m}), 3080(\mathrm{~m}), 3004(\mathrm{~m}), 2936(\mathrm{~m}), 2865(\mathrm{~m})$, 2366 (w), 1531 (s), 1458 (m), 1430 (m), 1389 (s). 
HRMS (EI(+)): calcd $(m / z)$ for $\mathrm{C}_{10} \mathrm{H}_{9} \mathrm{~N}_{4} \mathrm{O}[\mathrm{M}+\mathrm{H}]^{+}:$201.07709. Found: 201.07698.

\section{2,6-Bis(5-methylpyrrol-2-yl)pyridine (27d)}

A mixture of 2,6-Bis(4-methyl-1,4-dioxobutyl)pyridine $(28,13.1 \mathrm{~g}, 47.6 \mathrm{mmol})$ and an excess of ammonium acetate $(96.7 \mathrm{~g}, 1.25 \mathrm{~mol})$ was melted and stirred at $125^{\circ} \mathrm{C}$ for $2 \mathrm{~h}$. After cooling to room temperature the reaction mixture was diluted with water to a total volume of 11 . The phases were separated and the aqueous phase was extracted with $\mathrm{CH}_{2} \mathrm{Cl}_{2}(3 \times 150 \mathrm{ml})$. The combined organic phases were dried over $\mathrm{Na}_{2} \mathrm{SO}_{4}$, filtered and the solvents evaporated in vacuo. The residue was purified by column chromatography (EtOAc $\left./ \mathrm{CH}_{2} \mathrm{Cl}_{2} 1 / 10\right)$ to yield the product $27 \mathrm{~d}$ as a yellow solid $(9.26 \mathrm{~g}, 39.0 \mathrm{mmol}$, $82 \%)$.

Mp (uncorrected) $212^{\circ} \mathrm{C}$.

${ }^{1} \mathrm{H}$ NMR $\left(300 \mathrm{MHz}\right.$, DMSO-d $\left.\mathrm{d}_{6}\right): \delta=2.34\left(\mathrm{~s}, 6 \mathrm{H}, \mathrm{CH}_{3}\right), 5.85(\mathrm{~m}, 2 \mathrm{H}$, pyrrole- $\mathrm{H}), 6.61$ $\left(\mathrm{m}, 2 \mathrm{H}\right.$, pyrrole-H), $7.22\left(\mathrm{~d},{ }^{3} \mathrm{~J}_{\mathrm{H}, \mathrm{H}}=7.5 \mathrm{~Hz}, 2 \mathrm{H}\right.$, pyridine- $\left.\mathrm{H}\right), 7.53\left(\mathrm{t},{ }^{3} J_{\mathrm{H}, \mathrm{H}}=7.5 \mathrm{~Hz}\right.$, $1 \mathrm{H}$, pyridine- $\mathrm{H}), 10.03$ (br s, $2 \mathrm{H}, \mathrm{NH}$ ).

${ }^{13} \mathrm{C}$ NMR $\left(75 \mathrm{MHz}\right.$, DMSO-d $\left.{ }_{6}\right): \delta=13.2\left(\mathrm{CH}_{3}\right), 107.7$ (pyrrole-C), 107.9 (pyrroleC), 112.8 (pyridine-C), 129.7 (pyrrole-C), 130.2 (pyrrole-C), 136.9 (pyridine-C), 149.5 (pyridine-C).

MS $(\mathrm{EI}(+)): m / z(\%)=237(100)[\mathrm{M}]^{+}$,

IR (KBr): $\nu\left(\mathrm{cm}^{-1}\right)=3290(\mathrm{~s}), 2912(\mathrm{w}), 1555(\mathrm{~s}), 1498(\mathrm{~s}), 1448(\mathrm{~s}), 1213(\mathrm{~s}), 1160(\mathrm{~s})$.

Elemental analysis: calcd (\%) for $\mathrm{C}_{15} \mathrm{H}_{15} \mathrm{~N}_{3}$ : C 75.92, H 6.37, N 17.71. Found: C 75.27, H 6.26, N 17.58. 


\title{
7.3 Synthesis of $\mathrm{Fe} / \mathrm{S}$ Clusters
}

\author{
Bis(tetraethylammonium) bis[(3,3'-diallylbiphenyl-2,2'-diolato $)(\mu$ - \\ sulfido)ferrate(III)] (11a)
}

3,3'-Diallyl-2,2'-dihydroxybiphenyl (3a, $640 \mathrm{mg}, 2.4 \mathrm{mmol}$ ) was added to a suspension of $\left.\left(\mathrm{NEt}_{4}\right)_{2}\left[\mathrm{Fe}_{2} \mathrm{~S}_{2} \text { (indolate }\right)_{4}\right](10,900 \mathrm{mg}, 1.0 \mathrm{mmol})$ in $\mathrm{MeCN}(50 \mathrm{ml})$ and the reaction mixture was stirred overnight whereupon the purple suspension turned into a deep red solution. After filtration via cannula leaving a small amount of black solid material behind the filtrate was evaporated to dryness and washed with a mixture of $40 \mathrm{ml} \mathrm{Et}_{2} \mathrm{O}$ and $10 \mathrm{ml}$ THF. Filtration yielded the complex 11a as a brown powder reasonably pure by NMR and elemental analysis $(500 \mathrm{mg}, 0.52 \mathrm{mmol}, 52 \%)$. Crystalline material could be obtained by layering a complex solution in $\mathrm{MeCN}(40 \mathrm{ml})$ with $\mathrm{Et}_{2} \mathrm{O}(80 \mathrm{ml})$. After diffusion and precipitation at $-20^{\circ} \mathrm{C}$ the black microcrystalline powder is filtered and washed with additional $\mathrm{Et}_{2} \mathrm{O}$.

Complex 11a could also be obtained via salt metathesis reaction: To a solution of $3 \mathrm{a}(560 \mathrm{mg}, 2.1 \mathrm{mmol})$ in THF $(20 \mathrm{ml})$ was added $\mathrm{KH}(170 \mathrm{mg}, 4.2 \mathrm{mmol})$ in one portion with vigourous stirring. Evolution of hydrogen was observed and after $1 \mathrm{~h}$ the pale yellow solution was treated with $\mathrm{MeCN}(60 \mathrm{ml})$ and with solid $\left(\mathrm{NEt}_{4}\right)_{2}\left[\mathrm{Fe}_{2} \mathrm{~S}_{2} \mathrm{Cl}_{4}\right]$ (9, $580 \mathrm{mg}, 1.0 \mathrm{mmol})$. After stirring for $24 \mathrm{~h}$ the deep red solution was evaporated to dryness, washed with THF $(60 \mathrm{ml})$ and extracted with $\mathrm{MeCN}(40 \mathrm{ml})$ via cannula. The filtrate was condensed to a volume of $30 \mathrm{ml}$ and stored at $-20^{\circ} \mathrm{C}$ overnight to afford dark brown needles which were filtered off, washed with $\mathrm{Et}_{2} \mathrm{O}(10 \mathrm{ml})$ and dried in vacuo yielding the pure target compound $11 \mathrm{a}(130 \mathrm{mg}, 0.13 \mathrm{mmol}, 13 \%)$.

${ }^{1} \mathrm{H}$ NMR $\left(500 \mathrm{MHz}, \mathrm{MeCN}_{-} \mathrm{d}_{3}\right): \delta=1.15$ (br s, 24H, $\mathrm{NEt}_{4}$ ) 2.57 (br s, 4H, Ar-H), 3.05 (br s, 16H, $\mathrm{NEt}_{4}$ ), 5.08 (br s, 4H), 5.16 (br s, 4H), 5.76 (br s, 4H), 6.13 (br s, 4H), 6.71 (br s, 4H), 9.30 (br s, 4H, Ar-H), 9.87 (br s, 4H, Ar-H).

$\mathrm{UV} / \mathrm{vis}(\mathrm{MeCN}): \lambda_{\max } / \mathrm{nm}(\epsilon /(\mathrm{l} /(\mathrm{mol} \cdot \mathrm{cm})))=295$ (48000), $424(14500)$.

MS (ESI(+), MeCN): $m / z(\%)=1094(90)\left[\mathrm{M}+\mathrm{NEt}_{4}\right]^{+}, 965(40)[\mathrm{M}]^{+}, 844(100)$ $\left[\left(\mathrm{NEt}_{4}\right)_{2} \mathrm{~L}_{2} \mathrm{Fe}\right]^{+}$.

MS (ESI(-), MeCN): $m / z(\%)=834.0(100)\left[\mathrm{M}-\mathrm{NEt}_{4}\right]^{-}, 705.0(40)\left[\mathrm{M}-2 \mathrm{NEt}_{4}\right]^{-}$. HRMS (ESI(-), MeCN): calcd $(m / z)$ for $\mathrm{C}_{44} \mathrm{H}_{52} \mathrm{Fe}_{2} \mathrm{NO}_{4} \mathrm{~S}_{2}\left[\mathrm{M}-\mathrm{NEt}_{4}\right]^{-}:$834.2044. Found: 834.2062.

Elemental analysis: calcd (\%) for $\mathrm{C}_{52} \mathrm{H}_{72} \mathrm{Fe}_{2} \mathrm{~N}_{2} \mathrm{O}_{4} \mathrm{~S}_{2}$ : C 64.72, H 7.52, N 2.90. Found: C 64.89, H 7.37, N 2.95. 
Bis(tetraethylammonium) bis[(3-allylbiphenyl-2,2'-diolato)( $\mu$-sulfido)ferrate(III)] (11b)

Pure 3-Allyl-2,2'-dihydroxybiphenyl (3b, $500 \mathrm{mg}, 2.4 \mathrm{mmol}$ ) was added to a suspension of $\left.\left(\mathrm{NEt}_{4}\right)_{2}\left[\mathrm{Fe}_{2} \mathrm{~S}_{2} \text { (indolate) }\right)_{4}\right](10,900 \mathrm{mg}, 1.0 \mathrm{mmol})$ in $\mathrm{MeCN}(50 \mathrm{ml})$ and the reaction mixture was stirred overnight whereupon the purple suspension turned into a deep red solution. After filtration via cannula leaving a small amount of black solid material behind the filtrate was evaporated to dryness and dissolved in THF $(30 \mathrm{ml})$. The target compound which at first was completely dissolved precipitated after some minutes as a voluminous brown solid. After addition of $\mathrm{Et}_{2} \mathrm{O}(60 \mathrm{ml})$ this was filtered, washed with a further amount of $\mathrm{Et}_{2} \mathrm{O}(20 \mathrm{ml})$ and dried in vacuo affording compound $11 \mathrm{~b}$ reasonably pure by NMR and elemental analysis (560 mg, $0.63 \mathrm{mmol}, 63 \%$ ).

Complex $11 \mathrm{~b}$ could also be obtained via salt metathesis reaction: To a solution of $\mathbf{3 b}$ $(450 \mathrm{mg}, 2.0 \mathrm{mmol})$ in THF $(20 \mathrm{ml})$ was added $\mathrm{KH}(170 \mathrm{mg}, 4.2 \mathrm{mmol})$ in one portion with vigourous stirring. Evolution of hydrogen was observed during the first minutes and after $2 \mathrm{~h}$ the pale yellow solution was treated with $\mathrm{MeCN}(60 \mathrm{ml})$ and subsequently with solid $\left(\mathrm{NEt}_{4}\right)_{2}\left[\mathrm{Fe}_{2} \mathrm{~S}_{2} \mathrm{Cl}_{4}\right](9,580 \mathrm{mg}, 1.0 \mathrm{mmol})$. After stirring for $24 \mathrm{~h}$ the deep red solution was evaporated to dryness and extracted with $\mathrm{MeCN}(40 \mathrm{ml})$ via cannula. The filtrate was condensed to a volume of $25 \mathrm{ml}$, and stored at $-20^{\circ} \mathrm{C}$ overnight to afford a dark brown powder which was filtered off, washed with $\mathrm{Et}_{2} \mathrm{O}(20 \mathrm{ml})$ and dried in vacuo yielding the target compound $11 \mathrm{~b}(150 \mathrm{mg}, 0.17 \mathrm{mmol}, 17 \%)$.

${ }^{1} \mathrm{H}$ NMR $\left(500 \mathrm{MHz}, \mathrm{MeCN}-\mathrm{d}_{3}\right): \delta=1.16$ (br s, 24H, NEt $\left.{ }_{4}\right) 2.65$ (br s, 4H, Ar-H), 3.07 (br s, 16H, NEt ${ }_{4}$ ), 5.08 (br s, 2H), 5.16 (br s, 2H), 6.10 (br s, 2H, Ar-H), 5.5-7.5 (br m, 6H), 9.35 (br s, 4H, Ar-H), 9.67 (br s, 2H, Ar-H), 9.87 (br s, 2H, Ar-H).

$\mathrm{UV} / \mathrm{vis}(\mathrm{MeCN}): \lambda_{\max } / \mathrm{nm}(\epsilon /(\mathrm{l} /(\mathrm{mol} \cdot \mathrm{cm})))=283(38000), 424(10700)$.

MS (ESI(+), MeCN): $m / z(\%)=1014(100)\left[\mathrm{M}+\mathrm{NEt}_{4}\right]^{+}, 764(50)\left[\left(\mathrm{NEt}_{4}\right)_{2} \mathrm{~L}_{2} \mathrm{Fe}\right]^{+}$.

MS (ESI $(-), \mathrm{MeCN}): m / z(\%)=754(10)\left[\mathrm{M}-\mathrm{NEt}_{4}\right]^{-}, 624$ (100) $\left[\mathrm{M}-2 \mathrm{NEt}_{4}\right]^{-}$.

HRMS (ESI(-), MeCN): calcd (m/z) for $\mathrm{C}_{38} \mathrm{H}_{44} \mathrm{Fe}_{2} \mathrm{NO}_{4} \mathrm{~S}_{2}\left[\mathrm{M}-\mathrm{NEt}_{4}\right]^{-}: 754.1417$. Found: 754.1435.

Elemental analysis: calcd (\%) for $\mathrm{C}_{46} \mathrm{H}_{64} \mathrm{Fe}_{2} \mathrm{~N}_{2} \mathrm{O}_{4} \mathrm{~S}_{2}$ : C 62.44, H 7.29, N 3.17, S 7.23. Found: C 60.88, H 6.89, N 2.74, S 5.95. 
Bis(tetraethylammonium) bis[(3,3'-diallyl-5,5'-di-tert-butylbiphenyl-2,2'diolato)( $(\mu$-sulfido)ferrate(III)] (11c)

A solution of 3,3'-Diallyl-5,5'-di-tert-butyl-2,2'-dihydroxybiphenyl (3c, $600 \mathrm{mg}$, $1.6 \mathrm{mmol})$ in $\mathrm{MeCN}(10 \mathrm{ml})$ was added to a suspension of $\left.\left(\mathrm{NEt}_{4}\right)_{2}\left[\mathrm{Fe}_{2} \mathrm{~S}_{2} \text { (indolate) }\right)_{4}\right]$ $(10,650 \mathrm{mg}, 0.72 \mathrm{mmol})$ in $\mathrm{MeCN}(40 \mathrm{ml})$. Within $2 \mathrm{~h}$ the purple suspension turned into a dark red solution which was stirred overnight and subsequently evaporated to dryness. The residue was suspended in $\mathrm{Et}_{2} \mathrm{O}$ and vigourously stirred for $1 \mathrm{~h}$. After filtration and rinsing with $\mathrm{Et}_{2} \mathrm{O}(3 \times 20 \mathrm{ml})$ the target complex $11 \mathrm{c}$ was obtained as a brown powder (525 mg, $0.44 \mathrm{mmol}, 61 \%$ ). Recrystallisation from either $\mathrm{MeCN} / \mathrm{Et}_{2} \mathrm{O}$, $\mathrm{MeCN} / \mathrm{Et}_{2} \mathrm{O} /$ pentane, $\mathrm{THF} / \mathrm{Et}_{2} \mathrm{O}$ or $\mathrm{THF} /$ pentane afforded only little amounts of crystalline material while most of the compound precipitated as a powder with no increase in purity.

Complex 11c could also be obtained via salt metathesis reaction: To a solution of $3 \mathrm{c}$ $(780 \mathrm{mg}, 2.0 \mathrm{mmol})$ in THF $(20 \mathrm{ml})$ was added $\mathrm{KH}(170 \mathrm{mg}, 4.2 \mathrm{mmol})$ in one portion with vigourous stirring. Evolution of hydrogen was observed during the first minutes and after $1 \mathrm{~h}$ the yellow suspension was treated with $\mathrm{MeCN}(60 \mathrm{ml})$ and subsequently with solid $\left(\mathrm{NEt}_{4}\right)_{2}\left[\mathrm{Fe}_{2} \mathrm{~S}_{2} \mathrm{Cl}_{4}\right](9,580 \mathrm{mg}, 1.0 \mathrm{mmol})$. After stirring for $24 \mathrm{~h}$ the deep red solution was evaporated to dryness. Crystallisation attempts as above afforded only small amounts of the product (ca. $150 \mathrm{mg}, 0.13 \mathrm{mmol}, 13 \%$ ) due to the high solubility in both MeCN and THF.

${ }^{1} \mathrm{H}$ NMR $\left(500 \mathrm{MHz}, \mathrm{MeCN}-\mathrm{d}_{3}\right): \delta=1.17$ (br s, 24H, $\left.\mathrm{NEt}_{4}\right) 1.50$ (br s, $\left.36 \mathrm{H},{ }^{t} \mathrm{Bu}\right) 3.09$ (br s, 16H, NEt ${ }_{4}$ ), 5.08 (br s, 4H), 5.18 (br s, 4H), 4.5-7.5 (br m, 12H), 9.38 (br s, 4H, Ar-H), 10.11 (br s, 4H, Ar-H).

$\mathrm{UV} / \mathrm{vis}(\mathrm{MeCN}): \lambda_{\max } / \mathrm{nm}(\epsilon /(\mathrm{l} /(\mathrm{mol} \cdot \mathrm{cm})))=290$ (43000), 443 (13000).

MS (ESI(+), MeCN): $m / z(\%)=1319(100)\left[\mathrm{M}+\mathrm{NEt}_{4}\right]^{+}$.

MS (ESI(-), MeCN): $m / z(\%)=1058(10)\left[\mathrm{M}-\mathrm{NEt}_{4}\right]^{-}, 465(100)\left[\mathrm{M}-2 \mathrm{NEt}_{4}\right]^{2-}$.

HRMS (ESI(-), MeCN): calcd $(m / z)$ for $\mathrm{C}_{60} \mathrm{H}_{84} \mathrm{Fe}_{2} \mathrm{NO}_{4} \mathrm{~S}_{2}\left[\mathrm{M}-\mathrm{NEt}_{4}\right]^{-}: 1058.4549$. Found: 1058.4579.

Elemental analysis: calcd (\%) for $\mathrm{C}_{68} \mathrm{H}_{104} \mathrm{Fe}_{2} \mathrm{~N}_{2} \mathrm{O}_{4} \mathrm{~S}_{2}: \mathrm{C}$ 68.67, H 8.81, N 2.36, S 5.39. Found: C 65.87, H 8.08, N 4.03, S 5.45. 
Bis(tetraethylammonium) bis[(3,3'-diallylbiphenyl-2,2'-dithiolato $)(\mu$ sulfido)ferrate(III)] (12a)

A solution of 3,3'-diallyl-2,2'-dithiobiphenyl (6a, $370 \mathrm{mg}, 1.2 \mathrm{mmol})$ in THF (15 ml) was added to a suspension of $\left.\left(\mathrm{NEt}_{4}\right)_{2}\left[\mathrm{Fe}_{2} \mathrm{~S}_{2} \text { (indolate) }\right)_{4}\right](10,450 \mathrm{mg}, 0.50 \mathrm{mmol})$ in $\mathrm{MeCN}(60 \mathrm{ml})$. Within $4 \mathrm{~h}$ the purple suspension turned into a dark red solution which was then evaporated to dryness. The residue was dissolved in $\mathrm{MeCN}(15 \mathrm{ml})$ and layered with $\mathrm{Et}_{2} \mathrm{O}(30 \mathrm{ml})$. After initial crystallisation at room temperature precipitation was completed at $-20^{\circ} \mathrm{C}$. After filtration and rinsing with $\mathrm{Et}_{2} \mathrm{O}(20 \mathrm{ml})$ the target complex $12 \mathrm{a}$ was obtained as black needles ( $280 \mathrm{mg}, 0.27 \mathrm{mmol}, 54 \%)$.

Complex 12a could also be obtained via salt metathesis reaction: To a solution of $\mathbf{6 a}$ $(630 \mathrm{mg}, 2.1 \mathrm{mmol})$ in THF $(20 \mathrm{ml})$ was added KH $(170 \mathrm{mg}, 4.2 \mathrm{mmol})$ in one portion with vigourous stirring. Evolution of hydrogen was observed during the first minutes and after $2 \mathrm{~h}$ the yellow solution was treated with $\mathrm{MeCN}(60 \mathrm{ml})$ and subsequently with solid $\left(\mathrm{NEt}_{4}\right)_{2}\left[\mathrm{Fe}_{2} \mathrm{~S}_{2} \mathrm{Cl}_{4}\right](9,580 \mathrm{mg}, 1.0 \mathrm{mmol})$. After stirring for $24 \mathrm{~h}$ the deep red solution was evaporated to dryness and extracted with THF $(40 \mathrm{ml})$ via cannula. The filtrate was condensed to dryness and recrystallised from $\mathrm{MeCN}_{2} \mathrm{Et}_{2} \mathrm{O}(40 \mathrm{ml} / 80 \mathrm{ml})$. The precipitate was filtered, washed with $\mathrm{Et}_{2} \mathrm{O}(20 \mathrm{ml})$ and dried in vacuo yielding the pure target compound 12a.

${ }^{1} \mathrm{H}$ NMR $\left(500 \mathrm{MHz}, \mathrm{MeCN}_{-} \mathrm{d}_{3}\right): \delta=1.18$ (br s, 24H, NEt $\left.{ }_{4}\right) 2.82$ (br s, 4H, Ar-H), 3.11 (br s, 16H, $\mathrm{NEt}_{4}$ ), 5.11 (s, 4H), 5.31 (s, 4H), 6.47 (br m, 12H), 8.97 (br s, 4H, Ar-H), 9.44 (br s, 4H, Ar-H).

$\mathrm{UV} / \mathrm{vis}(\mathrm{MeCN}): \lambda_{\max } / \mathrm{nm}(\epsilon /(\mathrm{l} /(\mathrm{mol} \cdot \mathrm{cm})))=341$ (25000), 379 (21000), 429 (25000), 544 (sh, 12000).

$$
\begin{aligned}
& \text { MS (ESI(+), MeCN): } m / z(\%)=1159(100)\left[\mathrm{M}+\mathrm{NEt}_{4}\right]^{+} . \\
& \text {MS (ESI(-), MeCN): } m / z(\%)=898.0(10)\left[\mathrm{M}-\mathrm{NEt}_{4}\right]^{-}, 384(100)\left[\mathrm{M}-2 \mathrm{NEt}_{4}\right]^{2-} \text {. } \\
& \text { HRMS (ESI(-), MeCN): calcd }(m / z) \text { for } \mathrm{C}_{44} \mathrm{H}_{52} \mathrm{Fe}_{2} \mathrm{NOS}_{6}\left[\mathrm{M}-\mathrm{NEt}_{4}\right]^{-}: 898.1130 .
\end{aligned}
$$

Found: 834.1145.

Elemental analysis: calcd (\%) for $\mathrm{C}_{52} \mathrm{H}_{72} \mathrm{Fe}_{2} \mathrm{~N}_{2} \mathrm{~S}_{6}$ : C 60.68, H 7.05, N 2.72, S 18.69. Found: C 60.44, H 6.78, N 2.65, S 18.20. 
Bis(tetraethylammonium) bis[(3-allylbiphenyl-2,2'-dithiolato)( $\mu$-sulfido)ferrate(III)] (12b)

3-Allyl-2,2'-dithiobiphenyl (6b, $1.1 \mathrm{~g}, 4.3 \mathrm{mmol})$ in THF $(20 \mathrm{ml})$ was added to a suspension of $\left.\left(\mathrm{NEt}_{4}\right)_{2}\left[\mathrm{Fe}_{2} \mathrm{~S}_{2} \text { (indolate) }\right)_{4}\right](10,1.6 \mathrm{~g}, 1.8 \mathrm{mmol})$ in $\mathrm{MeCN}(60 \mathrm{ml})$ and the reaction mixture was stirred for $4 \mathrm{~h}$ whereupon the purple suspension turned into a deep red solution. After filtration via cannula leaving a small amount of black solid material behind the filtrate was evaporated to dryness and dissolved in $\mathrm{MeCN}(60 \mathrm{ml})$, filtered and layered with $\mathrm{Et}_{2} \mathrm{O}(200 \mathrm{ml}$ in portions). After initial diffusion at room temperature the mixture was stored at $-20^{\circ} \mathrm{C}$, filtered and the brown residue washed with $\mathrm{Et}_{2} \mathrm{O}(3$ $\times 20 \mathrm{ml})$ to yield the target complex $12 \mathrm{~b}$ pure by ${ }^{1} \mathrm{H}$ NMR $(1.2 \mathrm{~g}, 1.3 \mathrm{mmol}, 72 \%)$.

${ }^{1} \mathrm{H}$ NMR (500 MHz, MeCN-d ${ }_{3}$ ): $\delta=1.18$ (br s, 24H, NEt ${ }_{4}$ ) 2.85 (br m, 4H, Ar-H), 3.09 (br s, 16H, $\mathrm{NEt}_{4}$ ), 5.08 (br m, 2H), 5.26 (br m, 2H), 6.47 (br m, 2H, Ar-H), 5.5-7.5 (br m, 6H), 8.84 (br s, 2H, Ar-H), 9.00 (br m, 4H, Ar-H), 9.45 (br m, 2H, Ar-H).

$\mathrm{UV} / \mathrm{vis}(\mathrm{MeCN}): \lambda_{\max } / \mathrm{nm}(\epsilon /(\mathrm{l} /(\mathrm{mol} \cdot \mathrm{cm})))=338$ (23000), 373 (sh, 17500), 427 (20000), 521 (9000).

MS (ESI(+), MeCN): $m / z(\%)=1078(100)\left[\mathrm{M}+\mathrm{NEt}_{4}\right]^{+}$.

MS (ESI (-), MeCN): $m / z(\%)=818(10)\left[\mathrm{M}-\mathrm{NEt}_{4}\right]^{-}, 345(100)\left[\mathrm{M}-2 \mathrm{NEt}_{4}\right]^{2-}$.

HRMS (ESI(-), MeCN): calcd $(m / z)$ for $\mathrm{C}_{38} \mathrm{H}_{44} \mathrm{Fe}_{2} \mathrm{NS}_{6}\left[\mathrm{M}-\mathrm{NEt}_{4}\right]^{-}: 818.0504$. Found: 818.0508.

Elemental analysis: calcd (\%) for $\mathrm{C}_{46} \mathrm{H}_{64} \mathrm{Fe}_{2} \mathrm{~N}_{2} \mathrm{~S}_{6}$ : C 58.21, H 6.80, N 2.95, S 20.27. Found: C 55.85, H 6.73, N 3.06, S 19.57.

Bis(tetraethylammonium) bis[(3,3'-bis(3-(methylthio)-1-propyl)biphenyl-2,2'-diolato)( $(\mu$-sulfido)ferrate(III)] (16)

3,3'-Bis(3-(methylthio)-1-propyl)-2,2'-bishydroxybiphenyl (15, $0.72 \mathrm{~g}, 2.0 \mathrm{mmol}$ ) was dissolved in THF $(20 \mathrm{ml})$ and treated with $\mathrm{KH}(170 \mathrm{mg}, 4.0 \mathrm{mmol})$ in one portion. After $1 \mathrm{~h}$, the colourless suspension was treated with $\mathrm{MeCN}(60 \mathrm{ml})$ and $\left(\mathrm{NEt}_{4}\right)_{2}\left[\mathrm{Fe}_{2} \mathrm{~S}_{2} \mathrm{Cl}_{4}\right]$ $(9,580 \mathrm{mg}, 1.0 \mathrm{mmol})$ and stirred for $24 \mathrm{~h}$. After complete evaporation, the residue was extracted with THF $(40 \mathrm{ml})$ and layered with $\mathrm{Et}_{2} \mathrm{O}$, yielding a small amount of complex 16 as a brown powder.

${ }^{1} \mathrm{H}$ NMR (500 MHz, MeCN-d ${ }_{3}$ ): $\delta=1.20$ (br s, 24H, NEt N $_{4}, 2.56$ (br s, 12H) 3.10 (br s, 16H, $\mathrm{NEt}_{4}$ ), 4.64 (br s, 4H), 5.82 (br s, 4H), 9.28 (br s, 4H, Ar-H), 9.92 (br s, 4H, Ar-H). 
Bis(tetraethylammonium) [(3,3'-bis(3-((phenyl-2-thiolato)thio)-1-

propyl)biphenyl-2,2'-diolato)bis(( $\mu$-sulfido)ferrate(III))] (21)

Synthesis of the $K^{+}$Salt of 20

Ligand $20(1.2 \mathrm{~g}, 2.2 \mathrm{mmol})$ was dissolved in THF $(20 \mathrm{ml})$ and treated with $\mathrm{KH}(0.35 \mathrm{~g}$, $8.7 \mathrm{mmol}$ ). After $2 \mathrm{~h}$ the reaction mixture was filtered to remove remaining $\mathrm{KH}$ and the filtrate was epaporated to dryness. The residue was taken up in $\mathrm{Et}_{2} \mathrm{O}(60 \mathrm{ml})$, stirred for several hours, filtered and washed repeatedly with $\mathrm{Et}_{2} \mathrm{O}$ to obtain the tetrapotassium salt of $20(0.87 \mathrm{~g}, 1.2 \mathrm{mmol}, 56 \%)$.

${ }^{1} \mathrm{H}$ NMR $\left(200 \mathrm{MHz}\right.$, DMSO-d $\left.\mathrm{d}_{6}\right): \delta=1.88\left(\mathrm{q},{ }^{3} \mathrm{~J}_{\mathrm{H}, \mathrm{H}}=7.0,4 \mathrm{H}, \mathrm{CH}_{2}\right), 2.66(\mathrm{~m}, 8 \mathrm{H}$, $\left.\mathrm{CH}_{2}\right)$, 6.35-7.46 (m, 14H, Ar-H).

Synthesis of the Li+ Salt of 20

Ligand $20(0.66 \mathrm{~g}, 1.2 \mathrm{mmol})$ was dissolved in THF $(20 \mathrm{ml})$ and treated dropwise with ${ }^{n} \mathrm{BuLi}(1.6 \mathrm{~mol} / \mathrm{l}$ in hexane, $3.0 \mathrm{ml}, 4.8 \mathrm{mmol})$. The resulting solution was evaporated to dryness and the resulting solid was taken up in $\mathrm{Et}_{2} \mathrm{O}(40 \mathrm{ml})$, stirred for several hours, filtered and washed repeatedly with $\mathrm{Et}_{2} \mathrm{O}$ to obtain the tetralithium salt of $20(0.87 \mathrm{~g}$, $1.2 \mathrm{mmol}, 56 \%)$.

${ }^{1} \mathrm{H}$ NMR $\left(200 \mathrm{MHz}\right.$, DMSO-d $\left.\mathrm{d}_{6}\right): \delta=1.85\left(\mathrm{~m}, 4 \mathrm{H}, \mathrm{CH}_{2}\right), 2.63\left(\mathrm{~m}, 8 \mathrm{H}, \mathrm{CH}_{2}\right), 6.35-$ $7.46(\mathrm{~m}, 14 \mathrm{H}, \mathrm{Ar}-\mathrm{H})$.

\section{Attempted Synthesis of Complex 21.}

A solution of the lithium or potassium salt of $20(290 \mathrm{mg}$ or $310 \mathrm{mg}, 0.50 \mathrm{mmol})$ and $\left(\mathrm{NEt}_{4}\right)_{2}\left[\mathrm{Fe}_{2} \mathrm{~S}_{2} \mathrm{Cl}_{4}\right](9,290 \mathrm{mg}, 0.50 \mathrm{mmol})$ in THF $/ \mathrm{MeCN}(30 \mathrm{ml} / 30 \mathrm{ml})$ was stirred for $12 \mathrm{~h}$ and evaporated to dryness. In ${ }^{1} \mathrm{H}$ NMR spectra of the residue and of THF and $\mathrm{MeCN}$ extracts, no signals typical for [2Fe-2S] clusters (9 to $10 \mathrm{ppm}$ ) were found.

Bis(tetraethylammonium) bis[di(2-methylindolato)( $\mu$-sulfido)ferrate(III)] (24)

A solution of 2-methylindole $(520 \mathrm{mg}, 4.0 \mathrm{mmol})$ in THF $(20 \mathrm{ml})$ was treated with ${ }^{n} \operatorname{BuLi}(1.6 \mathrm{~mol} / \mathrm{l}$ in hexane, $2.5 \mathrm{ml}, 4.0 \mathrm{mmol})$. After $1 \mathrm{~h}\left(\mathrm{NEt}_{4}\right)_{2}\left[\mathrm{Fe}_{2} \mathrm{~S}_{2} \mathrm{Cl}_{4}\right](9,580 \mathrm{mg}$, $1.0 \mathrm{mmol}$ ) was added followed by a small amount of $\mathrm{MeCN}(10 \mathrm{ml})$ to enable partial dissolving of 9. After $1 \mathrm{~h}$, a brown solid was filtered off and washed with $\mathrm{Et}_{2} \mathrm{O}(20 \mathrm{ml})$. 
The precipitate was then extracted with $\mathrm{CH}_{2} \mathrm{Cl}_{2}(300 \mathrm{ml})$ under vigorous stirring. After filtration the filtrate was layered with $\mathrm{Et}_{2} \mathrm{O}(300 \mathrm{ml})$ in portions over several days to allow slow diffusion. After diffusion was complete pentane $(150 \mathrm{ml})$ was added to ensure complete product precipitation. The resulting black microcrystalline solid was filtered off, washed with $\mathrm{Et}_{2} \mathrm{O}$ and dried in vacuo to yield the target compound 24 in moderate yield (160 mg, $0.17 \mathrm{mmol}, 17 \%$ ) and purity.

${ }^{1} \mathrm{H}$ NMR (500 MHz, MeCN-d ${ }_{3}$ ): $\delta=0.99$ (br s, 24H, NEt $), 1.75$ (br s, $12 \mathrm{H}, \mathrm{Me}$ ), 2.80 (br s, 16H, NEt $_{4}$, 4.70 (br s, 4H, Ar-H), 4.80 (br s, 4H, Ar-H), 6.66 (br s, 4H, Ar-H), 7.10 (br s, 4H, Ar-H), 10.06 (br s, 4H, Ar-H).

$\mathrm{UV} / \mathrm{vis}(\mathrm{MeCN}): \lambda_{\max } / \mathrm{nm}(\epsilon /(\mathrm{l} /(\mathrm{mol} \cdot \mathrm{cm})))=288$ (23000), 457 (6700), 540 (7100).

MS (ESI(+), MeCN): $m / z(\%)=1087(100)\left[\mathrm{M}+\mathrm{NEt}_{4}\right]^{+}$.

MS (ESI(-), MeCN): $m / z(\%)=826(10)\left[\mathrm{M}-\mathrm{NEt}_{4}\right]^{-}, 436(100)\left[\mathrm{M}-2 \mathrm{NEt}_{4}-2\right.$ methylindolate $]^{-}$.

HRMS (ESI(-), MeCN): calcd $(m / z)$ for $\mathrm{C}_{44} \mathrm{H}_{52} \mathrm{Fe}_{2} \mathrm{~N}_{5} \mathrm{~S}_{2}\left[\mathrm{M}-\mathrm{NEt}_{4}\right]^{-}:$826.2370. Found: 826.2374.

Bis(tetraethylammonium) tetrakis $\left[(2\right.$-methylindolato $)\left(\mu_{3}\right.$-sulfido)ferrate(II,III)] (25)

A solution of 2-methylindole $(240 \mathrm{mg}, 1.8 \mathrm{mmol})$ in THF $(10 \mathrm{ml})$ was treated with ${ }^{n} \mathrm{BuLi}(1.6 \mathrm{~mol} / \mathrm{l}$ in hexane, $1.15 \mathrm{ml}, 1.8 \mathrm{mmol})$. After $1 \mathrm{~h}$ a brown solution of $\left(\mathrm{NEt}_{4}\right)_{2}\left[\mathrm{Fe}_{4} \mathrm{~S}_{4} \mathrm{Cl}_{4}\right](\mathbf{2 6}, 350 \mathrm{mg}, 0.46 \mathrm{mmol})$ in $\mathrm{MeCN}(60 \mathrm{ml})$ was added. The reaction mixture turned red and after $3 \mathrm{~h}$ a black precipitate was filtered off, washed with THF $(20 \mathrm{ml})$ and $\mathrm{Et}_{2} \mathrm{O}(20 \mathrm{ml})$ and dried in vacuo.

${ }^{1} \mathrm{H}$ NMR (500 MHz, DMF-d f $_{7}: \delta=1.39$ (br s, 24H, NEt ${ }_{4}$ ), 2.22 (br s, 12H, Me), 3.40 (br s, 16H, NEt 4 ), 5.61 (br s, 4H, Ar-H), 6.05 (br s, 4H, Ar-H), 6.96 (br s, 4H, Ar-H), 8.1 (br s, 4H, Ar-H). Rapid decomposition in solution; one proton could not be assigned.

$\mathrm{UV} / \mathrm{vis}(\mathrm{DMF}): \lambda_{\max } / \mathrm{nm}(\epsilon /(\mathrm{l} /(\mathrm{mol} \cdot \mathrm{cm})))=277$ (41000), 287 (sh, 36000), 414 (6300). MS (ESI(+), MeCN + DMF): $m / z(\%)=1262(100)\left[\mathrm{M}+\mathrm{NEt}_{4}\right]^{+}$.

MS (ESI(-), MeCN + DMF): $m / z(\%)=1002$ (5) $\left[\mathrm{M}-\mathrm{NEt}_{4}\right]^{-}, 742(15)[\mathrm{M}-2$

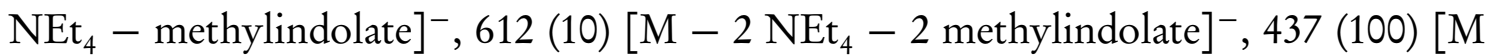
$\left.-2 \mathrm{NEt}_{4}\right]^{2-}$.

Elemental analysis: calcd (\%) for $\mathrm{C}_{52} \mathrm{H}_{72} \mathrm{Fe}_{4} \mathrm{~N}_{6} \mathrm{~S}_{4}$ : C 55.13, H 6.41, N 7.42, S 11.32. Found: C 51.90, H 6.32, N 6.96, S 11.23. 
Tetraethylammonium bis(2,6-bis(5-methyl-2-pyrrolato)pyridine)ferrate(III) (32d)

A solution of 2,6-Bis(5-methylpyrrol-2-yl)pyridine $(27 \mathrm{~d}, 475 \mathrm{mg}, 2.0 \mathrm{mmol})$ in THF $(20 \mathrm{ml})$ was treated with $\mathrm{KH}(170 \mathrm{mg}, 4.0 \mathrm{mmol})$ in one portion. After $1 \mathrm{~h}, \mathrm{MeCN}$ $(60 \mathrm{ml})$ was added to the suspension that displayed intensive yellow fluoresence and subsequently $\left(\mathrm{NEt}_{4}\right)_{2}\left[\mathrm{Fe}_{2} \mathrm{~S}_{2} \mathrm{Cl}_{4}\right](9,580 \mathrm{mg}, 1.0 \mathrm{mmol})$ in one portion. After stirring for $24 \mathrm{~h}$, the reaction mixture was evaporated to dryness and extracted with $\mathrm{MeCN}(40 \mathrm{ml})$ via cannula. The filtrate was layered with THF (ca. $80 \mathrm{ml}$ ) and after complete diffusion at $-20^{\circ} \mathrm{C}$, benzene $(40 \mathrm{ml})$ was added. After storing at $-20^{\circ} \mathrm{C}$ overnight, dark needles of the mononuclear complex 32d were filtered off and washed with $\mathrm{Et}_{2} \mathrm{O}$.

\section{Bis(tetraethylammonium) bis[(2,6-di(2-imidazolato)pyridine)( $\mu$-sulfido)- ferrate(III)] (33)}

2,6-Bis(imidazol-2-yl)pyridine ( $27 \mathrm{c}, 425 \mathrm{mg}, 2.0 \mathrm{mmol}$ ) was dissolved in THF ( $40 \mathrm{ml}$; stirring for $10 \mathrm{~min}$ was required for complete dissolution) and subsequently treated with $\mathrm{KH}(170 \mathrm{mg}, 4.0 \mathrm{mmol})$ in one portion. After $2 \mathrm{~h}$ the white suspension was diluted with $\mathrm{MeCN}(60 \mathrm{ml})$ and treated with $\left(\mathrm{NEt}_{4}\right)_{2}\left[\mathrm{Fe}_{2} \mathrm{~S}_{2} \mathrm{Cl}_{4}\right](9,580 \mathrm{mg}, 1.0 \mathrm{mmol})$. The colourless solid dissolved within $2 \mathrm{~h}$ while the brown product was formed which precipitated from the solution within $3 \mathrm{~h}$. It was filtered, washed with THF $(2 \times 20 \mathrm{ml})$ and dried in vacuo to yield the target compound $33(650 \mathrm{mg}, 0.76 \mathrm{mmol}, 76 \%)$ pure by NMR and Mössbauer spectroscopy although elemental analysis showed some inorganic impurity (most probably $\mathrm{KCl}$ ). Recrystallisation from $\mathrm{DMF} / \mathrm{Et}_{2} \mathrm{O}$ yielded some crystalline material suitable for X-ray diffraction but did not improve purity of the complex due to decomposition.

${ }^{1} \mathrm{H}$ NMR $\left(500 \mathrm{MHz}, \mathrm{MeCN}-\mathrm{d}_{3}\right): \delta=1.17$ (br s, 24H, NEt $\left.{ }_{4}\right) 3.09$ (br s, $16 \mathrm{H}, \mathrm{NEt}_{4}$ ) 6.90 (br s, 2H, Ar-H) 9.00 (br s, 4H, Ar-H) 12.83 (br s, 4H, Ar-H) 13.71 (br s, 4H, Ar-H).

$\mathrm{UV} / \mathrm{vis}(\mathrm{DMSO}): \lambda_{\max } / \mathrm{nm}(\epsilon /(1 /(\mathrm{mol} \cdot \mathrm{cm})))=310(34000), 489(3000)$.

MS (ESI $(+), \mathrm{MeCN}): m / z(\%)=1235(50)\left[\mathrm{M}+3 \mathrm{NEt}_{4}\right]^{+}, 1105(100)\left[\mathrm{M}+2 \mathrm{NEt}_{4}\right]^{+}$, $985(20)\left[\mathrm{M}+\mathrm{NEt}_{4}\right]^{+}$.

MS (ESI $(-), \mathrm{MeCN}): m / z(\%)=724(10)\left[\mathrm{M}-\mathrm{NEt}_{4}\right]^{-}, 595(20)\left[\mathrm{M}-\mathrm{NEt}_{4}+\mathrm{H}\right]^{-}$, $474(100)\left[\mathrm{L}_{2} \mathrm{Fe}\right]^{+}$.

HRMS (ESI(-), MeCN): calcd (m/z) for $\mathrm{C}_{30} \mathrm{H}_{34} \mathrm{Fe}_{2} \mathrm{~N}_{11} \mathrm{~S}_{2}\left[\mathrm{M}-\mathrm{NEt}_{4}\right]^{-}: 724.1145$. Found: 724.1147. 
Dilithium bis[(2,6-di(3-pyrazolato)pyridine)( $\mu$-sulfido)ferrate(III)] (34)

In a typical experiment, ligand $27 \mathrm{a}(210 \mathrm{mg}, 1.0 \mathrm{mmol})$ was dissolved in DMF $(10 \mathrm{ml})$, cooled to $-40^{\circ} \mathrm{C}$ and added to a pre-cooled solution of $\left(\mathrm{NEt}_{4}\right)_{2}\left[\mathrm{Fe}_{2} \mathrm{~S}_{2} \mathrm{Cl}_{4}\right](9,290 \mathrm{mg}$, $0.5 \mathrm{mmol})$ in $\mathrm{DMF}(10 \mathrm{ml})$. Immediately, ${ }^{n} \mathrm{BuLi}(3.0 \mathrm{~mol} / 1$ in hexane, $0.66 \mathrm{ml}, 2.0 \mathrm{mmol})$ was added dropwise. Diffusion of $\mathrm{Et}_{2} \mathrm{O}$ into an aliquot of the reaction mixture yielded some single crystals of complex 34 .

Bis(tetraethylammonium) tris(2,6-bis(thiolatomethyl))( $\mu_{3}$-sulfido)triferrate(II) (35)

In a typical experiment, ligand $27 \mathrm{e}(340 \mathrm{mg}, 2.0 \mathrm{mmol})$ was dissolved in THF $(20 \mathrm{ml})$ and treated with $\mathrm{KH}(170 \mathrm{mg}, 4.0 \mathrm{mmol})$ in one portion. After stirring for $1 \mathrm{~h}$, the reaction mixture was cooled to $-20^{\circ} \mathrm{C}$ and treated with a pre-cooled solution of $\left(\mathrm{NEt}_{4}\right)_{2}\left[\mathrm{Fe}_{2} \mathrm{~S}_{2} \mathrm{Cl}_{4}\right](9,580 \mathrm{mg}, 1.0 \mathrm{mmol})$ in $\mathrm{MeCN}(60 \mathrm{ml})$. Diffusion of $\mathrm{Et}_{2} \mathrm{O}$ in an aliquot of the reaction mixture yielded some single crystals of complex 35 . 


\subsection{Synthesis of Non-Iron Complexes}

(3,3'-Diallylbiphenyl-2,2'-dithio)(4,4'-di-tert-butylbipyridine)zinc (7)

To a solution of 4,4'-di-tert-butylbipyridine $(0.50 \mathrm{~g}, 1.85 \mathrm{mmol})$ in toluene $(10 \mathrm{ml})$ was slowly added dimethylzinc $(2.0 \mathrm{~mol} / 1$ in toluene, $0.93 \mathrm{ml}, 1.85 \mathrm{mmol})$ at $-78^{\circ} \mathrm{C}$ yielding a yellow suspension. After $10 \mathrm{~min}$, a solution of 3,3'-diallyl-2,2'-dithiobiphenyl (6a, $0.55 \mathrm{~g}, 1.85 \mathrm{mmol})$ in toluene $(5 \mathrm{ml})$ was added. Warming to room temperature yielded a yellow solution which was evaporated to dryness. The residue was dissolved in a minimal amount of $\mathrm{CCl}_{4}$ and layered with pentane $(10 \mathrm{ml})$. The resulting yellow powder was filtered off, washed with pentane $(2 \times 10 \mathrm{ml})$, and dried in vacuo overnight to afford the product $(0.50 \mathrm{~g}, 0.79 \mathrm{mmol}, 43 \%)$. Despite repeated recrystallisation, no satisfying elemental analysis could be obtained although the composition is confirmed by HRMS.

$\mathrm{Mp}$ (uncorrected) $125^{\circ} \mathrm{C}$.

${ }^{1} \mathrm{H}$ NMR $\left(500 \mathrm{MHz}, \mathrm{CD}_{2} \mathrm{Cl}_{2}\right): \delta=1.44\left(\mathrm{~s}, 18 \mathrm{H}, 4,4^{\prime}{ }^{-} \mathrm{Bu}\right), 3.58\left(\mathrm{dd},{ }^{2} J_{\mathrm{H}, \mathrm{H}}=15.5 \mathrm{~Hz}\right.$, $\left.{ }^{3} J_{\mathrm{H}, \mathrm{H}}=6.5 \mathrm{~Hz}, 2 \mathrm{H}, \mathrm{CH}_{2}\right), 3.70\left(\mathrm{dd},{ }^{2} J_{\mathrm{H}, \mathrm{H}}=15.5 \mathrm{~Hz},{ }^{3} J_{\mathrm{H}, \mathrm{H}}=6.5 \mathrm{~Hz}, 2 \mathrm{H}, \mathrm{CH}_{2}\right), 4.95$ $\left(\mathrm{m}, 2 \mathrm{H}, \mathrm{CH}=\mathrm{CH}_{2}\right), 5.02\left(\mathrm{~m}, 2 \mathrm{H}, \mathrm{CH}=\mathrm{CH}_{2}\right), 6.06\left(\mathrm{ddt},{ }^{3} J_{\mathrm{H}, \mathrm{H}}=16.5,10.0,6.5 \mathrm{~Hz}, 2 \mathrm{H}\right.$, $\left.\mathrm{CH}=\mathrm{CH}_{2}\right), 6.96\left(\mathrm{dd},{ }^{3} J_{\mathrm{H}, \mathrm{H}}=7.5 \mathrm{~Hz},{ }^{4} J_{\mathrm{H}, \mathrm{H}}=1.5 \mathrm{~Hz}, 2 \mathrm{H}, 6,6\right.$ '-Ar-H), $7.09\left(\mathrm{t},{ }^{3} J_{\mathrm{H}, \mathrm{H}}=\right.$ $\left.7.5 \mathrm{~Hz}, 2 \mathrm{H}, 5,5^{\prime}-\mathrm{Ar}-\mathrm{H}\right), 7.16\left(\mathrm{dd},{ }^{3} J_{\mathrm{H}, \mathrm{H}}=7.5 \mathrm{~Hz},{ }^{4} J_{\mathrm{H}, \mathrm{H}}=1.5 \mathrm{~Hz}, 2 \mathrm{H}, 4,4{ }^{\prime}-\mathrm{Ar}-\mathrm{H}\right), 7.58$ $\left(\mathrm{dd}, 2 \mathrm{H},{ }^{3} J_{\mathrm{H}, \mathrm{H}}=5.5 \mathrm{~Hz},{ }^{4} J_{\mathrm{H}, \mathrm{H}}=1.0 \mathrm{~Hz}, 5,5^{\prime}-\mathrm{Bipy}-\mathrm{H}\right), 8.10\left(\mathrm{~d}, 2 \mathrm{H},{ }^{3} J_{\mathrm{H}, \mathrm{H}}=5.5 \mathrm{~Hz}, 6,6\right.$ 'Bipy-H), $8.18\left(\mathrm{~d}, 2 \mathrm{H},{ }^{4} J_{\mathrm{H}, \mathrm{H}}=1.0 \mathrm{~Hz}, 3,3\right.$ '-Bipy-H).

${ }^{13} \mathrm{C} \mathrm{NMR}\left(125 \mathrm{MHz}, \mathrm{CD}_{2} \mathrm{Cl}_{2}\right): \delta=30.5\left({ }^{t} \mathrm{Bu}\right), 36.0\left(\mathrm{CMe}_{3}\right), 40.9\left(\mathrm{CH}_{2}\right), 114.9$ $\left(\mathrm{CH}=\mathrm{CH}_{2}\right), 118.6$ (3,3'-Bipy-C), 123.6 (5,5'-Ar-C), 124.3 (5,5'-Bipy-C), 127.1 (4,4'-ArC), 128.0 (6,6'-Ar-C), $138.7\left(\mathrm{CH}=\mathrm{CH}_{2}\right.$ ), 140.2 (Ar-C), 142.8 (Ar-C), 149.3 (Ar-C), 149.7 (Ar-C), 150.0 (2,2'-Bipy-C), 166.3 (4,4'-Bipy-C).

MS (ESI(+), MeCN): $m / z(\%)=630(100)[\mathrm{M}]^{+}, 1260(100)\left[\mathrm{M}_{2}\right]^{+}$.

IR (KBr): $\nu\left(\mathrm{cm}^{-1}\right)=3050(\mathrm{~m}), 2966(\mathrm{~s}), 2905(\mathrm{~m}), 2871(\mathrm{~m}), 1614(\mathrm{~s}), 1549(\mathrm{~m}), 1410$ (m).

HRMS (ESI(+), MeCN): calcd $(m / z)$ for $\mathrm{C}_{36} \mathrm{H}_{41} \mathrm{~N}_{2} \mathrm{~S}_{2} \mathrm{Zn}\left(\mathrm{M}+\mathrm{H}^{+}\right)$: 629.1997. Found: 629.1998 . 


\section{(3,3'-Diallylbiphenyl-2,2'-dithio)(diphenyl)tin (8)}

A solution of 3,3'-diallyl-2,2'-dithiobiphenyl (6a, $0.3 \mathrm{~g}, 1.0 \mathrm{mmol})$ and diphenyltindichloride $(0.34 \mathrm{~g}, 1.0 \mathrm{mmol})$ in THF $(10 \mathrm{ml})$ was cooled to $0^{\circ} \mathrm{C}$ and treated with triethylamine $(0.15 \mathrm{ml}, 0.11 \mathrm{~g}, 1.1 \mathrm{mmol})$. After $1 \mathrm{~h}, \mathrm{Et}_{2} \mathrm{O}(20 \mathrm{ml})$ was added and a white precipitate (triethylammonium chloride) was removed by filtration. Removal of the solvents in vacuo yielded $\mathbf{8}$ as a colourless solid. Large single crystals suitable for X-ray diffraction were obtained by diffusion of pentane into a THF solution of the complex.

$\mathrm{Mp} 60^{\circ} \mathrm{C}$ (decomposition).

${ }^{1} \mathrm{H}$ NMR $\left(500 \mathrm{MHz}, \mathrm{CDCl}_{3}\right): \delta=3.26\left(\mathrm{dd},{ }^{2} J_{\mathrm{H}, \mathrm{H}}=15.5 \mathrm{~Hz},{ }^{3} J_{\mathrm{H}, \mathrm{H}}=6.5 \mathrm{~Hz}\right.$, $\left.2 \mathrm{H}, \mathrm{CH}_{2}\right), 3.57\left(\mathrm{dd},{ }^{2} J_{\mathrm{H}, \mathrm{H}}=15.5 \mathrm{~Hz},{ }^{3} J_{\mathrm{H}, \mathrm{H}}=6.5 \mathrm{~Hz}, 2 \mathrm{H}, \mathrm{CH}_{2}\right), 4.88-4.84(\mathrm{~m}, 4 \mathrm{H}$, $\left.\mathrm{CH}=\mathrm{CH}_{2}\right), 5.72\left(\mathrm{ddt},{ }^{3} J_{\mathrm{H}, \mathrm{H}}=16.5,10.0,6.5 \mathrm{~Hz}, 2 \mathrm{H}, \mathrm{CH}=\mathrm{CH}_{2}\right), 7.12\left(\mathrm{dd},{ }^{3} \mathrm{~J}_{\mathrm{H}, \mathrm{H}}=\right.$ $\left.7.5 \mathrm{~Hz},{ }^{4} J_{\mathrm{H}, \mathrm{H}}=1.5 \mathrm{~Hz}, 2 \mathrm{H}, \mathrm{Ar}-\mathrm{H}\right), 7.17\left(\mathrm{dd},{ }^{3} J_{\mathrm{H}, \mathrm{H}}=7.5 \mathrm{~Hz},{ }^{4} J_{\mathrm{H}, \mathrm{H}}=1.5 \mathrm{~Hz}, 2 \mathrm{H}, \mathrm{Ar}-\mathrm{H}\right)$, $7.29\left(\mathrm{t},{ }^{3} J_{\mathrm{H}, \mathrm{H}}=7.5 \mathrm{~Hz}, 2 \mathrm{H}, \mathrm{Ar}-\mathrm{H}\right), 7.33-7.42(\mathrm{~m}, 10 \mathrm{H}, \mathrm{Ar}-\mathrm{H})$.

${ }^{13} \mathrm{C}$ NMR $\left(125 \mathrm{MHz}, \mathrm{CDCl}_{3}\right): \delta=39.7\left(\mathrm{CH}_{2}\right), 116.0\left(\mathrm{CH}=\mathrm{CH}_{2}\right), 127.5$ (Ar-C), 127.7 (Ar-C), 128.4 (Ar-C), 129.0 (Ar-C), 129.6 (Ar-C), 130.5 (Ar-C), 136.0 (Ar-C), 136.7 $\left(\mathrm{CH}=\mathrm{CH}_{2}\right.$ ), 137.9 (Ar-C), 144.4 (Ar-C), 149.3 (Ar-C).

${ }^{119} \mathrm{Sn}$ NMR $\left(187 \mathrm{MHz}, \mathrm{CDCl}_{3}\right): \delta=42.4$.

MS $(\mathrm{EI}(+)): m / z(\%)=570(10)[\mathrm{M}]^{+}$.

IR (KBr): $\nu\left(\mathrm{cm}^{-1}\right)=3045$ (br), 2970 (br), 1450 (m), 1430 (s), 1395 (m), 774 (m), 730 (s), $695(\mathrm{~m})$.

HRMS (EI(+)): calcd $(m / z)$ for $\mathrm{C}_{30} \mathrm{H}_{27} \mathrm{~S}_{2} \mathrm{Sn}\left(\mathrm{M}+\mathrm{H}^{+}\right)$: 571.0573 . Found: 571.0571 . 


\subsection{Electrochemical Measurements}

Cyclic voltammetry was performed at room temperature with a Perkin Elmer Model $263 \mathrm{~A}$ potentiostat/galvanostat with glassy carbon working electrode and platinum reference and counter electrodes in $\mathrm{MeCN} / \mathrm{N}^{n} \mathrm{Bu}_{4} \mathrm{PF}_{6}(0.1 \mathrm{~mol} / \mathrm{l})$ or $\mathrm{DMF} / \mathrm{N}^{n} \mathrm{Bu}_{4} \mathrm{PF}_{6}$ (0.1 mol/l). Cp ${ }_{2}^{*} \mathrm{Fe}$ (added after the measurements) was used as internal standards. Potentials were measured at a scan rate of $100 \mathrm{mV} / \mathrm{s}$ vs. $\mathrm{Cp}_{2}^{*} \mathrm{Fe} / \mathrm{Cp}_{2}^{*} \mathrm{Fe}^{+}$and referenced $v$ s. the $\mathrm{Cp}_{2}^{*} \mathrm{Fe} / \mathrm{Cp}_{2}^{*} \mathrm{Fe}^{+}$couple and vs. NHE $\left(\mathrm{Cp}_{2}^{*} \mathrm{Fe} / \mathrm{Cp}_{2}^{*} \mathrm{Fe}^{+}\right.$vs. NHE: $-0.11 \mathrm{~V}$ in $\mathrm{MeCN}$, $-0.23 \mathrm{~V}$ in DMF). ${ }^{[189]}$ Experimental values are given in Table 7.1 together with calculated values (see Chapter 7.8.1 for details).

Table 7.1: Experimental and calculated electrochemical data of synthetic Fe/S Clusters.

\begin{tabular}{lcccccc}
\hline & solvent & $E_{\mathrm{p}} / E_{\mathrm{p}}^{\mathrm{a})} / \mathrm{V}$ & $E_{1 / 2}{ }^{\mathrm{a})} / \mathrm{V}$ & $E_{1 / 2}{ }^{\mathrm{b})} / \mathrm{V}$ & $E_{1 / 2}(\mathrm{calc} .)^{\mathrm{b}, \mathrm{c}} / \mathrm{V}$ & functional \\
\hline $11 \mathrm{a}$ & $\mathrm{MeCN}$ & $-1.51 /-^{\mathrm{d})}$ & $-{ }^{\mathrm{d})}$ & $-{ }^{\mathrm{d})}$ & -2.14 & $\mathrm{BP} 86$ \\
$11 \mathrm{~b}$ & $\mathrm{MeCN}$ & $-1.40 /-^{\mathrm{d})}$ & $-{ }^{\mathrm{d})}$ & $-{ }^{\mathrm{d})}$ & -2.20 & $\mathrm{BP} 86$ \\
$11 \mathrm{c}$ & $\mathrm{MeCN}$ & $\left.-{ }^{\mathrm{e}}\right)$ & $-{ }^{\mathrm{e})}$ & $-{ }^{\mathrm{e})}$ & -2.17 & $\mathrm{BP} 86$ \\
$12 \mathrm{a}$ & $\mathrm{MeCN}$ & $-1.23 /-1.09$ & -1.16 & -1.05 & -2.04 & $\mathrm{BP} 86$ \\
$12 \mathrm{~b}$ & $\mathrm{MeCN}$ & $-1.24 /-1.12$ & -1.18 & -1.07 & -1.99 & BP86 \\
33 & $\mathrm{DMF}$ & $-0.78 /-0.66$ & -0.72 & -0.49 & -1.85 & BP86 \\
& & & & & -1.68 & B3LYP \\
\hline
\end{tabular}

a) vs. $\mathrm{Cp}_{2}^{*} \mathrm{Fe} / \mathrm{Cp}_{2}^{*} \mathrm{Fe}^{+}$. b) vs. NHE. c) Data from Table 7.4. Calculated potentials were obtained from optimised coordinates; see Chapter 7.8.1 for details. d) irreversible. e) no potential could be determined due to decomposition upon reduction. 


\subsection{Magnetic Susceptibility Measurements}

Temperature-dependent magnetic susceptibilities of powdered samples were measured using a Quantum Design MPMS-5S SQUID magnetometer. Simulation of the experimental data with a full-matrix diagonalisation of exchange coupling and Zeeman splitting was performed with the julX programme by E. Bill (Max Planck Institute for Bioinorganic Chemistry, Mülheim) according to

$$
\mathscr{H}=-2 J \vec{S}_{1} \cdot \overrightarrow{S_{2}}+g \mu_{B}\left(\overrightarrow{S_{1}}+\overrightarrow{S_{2}}\right) \cdot \vec{B}
$$

Before simulation the experimental data were corrected for the underlying diamagnetism and for temperature-independent paramagnetism (TIP). A Curie-Weiss-behaved paramagnetic impurity $(P I)$ with spin $S=5 / 2$ was included according to

$$
\chi=(1-P I) \cdot \chi+P I \cdot \chi_{\text {mono }}
$$

The data are collected in Table 7.2.

Table 7.2: Best fit parameters for magnetic susceptibility measurements.

\begin{tabular}{cccccc}
\hline & $J /\left(\mathrm{cm}^{-1}\right)$ & $P I / \%$ & $\chi(T I P) /\left(10^{-6} \mathrm{~cm}^{3} / \mathrm{mol}\right)$ & $\theta_{\text {mono }} / \mathrm{K}$ & $B / \mathrm{T}$ \\
\hline 24 & -180 & 1.6 & 43.8 & 0 & 2 \\
33 & -167 & 9.2 & 134.2 & -5 & 0.5 \\
\hline
\end{tabular}




\subsection{Mössbauer Experiments}

Mössbauer spectra were recorded at $80 \mathrm{~K}$ or at $7 \mathrm{~K}$ on a WissEl alternating constantacceleration spectrometer. Isomer shifts are given relative to $\alpha$-iron metal at room temperature. The experimental data were fitted with Lorentzian line shapes using the MFit programme by E. Bill (Max Planck Institute for Bioinorganic Chemistry, Mülheim).

Table 7.3: Experimental and calculated Mössbauer parameters of synthetic Fe/S Clusters.

\begin{tabular}{|c|c|c|c|c|c|}
\hline & \multicolumn{2}{|c|}{ experimental } & \multicolumn{3}{|c|}{ calculated } \\
\hline & $\delta /(\mathrm{mm} / \mathrm{s})$ & $\Delta E_{\mathrm{Q}} /(\mathrm{mm} / \mathrm{s})$ & $\Delta E_{\mathrm{Q}}^{\mathrm{a})} /(\mathrm{mm} / \mathrm{s})$ & $\Delta E_{\mathrm{Q}}^{\mathrm{b})} /(\mathrm{mm} / \mathrm{s})$ & functional \\
\hline $11 \mathrm{a}$ & 0.32 & 1.06 & $0.32 / 0.39$ & $0.47 / 0.48$ & BP86 \\
\hline $11 b$ & 0.32 & 1.04 & $0.09 / 0.19$ & $0.44 / 0.45$ & BP86 \\
\hline $11 \mathrm{c}$ & 0.33 & 1.02 & 0.34 & 0.44 & BP86 \\
\hline $12 a$ & 0.29 & 0.76 & 0.52 & $0.29 / 0.39$ & BP86 \\
\hline $12 b$ & 0.29 & 0.79 & $0.28 / 0.29$ & $0.28 / 0.20$ & BP86 \\
\hline 24 & 0.29 & 0.53 & 0.20 & 0.25 & BP86 \\
\hline 25 & 0.44 & 1.13 & $1.02-1.04$ & 0.75 & BP86 \\
\hline $32 d^{c)}$ & 0.14 & 3.31 & - & - & - \\
\hline 33 & 0.44 & 0.43 & $\begin{array}{l}0.18 / 0.17 \\
0.13 / 0.15\end{array}$ & $\begin{array}{l}0.30 \\
0.22\end{array}$ & $\begin{array}{c}\text { BP86 } \\
\text { B3LYP }\end{array}$ \\
\hline $33^{\mathrm{red}}$ & - & - & - & $\begin{array}{l}1.20 / 0.83 \\
0.10 / 1.09\end{array}$ & $\begin{array}{c}\text { BP86 } \\
\text { B3LYP }\end{array}$ \\
\hline
\end{tabular}

a) Crystal coordinates, data from Table 7.6; b) optimised coordinates, data from Table 7.7; c) recorded at $7 \mathrm{~K}$, all other spectra recorded at $80 \mathrm{~K}$. 


\subsection{DFT and QM/MM Calculations}

\subsubsection{DFT Calculations}

The DFT calculations were performed using the Turbomole 5.9 ${ }^{[239]}$ programme with the BP86 functional ${ }^{[240,241]}$ or the B3LYP functional ${ }^{[233,234]}$ and the def2-SV(P) ${ }^{[242]}$ basis set. Calculations were based on atom coordinates of the complex dianions obtained from crystal structure data. Geometry optimisations were performed using the RELAX module. Solvent effects for calculation of redox potentials $E_{1 / 2}$ were simulated using the COSMO module. A dielectric constant $\epsilon=37$ for MeCN and DMF was used.

Theoretical reduction potentials $E v$ s. NHE were calculated according to $E_{0}=\left(E_{\mathrm{ox}}-\right.$ $\left.E_{\text {red }}\right) \cdot 27.211214914-4.43 \mathrm{eV}^{[243]}$ from single-point energy calculations on optimised coordinates of the oxidised and reduced states, respectively. ${ }^{[244]}$

Theoretical quadrupole splittings $\Delta E_{\mathrm{Q}}$ were calculated from eigenvalues $V$ of the electric field gradients according to $\Delta E_{\mathrm{Q}}=\frac{1}{2} e Q V_{\mathrm{zz}} \cdot\left(1+\frac{\eta^{2}}{3}\right)^{\frac{1}{2}}$ with $\mathrm{Q}=0.16 \mathrm{barn}=$ $1.6 \cdot 10^{-29} \mathrm{~m}^{2}, \eta=\frac{V_{\mathrm{xx}}-V_{\mathrm{yy}}}{V_{z z}},\left|V_{\mathrm{xx}}\right|<\left|V_{\mathrm{xx}}\right|<\left|V_{\mathrm{xx}}\right|, 1$ a.u. $=9.72 \cdot 10^{21} \mathrm{~V} / \mathrm{m}^{2}$ and $1 \mathrm{~mm} / \mathrm{s}=$ $4.8075 \cdot 10^{-8} \mathrm{eV}$. The values are summarised in Tables 7.6 (crystal coordinates) and 7.7 (optimised coordinates).

Illustrations of spin densities and molecular orbitals were prepared using the VMD $1.8 .6^{[245]}$ programme and ray-traced using the POV-Ray $3.6^{[246]}$ software. 
Table 7.4: Calculated energies and resulting reduction potentials $E_{1 / 2}$ for synthetic $\mathrm{Fe} / \mathrm{S}$ clusters.

\begin{tabular}{|c|c|c|c|c|}
\hline & functional & $E_{\text {vacuum}} /$ a.u. & $E_{\text {solvent }} /$ a.u. & $E_{1 / 2}{ }^{\mathrm{a})} / \mathrm{V}$ \\
\hline $\begin{array}{l}11 \mathrm{a} \\
11 \mathrm{a}^{\mathrm{red}}\end{array}$ & BP86 & $\begin{array}{l}-5014.851526763 \\
-5014.714154123\end{array}$ & $\begin{array}{l}-5015.055783510 \\
-5015.139768504\end{array}$ & -2.14 \\
\hline $\begin{array}{l}11 b \\
11 b^{\text {red }}\end{array}$ & BP86 & $\begin{array}{l}-4781.606898125 \\
-4781.459301672\end{array}$ & $\begin{array}{l}-4781.819128622 \\
-4781.901210825\end{array}$ & -2.20 \\
\hline $\begin{array}{l}11 \mathrm{c} \\
11 c^{\text {red }}\end{array}$ & BP86 & $\begin{array}{l}-5643.339038587 \\
-5643.211308158\end{array}$ & $\begin{array}{l}-5643.537640307 \\
-5643.620769470\end{array}$ & -2.17 \\
\hline $\begin{array}{l}12 \mathrm{a} \\
12 \mathrm{a}^{\mathrm{red}}\end{array}$ & BP86 & $\begin{array}{l}-6306.629312355 \\
-6306.498330259\end{array}$ & $\begin{array}{l}-6306.830910047 \\
-6306.918733762\end{array}$ & -2.04 \\
\hline $\begin{array}{l}12 b \\
12 b^{\text {red }}\end{array}$ & BP86 & $\begin{array}{l}-6073.387278821 \\
-6073.249298752\end{array}$ & $\begin{array}{l}-6073.597657137 \\
-6073.687456726\end{array}$ & -1.99 \\
\hline $\begin{array}{l}33 \\
33^{\text {red }} \\
33 \\
33^{\text {red }}\end{array}$ & B3LYP & $\begin{array}{l}-4717.518985242 \\
-4717.376042603 \\
-4715.7930839130 \\
-4715.651519632\end{array}$ & $\begin{array}{l}-4717.730404041 \\
-4717.825138268 \\
-4716.0071798910 \\
-4716.1080845930\end{array}$ & -1.68 \\
\hline
\end{tabular}

a) vs. NHE. 
Table 7.5: Calculated energies of $33 .^{\text {a) }}$

\begin{tabular}{|c|c|c|c|c|c|c|}
\hline & \multirow[b]{2}{*}{ functional } & & \multicolumn{2}{|l|}{ vacuum } & \multicolumn{2}{|l|}{ solvent } \\
\hline & & & $E /$ a.u. & $\begin{array}{l}E_{\text {relative }} / \\
\mathrm{kJ} / \mathrm{mol}\end{array}$ & $E /$ a.u. & $\begin{array}{l}E_{\text {relative }} / \\
\mathrm{kJ} / \mathrm{mol}\end{array}$ \\
\hline \multicolumn{7}{|c|}{ crystal coordinates } \\
\hline \multirow{4}{*}{33} & BP86 & $\mathrm{F}$ & -4717.104496949 & +106 & - & - \\
\hline & 0100 & $\mathrm{AF}$ & -4717.144806059 & 0 & - & - \\
\hline & B3LYP & $\mathrm{F}$ & -4715.41936048 & +63 & - & - \\
\hline & DJLYP & $\mathrm{AF}$ & -4715.443423756 & 0 & - & - \\
\hline \multicolumn{7}{|c|}{ optimised coordinates } \\
\hline \multirow{4}{*}{33} & RP86 & $\mathrm{F}$ & -4717.488182282 & +81 & -4717.70101242 & +77 \\
\hline & DP 00 & $\mathrm{AF}$ & -4717.518985242 & 0 & -4717.730404041 & 0 \\
\hline & B3IYP & $\mathrm{F}$ & -4715.777882708 & +40 & -4715.993333203 & +36 \\
\hline & BJLYP & $\mathrm{AF}$ & -4715.7930839130 & 0 & -4716.0071798910 & 0 \\
\hline \multirow{4}{*}{$33^{\mathrm{red}}$} & BP86 & $\mathrm{F}$ & -4717.366607813 & +25 & -4717.821182918 & +10 \\
\hline & $D 100$ & $\mathrm{AF}$ & -4717.376042603 & 0 & -4717.825138268 & 0 \\
\hline & B3IYP & $\mathrm{F}$ & -4715.649667534 & +5 & -4716.109982712 & -5 \\
\hline & DJLIP & $\mathrm{AF}$ & -4715.651519632 & 0 & -4716.1080845930 & 0 \\
\hline
\end{tabular}

a) Energies were calculated at two levels of theory (BP86 and B3LYP) for the ferromagnetic (F) or antiferromagnetic (AF) states. The oxidised state was considered on crystal and optimised coordinates, the reduced state on optimised coordinates only. 
Table 7.6: Calculated eigenvalues $V$ of the electric field gradients and quadrupole splittings $\Delta E_{\mathrm{Q}}$ of synthetic $\mathrm{Fe} / \mathrm{S}$ clusters (crystal coordinates).

\begin{tabular}{|c|c|c|c|c|c|}
\hline & functional & $V_{\mathrm{zz}} / \mathrm{a} . \mathrm{u}$. & $V_{\text {yy }} /$ a.u. & $V_{\mathrm{xx}} / \mathrm{a} . \mathrm{u}$. & $\Delta E_{\mathrm{Q}} /(\mathrm{mm} / \mathrm{s})$ \\
\hline \multirow{2}{*}{$11 \mathrm{a}$} & \multirow{2}{*}{ BP86 } & -0.1943 & 0.1374 & 0.05688 & 0.32 \\
\hline & & -0.2240 & 0.1837 & 0.04032 & 0.39 \\
\hline \multirow{2}{*}{$11 b$} & \multirow{2}{*}{ BP86 } & -0.05321 & 0.04499 & 0.008219 & 0.09 \\
\hline & & 0.1097 & -0.09804 & -0.01161 & 0.19 \\
\hline \multirow{2}{*}{$11 \mathrm{c}$} & \multirow{2}{*}{ BP86 } & 0.2111 & -0.1075 & -0.1036 & 0.34 \\
\hline & & 0.2117 & -0.1097 & -0.1021 & 0.34 \\
\hline \multirow{2}{*}{$12 a$} & \multirow{2}{*}{ BP86 } & -0.3191 & 0.1832 & 0.1359 & 0.52 \\
\hline & & -0.3200 & 0.1855 & 0.1345 & 0.52 \\
\hline \multirow{2}{*}{$12 b$} & \multirow{2}{*}{ BP86 } & 0.1643 & -0.1209 & -0.04335 & 0.28 \\
\hline & & -0.1729 & 0.1331 & 0.03976 & 0.29 \\
\hline \multirow{2}{*}{24} & \multirow{2}{*}{ BP86 } & -0.1251 & 0.06461 & 0.06045 & 0.20 \\
\hline & & -0.1246 & 0.06388 & 0.06072 & 0.20 \\
\hline \multirow{4}{*}{25} & \multirow{4}{*}{ BP86 } & -0.6259 & 0.4048 & 0.2211 & 1.03 \\
\hline & & -0.6226 & 0.4041 & 0.2186 & 1.02 \\
\hline & & -0.6328 & 0.4139 & 0.2189 & 1.04 \\
\hline & & -0.6346 & 0.4127 & 0.2219 & 1.04 \\
\hline \multirow{4}{*}{33} & \multirow{2}{*}{ BP86 } & -0.1065 & 0.07972 & 0.02673 & 0.18 \\
\hline & & -0.09509 & 0.08003 & 0.01506 & 0.17 \\
\hline & \multirow{2}{*}{ B3LYP } & 0.07721 & -0.05111 & -0.02611 & 0.13 \\
\hline & & 0.08648 & -0.06758 & -0.01889 & 0.15 \\
\hline
\end{tabular}


Table 7.7: Calculated eigenvalues $V$ of the electric field gradients and quadrupole splittings $\Delta E_{\mathrm{Q}}$ of synthetic $\mathrm{Fe} / \mathrm{S}$ clusters (optimised coordinates).

\begin{tabular}{|c|c|c|c|c|c|}
\hline & functional & $V_{\mathrm{zz}} / \mathrm{a} \cdot \mathrm{u}$. & $V_{\text {yy }} /$ a.u. & $V_{\mathrm{xx}} / \mathrm{a} . \mathrm{u}$. & $\Delta E_{\mathrm{Q}} /(\mathrm{mm} / \mathrm{s})$ \\
\hline \multirow{2}{*}{$11 \mathrm{a}$} & \multirow{2}{*}{ BP86 } & 0.2590 & -0.2428 & -0.01618 & 0.47 \\
\hline & & 0.2591 & -0.2517 & -0.007414 & 0.48 \\
\hline \multirow{2}{*}{$11 b$} & \multirow{2}{*}{ BP86 } & 0.2493 & -0.2203 & -0.02905 & 0.44 \\
\hline & & 0.2544 & -0.2307 & -0.02372 & 0.45 \\
\hline \multirow{2}{*}{$11 \mathrm{c}$} & \multirow{2}{*}{ BP86 } & 0.2631 & -0.1876 & -0.07549 & 0.44 \\
\hline & & 0.2627 & -0.1866 & -0.07604 & 0.44 \\
\hline \multirow{2}{*}{$12 a$} & \multirow{2}{*}{ BP86 } & 0.1772 & -0.1254 & -0.05175 & 0.29 \\
\hline & & 0.2355 & -0.1726 & -0.06296 & 0.39 \\
\hline \multirow{2}{*}{$12 b$} & \multirow{2}{*}{ BP86 } & 0.1661 & -0.1281 & -0.03798 & 0.28 \\
\hline & & -0.1093 & 0.1030 & 0.006288 & 0.20 \\
\hline \multirow{2}{*}{24} & \multirow{2}{*}{ BP86 } & 0.1545 & -0.1038 & -0.05072 & 0.25 \\
\hline & & 0.1543 & -0.1034 & -0.05091 & 0.25 \\
\hline \multirow{4}{*}{25} & \multirow{4}{*}{ BP86 } & -0.4339 & 0.3569 & 0.07696 & 0.75 \\
\hline & & -0.4328 & 0.3549 & 0.07789 & 0.75 \\
\hline & & -0.4335 & 0.3566 & 0.07694 & 0.75 \\
\hline & & -0.4334 & 0.3563 & 0.07704 & 0.75 \\
\hline \multirow{4}{*}{33} & \multirow{2}{*}{ BP86 } & -0.1872 & 0.1004 & 0.08672 & 0.30 \\
\hline & & -0.1869 & 0.1003 & 0.08656 & 0.30 \\
\hline & \multirow{2}{*}{ B3LYP } & 0.1212 & -0.1159 & -0.005317 & 0.22 \\
\hline & & 0.1200 & -0.1145 & -0.005530 & 0.22 \\
\hline \multirow{4}{*}{$33^{\mathrm{red}}$} & \multirow{2}{*}{ BP86 } & -0.6681 & 0.6118 & 0.05633 & 1.20 \\
\hline & & 0.4518 & -0.4341 & -0.01763 & 0.83 \\
\hline & \multirow{2}{*}{ B3LYP } & 0.05977 & -0.01381 & 0.01321 & 0.10 \\
\hline & & 0.6570 & -0.4572 & -0.1997 & 1.09 \\
\hline
\end{tabular}




\subsubsection{QM/MM Calculations}

The QM/MM calculations were performed with the ComQum programme suite ${ }^{[247,248]}$ utilising Turbomole 5.9.$^{[239]}$ for the quantum mechanical (QM) calculations and Amber ${ }^{\left.9{ }^{[29}\right]}$ for the molecular mechanical (MM) calculations. The QM calculations were performed using the BP86 functional ${ }^{[240,241]}$ and the def2-SV(P) basis sets ${ }^{[242]}$. For the MM calculations, the Amber-99 force field ${ }^{[250,251]}$ was used. For the [4Fe-4S] cluster and the dethiobiotin and $S$-adenosylmethionine molecules, force-field parameters previously determined in the Ryde group were used. ${ }^{[252-254]}$

In the QM/MM approach, the protein and solvent are split into three subsystems: The QM region (system 1) contains the most interesting atoms and is relaxed by QM methods. System 2 consists of the residues closest to the QM system and is optimised by MM. The remaining part of the protein and the surrounding solvent molecules (system 3) are kept fixed at the crystallographic coordinates. In the QM calculations, system 1 is represented by a wavefunction, whereas all the other atoms are represented by an array of partial point charges, one for each atom, taken from MM libraries. Thereby, the polarisation of the quantum chemical system by the surroundings is included in a self-consistent manner. When there is a bond between systems 1 and 2 (a junction), the quantum region is truncated by hydrogen atoms, the positions of which are linearly related to the corresponding carbon atoms in the full system (the hydrogen link-atom approach) ${ }^{[248]}$. The exact method is described in the literature. ${ }^{[237,247,248]}$

The calculations were based on the crystal structure (PDB code $1 \mathrm{R} 30)^{[64]}$. As the enzyme was crystallised as a homodimer with little difference in atom positions (less than $0.1 \AA$ differences within the [2Fe-2S] cluster), only the A monomer was used for the investigations and only this monomer is discussed. Hydrogen atoms were added to the crystal structure and the protein was solvated in a sphere of water molecules with a radius of $36 \AA$ using the Leap module in the Amber suite. The protonation status of all residues was checked by the Propka programme ${ }^{[25]}$ and it was concluded that no residues have strongly perturbed $\mathrm{p} K_{\mathrm{a}}$ values (thus, all arginine and lysine residues, except $\mathrm{Arg}^{260}$, see below, were considered in their protonated state, while all aspartate and glutamate residues were considered in their deprotonated state). For the histidine residues, the protonation was decided from a detailed study of the solvent exposure and hydrogen-bond pattern. This procedure lead to the following assignment: $\mathrm{His}^{34}$ and $\mathrm{His}^{107}$ were protonated on both nitrogen atoms while $\mathrm{His}^{31}$ was protonated on $\mathrm{N}^{{ }^{2}}$ only and His ${ }^{152}$ was protonated on $\mathrm{N}^{\delta 1}$ only. The cysteine residues coordinating the 
$\mathrm{Fe} / \mathrm{S}$ clusters were assumed to be deprotonated. The [4Fe-4S] cluster, SAM and the dethiobiotin molecule found in the crystal structure were all included in the calculations. The total charge of the simulated system was -8 (neutral Arg) or -7 (protonated Arg). The position of the added atoms was optimised by a 90 ps simulated-annealing molecular dynamics simulation, followed by 10000 steps of conjugate gradient energy minimisation. All bond lengths involving hydrogen atoms were constrained by the SHAKE algorithm. ${ }^{[256]}$ The water solvent was described explicitly using the TIP3P model. ${ }^{[257]}$ The temperature was kept constant at $300 \mathrm{~K}$ using the Berendsen weak-coupling algorithm ${ }^{[258]}$ with a time constant of $1 \mathrm{ps}$. The molecular dynamics time step was $2 \mathrm{fs}$. The non-bonded cut-off was $15 \AA$ and the pair list was updated every $50 \mathrm{fs}$. In the QM/MM calculations, an infinite cut-off was used instead.

The entire system was then divided into three subsystems: System 1 contained the $[2 \mathrm{Fe}-2 \mathrm{~S}]$ cluster and the relevant atoms of the four coordinating amino acids $\left(\mathrm{Cys}^{97}, \mathrm{Cys}^{128}\right.$, $\mathrm{Cys}^{188}$ and $\left.\mathrm{Arg}^{260}\right)$ and was treated with QM methods. The side chains were included as far as $\mathrm{C}^{\beta}$ for the Cys residues (replacing $\mathrm{C}^{\alpha}$ by a $\mathrm{H}$ atom) and as far as $\mathrm{C}^{\delta}$ for the Arg residue (replacing $\mathrm{C}^{\gamma}$ by a $\mathrm{H}$ atom). Thus it consisted of $\left[\left(\mathrm{CH}_{3} \mathrm{~S}\right)_{3}\left(\mathrm{CH}_{3} \mathrm{NHCH}(\mathrm{NH}) \mathrm{NH}_{2}\right) \mathrm{Fe}_{2} \mathrm{~S}_{2}\right]^{-}$for the calculations with neutral arginine or $\left[\left(\mathrm{CH}_{3} \mathrm{~S}\right)_{3}\left(\mathrm{CH}_{3} \mathrm{NHCH}\left(\mathrm{NH}_{2}\right) \mathrm{NH}_{2}\right) \mathrm{Fe}_{2} \mathrm{~S}_{2}\right]$ for the calculations with protonated arginine. System 2 included all residues with any atom within $6 \AA$ of any atom in system 1 and was either kept fixed (protein-fixed calculations) or relaxed with MM methods (proteinfree calculations). System 3 included the remaining protein atoms as well as the water molecules and was kept fixed at the crystallographic coordinates.

As both $\mathrm{Fe}$ atoms of the (oxidized) $[2 \mathrm{Fe}-2 \mathrm{~S}]$ cluster are in the $\mathrm{Fe}^{\mathrm{III}}$ high-spin state $(S=5 / 2)$, two spin states are possible (the ferromagnetically, F, $S=5$, or antiferromagnetically coupled states, AF, $S=0$ ). The AF state always had a lower energy than the $\mathrm{F}$ state and it is also the experimentally observed one. Therefore, all presented results are $\mathrm{AF}$ energies with protein free, unless otherwise specified. To ensure that the QM/MM energy differences are stable, the protein-free calculations were in general run forth and back between the relevant states until the energies were stable within $4 \mathrm{~kJ} / \mathrm{mol}$. Similar calculations were also performed on one-electron reduced clusters, i.e., clusters containing one $\mathrm{Fe}^{\mathrm{II}}$ and one $\mathrm{Fe}^{\mathrm{III}}$ ion (net charge of $\mathrm{QM}$ system -1 or -2 , depending on the protonation of the Arg model), on two-electron reduced clusters (net charge -2 or -3 ) and on clusters with one of the bridging $S$ atoms removed (the one closest to dethiobiotin; net charge 0 or -1 . This is equivalent to remove a $S^{2-}$ ion and reduce both iron ions to $\left.\mathrm{Fe}^{\mathrm{II}}\right)$, in all cases in the $\mathrm{AF}(S=1 / 2$ or $S=0)$ state). 
Electric field gradients $V$ and theoretical quadrupole splittings $\Delta E_{\mathrm{Q}}$ were calculated as described in Chapter 7.8.1 and are listed in Table 7.8. Illustrations of protein structures were prepared using the $P y M O L 0.99^{[259]}$ software.

Table 7.8: Calculated eigenvalues $V$ of the electric field gradients and quadrupole splittings $\Delta E_{\mathrm{Q}}$ of the $[2 \mathrm{Fe}-2 \mathrm{~S}]$ cluster in biotin synthase in possible coordination modes i-iv (optimised coordinates).

\begin{tabular}{lcccc}
\hline Structure & $V_{\mathrm{zz}} /$ a.u. & $V_{\mathrm{yy}} /$ a.u. & $V_{\mathrm{xx}} /$ a.u. & $\Delta E_{\mathrm{Q}} /(\mathrm{mm} / \mathrm{s})$ \\
\hline i & 0.2057 & -0.1156 & -0.09017 & 0.33 \\
& 0.7709 & 0.2414 & -0.01012 & 1.27 \\
ii & 0.1863 & -0.1647 & -0.02156 & 0.33 \\
& -0.3617 & 0.1918 & 0.1699 & 0.59 \\
iii & 0.2435 & -0.2362 & -0.007232 & 0.45 \\
& -0.7615 & 0.4065 & 0.355 & 1.23 \\
iv & -0.2515 & 0.1981 & 0.05339 & 0.43 \\
& -0.6930 & 0.4605 & 0.2324 & 1.14 \\
\hline
\end{tabular}




\section{Appendix}

\section{Crystallography}

X-ray diffraction data were collected on a STOE IPDS II diffractometer using graphite monochromated $\mathrm{Mo} \mathrm{K}_{\alpha}$ radiation $(\lambda=0.71073 \AA)$ at $133 \mathrm{~K}$. Collected data were corrected in terms of Lorentz and polarisation effects; in addition, absorption corrections were made. ${ }^{[260]}$ Crystal structure solution and refinement were performed using the programmes SHELXS-97 and SHELXL-97. [261-263] 
Table 7.9: Crystal data and refinement details of compounds 8, 11a and 11b.

\begin{tabular}{|c|c|c|c|}
\hline & 8 & $11 \mathrm{a}$ & $11 b$ \\
\hline Empirical formula & $\mathrm{C}_{30} \mathrm{H}_{26} \mathrm{~S}_{2} \mathrm{Sn}$ & $\mathrm{C}_{52} \mathrm{H}_{72} \mathrm{Fe}_{2} \mathrm{~N}_{2} \mathrm{O}_{4} \mathrm{~S}_{2}$ & $\mathrm{C}_{46} \mathrm{H}_{64} \mathrm{Fe}_{2} \mathrm{~N}_{2} \mathrm{O}_{4} \mathrm{~S}_{2}$ \\
\hline Formula weight & 569.32 & 964.94 & 884.81 \\
\hline Crystal system & Monoclinic & Triclinic & Triclinic \\
\hline Space group & $C 2 / c$ & $P \overline{1}$ & $P \overline{1}$ \\
\hline$a / \AA$ & $10.2473(4)$ & $10.8209(8)$ & $9.0426(5)$ \\
\hline$b / \AA$ & $14.4191(6)$ & $15.1622(9)$ & $13.4446(8)$ \\
\hline$c / \AA$ & $17.4389(7)$ & $16.5475(12)$ & $19.8989(12)$ \\
\hline$\alpha /^{\circ}$ & 90 & $85.151(5)$ & $100.635(5)$ \\
\hline$\beta /^{\circ}$ & $97.553(3)$ & $78.697(5)$ & $92.599(5)$ \\
\hline$\gamma /{ }^{\circ}$ & 90 & $71.316(5)$ & $106.041(5)$ \\
\hline$V / \AA^{3}$ & $2554.36(18)$ & 2521.3(3) & $2273.1(2)$ \\
\hline$Z^{\prime}$ & 4 & 2 & 2 \\
\hline$\rho_{\text {calculated }} /\left(\mathrm{Mg} / \mathrm{m}^{3}\right)$ & 1.480 & 1.271 & 1.293 \\
\hline$\mu /(1 / \mathrm{mm})$ & 1.180 & 0.703 & 0.773 \\
\hline$F(000)$ & 1152 & 1028 & 940 \\
\hline Crystal size $/ \mathrm{mm}^{3}$ & $0.28 \times 0.23 \times 0.18$ & $0.37 \times 0.18 \times 0.12$ & $0.50 \times 0.10 \times 0.09$ \\
\hline$\Theta$ range $/^{\circ}$ & $2.36-26.97$ & 1.87-24.77 & $1.61-27.03$ \\
\hline \multirow[t]{3}{*}{ Index ranges } & $-13 \leq b \leq 12$ & $-12 \leq b \leq 12$ & $-11 \leq b \leq 10$ \\
\hline & $-18 \leq k \leq 18$ & $-17 \leq k \leq 17$ & $-17 \leq k \leq 17$ \\
\hline & $-22 \leq l \leq 22$ & $-19 \leq l \leq 19$ & $-25 \leq k \leq 25$ \\
\hline Reflections collected & $1 \overline{4} 04 \overline{7}$ & $3 \overline{3} 79 \overline{1}$ & $2 \overline{7} 493$ \\
\hline Independent reflections & 2776 & 8587 & 9875 \\
\hline$R_{\text {int }}$ & 0.0278 & 0.0693 & 0.0490 \\
\hline Completeness to $\Theta / \%$ & 99.8 & 99.1 & 99.0 \\
\hline Absorption correction & Numerical & Numerical & Numerical \\
\hline Max./min. transmission & $0.8077 / 0.6578$ & $0.8995 / 0.7007$ & $0.9067 / 0.7246$ \\
\hline Data & 2776 & 8587 & 9875 \\
\hline Restraints & 38 & 4 & 2 \\
\hline Parameters & 240 & 586 & 520 \\
\hline Goodness-of-fit on $F^{2}$ & 1.056 & 1.008 & 1.002 \\
\hline$R 1, w R 2(I>2 \sigma(I))$ & $0.0185,0.0457$ & $0.0370,0.0674$ & $0.0460,0.1041$ \\
\hline$R 1, w R 2$ (all data) & $0.0215,0.0465$ & $0.0679,0.0722$ & $0.0735,0.1128$ \\
\hline resid. el. dens. $/\left(\mathrm{e} / \AA^{3}\right)$ & $0.208 /-0.448$ & $0.281 /-0.286$ & $0.704 /-0.774$ \\
\hline
\end{tabular}


Table 7.10: Crystal data and refinement details of compounds 11c, 12a and 12b.

\begin{tabular}{|c|c|c|c|}
\hline & $11 \mathrm{c}$ & $12 \mathrm{a}$ & $12 b$ \\
\hline Empirical formula & $\mathrm{C}_{68} \mathrm{H}_{104} \mathrm{Fe}_{2} \mathrm{~N}_{2} \mathrm{O}_{4} \mathrm{~S}_{2}$ & $\mathrm{C}_{52} \mathrm{H}_{72} \mathrm{Fe}_{2} \mathrm{~N}_{2} \mathrm{~S}_{6}$ & $\mathrm{C}_{48} \mathrm{H}_{67} \mathrm{Fe}_{2} \mathrm{~N}_{3} \mathrm{~S}_{6}$ \\
\hline Formula weight & 1189.35 & 1029.18 & 990.11 \\
\hline Crystal system & Monoclinic & Monoclinic & Monoclinic \\
\hline Space group & $P 2_{1} / n$ & $P 2_{1} / c$ & $P 2_{1} / c$ \\
\hline$a / \AA$ & $9.0654(6)$ & $10.2869(4)$ & $16.7174(7)$ \\
\hline$b / \AA$ & $17.2512(8)$ & $20.1216(11)$ & $10.5657(3)$ \\
\hline$c / \AA$ & $21.5472(15)$ & $15.2748(6)$ & $28.6500(11)$ \\
\hline$\alpha /^{\circ}$ & 90 & 90 & 90 \\
\hline$\beta /^{\circ}$ & $90.921(5)$ & $91.981(3)$ & $96.995(3)$ \\
\hline$\gamma /{ }^{\circ}$ & 90 & 90 & 90 \\
\hline$V / \AA^{3}$ & $3369.3(4)$ & $3159.8(2)$ & $5022.8(3)$ \\
\hline$Z^{\prime}$ & 2 & 2 & 4 \\
\hline$\rho_{\text {calculated }} /\left(\mathrm{Mg} / \mathrm{m}^{3}\right)$ & 1.172 & 1.082 & 1.309 \\
\hline$\mu /(1 / \mathrm{mm})$ & 0.538 & 0.687 & 0.862 \\
\hline$F(000)$ & 1284 & 1092 & 2096 \\
\hline Crystal size $/ \mathrm{mm}^{3}$ & $0.50 \times 0.05 \times 0.03$ & $0.30 \times 0.26 \times 0.21$ & $0.31 \times 0.30 \times 0.07$ \\
\hline$\Theta$ range $1^{\circ}$ & $1.51-26.80$ & $1.67-24.81$ & $1.23-25.66$ \\
\hline Index ranges & $-11 \leq b \leq 9$ & $-12 \leq b \leq 12$ & $-20 \leq h \leq 20$ \\
\hline & $-21 \leq k \leq 21$ & $-23 \leq k \leq 23$ & $-12 \leq k \leq 12$ \\
\hline & $-27 \leq l \leq 27$ & $-17 \leq l \leq 16$ & $-34 \leq l \leq 34$ \\
\hline Reflections collected & $2 \overline{2} 85 \overline{6}$ & $4 \overline{1} 16 \overline{0}$ & 49944 \\
\hline Independent reflections & 7147 & 5408 & 9453 \\
\hline$R_{\text {int }}$ & 0.1213 & 0.0589 & 0.1404 \\
\hline Completeness to $\Theta / \%$ & 99.2 & 99.4 & 99.4 \\
\hline Absorption correction & Numerical & None & Numerical \\
\hline Max./min. transmission & $0.9128 / 0.6669$ & - & $0.8205 / 0.5643$ \\
\hline Data & 7147 & 5408 & 9453 \\
\hline Restraints & 1 & 4 & 0 \\
\hline Parameters & 369 & 282 & 541 \\
\hline Goodness-of-fit on $F^{2}$ & 1.014 & 1.068 & 1.034 \\
\hline$R 1, w R 2(I>2 \sigma(I))$ & $0.0646,0.1306$ & $0.0597,0.1334$ & $0.0721,0.1678$ \\
\hline$R 1, w R 2$ (all data) & $0.1078,0.1464$ & $0.0803,0.1392$ & $0.1067,0.1846$ \\
\hline res. el. dens. $/\left(\mathrm{e} / \AA^{3}\right)$ & $0.582 /-0.661$ & $0.699 /-0.502$ & $1.923 /-0.710$ \\
\hline
\end{tabular}


Table 7.11: Crystal data and refinement details of compounds 24, 25 and 32a.

\begin{tabular}{|c|c|c|c|}
\hline & 24 & 25 & $32 a$ \\
\hline Empirical formula & $\mathrm{C}_{52} \mathrm{H}_{72} \mathrm{Fe}_{2} \mathrm{~N}_{6} \mathrm{~S}_{2}$ & $\mathrm{C}_{52} \mathrm{H}_{72} \mathrm{Fe}_{4} \mathrm{~N}_{6} \mathrm{~S}_{4}$ & $\mathrm{C}_{32} \mathrm{H}_{40} \mathrm{FeN}_{13} \mathrm{O}_{2}$ \\
\hline Formula weight & 956.98 & 1132.80 & 694.62 \\
\hline Crystal system & Orthorhombic & Tetragonal & Monoclinic \\
\hline Space group & Ccca & $I \overline{4} 2 d$ & $P 2_{1} / n$ \\
\hline$a / \AA$ & $20.4074(10)$ & $15.0896(7)$ & $13.4205(4)$ \\
\hline$b / \AA$ & $24.2465(16)$ & $15.0896(7)$ & $18.2973(4)$ \\
\hline$c / \AA$ & $21.9257(10)$ & $23.4008(14)$ & $14.2005(5)$ \\
\hline$\alpha /^{\circ}$ & 90 & 90 & 90 \\
\hline$\beta /^{\circ}$ & 90 & 90 & $101.370(3)$ \\
\hline$\gamma /{ }^{\circ}$ & 90 & 90 & 90 \\
\hline$V / \AA^{3}$ & $10849.0(10)$ & $5328.3(5)$ & $3418.62(17)$ \\
\hline$Z$ & 8 & 4 & 4 \\
\hline$\rho_{\text {calculated }} /\left(\mathrm{Mg} / \mathrm{m}^{3}\right)$ & 1.172 & 1.412 & 1.350 \\
\hline$\mu /(1 / \mathrm{mm})$ & 0.649 & 1.265 & 0.492 \\
\hline$F(000)$ & 4080 & 2376 & 1460 \\
\hline Crystal size $/ \mathrm{mm}^{3}$ & $0.49 \times 0.13 \times 0.03$ & $0.11 \times 0.08 \times 0.07$ & $0.44 \times 0.34 \times 0.14$ \\
\hline$\Theta$ range $/^{\circ}$ & $1.60-25.71$ & $1.61-24.45$ & 1.84-26.74 \\
\hline \multirow[t]{3}{*}{ Index ranges } & $-22 \leq b \leq 24$ & $-14 \leq b \leq 16$ & $-16 \leq b \leq 16$ \\
\hline & $-29 \leq k \leq 29$ & $-15 \leq k \leq 17$ & $-23 \leq k \leq 22$ \\
\hline & $-26 \leq l \leq 23$ & $-27 \leq l \leq 26$ & $-17 \leq l \leq 17$ \\
\hline Reflections collected & $2 \overline{9} 818$ & $\overline{6932}$ & $3 \overline{6} 65 \overline{6}$ \\
\hline Independent reflections & 5131 & 2136 & 7232 \\
\hline$R_{\text {int }}$ & 0.1524 & 0.1190 & 0.0261 \\
\hline Completeness to $\Theta / \%$ & 99.2 & 99.4 & 99.7 \\
\hline Absorption correction & None & Numerical & Numerical \\
\hline Max./min. transmission & - & $0.9358 / 0.8507$ & $0.8980 / 0.7695$ \\
\hline Data & 5131 & 2136 & 7232 \\
\hline Restraints & 23 & 9 & 0 \\
\hline Parameters & 237 & 146 & 441 \\
\hline Goodness-of-fit on $F^{2}$ & 0.832 & 1.008 & 1.050 \\
\hline$R 1, w R 2(I>2 \sigma(I))$ & $0.0554,0.1020$ & $0.0613,0.1148$ & $0.0314,0.0825$ \\
\hline$R 1, w R 2$ (all data) & $0.1223,0.1186$ & $0.0889,0.1240$ & $0.0371,0.0849$ \\
\hline res. el. dens. $/\left(\mathrm{e} / \AA^{3}\right)$ & $0.296 /-0.505$ & $0.732 /-0.420$ & $0.300 /-0.376$ \\
\hline
\end{tabular}


Table 7.12: Crystal data and refinement details of compounds 32b, 32d and 33.

\begin{tabular}{|c|c|c|c|}
\hline & $32 b$ & $32 d$ & 33 \\
\hline Empirical formula & $\mathrm{C}_{58.875} \mathrm{H}_{73.625} \mathrm{Fe}$ & $\mathrm{C}_{39} \mathrm{H}_{47.50} \mathrm{FeN}_{7.50}$ & $\mathrm{C}_{38} \mathrm{H}_{54} \mathrm{Fe}_{2} \mathrm{~N}_{12} \mathrm{~S}_{2}$ \\
\hline Formula weight & 1045.03 & 677.20 & 854.75 \\
\hline Crystal system & Triclinic & Monoclinic & Monoclinic \\
\hline Space group & $P \overline{1}$ & $P 2_{1} / c$ & $P 2_{1} / c$ \\
\hline$a / \AA$ & $15.3427(3)$ & $13.7013(3)$ & $11.2144(4)$ \\
\hline$b / \AA$ & $15.9420(4)$ & $29.2105(5)$ & $14.4686(4)$ \\
\hline$c / \AA$ & $24.0275(5)$ & $19.5383(4)$ & $13.7454(5)$ \\
\hline$\alpha /^{\circ}$ & $103.080(2)$ & 90 & 90 \\
\hline$\beta / 0$ & $93.357(2)$ & $94.452(2)$ & $113.658(3)$ \\
\hline$\gamma /{ }^{\circ}$ & $102.194(2)$ & 90 & 90 \\
\hline$V / \AA^{3}$ & $5560.3(2)$ & $7796.1(3)$ & $2042.84(12)$ \\
\hline Z & 4 & 8 & 2 \\
\hline$\rho_{\text {calculated }} /\left(\mathrm{Mg} / \mathrm{m}^{3}\right)$ & 1.248 & 1.154 & 1.390 \\
\hline$\mu /(1 / \mathrm{mm})$ & 0.325 & 0.422 & 0.857 \\
\hline$F(000)$ & 2227 & 2880 & 900 \\
\hline Crystal size $/ \mathrm{mm}^{3}$ & $0.50 \times 0.48 \times 0.47$ & $0.50 \times 0.33 \times 0.23$ & $0.50 \times 0.50 \times 0.36$ \\
\hline$\Theta$ range $1^{\circ}$ & $1.35-26.75$ & $1.26-25.64$ & $1.98-26.94$ \\
\hline \multirow[t]{3}{*}{ Index ranges } & $-19 \leq h \leq 19$ & $-16 \leq h \leq 15$ & $-14 \leq h \leq 14$ \\
\hline & $-20 \leq k \leq 20$ & $-35 \leq k \leq 35$ & $-18 \leq k \leq 18$ \\
\hline & $-30 \leq l \leq 30$ & $-23 \leq l \leq 23$ & $-17 \leq l \leq 17$ \\
\hline Reflections collected & $7 \overline{1835}$ & $8 \overline{7} 30 \overline{8}$ & $2 \overline{6} 07 \overline{2}$ \\
\hline Independent reflections & 23581 & 14693 & 4445 \\
\hline$R_{\text {int }}$ & 0.0286 & 0.0617 & 0.0317 \\
\hline Completeness to $\Theta / \%$ & 99.7 & 99.7 & 99.9 \\
\hline Absorption correction & Numerical & None & Numerical \\
\hline Max./min. transmission & $0.8952 / 0.8192$ & - & $0.7269 / 0.6373$ \\
\hline Data & 23581 & 14693 & 4445 \\
\hline Restraints & 149 & 0 & 0 \\
\hline Parameters & 1336 & 873 & 248 \\
\hline Goodness-of-fit on $F^{2}$ & 1.041 & 1.021 & 1.028 \\
\hline$R 1, w R 2(I>2 \sigma(I))$ & $0.0584,0.1763$ & $0.0446,0.1171$ & $0.0263,0.0699$ \\
\hline$R 1, w R 2$ (all data) & $0.0718,0.1867$ & $0.0615,0.1234$ & $0.0282,0.0709$ \\
\hline resid. el. dens. $/\left(\mathrm{e} / \AA^{3}\right)$ & $1.473 /-0.735$ & $0.914 /-0.523$ & $0.383 /-0.363$ \\
\hline
\end{tabular}


Table 7.13: Crystal data and refinement details of compounds 34 and $\mathbf{3 5 .}$

\begin{tabular}{|c|c|c|}
\hline & 34 & 35 \\
\hline Empirical formula & $\mathrm{C}_{31} \mathrm{H}_{35} \mathrm{Fe}_{2} \mathrm{Li}_{2} \mathrm{~N}_{13} \mathrm{O}_{3} \mathrm{~S}_{2}$ & $\mathrm{C}_{43} \mathrm{H}_{70} \mathrm{Fe}_{3} \mathrm{~N}_{8} \mathrm{~S}_{7}$ \\
\hline Formula weight & 827.42 & 1091.04 \\
\hline Crystal system & Monoclinic & Monoclinic \\
\hline Space group & $P 2_{1} / n$ & $P 2_{1} / n$ \\
\hline$a / \AA$ & $13.3229(4)$ & $11.9447(4)$ \\
\hline$b / \AA$ & $17.0023(5)$ & $33.0015(9)$ \\
\hline$c / \AA$ & $16.5848(5)$ & $12.8251(4)$ \\
\hline$\alpha /^{\circ}$ & 90 & 90 \\
\hline$\beta /{ }^{\circ}$ & $95.247(2)$ & $96.853(3)$ \\
\hline$\gamma /{ }^{\circ}$ & 90 & 90 \\
\hline$V / \AA^{3}$ & $3741.05(19)$ & $5019.4(3)$ \\
\hline$Z$ & 4 & 4 \\
\hline$\rho_{\text {calculated }} /\left(\mathrm{Mg} / \mathrm{m}^{3}\right)$ & 1.469 & 1.444 \\
\hline$\mu /(1 / \mathrm{mm})$ & 0.939 & 1.187 \\
\hline$F(000)$ & 1704 & 2296 \\
\hline Crystal size $/ \mathrm{mm}^{3}$ & $0.26 \times 0.21 \times 0.13$ & $0.36 \times 0.21 \times 0.07$ \\
\hline$\Theta$ range $/^{\circ}$ & $1.72-26.96$ & $1.71-25.62$ \\
\hline \multirow[t]{3}{*}{ Index ranges } & $-16 \leq b \leq 16$ & $-14 \leq h \leq 12$ \\
\hline & $-21 \leq k \leq 21$ & $-40 \overline{\leq} k \leq 40$ \\
\hline & $-19 \leq l \leq 21$ & $-15 \leq l \leq 15$ \\
\hline Reflections collected & $4 \overline{23} 1 \overline{7}$ & $3 \overline{5} 68 \overline{7}$ \\
\hline Independent reflections & 8116 & 9408 \\
\hline$R_{\text {int }}$ & 0.0562 & 0.0871 \\
\hline Completeness to $\Theta / \%$ & 99.8 & 99.3 \\
\hline Absorption correction & Numerical & Numerical \\
\hline Max./min. transmission & $0.9030 / 0.8041$ & $0.9391 / 0.7457$ \\
\hline Data & 8116 & 9408 \\
\hline Restraints & 0 & 16 \\
\hline Parameters & 484 & 549 \\
\hline Goodness-of-fit on $F^{2}$ & 1.026 & 1.098 \\
\hline$R 1, w R 2(I>2 \sigma(I))$ & $0.0303,0.0664$ & $0.0673,0.1535$ \\
\hline$R 1, w R 2$ (all data) & $0.0423,0.0696$ & $0.0987,0.1643$ \\
\hline resid. el. dens. $/\left(\mathrm{e} / \AA^{3}\right)$ & $0.344 /-0.380$ & $0.772 /-0.598$ \\
\hline
\end{tabular}




\section{Bibliography}

[1] J. Meyer, J. Biol. Inorg. Chem. 2008, 13, 157-170.

[2] G. L. Holliday, J. M. Thornton, A. Marquet, A. G. Smith, F. Rébeillé, R. Mendel, H. L. Schubert, A. D. Lawrence, M. J. Warren, Nat. Prod. Rep. 2007, 24, 972-987.

[3] G. Wächtershäuser, Proc. Natl. Acad. Sci. U. S. A. 1990, 87, 200-204.

[4] G. Wächtershäuser, Pure Appl. Chem. 1993, 65, 1343-1348.

[5] G. Wächtershäuser, in Origin of Life: Chemical Approach, (Eds.: P. Herdewijn, M. V. Kısakürek), Verlag Helvetica Chimica Acta, Zürich, 2008, 61-79.

[6] C. Huber, G. Wächtershäuser, Science 1997, 276, 245-247.

[7] H. Beinert, R. H. Sands, Biochem. Biophys. Res. Commun. 1960, 3, 41-46.

[8] L. E. Mortenson, R. C. Valentine, J. E. Carnahan, Biochem. Biophys. Res. Commun. 1962, 7, 448-452.

[9] K. Tagawa, D. I. Arnon, Nature 1962, 195, 537-543.

[10] W. Lovenberg, B. B. Buchanan, J. C. Rabinowitz, J. Biol. Chem. 1963, 238, 38993913.

[11] R. Malkin, J. C. Rabinowitz, Biochem. Biophys. Res. Commun. 1966, 23, 822-827.

[12] K. P. Jensen, J. Inorg. Biochem. 2006, 100, 1436-1439.

[13] H. Beinert, J. Biol. Inorg. Chem. 2000, 5, 2-15.

[14] H. Beinert, Eur. J. Biochem. 2000, 267, 5657-5664.

[15] L. Noodleman, D. A. Case, Adv. Inorg. Chem. 1992, 38, 423-470.

[16] T. Glaser, B. Hedman, K. O. Hodgson, E. I. Solomon, Acc. Chem. Res. 2000, 33, 859-868.

[17] F. Capozzi, S. Ciurli, C. Luchinat, Struct. Bonding 1998, 127-160. 
[18] L. Banci, I. Bertini, C. Luchinat, P. Turano, in Biological Inorganic Chemistry: Structure and Reactivity, (Eds.: I. Bertini, H. B. Gray, E. I. Stiefel, J. S. Valentine), University Science Books, Sausalito, 2007, 229-261.

[19] H. Beinert, M. C. Kennedy, C. D. Stout, Chem. Rev. 1996, 96, 2335-2373.

[20] D. H. Flint, R. M. Allen, Chem. Rev. 1996, 96, 2315-2334.

[21] H. Beinert, R. H. Holm, E. Münck, Science 1997, 277, 653-659.

[22] M. K. Johnson, Curr. Opin. Chem. Biol. 1998, 2, 173-181.

[23] D. C. Johnson, D. R. Dean, A. D. Smith, M. K. Johnson, Annu. Rev. Biochem. 2005, 74, 247-281.

[24] L. Banci, I. Bertini, C. Luchinat, P. Turano, in Biological Inorganic Chemistry: Structure and Reactivity, (Eds.: I. Bertini, H. B. Gray, E. I. Stiefel, J. S. Valentine), University Science Books, Sausalito, 2007, 43-56.

[25] D. C. Rees, Annu. Rev. Biochem. 2002, 71, 221-246.

[26] M. F. J. M. Verhagen, T. A. Link, W. R. Hagen, FEBS Letters 1995, 361, 75-78.

[27] B. K. Burgess, D. J. Lowe, Chem. Rev. 1996, 96, 2983-3011.

[28] T. A. Kent, J.-L. Dreyer, M. C. Kennedy, B. H. Huynh, M. Emptage, H. Beinert, E. Münck, Proc. Natl. Acad. Sci. U. S. A. 1982, 79, 1096-1100.

[29] M. Emptage, T. A. Kent, B. H. Huynh, J. Rawlings, W. H. Orme-Johnson, E. Münck, J. Biol. Chem. 1980, 255, 1793-1796.

[30] B. H. Huynh, J. J. G. Moura, I. Moura, T. A. Kent, J. LeGall, A. V. Xavier, E. Münck, J. Biol. Chem. 1980, 255, 3242-3244.

[31] M. C. Kennedy, T. A. Kent, M. Emptage, H. Merkle, H. Beinert, E. Münck, J. Biol. Chem. 1984, 259, 14463-14471.

[32] H. Beinert, M. C. Kennedy, Eur. J. Biochem. 1989, 186, 5-15.

[33] D. W. Plank, M. C. Kennedy, H. Beinert, J. B. Howard, J. Biol. Chem. 1989, 264, 20385-20393. 
[34] J. Kim, D. C. Rees, Science 1992, 257, 1677-1682.

[35] O. Einsle, F. A. Tezcan, S. L. A. Andrade, B. Schmid, M. Yoshida, J. B. Howard, D. C. Rees, Science 2002, 297, 1696-1700.

[36] J. W. Peters, W. N. Lanzilotta, B. J. Lemon, L. C. Seefeldt, Science 1998, 282, 1853-1858.

[37] Y. Nicolet, C. Piras, P. Legrand, C. E. Hatchikian, J. C. Fontecilla-Camps, Structure 1999, 7, 13-23.

[38] Y. Nicolet, C. Cavazza, J. C. Fontecilla-Camps, J. Inorg. Biochem. 2002, 91, 1-8.

[39] B. R. Crane, L. M. Siegel, E. D. Getzoff, Science 1995, 270, 59-67.

[40] T. I. Doukov, T. M. Iverson, J. Seravalli, S. W. Ragsdale, C. L. Drennan, Science 2002, 298, 567-572.

[41] C. Darnault, A. Volbeda, E. J. Kim, P. Legrand, X. Vernède, P. A. Lindahl, J. C. Fontecilla-Camps, Nat. Struct. Biol. 2003, 10, 271-279.

[42] V. Svetlitchnyi, H. Dobbek, W. Meyer-Klaucke, T. Meins, B. Thiele, P. Römer, R. Huber, O. Meyer, Proc. Natl. Acad. Sci. U. S. A. 2004, 101, 446-451.

[43] H. Dobbek, V. Svetlitchnyi, L. Gremer, R. Huber, O. Meyer, Science 2001, 293, 1281-1283.

[44] S. W. Ragsdale, M. Kumar, Chem. Rev. 1996, 96, 2515-2539.

[45] W. E. Newton, in Biological Inorganic Chemistry: Structure and Reactivity, (Eds.: I. Bertini, H. B. Gray, E. I. Stiefel, J. S. Valentine), University Science Books, Sausalito, 2007, 468-493.

[46] M. J. Maroney, in Biological Inorganic Chemistry: Structure and Reactivity, (Eds.: I. Bertini, H. B. Gray, E. I. Stiefel, J. S. Valentine), University Science Books, Sausalito, 2007, 443-452.

[47] S. W. Ragsdale, in Biological Inorganic Chemistry: Structure and Reactivity, (Eds.: I. Bertini, H. B. Gray, E. I. Stiefel, J. S. Valentine), University Science Books, Sausalito, 2007, 452-467. 
[48] A. Volbeda, J. C. Fontecilla-Camps, Dalton Trans. 2005, 3443-3450.

[49] R. Lill, U. Mühlenhoff, Trends Biochem. Sci. 2005, 30, 133-141.

[50] D. J. A. Netz, A. J. Pierik, M. Stümpfig, U. Mühlenhoff, R. Lill, Nature Chem. Biol. 2007, 3, 278-286.

[51] L. Zheng, R. H. White, V. L. Cash, R. F. Jack, D. R. Dean, Proc. Natl. Acad. Sci. U. S. A. 1993, 90, 2754-2758.

[52] R. Lill, Nature 2009, 460, 831-838.

[53] X. M. Xu, S. G. Møller, ChemBioChem 2008, 9, 2355-2362.

[54] M. Fontecave, S. Ollagnier-de Choudens, Arch. Biochem. Biophys. 2008, 474, 226237.

[55] C. Ayala-Castro, A. Saini, F. W. Outten, Microbiol. Mol. Biol. Rev. 2008, 72, 110125.

[56] Y. Hu, A. W. Fay, C. C. Lee, J. Yoshizawa, M. W. Ribbe, Biochemistry 2008, 47, 3973-3981.

[57] J.-M. Moulis, V. Davasse, M.-P. Golinelli, J. Meyer, I. Quinkal, J. Biol. Inorg. Chem. 1996, 1, 2-14.

[58] A. H. Robbins, C. D. Stout, Proc. Natl. Acad. Sci. U. S. A. 1989, 86, 3639-3643.

[59] J. S. Rieske, D. H. MacLennan, R. Coleman, Biochem. Biophys. Res. Commun. 1964, 15, 338-344.

[60] S. Iwata, M. Saynovits, T. A. Link, H. Michel, Structure 1996, 4, 567-579.

[61] D. Xia, C.-A. Yu, H. Kim, J.-Z. Xia, A. M. Kachurin, L. Zhang, L. Yu, J. Deisenhofer, Science 1997, 277, 60-66.

[62] C. L. Colbert, M. M.-J. Couture, L. D. Eltis, J. T. Bolin, Structure 2000, 8, 12671278.

[63] R. Morales, M.-H. Chron, G. Hudry-Clergeon, Y. Pétillot, S. Norager, M. Medina, M. Frey, Biochemistry 1999, 38, 15764-15773. 
[64] F. Berkovitch, Y. Nicolet, J. T. Wan, J. T. Jarrett, C. L. Drennan, Science 2004, $303,76-79$.

[65] S. E. Wiley, M. L. Paddock, E. C. Abresch, L. Gross, P. van der Geer, R. Nechushtai, A. N. Murphy, P. A. Jennings, J. E. Dixon, J. Biol. Chem. 2007, 282, 2374523749 .

[66] M. L. Paddock, S. E. Wiley, H. L. Axelrod, A. E. Cohen, M. Roy, E. C. Abresch, D. Capraro, A. N. Murphy, R. Nechushtai, J. E. Dixon, P. A. Jennings, Proc. Natl. Acad. Sci. U. S. A. 2007, 104, 14342-14347.

[67] W. R. Hagen, P. J. Silva, M. A. Amorim, P.-L. Hagedoorn, H. Wassink, H. Haaker, F. T. Robb, J. Biol. Inorg. Chem. 2000, 5, 527-534.

[68] J. Fujinaga, J. Gaillard, J. Meyer, Biochem. Biophys. Res. Commun. 1993, 194, 104111.

[69] B. R. Crouse, J. Meyer, M. K. Johnson, J. Am. Chem. Soc. 1995, 117, 9612-9613.

[70] C. Achim, M.-P. Golinelli, E. L. Bominaar, J. Meyer, E. Münck, J. Am. Chem. Soc. 1996, 118, 8168-8169.

[71] A. P. Yeh, X. I. Ambroggio, S. L. A. Andrade, O. Einsle, C. Chatelet, J. Meyer, D. C. Rees, J. Biol. Chem. 2002, 277, 34499-34507.

[72] L. Di Costanzo, L. V. Flores Jr., D. W. Christianson, Proteins 2006, 65, 637-642.

[73] J. Lin, T. Zhou, K. Ye, J. Wang, Proc. Natl. Acad. Sci. U. S. A. 2007, 104, 1464014645.

[74] Y. Shimomura, K. Wada, K. Fukuyama, Y. Takahashi, J. Mol. Biol. 2008, 383, 133-143.

[75] N. Rouhier, H. Unno, S. Bandyopadhyay, L. Masip, S.-K. Kim, M. Hirasawa, J. M. Gualberto, V. Lattard, M. Kusunoki, D. B. Knaff, G. Georgiou, T. Hase, M. K. Johnson, J.-P. Jacquot, Proc. Natl. Acad. Sci. U. S. A. 2007, 104, 7379-7384.

[76] T. Iwema, A. Picciocchi, D. A. K. Traore, J.-L. Ferrer, F. Chauvat, L. Jacquamet, Biochemistry 2009, 48, 6041-6043. 
[77] Y. Nicolet, J. K. Rubach, M. C. Posewitz, P. Amara, C. Mathevon, M. Atta, M. Fontecave, J. C. Fontecilla-Camps, J. Biol. Chem. 2008, 283, 18861-18872.

[78] D. Kuila, J. A. Fee, J. Biol. Chem. 1986, 261, 2768-2771.

[79] Y. Zu, J. A. Fee, J. Hirst, Biochemistry 2002, 41, 14054-14065.

[80] D. R. J. Kolling, R. I. Samoilova, A. A. Shubin, A. R. Crofts, S. A. Dikanov, J. Phys. Chem. A 2009, 113, 653-667.

[81] E. N. Brown, R. Friemann, A. Karlsson, J. V. Parales, M. M.-J. Couture, L. D. Eltis, S. Ramaswamy, J. Biol. Inorg. Chem. 2008, 13, 1301-1313.

[82] D. J. Kolling, J. S. Brunzelle, S. Lhee, A. R. Crofts, S. K. Nair, Structure 2007, 15, 29-38.

[83] I.-J. Lin, Y. Chen, J. A. Fee, J. Song, W. M. Westler, J. M. Markley, J. Am. Chem. Soc. 2006, 128, 10672-10673.

[84] S. A. Dikanov, D. R. J. Kolling, B. Endeward, R. I. Samoilova, T. F. Prisner, S. K. Nair, A. R. Crofts, J. Biol. Chem. 2006, 281, 27416-27425.

[85] E. J. Leggate, J. Hirst, Biochemistry 2005, 44, 7048-7058.

[86] D. Schneider, C. L. Schmidt, Biochim. Biophys. Acta 2005, 1710, 1-12.

[87] E. Lebrun, M. Brugna, F. Baymann, D. Muller, D. Lièvrement, M.-C. Lett, W. Nitschke, Molecular Biology and Evolution 2003, 20, 686-693.

[88] R. B. Broach, J. T. Jarrett, Biochemistry 2006, 45, 14166-14174.

[89] G. Sainz, J. Jakoncic, L. C. Sieker, V. Stojanoff, N. Sanishvili, M. Asso, P. Bertrand, J. Armengaud, Y. Jouanneau, J. Biol. Inorg. Chem. 2006, 11, 235246.

[90] R. C. Conover, A. T. Kowal, W. Fu, J.-B. Park, S. Aono, M. W. W. Adams, M. K. Johnson, J. Biol. Chem. 1990, 265, 8533-8541.

[91] Y. Hu, S. Faham, R. Roy, M. W. W. Adams, D. C. Rees, J. Mol. Biol. 1999, 286, 899-914. 
[92] A. Volbeda, M.-H. Charon, C. Piras, E. C. Hatchikian, M. Frey, J. C. FontecillaCamps, Nature 1995, 373, 580-587.

[93] L. Calzolai, C. M. Gorst, K. L. Bren, Z.-H. Zhou, M. W. W. Adams, G. M. La Mar, J. Am. Chem. Soc. 1997, 119, 9341-9350.

[94] T. E. Messick, N. H. Chmiel, M.-P. Golinelli, M. R. Langer, L. Joshua-Tor, S. S. David, Biochemistry 2002, 41, 3931-3942.

[95] A. Volbeda, E. Garcin, C. Piras, A. L. de Lacey, V. M. Fernandez, E. C. Hatchikian, M. Frey, J. C. Fontecilla-Camps, J. Am. Chem. Soc. 1996, 118, 1298912996.

[96] M. S. Nielsen, P. Harris, B. L. Ooi, H. E. M. Christensen, Biochemistry 2004, 43, 5188-5194.

[97] M. C. Kennedy, H. Beinert, in Biological Inorganic Chemistry: Structure and Reactivity, (Eds.: I. Bertini, H. B. Gray, E. I. Stiefel, J. S. Valentine), University Science Books, Sausalito, 2007, 209-215.

[98] H. J. Sofia, G. Chen, B. G. Hetzler, J. F. Reyes-Spindola, N. E. Miller, Nucleic Acids Res. 2001, 29, 1097-1106.

[99] G. Layer, J. Moser, D. W. Heinz, D. Jahn, W.-D. Schubert, EMBO J. 2003, 22, 6214-6224.

[100] P. A. Frey, FASEB J. 1993, 7, 662-670.

[101] P. A. Frey, M. D. Ballinger, G. H. Reed, Biochem. Soc. Trans. 1998, 26, 304-310.

[102] P. A. Frey, O. T. Magnusson, Chem. Rev. 2003, 103, 2129-2148.

[103] P. A. Frey, Annu. Rev. Biochem. 2001, 70, 121-148.

[104] J. Cheek, J. B. Broderick, J. Biol. Inorg. Chem. 2001, 6, 209-226.

[105] M. Fontecave, E. Mulliez, S. Ollagnier-de Choudens, Curr. Opin. Chem. Biol. 2001, 5, 506-511.

[106] M. Fontecave, S. Ollagnier-de Choudens, E. Mulliez, Chem. Rev. 2003, 103, 2149-2166. 
[107] J. T. Jarrett, Curr. Opin. Chem. Biol. 2003, 7, 174-182.

[108] G. Layer, D. W. Heinz, D. Jahn, W.-D. Schubert, Curr. Opin. Chem. Biol. 2004, 8, 468-476.

[109] S. C. Wang, P. A. Frey, Trends Biochem. Sci. 2007, 32, 101-110.

[110] A. Marquet, B. Tse Sum Bui, A. G. Smith, M. J. Warren, Nat. Prod. Rep. 2007, 24, 1027-1040.

[111] S. J. Booker, R. M. Cicchillo, T. L. Grove, Curr. Opin. Chem. Biol. 2007, 11, 543-552.

[112] J. B. Broderick, in Biological Inorganic Chemistry: Structure and Reactivity, (Eds.: I. Bertini, H. B. Gray, E. I. Stiefel, J. S. Valentine), University Science Books, Sausalito, 2007, 582-595.

[113] P. A. Frey, A. D. Hegeman, F. J. Ruzicka, Crit. Rev. Biochem. Mol. Biol. 2008, 43, 63-88.

[114] S. Dai, R. Friemann, D. A. Glauser, F. Bourquin, W. Manieri, P. Schürmann, H. Eklund, Nature 2007, 448, 92-98.

[115] M. Fontecave, E. Mulliez, M. Atta, Chem. Biol. 2008, 15, 209-210.

[116] I. Sanyal, G. Cohen, D. H. Flint, Biochemistry 1994, 33, 3625-3631.

[117] D. Florentin, B. Tse Sum Bui, A. Marquet, T. Ohshiro, Y. Izumi, C. R. Acad. Sci. Paris 1994, 317, 485-488.

[118] A. Méjean, B. Tse Sum Bui, D. Florentin, O. Ploux, Y. Izumi, A. Marquet, Biochem. Biophys. Res. Commun. 1995, 217, 1231-1237.

[119] I. Sanyal, K. J. Gibson, D. H. Flint, Arch. Biochem. Biophys. 1996, 326, 48-56.

[120] B. Tse Sum Bui, D. Florentin, F. Fournier, O. Ploux, A. Méjean, A. Marquet, FEBS Letters 1998, 440, 226-230.

[121] K. J. Gibson, D. A. Pelletier, S. Turner, Ivan M., Biochem. Biophys. Res. Commun. 1998, 254, 632-635. 
[122] B. Tse Sum Bui, A. Marquet, R. Benda, A. X. Trautwein, FEBS Letters 1999, 459, 411-414.

[123] M. Lotierzo, B. Tse Sum Bui, H. K. Leech, M. J. Warren, A. Marquet, S. E. J. Rigby, Biochem. Biophys. Res. Commun. 2009, 381, 487-490.

[124] S. Ollagnier-de Choudens, Y. Sanakis, K. S. Hewitson, P. Roach, J. E. Baldwin, E. Münck, M. Fontecave, Biochemistry 2000, 39, 4165-4173.

[125] N. B. Ugulava, B. R. Gibney, J. T. Jarrett, Biochemistry 2001, 40, 8343-8351.

[126] N. B. Ugulava, C. J. Sacanell, J. T. Jarrett, Biochemistry 2001, 40, 8352-8358.

[127] T. J. Vanden Boom, K. E. Reed, J. E. Cronan Jr., J. Bacteriol. 1991, 173, 64116420.

[128] J. R. Miller, R. W. Busby, S. W. Jordan, J. Cheek, T. F. Henshaw, G. W. Ashley, J. B. Broderick, J. E. Cronan Jr., M. E. Marletta, Biochemistry 2000, 39, 1516615178 .

[129] R. M. Cicchillo, D. F. Iwig, A. D. Jones, N. M. Nesbitt, C. Baleanu-Gogonea, M. G. Souder, L. Tu, S. J. Booker, Biochemistry 2004, 43, 6378-6386.

[130] R. M. Cicchillo, S. J. Booker, J. Am. Chem. Soc. 2005, 127, 2860-2861.

[131] P. Douglas, M. Kriek, P. Bryant, P. L. Roach, Angew. Chem. 2006, 118, 53215323.

[132] R. M. Cicchillo, K.-H. Lee, C. Baleanu-Gogonea, N. M. Nesbitt, C. Krebs, S. J. Booker, Biochemistry 2004, 43, 11770-11781.

[133] S. Ollagnier-de Choudens, Y. Sanakis, K. S. Hewitson, P. Roach, E. Münck, M. Fontecave, J. Biol. Chem. 2002, 16, 13449-13454.

[134] F. Pierrel, H. L. Hernández, M. K. Johnson, M. Fontecave, M. Atta, J. Biol. Chem. 2003, 278, 29515-29524.

[135] F. Pierrel, T. Douki, M. Fontecave, M. Atta, J. Biol. Chem. 2004, 279, 4755547563.

[136] H. L. Hernández, F. Pierrel, E. Elleingand, R. García-Serres, B. H. Huynh, M. K. Johnson, M. Fontecave, M. Atta, Biochemistry 2007, 46, 5140-5147. 
[137] B. P. Anton, L. Saleh, J. S. Benner, E. A. Raleigh, S. Kasif, R. J. Roberts, Proc. Natl. Acad. Sci. U. S. A. 2008, 105, 1826-1831.

[138] T. Herskovitz, B. A. Averill, R. H. Holm, J. A. Ibers, W. D. Phillips, J. F. Weiher, Proc. Natl. Acad. Sci. U. S. A. 1972, 69, 2437-2441.

[139] J. J. Mayerle, R. B. Frankel, R. H. Holm, J. A. Ibers, W. D. Phillips, J. F. Weiher, Proc. Natl. Acad. Sci. U. S. A. 1973, 70, 2429-2433.

[140] P. Venkateswara Rao, R. H. Holm, Chem. Rev. 2004, 104, 527-559.

[141] S. Groysman, R. H. Holm, Biochemistry 2009, 48, 2310-2320.

[142] Y. Ohki, Y. Sunada, K. Tatsumi, Chem. Lett. 2005, 34, 172-173.

[143] J. Ballmann, A. Albers, S. Demeshko, S. Dechert, E. Bill, E. Bothe, U. Ryde, F. Meyer, Angew. Chem. 2008, 120, 9680-9684.

[144] W. E. Cleland, Jr., B. A. Averill, Inorg. Chem. 1984, 23, 4192-4197.

[145] D. Coucouvanis, A. Salifoglou, M. G. Kanatzidis, A. Simopoulos, G. C. Papaefthymiou, J. Am. Chem. Soc. 1984, 106, 6081-6082.

[146] P. Beardwood, J. F. Gibson, J. Chem. Soc. Chem. Commun. 1985, 102-104.

[147] P. Beardwood, J. F. Gibson, J. Chem. Soc. Chem. Commun. 1985, 1345-1347.

[148] P. Beardwood, J. F. Gibson, J. Chem. Soc. Chem. Commun. 1986, 490-492.

[149] M. A. Bobrik, K. O. Hodgson, R. H. Holm, Inorg. Chem. 1977, 16, 1851-1858.

[150] Y. Do, E. D. Simhon, R. H. Holm, Inorg. Chem. 1983, 22, 3809-3812.

[151] J. Ballmann, X. Sun, S. Dechert, B. Schneider, F. Meyer, Dalton Trans. 2009, 4908-4917.

[152] S. Ueno, N. Ueyama, A. Nakamura, T. Tukihara, Inorg. Chem. 1986, 25, 10001005.

[153] N. Ueyama, Y. Yamada, T. Okamura, S. Kimura, A. Nakamura, Inorg. Chem. 1996, 35, 6473-6484. 
[154] J. Ballmann, S. Dechert, E. Bill, U. Ryde, F. Meyer, Inorg. Chem. 2008, 47, 15861596.

[155] S. Ciurli, M. Carrié, J. A. Weigel, M. J. Carney, T. D. P. Stack, G. C. Papaefthymiou, R. H. Holm, J. Am. Chem. Soc. 1990, 112, 2654-2664.

[156] J. A. Weigel, R. H. Holm, J. Am. Chem. Soc. 1991, 113, 4184-4191.

[157] G. P. F. van Strijdonck, P. T. J. H. ten Have, M. C. Feiters, J. G. M. van der Linden, J. J. Steggerda, R. J. M. Nolte, Chem. Ber. 1997, 130, 1151-1157.

[158] C. Zhou, R. H. Holm, Inorg. Chem. 1997, 36, 4066-4077.

[159] E. Münck, E. L. Bominaar, Science 2008, 321, 1452-1453.

[160] L. Deng, R. H. Holm, J. Am. Chem. Soc. 2008, 130, 9878-9886.

[161] G. B. Wong, M. A. Bobrik, R. H. Holm, Inorg. Chem. 1978, 17, 578-584.

[162] W. E. Cleland, D. A. Holtman, M. Sabat, J. A. Ibers, G. C. DeFotis, B. A. Averill, J. Am. Chem. Soc. 1983, 105, 6021-6031.

[163] N. Ueyama, T. Terakawa, M. Nakata, A. Nakamura, J. Am. Chem. Soc. 1983, 105, 7098-7102.

[164] M. A. Walters, C. L. Roche, A. L. Rheingold, S. W. Kassel, Inorg. Chem. 2005, 44, 3777-3779.

[165] J. Cambray, R. W. Lane, A. G. Wedd, R. W. Johnson, R. H. Holm, Inorg. Chem. $1977,16,2565-2571$.

[166] K. S. Hagen, J. G. Reynolds, R. H. Holm, J. Am. Chem. Soc. 1981, 103, 40544063.

[167] K. Bates, B. Garrett, R. A. Henderson, Inorg. Chem. 2007, 46, 11145-11155.

[168] K. Bates, R. A. Henderson, Inorg. Chem. 2008, 47, 5850-5858.

[169] K. Bates, L. Johnson, R. A. Henderson, Inorg. Chem. 2006, 45, 9423-9433.

[170] K. Bates, M. Wouldhave, R. A. Henderson, Dalton Trans. 2008, 6527-6529.

[171] C. J. A. Daley, R. H. Holm, J. Inorg. Biochem. 2003, 97, 287-298. 
[172] J. Ballmann, X. Sun, S. Dechert, E. Bill, F. Meyer, J. Inorg. Biochem. 2007, 101, 305-312.

[173] D. P. J. Pearson, S. J. Leigh, I. O. Sutherland, J. Chem. Soc. Perkin Trans. 1 1979, $12,3113-3126$.

[174] A. Alexakis, D. Polet, S. Rosset, S. March, J. Org. Chem. 2004, 69, 5660-5667.

[175] S. Cossu, O. De Lucchi, D. Fabbri, G. Valle, G. F. Painter, R. A. J. Smith, Tetrabedron 1997, 53, 6073-6084.

[176] C. Zonta, O. De Lucchi, R. Volpicelli, L. Cotarca, Top. Curr. Chem. 2007, 275, 131-161.

[177] T. Yamato, K.-i. Hasegawa, Y. Saruwatari, L. K. Doamekpor, Chem. Ber. 1993, 126, 1435-1439.

[178] T. N. Sorrell, E. H. Cheesman, Synth. Commun. 1981, 11, 909-912.

[179] J. Ballmann, M. G. G. Fuchs, S. Dechert, M. John, F. Meyer, Inorg. Chem. 2009, 48, 90-99.

[180] H. Kwart, E. R. Evans, J. Org. Chem. 1966, 31, 413-419.

[181] A. E. Lemire, J. C. Thompson, Can. J. Chem. 1970, 48, 824-829.

[182] D. W. Christianson, Adv. Protein Chem. 1991, 42, 281-355.

[183] K. Andrä, H.-R. Hopper, Z. Chem. 1980, 20, 267-268.

[184] G. Gualtieri, S. J. Geib, D. P. Curran, J. Org. Chem. 2003, 68, 5013-5019.

[185] N. L. Speziali, B. G. Guimaraes, R. M. Silva, P. H. Duarte, S. R. Aguiar, Acta Crystallogr. 1994, C50, 1059-1062.

[186] A. Salifoglou, A. Simopoulos, A. Kostikas, R. W. Dunham, M. G. Kanatzidis, D. Coucouvanis, Inorg. Chem. 1988, 27, 3394-3406.

[187] J. Ballmann, S. Dechert, S. Demeshko, F. Meyer, Eur. J. Inorg. Chem. 2009, 32193225.

[188] L. Yang, D. R. Powell, R. P. Houser, Dalton Trans. 2007, 955-964. 
[189] J. R. Aranzaes, M.-C. Daniel, D. Astruc, Can. J. Chem. 2006, 84, 288-299.

[190] T. N. Sorrell, D. J. Ellis, J. Org. Chem. 1985, 50, 5765-5769.

[191] B. Kersting, G. Steinfeld, Z. Naturforsch. 1998, 53b, 1239-1240.

[192] D. Sellmann, P. Frank, F. Koch, J. Organomet. Chem. 1988, 339, 345-356.

[193] S. Inagaki, Y. Nishizawa, T. Sugiura, H. Ishihara, J. Chem. Soc. Perkin Trans. 1 1990, 179-180.

[194] W. Wu, A. C. Grimsdale, K. Müllen, Chem. Commun. 2003, 1044-1045.

[195] G. A. Grasa, R. Singh, E. D. Stevens, S. P. Nolan, J. Organomet. Chem. 2003, 687, 269-279.

[196] D. J. Evans, G. J. Leigh, J. Chem. Soc. Chem. Commun. 1988, 395-396.

[197] H. Ogino, S. Inomata, H. Tobita, Chem. Rev. 1998, 98, 2093-2121.

[198] H. J. Ballmann, Dissertation, Georg-August-Universität Göttingen, 2008.

[199] M. A. Halcrow, Coord. Chem. Rev. 2005, 249, 2880-2908.

[200] Y.-i. Lin, S. A. Lang Jr., J. Heterocyclic Chem. 1977, 14, 345-347.

[201] C. M. Grunert, H. A. Goodwin, C. Carbonera, J.-F. Létard, J. Kusz, P. Gütlich, J. Phys. Chem. B 2007, 111, 6738-6747.

[202] S. Rüttimann, C. M. Moreau, A. F. Williams, G. Bernardinelli, A. W. Addison, Polyhedron 1992, 11, 635-646.

[203] G. Stupka, L. Gremaud, G. Bernardinelli, A. F. Williams, Dalton Trans. 2004, 407-412.

[204] R. F. Carina, L. Verzegnassi, G. Bernardinelli, A. F. Williams, Chem. Commun. 1998, 2681-2682.

[205] J.-i. Setsune, M. Toda, K. Watanabe, P. K. Panda, T. Yoshida, Tetrahedron Lett. 2006, 47, 7541-7544.

[206] R. A. Jones, M. Karatza, T. N. Voro, P. U. Civcir, A. Franck, O. Ozturk, J. P. Seaman, A. P. Whitmore, D. J. Williamson, Tetrahedron 1996, 52, 8707-8724. 
[207] R. A. Jones, P. U. Civcir, Tetrahedron 1997, 53, 11529-11540.

[208] M. Seitz, A. Kaiser, A. Tereshchenko, C. Geiger, U. Yukitaka, O. Reiser, Tetrabedron 2006, 62, 9973-9980.

[209] M. A. Keegstra, A. J. A. Klomp, L. Brandsma, Synth. Commun. 1990, 20, 33713374.

[210] K. H. Sugiyarto, D. C. Craig, A. D. Rae, H. A. Goodwin, Aust. J. Chem. 1994, 47, 869-890.

[211] K. H. Sugiyarto, W.-A. McHale, D. C. Craig, A. D. Rae, M. L. Scudder, H. A. Goodwin, Dalton Trans. 2003, 2443-2448.

[212] M. L. Scudder, D. C. Craig, H. A. Goodwin, CrystEngComm 2005, 7, 642-649.

[213] R. Boča, P. Baran, L. Dlháň, H. Fuess, W. Haase, F. Renz, W. Linert, I. Svoboda, R. Werner, Inorg. Chim. Acta 1997, 260, 129-136.

[214] R. Boča, F. Renz, M. Boca, H. Fuess, W. Haase, G. Kickelbick, W. Linert, M. Vrbová-Schikora, Inorg. Chem. Commun. 2005, 8, 227-230.

[215] M. S. Haddad, M. W. Lynch, W. D. Federer, D. N. Hendrickson, Inorg. Chem. 1981, 20, 123-131.

[216] A. W. Addison, T. N. Rao, J. Reedijk, J. van Rijn, G. C. Verschoor, J. Chem. Soc. Dalton Trans. 1984, 1349-1356.

[217] G. Henkel, W. Tremel, B. Krebs, Angew. Chem. 1981, 93, 1072-1073.

[218] K. S. Hagen, G. Christou, R. H. Holm, Inorg. Chem. 1983, 22, 309-314.

[219] J. T. Hoggins, H. Steinfink, Inorg. Chem. 1976, 15, 1682-1685.

[220] K. J. Gibson, D. A. Pelletier, S. Turner, Ivan M., Biochem. Biophys. Res. Commun. 1999, 254, 632-635.

[221] J. J. Wilker, S. J. Lippard, Inorg. Chem. 1999, 38, 3569-3574.

[222] Z. J. Tonzetich, L. H. Do, S. J. Lippard, J. Am. Chem. Soc. 2009, 131, 7964-7965. 
[223] T. C. Harrop, Z. J. Tonzetich, E. Reisner, S. J. Lippard, J. Am. Chem. Soc. 2008, 130, 15602-15610.

[224] G. Christou, C. D. Garner, J. Chem. Soc. Dalton Trans. 1979, 1093-1094.

[225] R. A. Schunn, C. J. Fritchie Jr., C. T. Prewitt, Inorg. Chem. 1966, 5, 892-899.

[226] P. K. Mascharak, M. C. Smith, W. H. Armstrong, B. K. Burgess, R. H. Holm, Proc. Natl. Acad. Sci. U. S. A. 1982, 79, 7056-7060.

[227] J. Meijer, A. H. Hogt, B. Fischer, Acros Organics Review 6.

[228] Y. Hayakawa, N. Terasawa, H. Sawada, Polymer 2001, 42, 4081-4086.

[229] C. E. Farrar, J. T. Jarrett, Biochemistry 2009, 48, 2448-2458.

[230] G. M. Ullmann, E.-W. Knapp, Eur. Biophys. J. 1999, 28, 533-551.

[231] A. M. Taylor, C. E. Farrar, J. T. Jarrett, Biochemistry 2008, 47, 9309-9317.

[232] J. T. Jarrett, Arch. Biochem. Biophys. 2005, 433, 312-321.

[233] A. D. Becke, J. Chem. Phys. 1993, 98, 5648-5652.

[234] P. J. Stephens, F. J. Devlin, M. J. Frisch, C. F. Chabalowski, J. Phys. Chem. 1994, 98, 11623-11627.

[235] M. M. Cosper, G. N. L. Jameson, H. L. Hernández, C. Krebs, B. H. Huynh, M. K. Johnson, Biochemistry 2004, 43, 2007-2021.

[236] B. Tse Sum Bui, R. Benda, V. Schünemann, D. Florentin, A. X. Trautwein, A. Marquet, Biochemistry 2003, 42, 8791-8798.

[237] M. G. G. Fuchs, F. Meyer, U. Ryde, J. Biol. Inorg. Chem. accepted; DOI: $10.1007 /$ s00775-009-0585-6.

[238] H. Salman, S. Tal, Y. Chuvilov, O. Solovey, Y. Abraham, M. Kapon, K. Suwinska, Y. Eichen, Inorg. Chem. 2006, 45, 5315-5320.

[239] R. Ahlrichs, M. Bär, M. Häser, H. Horn, C. Kölmel, Chem. Phys. Lett. 1989, 162, 165-169.

[240] J. P. Perdew, Phys. Rev. B 1986, 33, 8822-8824. 
[241] A. D. Becke, Phys. Rev. A 1988, 38, 3098-3100.

[242] F. Weigend, R. Ahlrichs, Phys. Chem. Chem. Phys. 2005, 7, 3297-3305.

[243] J. Li, C. L. Fisher, R. Konecny, D. Bashford, L. Noodleman, Inorg. Chem. 1999, $38,929-939$.

[244] M. H. M. Olsson, U. Ryde, J. Biol. Inorg. Chem. 1999, 4, 654-663.

[245] W. Humphrey, A. Dalke, K. Schulten, J. Molec. Graphics 1996, 14, 33-38.

[246] Persistance of Vision Pty. Ltd. (Version 3.6), 2004, retrieved from http://www.povray.org.

[247] U. Ryde, J. Comput.-Aided Mol. Des. 1996, 10, 153-164.

[248] U. Ryde, M. H. M. Olsson, Int. J. Quantum Chem. 2001, 81, 335-347.

[249] D. A. Case, T. A. Darden, T. E. Cheatham III, T. L. Simmerling, J. Wang, R. E. Duke, R. Luo, K. M. Merz, D. A. Pearlman, M. Crowley, R. C. Walker, W. Zhang, B. Wang, S. Hayik, A. Roitberg, G. Seabra, K. F. Wong, F. Paesani, X. Wu, S. Brozell, V. Tsui, H. Gohlke, L. Yang, C. Tan, J. Mongan, V. Hornak, G. Cui, P. Beroza, D. H. Mathews, C. Schafmeister, W. S. Ross, P. A. Kollman, AMBER 9, 2006, University of California, San Francisco.

[250] W. D. Cornell, P. I. Cieplak, C. I. Bayly, I. R. Gould, K. M. Merz, D. M. Ferguson, D. C. Spellmeyer, T. Fox, J. W. Caldwell, P. A. Kollman, J. Am. Chem. Soc. 1995, 117, 5179-5197.

[251] J. Wang, P. Cieplak, P. A. Kollman, J. Comput. Chem. 2000, 21, 1049-1074.

[252] T. H. Rod, U. Ryde, J. Chem. Theory Comput. 2005, 1, 1240-1251.

[253] P. Söderhjelm, U. Ryde, J. Mol. Struct. Theochem. 2006, 770, 199-219.

[254] A. Weis, K. Katebzadeh, P. Söderhjelm, I. Nilsson, U. Ryde, J. Med. Chem. 2006, 49, 6596-6606.

[255] H. Li, A. D. Robertson, J. H. Jensen, Proteins 2005, 61, 704-721.

[256] J. P. Ryckaert, G. Ciccotti, H. J. C. Berendsen, J. Comput. Phys. 1977, 23, 327341. 
[257] W. L. Jorgensen, J. Chandrasekhar, J. Madura, M. L. Klein, J. Chem. Phys. 1983, 79, 926-935.

[258] H. J. C. Berendsen, J. P. M. Postma, W. F. van Gunsteren, A. DiNola, J. R. Haak, J. Chem. Phys. 1984, 81, 3684-3690.

[259] W. L. DeLano, The PyMOL Molecular Graphics System, DeLano Scientific, Palo Alto, CA, USA, 2002, retrieved from http://www.pymol.org.

[260] STOE \& CIE GmbH, X-RED, Darmstadt, Germany, 2002.

[261] G. M. Sheldrick, SHELXL-97, Program for Crystal Structure Refinement, 1997.

[262] G. M. Sheldrick, SHELXS-97, Program for Crystal Structure Solution, 1997.

[263] G. M. Sheldrick, Acta Crystallogr. 2008, A64, 112-122. 
Structures of Ligands and Ligand Precursors<smiles>Oc1ccccc1-c1ccccc1O</smiles>

1a<smiles>C=CCOc1ccccc1-c1ccccc1OCC=C</smiles>

2a<smiles>C=CCc1cccc(-c2cccc(CC=C)c2O)c1O</smiles>

3a<smiles>C=CCOc1ccccc1-c1ccccc1O</smiles>

2b<smiles>C=CCc1cccc(-c2ccccc2O)c1O</smiles>

$3 b$<smiles>CC(C)(C)c1ccc(O)c(-c2cc(C(C)(C)C)ccc2O)c1</smiles>

1c<smiles>C=CCOc1ccc(C(C)(C)C)cc1-c1cc(C(C)(C)C)ccc1OCC=C</smiles>

2c<smiles>C=CCc1cc(C(C)(C)C)cc(-c2cc(C(C)(C)C)cc(CC=C)c2O)c1O</smiles>

$3 c$<smiles>C=CCc1cccc(-c2cccc(CC=C)c2OC(=S)NC(C)=O)c1OC(C)=S</smiles>

4a<smiles>C=CCc1cccc(-c2ccccc2OC(N)=S)c1OC(C)=S</smiles>

4b<smiles>C=CCc1cccc(-c2cccc(CC=C)c2SC(C)=O)c1SC(C)=O</smiles>

$5 a$<smiles>C=CCc1cccc(-c2ccccc2SC(C)=O)c1SC(=O)NC</smiles>

$5 b$ 
<smiles>C=CCc1cccc(-c2cccc(CC=C)c2S)c1S</smiles>

$6 a$

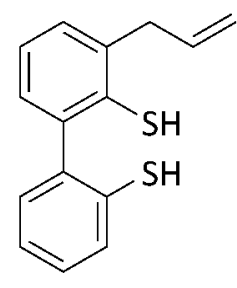

$6 b$

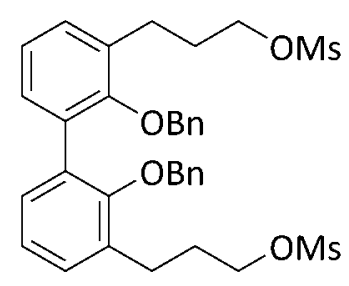

13<smiles>CSCCCc1cccc(-c2cccc(CCCSC)c2OCc2ccccc2)c1O</smiles>

14

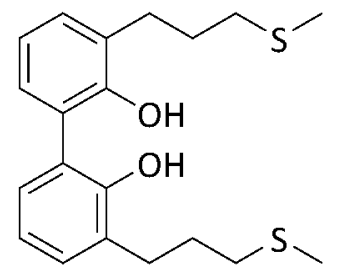

15<smiles>Cc1cc(I)cc(CCCCc2cccc(-c3cccc(CCCCc4cc(I)cc(C)c4S)c3O)c2O)c1O</smiles><smiles>Sc1ccccc1SCc1ccccc1</smiles>

18<smiles>c1ccc(CCCSc2ccccc2SCc2cccc(-c3cccc(CCCSc4ccccc4CCc4ccccc4)c3OCc3ccccc3)c2OCc2ccccc2)cc1</smiles><smiles>Oc1c(CCCSc2ccccc2S)cccc1-c1cccc(CCCSc2ccccc2S)c1O</smiles><smiles></smiles><smiles>Oc1c(/C=C/Cc2cccc(-c3nc4ccccc4[nH]3)c2O)cccc1C/C=C/c1cccc(-c2nc3ccccc3[nH]2)c1</smiles> 
<smiles>c1cc(-c2ccn[nH]2)nc(-c2ccn[nH]2)c1</smiles>

$27 a$<smiles>c1cc(-c2nc3ccccc3[nH]2)nc(-c2nc3ccccc3[nH]2)c1</smiles>

27b<smiles>c1cc(-c2ncc[nH]2)nc(-c2ncc[nH]2)c1</smiles>

27c<smiles>Cc1ccc(-c2cccc(-c3ccc(C)[nH]3)n2)[nH]1</smiles>

27d<smiles>CC(=O)CCC(=O)c1cccc(C(=O)CCC(C)=O)n1</smiles>

28<smiles>SCc1cccc(CS)n1</smiles>

$27 e$<smiles>O=C(O)c1cccc(C(=O)O)n1</smiles>

$27 f$<smiles>c1c[nH]c(-c2ccc(-c3ncc[nH]3)o2)n1</smiles>

$27 g$

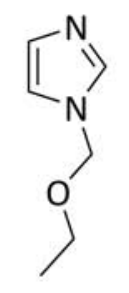

30

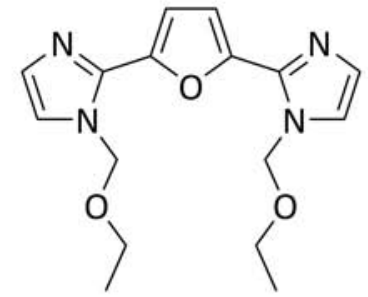

31 


\section{Structures of Complexes and Clusters}<smiles></smiles>

7<smiles>CCCCCN(CCCC)C(=S)n1ccc2ccccc21</smiles>

10<smiles></smiles>

$11 b$

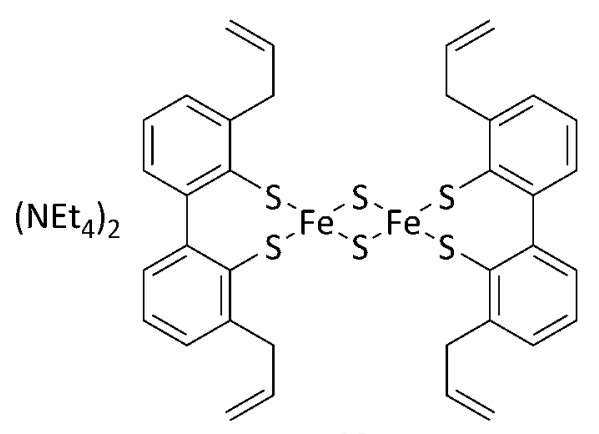

$12 a$<smiles>C=CCc1cccc2c1SS[Sn](c1ccccc1)(c1ccccc1)c1cccc(CC=C)c1-2</smiles>

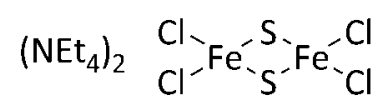

8<smiles></smiles>

11a<smiles>C=CCc1cc(C(C)(C)C)cc(-c2cc(C(C)(C)C)cc(CC=C)c2Op2oc3c(CC=C)cc(C(C)(C)C)cc3c3cc(C(C)(C)C)cc(CC=C)c3oc3c(CC=C)cc(C(C)(C)C)cc3s2)c1O</smiles>

$11 c$<smiles></smiles>

$12 b$ 


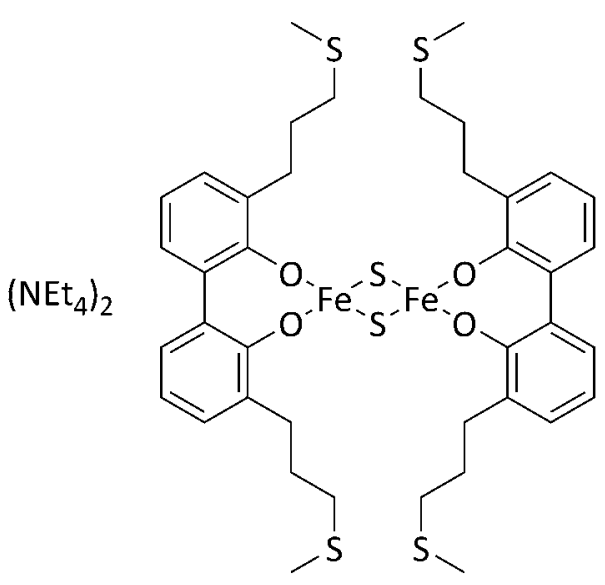

16

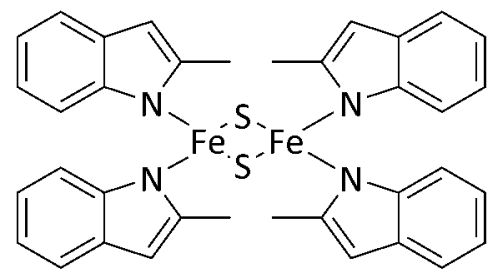

24

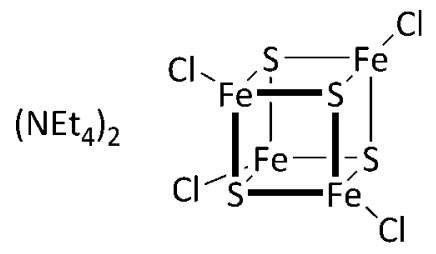

26

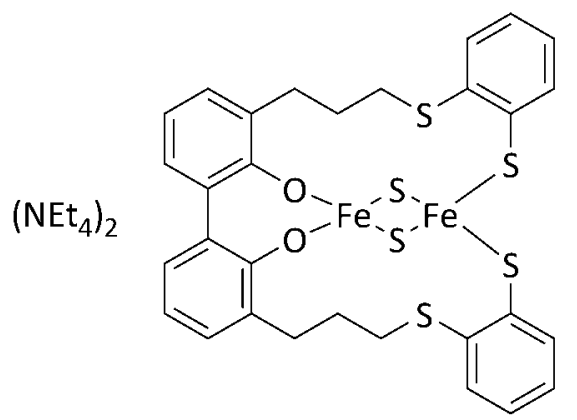

21

$\left(\mathrm{NEt}_{4}\right)_{2}$

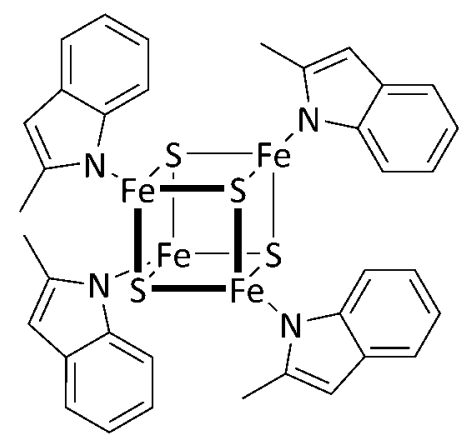

25

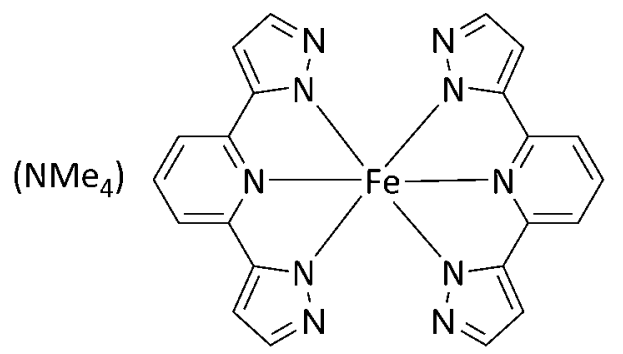

$32 a$ 


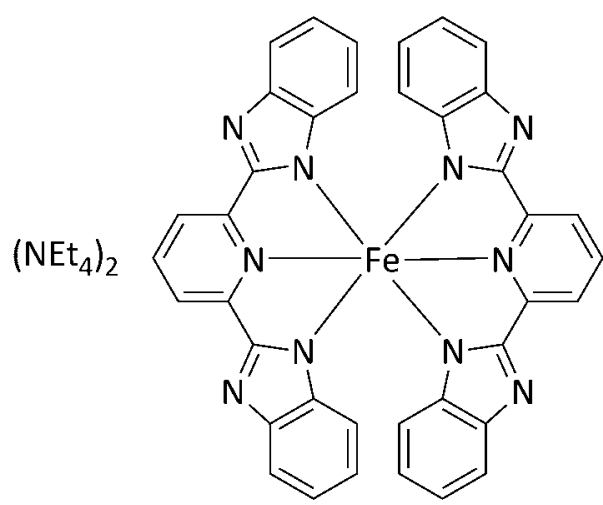

$32 b$

$\left(\mathrm{NEt}_{4}\right)$

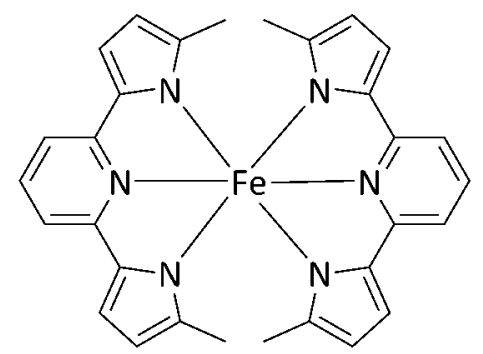

$32 d$

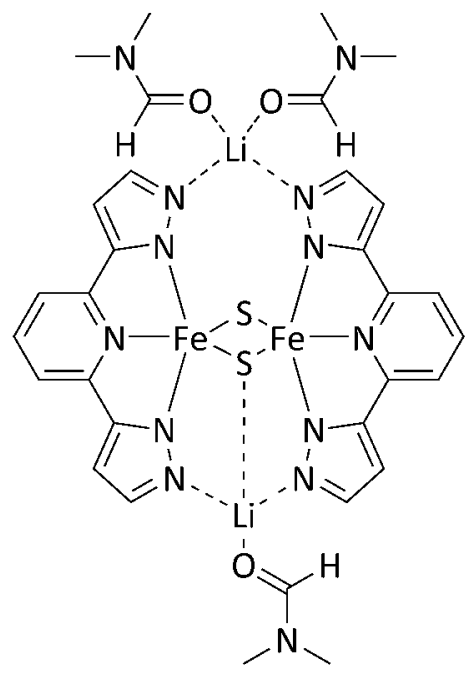

34

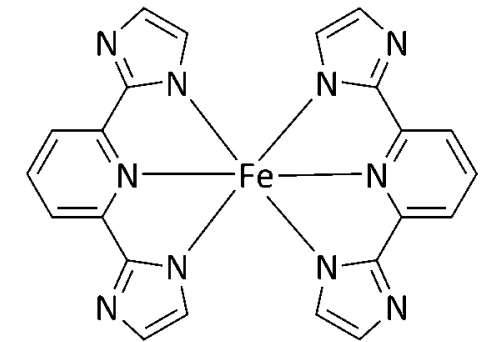

$32 c$

$\left(\mathrm{NEt}_{4}\right)_{2}$

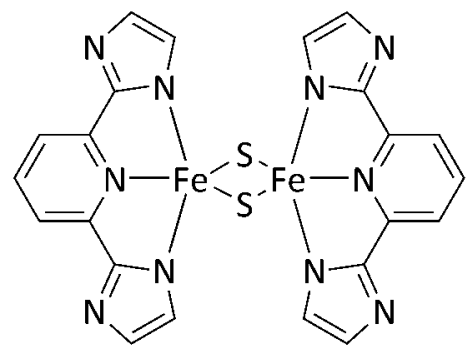

33

$\left(\mathrm{NEt}_{4}\right)_{2}$<smiles></smiles>

35 


\title{
List of Abbreviations
}

\author{
Ac acetyl \\ acac acetylacetonate \\ $\mathrm{AdoCH}_{3}$ adenosine \\ AdoMet $S$-adenosylmethionine \\ AF antiferromagnetic \\ Ar aryl \\ bipy bipyridine \\ Bn benzyl \\ br broad (NMR) \\ $\mathrm{Bu}$ butyl \\ Cp cyclopentadienyl \\ $\mathrm{Cp}^{*}$ pentamethylcyclopentadienyl \\ d doublet (NMR)
}

DAB-Cy $N, N^{\prime}$-dicyclohexyl-1,4-diazabutadiene

DFT density functional theory

DMA $N, N$-dimethylacetamide

DMF $N, N$-dimethylformamide

DMSO dimethyl sulfoxide

DOSY diffusion-ordered spectroscopy

DTB dethiobiotin

DTBP di-tert-butylperoxide

EA elemental analysis

EDTA ethylenediaminetetraacetic acid tetrasodium salt

EI electron impact

EPR electron paramagnetic resonance

eq equivalents

ESI electron spray ionisation

Et ethyl

F ferromagnetic

FeMoco iron-molybdenum cofactor

GC gas chromatography

HiPIP high-potential iron-sulphur protein

HMPA hexamethylphosphoramide 
HRMS high resolution mass spectrometry

IR infra-red

$\mathrm{L}$ ligand

LPO lauroyl peroxide

m multiplet (NMR); medium (IR)

Me methyl

Met methionine

MM molecular mechanic

Mp melting point

MS mass spectrometry

Ms methanesulfonyl

$\mathrm{NADH}$ nicotinamide adenine dinucleotide (reduced form)

NHE normal hydrogen electrode

NMR nuclear magnetic resonance

$\mathrm{Ph}$ phenyl

PI paramagnetic impurity

$\operatorname{Pr}$ propyl

q quartet (NMR)

QM quantum mechanic

$s \quad$ singlet (NMR); strong (IR)

SAM $S$-adenosylmethionine

sh shoulder (UV/vis)

$t$ triplet (NMR)

THF tetrahydrofurane

TIP temperature-independent paramagnetism

TLC thin layer chromatography

TMEDA tetramethylethylenediamine

tRNA transfer ribonucleic acid

$\mathrm{UV} / \mathrm{vis}$ ultra-violet/visible

w weak (IR) 


\section{List of Scientific Contributions}

\section{Publications}

T. Aslam, M. G. G. Fuchs, A. Le Formal, R. H. Wightman, "Synthesis of C-disaccharide analogues of the $\alpha$-D-arabinofuranosyl-(1 $\rightarrow 5)-\alpha$-D-arabinofuranosyl motif of mycobacterial cell walls via alkynyl intermediates”, Tetrabedron Lett. 2005, 46, 3249-3252.

J. Ballmann, M. G. G. Fuchs, S. Dechert, M. John, F. Meyer, "Synthesis and Coordination Properties of Chelating Dithiophenolate Ligands", Inorg. Chem. 2009, 48, 90-99.

M. G. G. Fuchs, F. Meyer, U. Ryde, "A Combined Computational and Experimental Investigation of the [2Fe-2S] Cluster in Biotin Synthase", J. Biol. Inorg. Chem., accepted, DOI: $10.1007 /$ s00775-009-0585-6.

\section{Presentations at International Workshops}

"Biomimetic and DFT Studies of Unusual Fe/S Clusters", $4^{\text {th }}$ Workshop of the International Research Training Group 1422 "Metal Sites in Biomolecules: Structures, Regulation and Mechanisms", Copenhagen, Denmark, 10.02.2009.

\section{Posters at Conferences and International Workshops}

M. G. G. Fuchs, S. Dechert, E. Bill, F. Meyer, "Polydentate ligands for biomimetic [2Fe2S] clusters with mixed ligation", $2^{\text {nd }}$ Workshop of the International Research Training Group 1422 "Metal Sites in Biomolecules: Structures, Regulation and Mechanisms", Lund, Sweden, 21.-22.06.2007.

M. G. G. Fuchs, J. Ballmann, S. Dechert, E. Bill, F. Meyer, "Polydentate ligands for biomimetic [2Fe2S] clusters with mixed ligation", $13^{\text {th }}$ International Conference on Biological Inorganic Chemistry (ICBIC XIII), Vienna, Austria, 15.-20.07.2007.

M. G. G. Fuchs, S. Dechert, E. Bill, F. Meyer, "Neue Funktionen Biologischer [2Fe2S]Cluster: Biomimetische Modelle”, 4. Deutsches Koordinationschemikertreffen, Gießen, Germany, 24.-26.02.2008.

M. G. G. Fuchs, S. Dechert, E. Bill, F. Meyer, "New Functions of Biological [2Fe2S] Clusters: Biomimetic Models", $3^{\text {rd }}$ Workshop of the International Research Training Group 1422 "Metal Sites in Biomolecules: Structures, Regulation and Mechanisms", Mariaspring, Germany, 03.-05.04.2008. 
M. G. G. Fuchs, S. Dechert, U. Ryde, F. Meyer, "Biomimetische Modelle für Fe/SCluster in enzymatischen Radikalreaktionen”, 2. Göttinger Chemieforum, Göttingen, Germany, 04.07.2008.

M. G. G. Fuchs, S. Dechert, U. Ryde, F. Meyer, "Biomimetic Models for Fe/S Clusters Involved in Radical Reactions", $9^{\text {th }}$ European Biological Inorganic Chemistry Conference (EuroBIC 9), Wroclaw, Poland, 02.-06.09.2008. 


\section{Acknowledgements}

First of all, I want to thank my Doktorvater Prof. Dr. Franc Meyer for supervising my thesis, his sympathetic guidance and the amount of academic freedom granted in connection with this work, especially with respect to the theoretic part. Furthermore, I am grateful for his appreciation of family needs and his support in these and all other matters.

I am also grateful to Prof. Dr. Ulf Ryde for teaching me how to tackle bioinorganic problems theoretically during the time in his group in Lund and in many e-mails thereafter, for the kind support and the interest in this work. Moreover, I would like to thank him for accepting to review this thesis.

There is hardly a page of this work in which Dr. Joachim Ballmann did not have a part, so thank you for everything, Achim.

For correcting parts of this thesis I thank Dr. Sarah Fakih, Boris Burger and especially Benjamin Schneider.

For solving my crystal structures, the patience with looking at the same complex a few times and for help in all kinds of computer problems I am grateful to Dr. Sebastian Dechert.

There are many more people who have contributed to parts of this work to whom I would like to address my thanks. I want to thank Dr. Serhiy Demeshko, Benjamin Schneider and Dr. Eckhard Bill (Max Planck Institute for Bioinorganic Chemistry, Mülheim) for Mössbauer and SQUID measurements; especially the generous support by Benni during the last months was a great help. For additional crystallography I would like to thank Boris Burger and Simone Wöckel. I am thankful to Jörg Teichgräber for cyclic voltammetry measurements, to Dr. Michael John for NMR measurements and to Dr. Holm Frauendorf for mass spectrometry measurements, and for the discussion of the respective results. I thank Matthias Hesse, Jörg Teichgräber and Andreas Schwarz for supply of chemicals and glassware, and Petra Unger and Dr. Claudia Stückl for administrative support. I am also thankful for the support by all people in the analytic laboratory, the NMR and MS facilities and the craft shops, the caretakers, the cleaning staff and all others who contributed with their work.

I thank all the students who did a great job in many time-consuming syntheses and columns during their time in my lab (in order of appearance): Friederike Fehr, Benjamin Schneider, Annegret Boll, Gesche Rauch, Timo Scheffer, Dirk Landsberg, Panupun Limpachayaporn, Daniela Behn, Wibke Meiser, Stefan Müllar, Kevin Pröpper, Steffen 
Meyer, Anett Sander, Ursula Kotyrba, Frank Stein, Aline Jatho, and Nils Hocke.

I thank Dr. Xian-Ru Sun and Dr. Marco Klingele from whose previous work on Fe/S clusters I could profit. For the great atmosphere and the ideally cooperative environment in the lab including many fruitful discussions I thank the whole Fe/S cluster team: Dr. Joachim Ballmann, Antonia Albers, Steffen Meyer, Nicole Kindermann and Thomas Bayer, and I apologise if my music was too annoying.

I thank Sabine Fenner for providing transportation during the last weeks, and I thank Peter Hilgers for helping to give this work a nice form.

I am thankful to Fonds der Chemischen Industrie and Deutsche Forschungsgemeinschaft (IRTG 1422: "Metal Sites in Biomolecules: Structures, Regulation and Mechanisms") for financial support. I would also like to thank the LUNARC facilities in Lund for providing the computer power.

For the time we spent together in the lab, on the balcony and on group tours, workshops and conferences I thank the whole group and all members of the IRTG. This goes especially to Benni, Achim, Boris, Sarah, Simone, Maria, Lina, Jarl and Angelina.

I thank all my family for being of great support throughout my life.

I am truly grateful to Gesche for her love and her immense support, and to Lotta for being there. 


\section{Curriculum Vitae}

\section{Personal Data}

Name: Michael Günther Georg Fuchs

Date of Birth: 21.08.1979

Place of Birth: Marburg

Nationality: German

Marital Status: Unmarried, one daughter (11 months)

\section{Pre-Academic Career}

$\begin{array}{ll}\text { 09/1986-07/1990 } & \text { Michelsberg-Grundschule Ulm } \\ \text { 09/1990-07/1995 } & \text { Humboldt-Gymnasium Ulm } \\ \text { 09/1995-06/1999 } & \text { Berthold-Gymnasium Freiburg } \\ 06 / 1999 & \text { Abitur, cumulative grade } 1.2\end{array}$

\section{Civil Service}

09/1999-07/2000 Dialyse-Trainings-Zentrum Freiburg

\section{Academic Career}

10/2000-10/2002 Undergraduate student, Philipps-Universität Marburg

$10 / 2002$

Diplomvorprüfung, cumulative grade 1.3

10/2002-12/2004 Diploma student, Philipps-Universität Marburg

10/2003-03/2004 Erasmus exchange student in the group of Prof. Dr. R. H. Wightman, Heriot-Watt University, Edinburgh, Scotland, UK: "Synthesis of a C-Disaccharide as a Potential Anti-Tuberculosis Drug”

12/2004 Mündliche Diplomprüfung

01/2005-10/2005 Diploma thesis in the group of Prof. Dr. M. Bröring, PhilippsUniversität Marburg: "Mangan- und Eisencorrole mit Nitridoliganden“ 
$10 / 2005$

since $12 / 2005$
Diplom, cumulative grade 1.2

Ph.D. thesis in the group of Prof. Dr. F. Meyer, Georg-AugustUniversität Göttingen: "Biomimetic and Theoretic Investigations of Unusual Iron-Sulphur Clusters“ 